ROMANIAN ACADEMY

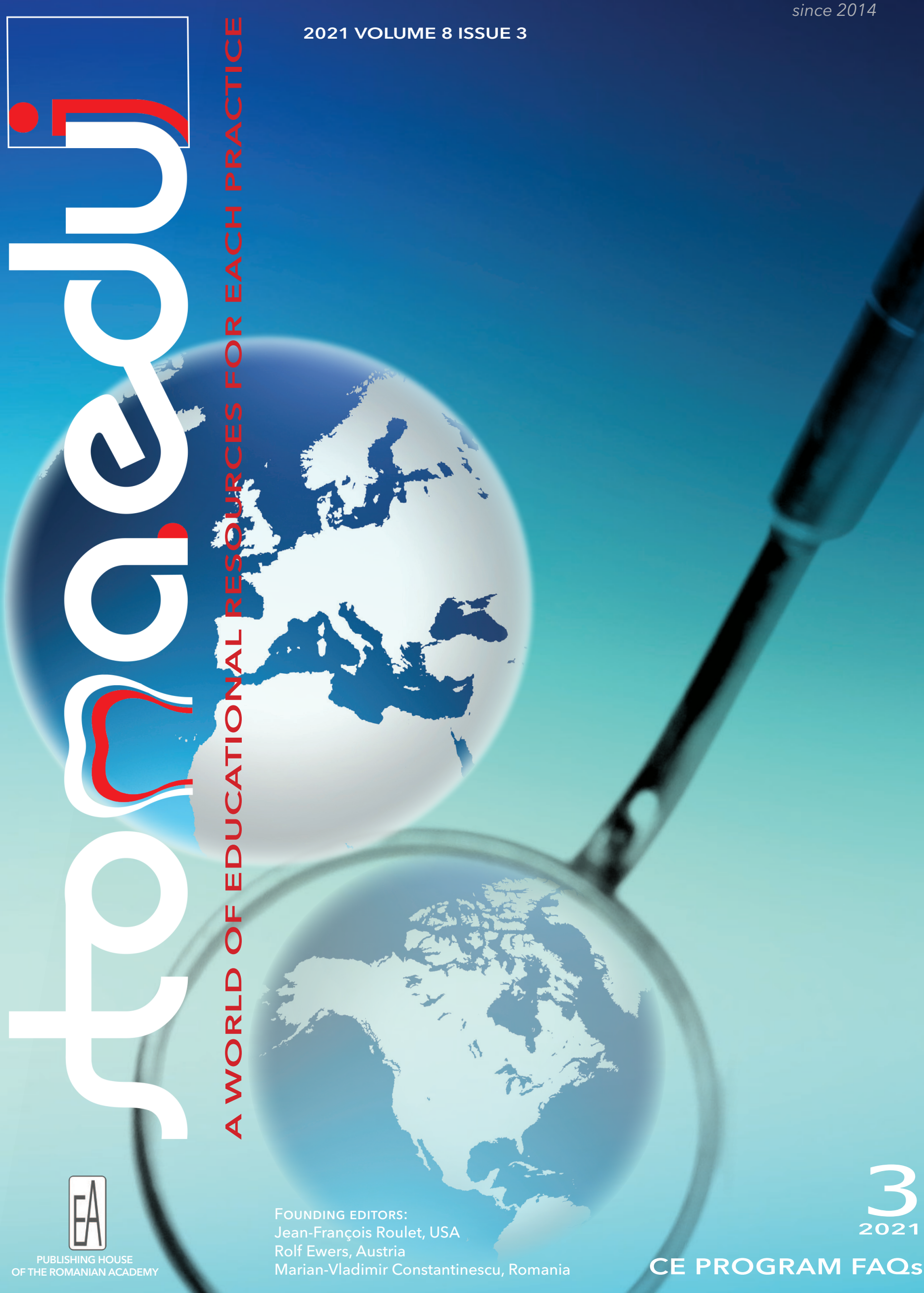

STOMATOLOGY EDU JOURNAL

2021 VOLUME 8 ISSUE 3 


\section{Neuromuscular Dentistry Powered by Myotronics}

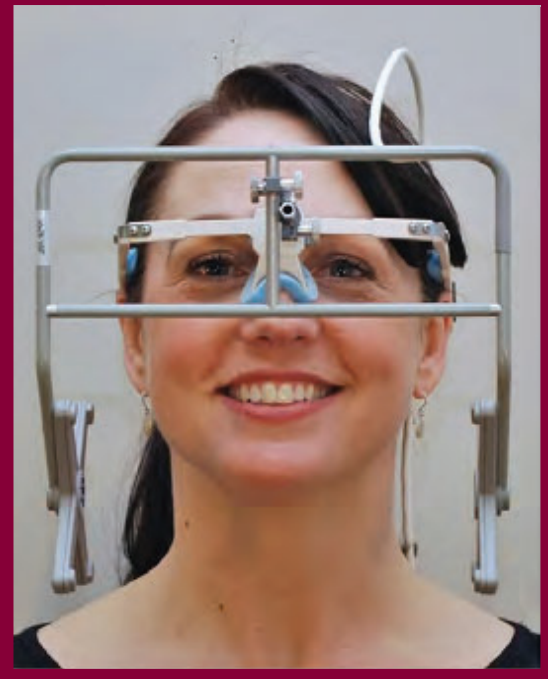

Dentists worldwide are discovering the science and the benefits of Neuromuscular Dentistry with Myotronics technology.

Evaluate and successfully treat occlusal and restorative cases with reliable, reproducible clinical data never seen before.

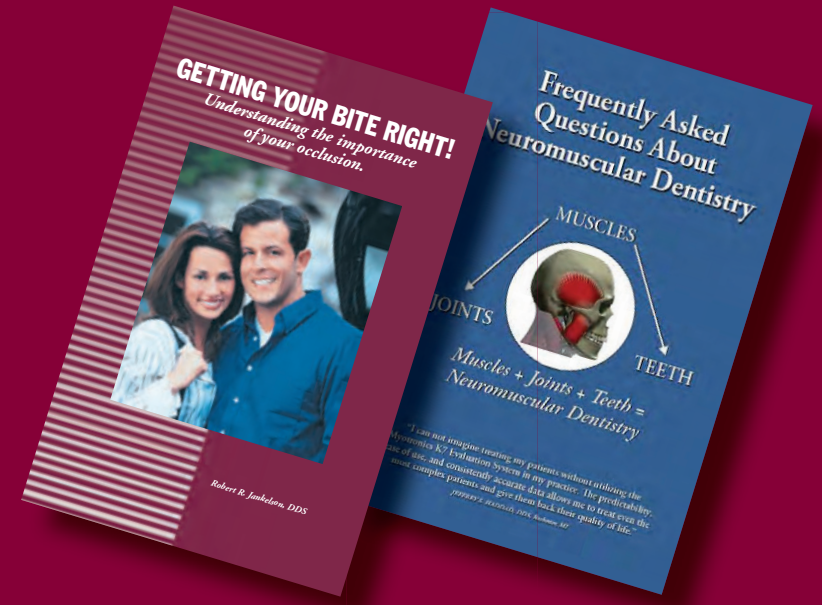

Contact Myotronics to receive information on upcoming CE courses and complimentary booklets on the benefits of Neuromuscular Dentistry. 800.426.0316 orinfo@myotronics.com.
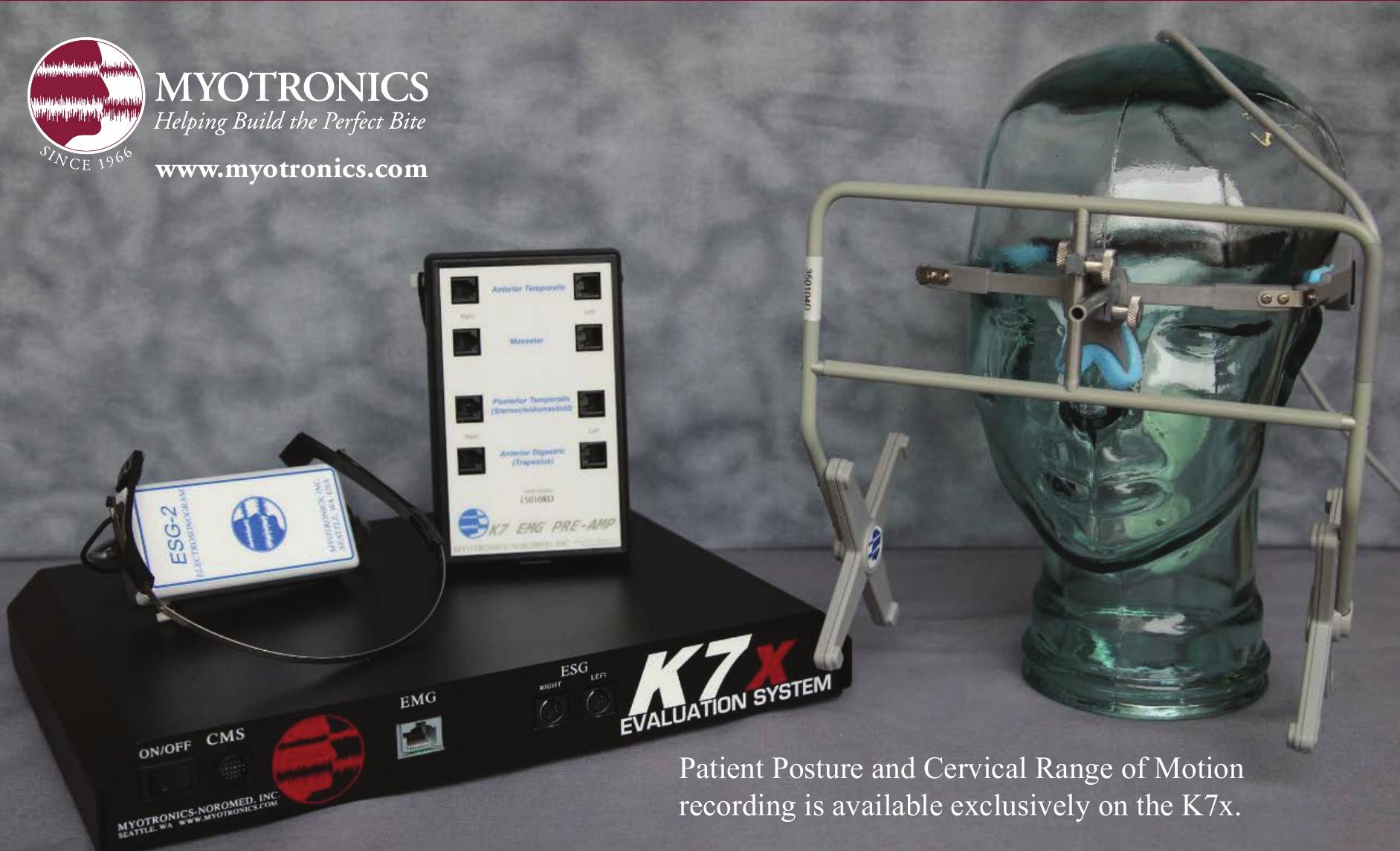


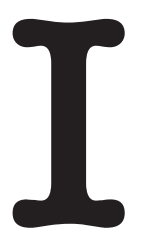

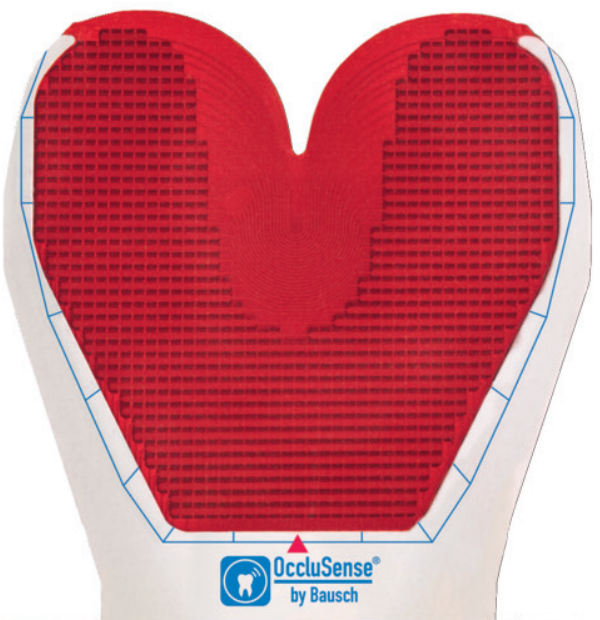

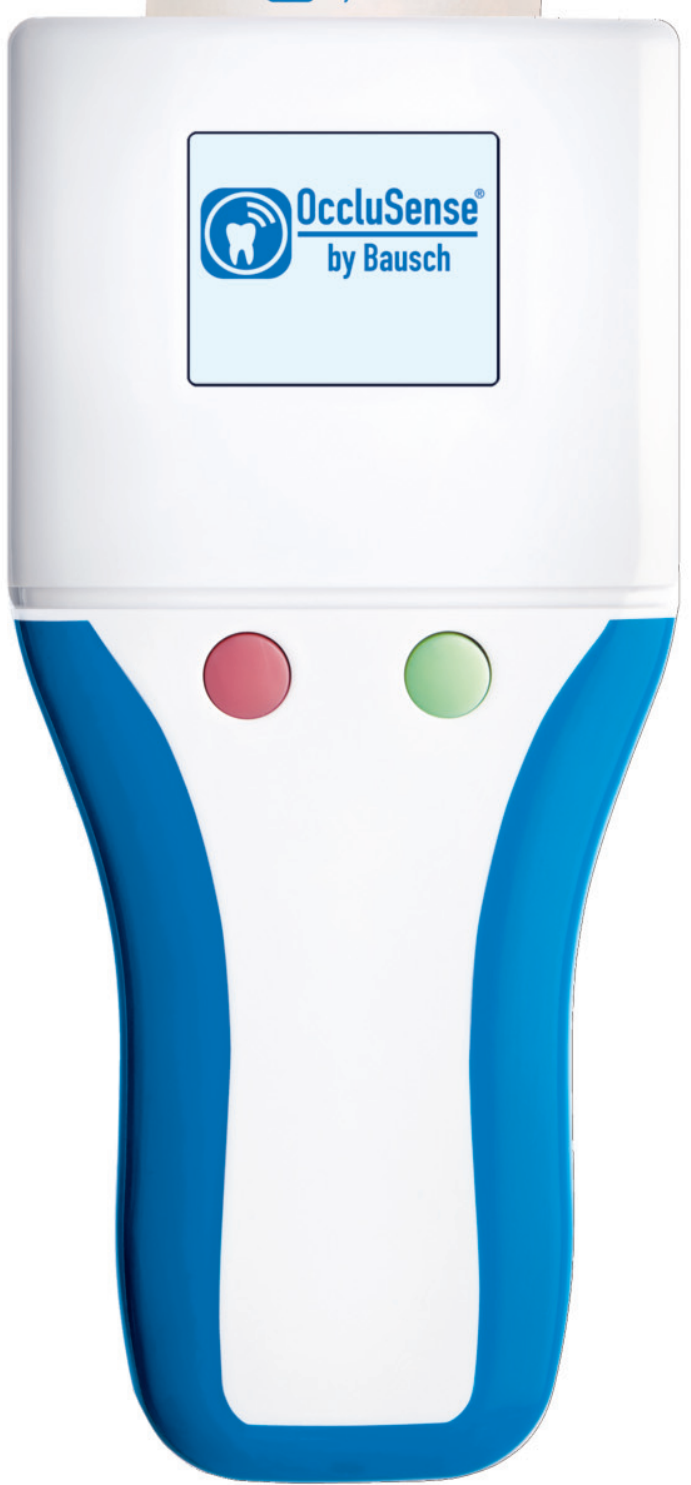

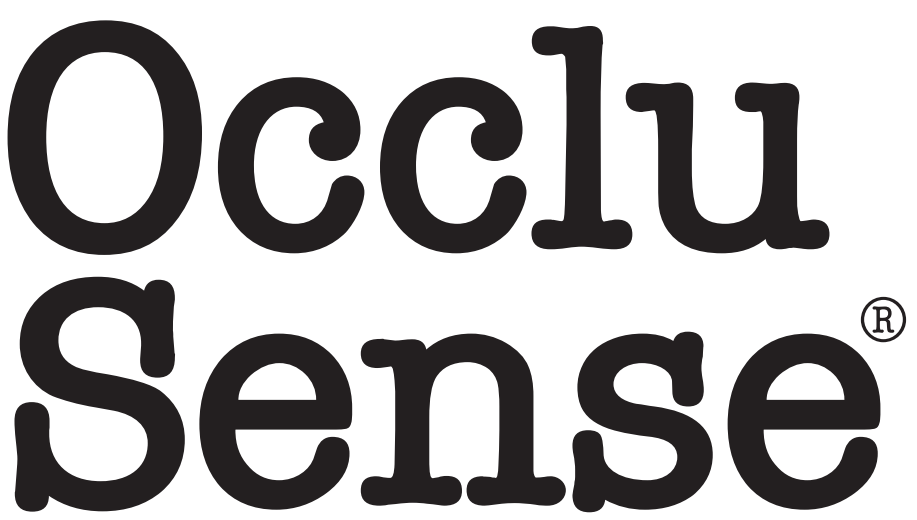

\section{Innovative device for digital occlusion control.}

Take advantage of the award-winning OccluSense ${ }^{\circledR}$ system:

- 60 microns thin, flexible pressure sensors record both static and dynamic occlusion

- Data transfer to OccluSense ${ }^{\circledR}$-iPad-App via wireless network

- Ergonomic design for intuitive handling

- Additionally, red colour coating marks the occlusal contacts on the patient's teeth

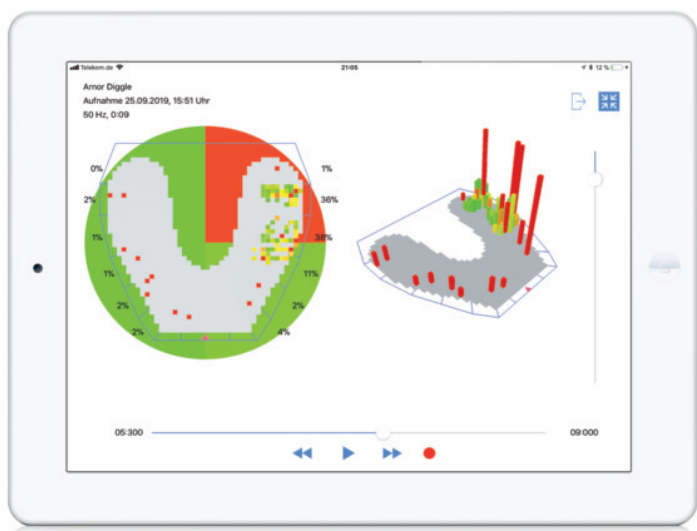

\section{(W) $\frac{\text { OccluSense }}{\text { by Bausch }}$}

WE MAKE OCCLUSION VISIBLE ${ }^{\circledR}$

Dr. Jean Bausch GmbH \& Co. KG | Oskar-Schindler-Str. 4 | 50769 Köln | Germany
More information: www.occlusense.com and YouTube 


\section{1}

Volume 8

Issue 3

Pages 151-226

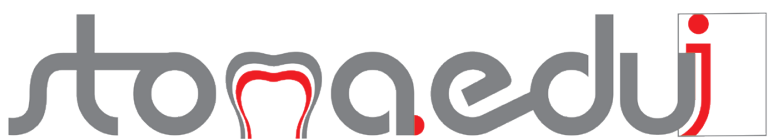

A WORLD OF EDUCATIONAL RESOURCES FOR EACH PRACTICE ISSN (print) 2360-2406; ISSN (on-line) 2502-0285; ISSN-L 2360-2406

\section{GUEST EDITORIAL}

151 COVID-19 and academic publishing ranking

Constantinus Politis

do) https://doi.org/10.25241/stomaeduj.2021.8(3).edit.1

\section{CONTINUING EDUCATION ONLINE}

155 JADA CE Online

\section{ORIGINAL ARTICLES}

ORTHODONTICS: Maxillary sinus volume in cleft lip and palate patients with and

157 without an oronasal fistula using $C B C T$

Bita Kiaee, Ladan Hafezi, Mahshid Karani, Faezeh Amiri, Abdolreza Jamilian

do) https://doi.org/10.25241/stomaeduj.2021.8(3).art.1

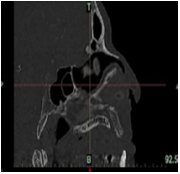

163

OCCLUSION and TMJ: On the track of bruxism: quantitative, qualitative and intraindividual analyses of the BruxChecker ${ }^{\circledast}$ in daily clinical routine Gregor Slavicek, David Grimmer, Anastasia Novitskaya, Florian Slavicek

do) https://doi.org/10.25241/stomaeduj.2021.8(3).art.2

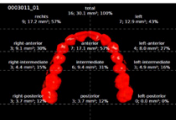

\section{REVIEW ARTICLES}

CARIOLOGY:The use of Er:YAG laser for dental caries removal

173 Geise dos Santos Marcelino, José Humberto Ribeiro Lopes, Juliana Jendiroba Faraoni,

Pâmella Coelho Dias

do) https://doi.org/10.25241/stomaeduj.2021.8(3).art.3

DENTOALVEOLAR SURGERY: Contribution of piezocision in oral surgery:

184 the example of the acceleration of orthodontic movements Thonnart François, Systermans Simon, Gilon Yves

do) https://doi.org/10.25241/stomaeduj.2021.8(3).art.4

PROSTHETIC DENTISTRY: Selecting an appropriate occlusal scheme when

fabricating implant-supported fixed dental prostheses: a systematic review Mariam Margvelashvili-Malament, Kenneth Albert Malament, Steven E. Eckert

d. https://doi.org/10.25241/stomaeduj.2021.8(3).art.5

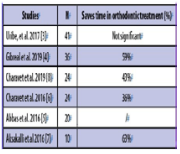

GERODONTOLOGY: Mechanisms linking oral health and frailty in older adults:

195 a narrative review

Kalliopi Konstantopoulou, Anastassia Kossioni

(6) https://doi.org/10.25241/stomaeduj.2021.8(3).art.6 


\section{CASE REPORT}

ORAL REHABILITATION: A multidisciplinary approach for the rehabilitation of a patient with chondrosarcoma: prosthetically-driven digital workflow for maxillary reconstruction 207 and implant treatment

Yanjun Ge, Danni Guo, Xiaofeng Shan, Lei Zhang, Ruifang Lu, Pan Shaoxia, Yongsheng Zhou do) https://doi.org/10.25241/stomaeduj.2021.8(3).art.7

\section{PRODUCT NEWS}

217 The gold standard in laser dentistry - SiroLaser Blue

Florin-Eugen Constantinescu

doi https://doi.org/10.25241/stomaeduj.2021.8(3).prodnews.1

\section{BOOKS REVIEW}

219 Books revew

\section{INSTRUCTIONS FOR AUTHORS}

224 instructions for authors

\section{SUBSCRIPTION}

226 subscription 

Marian-Vladimir Constantinescu DDS, MSC, PhD, Professor

"Carol Davila" University of Medicine and Pharmacy, Bucharest, Romania

\section{CO-EDITORS-IN-CHIEF (AMERICAS)}

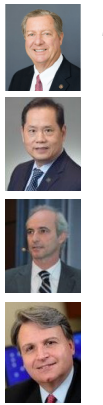

James Richard Hup

BS, DMD, MD, JD, MBA, Professor

Washington State University, Spokane, WA, USA

Hom-Lay Wang

DDS, MSD, PhD, Professor

University of Michigan, Ann Arbor, MI, USA

\section{Mauro Marincola}

MD, DDS, Clinical Professor

1. State University of Cartagena, Cartagena, Colombia

\section{George E. Romanos}

Stony Brook University, Stony Brook, NY, USA

CO-EDITORS-IN-CHIEF (ASIA-PACIFIC)

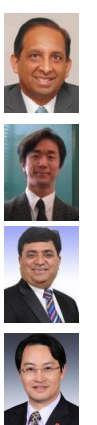

Lakshman Perera Samaranayake

Hon DSC, FDSRCS (Edin), FDS RCPS (Glas), FRACDS, FRCPath (UK), BDS, DDS

(Glas), FHKCPath, FCDSHK, FHKAM (Pathology), FHKAM (Dental Surgery)

Emeritus Professor, Department of Oral Biosciences, Faculty of Dentistry

Immediate-past Dean, University of Hong Kong, Hong Kong

Hiroshi Ogawa

DDS, MDSC, PhD, Associate Professor

Niigata University, Niigata, Japan

Mahesh Verma

BDS, MDS, MBA, FAMS, FDSRCS (England), FDSRCPSG (Glasgow), FDSRCS

(Edinburgh) PhD (HC), Professor

Maulana Azad Institute of Dental Sciences, New Delhi, India

Yongsheng Zhou

DDS, PhD, Professor and Chair, Associate Dean Department of Prosthodontics, School of Stomatology (PKUSS), Peking
University, Beijing, P.R.China

EMERITUS EDITORS-IN-CHIEF

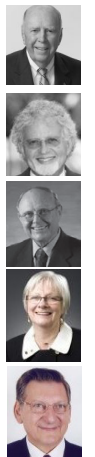

Peter E. Dawson

DDS, Founder Emeritus of The Dawson Academy

Saint Petersburg, FL, USA

\section{Adi A. Garfunkel}

DMD, PhD, Professor Emeritus

Hadassah Hebrew University, Jerusalem, Israel

Robert Louis Ibsen

DDS, OD, FAGD, FACD, FICD

Founder \& President DenMat Corporation, Santa Maria, CA, USA

\section{Birte Melsen}

DDS, Dr Odont, Professor

Aarhus University, Aarhus, Denmark

Alexandre Mersel

DDS, PhD, Professor, Director of Studies

Geneva Institute of Medical Dentistry (GIMD), Versoix, Switzerland

Constantin lonescu-Târgoviste MD, PhD, Professor, Acad (ÁR)

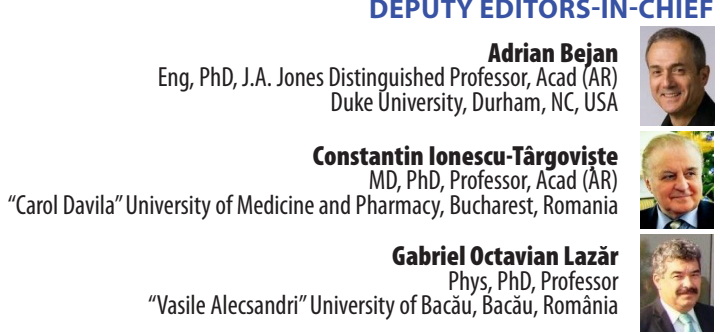

CO-EDITORS-IN-CHIEF (EUROPE)

Gavriel Chaushu

DMD, MSc, Professor, Head

Rabin Medical Center, Beilinson Campus, Petah Tikva, Israel The Maurice and Gabriela Goldschleger School of Dental Medicine

Tel Aviv University, Tel Aviv, Israel

Mutlu Özcan

DDS, PhD, Professor, Head Division of Dental Biomaterials Clinic of Reconstructive Dentistry, Center of Dental Medicine (ZZM) University of Zürich, Zürich, Switzerland

Letizia Perillo Letizia Perillo
MD, MS, PhD, Professor Head, Dean, University of Campania Luigi Vanvitelli, Naples, Italy

Hande Şar Sancakli DDS, PhD, Associate Professor

FDI Regional CE Director Europe, Geneva-Cointrin, Switzerland
SENIOR EDITORS

Bruce Robert Donoff

DMD, MD, Professor, Dean Medicine Harvard University, Boston, MA, USA

Rolf Ewers

MD, DMD, PhD Professor and Chairman em. Medical University of Vienna, Vienna, Austria

Adrian Podoleanu Eng, PhD, Professor, FinstP, FOSA, FSPIE, Professo University of Kent, Canterbury, Kent, UK

Saman Warnakulasuriya BDS, FDSRCS (Eng), FDSRCS (Edin), FDSRCPS (Glasg), PhD(Glasg) DSC, FKC, Professor King's College London, London, UK EMERITUS EDITORS-IN-CHIEF

Prathip Phantumvanit DDS, MS, FRCDT, Professor Thammasat University, Bangkok, Thailand

Rudolf Slavicek MD, DMD, Professor Medical University of Vienna, Vienna, Austria Jacques Vanobbergen MDS, PhD, Professor Em. Professor and Chairman Gent University, Gent, Belgium

Julian B. WOELFEL

DDS, FACD, FICD, Professor Emeritus College of Dentistry, The Ohio State University, Columbus, Ohio, U.S.A David Wray MD (Honours), BDS, MB ChB, FDS, RCPS (Glasgow), FDS RCS (Edinburgh) F Med Sci Professor Emeritus, Professor, University of Glasgow, Glasgow, UK
SECTIONS EDITORS

Joseph Nissan, DMD, Editor-in-Chief Paula Perlea, DDS, PhD, Co-Editor-in-Chief

Basic Research / Dental Materials / Dental Technology Gottfried Schmalz, DDS, PhD, Dr hc, Acad (Leopoldina), University of Regensburg, Regensburg, Germany Editor-in-Chief

Vasile Iulian Antoniac, Eng, PhD, Habil, Vice Dean, University "Politehnica" of Bucharest, Bucharest, Romania Bogdan Calenic, DDS, PhD, "Carol Davila" University of Medicine and Pharmacy Bucharest, Bucharest, Romania Horia Octavian Manolea, DMD, PhD, Head, University of Medicine and Pharmacy of Craiova, Dolj, Romania Annalisa Monaco, DDS, MSC, PhD, University of L'Aquila, L'Aquila, Italy
Clinical Research / Oral and Dental Diagnosis / Dental Radiology / Evidence-Based Dentistry

Sorin Uram-Țuculescu, DDS, PhD, Virginia Commonwealth University, Richmond, VA, USA - Editor-in-Chief Amid I. Ismail, BDS, MPH, MBA, Dr PH, Dean, Temple University, Philadelphia, PA, USA

Fawad Javed, BDS, PhD, University of Rochester, NY, USA Dalia Kaisarly, BDS, MDSC, PhD, University of Munich, Munich, Germany

Chiarella Sforza, MD, PhD, University of Milan, Milan, Italy

Community Dentistry / Oral Epidemiology / Oral Health / Dental Public Health / Health Promotion Poul Erik Petersen, DDS, Dr Odont, BA, MSC,

WHO Senior Consultant, University of Copenhagen, Copenhagen, Denmark - Editor-in-Chief

Noemí Bordoni, DDS, PhD, Director, Public Health Research Institute, Buenos Aires, Argentina Simona Stoleriu, DMD, PhD, "Gr. T. Popa" University of Medicine and Pharmacy lași, Iași, Romania
Mihnea Ioan Nicolescu, DMD, MD, PhD, "Carol Davila" University of Medicine and Pharmacy Bucharest, Bucharest, Romania

Mihaela Răescu, DDS, PhD, "Titu Maiorescu” University, Bucharest, Romania

Cariology / Pedodontics / Oro-Dental Prevention Luca Levrini, DDS, PhD, University of Insubria, Varese, Italy - Editor-in-Chief

Sorin Andrian, DDS, PhD, "Gr. T. Popa" University of Medicine and Pharmacy lasi, lași, Romania Dana Cristina Bodnar, DDS, PhD, "Carol Davila" University of Medicine and Pharmacy Bucharest, Bucharest, Romania

Iulia Georgievna Romanova, DMS, PhD, 0dessa National Medical University, Odessa, Ukraine Tamara Tserakhava, DDS, PhD, Belarusian State Medical University, Minsk, Belarus 
Minimally Invasive Dentistry / Dental Laser Akira Aoki, DDS, PhD, Tokyo Medical and Dental University (TMDU), Tokyo, Japan - Editor-in-Chief Marcus Oliver Ahlers, DDS, PhD, Hamburg University Eppendorf, Hamburg, Germany

Peter Hermann, DMD, MSc, PhD, Head, Vice-Rector, Semmelweis University Budapest, Budapest, Hungary Sanda-Mihaela Popescu, DDS, MSc, PhD, University of Medicine and Pharmacy of Craiova, Dolj, Romania Roman Šmucler, MD, PhD, Charles University Prague, Prague, Czech Republic

Aestethic Dentistry / Dental Photography Douglas A. Terry, DDS, PhD, University of Texas, Houston, TX, USA - Editor-in-Chief Lucian Toma Ciocan, DMD, PhD, Head, "Carol Davila" University of Medicine and Pharmacy Bucharest, Bucharest, Romania

Daniele Maria Gibelli, MD, PhD, University of Milan, Milan, Italy

Galip Gürel, DDS, MSc, Dentis Dental Clinic, Istanbul, Turkey

Henriette Lerner, DMD, PhD, HL Dentclinic \& Academy, Baden-Baden, Germany

Endodontics and Traumatology / Dental Microscopy Niraj Kinariwala, BDS, MDS, PhD, Karnavati University, Gandhinagar, India - Editor-in-Chief

Arnaldo Castellucci, DDS, PhD, University of Florence, Florence, Italy

Enrico Manca, DDS, PhD, Dental Clinic Dr. Enrico Manca, Cagliari, Italy

Paula Perlea, DDS, PhD, "Carol Davila" University of Medicine and Pharmacy Bucharest, Bucharest, Romania Zrinka Tarle, DMD, PhD, Dean, University of Zagreb, Zagreb, Croatia

Periodontology / Oral Microbiology / Dental Hygiene Mariano Alonso Sanz, DDS, MSD, PhD, Complutense University of Madrid, Madrid, Spain - Editor-in-Chief Gabriela Băncescu, MD, MSc, PhD, "Carol Davila", University of Medicine and Pharmacy Bucharest,

Bucharest, Romania

Radmila R. Obradović, DDS, PhD, University of Niš, Niš, Serbia

Alina Pürienė, BS, PhD, Dr hábil, Vilnius University,

Vilnius, Lithuania

Jon Byron Suzuki, DDS, PhD, MBA, Associate Dean, Temple University, Philadelphia, PA, USA

Oral Medicine / Oral Pathology

Mare Saag, DDS, PhD, University of Tartu, Tartu, Estonia - Editor-in-Chief

Asja Čelebić, DDS, MSc, PhD, University of Zagreb, Zagreb, Croatia

Valeriu Fala, DM, PhD, MSc, "Nicolae Testemițanu” State University of Medicine and Pharmacy, Chişinău, Republic of Moldova

Maria Greabu, Chem, PhD, Head, "Carol Davila" University of Medicine and Pharmacy Bucharest, Bucharest, Romania

Mei-Qing Wang, DDS, PhD, Air Force Medical University (AFMU), Xi'an, Shaanxi, P.R.China

Occlusion and TMJ / Orofacial Pain / Dental Occlusion and Posture

Noshir R. Mehta, DMD, MDS, MS, Associate Dean, Tufts University, Boston, MA, USA - Editor-in-Chief Nader Farhan Abdulhameed, BDS, MS, MSC, PhD, LECOM School of Dental Medicine, FL, USA Rafael Benoliel, DDS, PhD, BDS, Associate Dean, The State University of New Jersey, Newark, NJ, USA Jean-Daniel Orthlieb, DDS, PhD, Vice-Dean, Aix Marseille University, Marseille, France

Sven Erik Widmalm, DDS, Dr Odont, University of Michigan, Ann Arbor, MI, USA

Orthodontics and Dento-Facial Orthopedics Moschos A. Papadopoulos, DDS, DMD, Chairman, Aristotle University of Thessaloniki, Thessaloniki, Greece - Editor-in-Chief

Fabrizia d'Apuzzo, DDS, MSC PhD, Research Fellow, University of Campania "Luigi Vanvitelli", Naples, Italy Stella Chaushu, DMD, PhD, Chair, Hebrew University Hadassah Jerusalem, Jerusalem, Israel

Ecaterina lonescu, DDS, PhD, Vice-Rector, "Carol Davila" University of Medicine and Pharmacy Bucharest, Bucharest, Romania

Abdolreza Jamilian, DDS, PhD, Tehran University of

Medical Sciences, Tehran, Iran
Anesthesiology / Dentoalveolar Surgery / Maxillofacial Surgery / Oral Implantology / Emergencies at the Dentist's

Michael Frank, DDS, PhD, ERO President, German Dental Chamber, Frankfurt am Main, Germany -

Editor-in-Chief

Cristian Niky Cumpătă, DMD, MD, MSc, PhD, "Titu Maiorescu" University Bucharest, Bucharest, Romania Joel Motta Junior, DMD, PhD, State University of

Londrina, Londrina, Brazil

Giorgio Lombardo, MD, DDS, University of Verona, Verona, Italy

Heinz Kniha, DDS, MD, PhD, Ludwig-Maximilians München University, München, Germany

Prosthetic Dentistry / Oral Rehabilitation / Gerodontology Veronica Mercuț, DMD, PhD, Vice-Rector, University of Medicine and Pharmacy Craiova, Dolj, Romania Editor-in-Chief

Emilian Hutu, DDS, PhD, "Carol Davila" University of Medicine and Pharmacy Bucharest, Bucharest, Romania Marina Meleșcanu-Imre, DDS, PhD, "Carol Davila" University of Medicine and Pharmacy Bucharest,

Bucharest, Romania

Vjekoslav Jerolimov, DDS, PhD, Acad (CASA), University of Zagreb, Zagreb, Croatia

Anastassia E. Kossioni, DDS, PhD, University of Athens, Athens, Greece

Restorative Dentistry / Computerized Dental Prosthetics François Duret, DDS, DSO, PhD, MS, MD, PhD, Acad (ANCD), University of Montpellier, Montpellier, France Editor-in-Chief

Andreas Bindl, DMD, MSc, PhD, University of Zürich, Zürich, Switzerland, Switzerland

Joannis Katsoulis, DMD, PhD, University of Bern, Bern, Switzerland

Georg B. Meyer, DMD, PhD, Dr hc, Chairman, ErnstMoritz-Arndt University, Greifswald, Germany Roberto Carlo Spreafico, MD, DMD, Busto-Arsizio, Milan, Italy

EDITORIAL ADVISORY BOARD SECTIONS Stephen F. Rosenstiel, BDS, MSD, Prof. Em. Editor-in-Chief

Andrei Cristian lonescu, DDS, PhD,

Co-Editor-in-Chief

Basic Research / Dental Materials / Dental Technology Ralf Janda, Chem, Dr rer nat, Habil, Heinrich-HeineUniversity Düsseldorf, Düsseldorf, Germany-

Editor-in-Chief

Andrei Cristian Ionescu, DDS, PhD, University of Milan Milan, Italy

Nikolay Ishkitiev, DMD, PhD, Medical University of

Sofia, Sofia, Bulgaria

Clinical Research / Oral and Dental Diagnosis / Dental Radiology / Evidence-Based Dentistry Rodolfo Isaac Miralles Lozano, MD, PhD, University of Chile, Santiago, Chile - Editor-in-Chief

Cristina Teodora Preoteasa, DMD, PhD, "Carol

Davila" University of Medicine and Pharmacy Bucharest, Bucharest, Romania

Robert Sabiniu Şerban, Eng, PhD, MSc, "Carol Davila" University of Medicine and Pharmacy Bucharest, Bucharest, Romania

Community Dentistry / Oral Epidemiology / Oral Health / Dental Public Health / Health Promotion

Amar Hassan Khamis Mohamed Omer, PhD, DEA

MSC, BSC, Mohammed Bin Rashid University of Medicine and Health Sciences, Dubai, UAE - Editor-in-Chief Nina Mussurlieva, DDS, PhD, Medical University of Plovdiv, Plovdiv, Bulgaria

Aldo Fabián Squassi, DDS, PhD, Chair, University of Buenos Aires, Buenos Aires, Argentina

Cariology / Pedodontics / Oro-Dental Prevention

Vlademir Margvelashvili, MD, PhD, DMSci, Tbilisi State University, Tbilisi, Georgia - Editor-in-Chief

Dorjan Hysi, DDS, PhD, University of Medicine of Tirana, Tirana, Albania

Rodica Luca, DDS, PhD, "Carol Davila” University of

Medicine and Pharmacy Bucharest, Bucharest, Romania
Minimally Invasive Dentistry / Dental Laser

Domenico Massironi, DDS, MEG - Master Educational Group, Melegnano (MI), Italy - Editor-in-Chief Joanna Kempler, DDS, PhD, University of Maryland, Baltimore, MD, USA

Vygandas Rutkūnas, DDS, PhD, Vilnius University, Vilnius, Lithuania

Aestethic Dentistry / Dental Photography

Bernard Touati, DDS, PhD, Paris V University, Paris, FranceEditor-in-Chief

John C. Kois, DMD, MSD, Kois Center, LLC, Seattle, WA, USA

Joseph Nissan, DMD, Tel Aviv University, Tel Aviv, Israel

Periodontology / Oral Microbiology / Dental Hygien Anton Sculean, DMD, MS, Dr hc, University of Bern, Bern, Switzerland - Editor-in-Chief

Mario R. Cappellin, DDS, MBE, Clinica dentale Cappellin srl, Pinerolo (TO), Italy

Marian Negut, MD, PhD, Acad (ASM), "Carol Davila",

University of Medicine and Pharmacy Bucharest,

Bucharest, Romania

Oral Medicine / Oral Pathology

Ingrīda Čēma, DDS, PhD, Riga Stradins University,

Riga, Latvia - Editor-in-Chief

Romeo Călărașu, MD, PhD, Acad (ASM), "Carol Davila”,

University of Medicine and Pharmacy Bucharest,

Bucharest, Romania

Rashmi GS Phulari, BDS, MDS, Bhavnagar University, Vadodara, India

Occlusion and TMJ / Orofacial Pain / Dental Occlusion and Posture

Gregor Slavicek, DDS, PhD, Steinbeis University Berlin, Berlin, Germany - Editor-in-Chief

Minh Son Nguyen, DDS, PhD, Head, Danang University of Medical Technology and Pharmacy, Danang, Vietnam Sever Toma Popa, DDS, PhD, "Iuliu Hatieganu” University of Medicine and Pharmacy, Cluj-Napoca, Romania

Orthodontics and Dento-Facial Orthopedics Fabio Savastano, MD, MOrth, Jaume I University, Castellón de la Plana, Castellón, Spain - Editor-in-Chie Andreu Puigdollers-Pérez, DDS, PhD, International University of Cataluña (UiC), Barcelona, Spain Irina Nicoleta Zetu, DDS, PhD, "Gr. T. Popa" University of Medicine and Pharmacy lași, lași, Romania

Anesthesiology / Dentoalveolar Surgery / Maxillofacial Surgery / Oral Implantology / Emergencies at the Dentist's

Nardi Casap-Caspi, DMD, MD, Hebrew University Hadassah Jerusalem, Jerusalem, Israel -

Editor-in-Chief

Andrezza Lauria de Moura, DMD, PhD, Federal

University of Amazonas (FAO-UFAM), Manaus -

AM, Brazil

Gianluca Martino Tartaglia, DDS, PhD, University of

Milan, Milan, Italy

Prosthetic Dentistry / Oral Rehabilitation / Gerodontology Grigorios Polyzois, DDS, Dr. Dent, MScD, Nationa and Kapodistrian University of Athens, Athens, Greece Editor-in-Chief

Elena Preoteasa, DDS, PhD, “Carol Davila” University of Medicine and Pharmacy Bucharest, Bucharest, Romania Martina Schmid-Schwap, DDS, PhD, Medical University of Vienna, Vienna, Austria

Restorative Dentistry / Computerized Dental Prosthetics Stephen F. Rosenstiel, BDS, MSD, Prof. Em., The Ohio State University, Columbus, USA - Editor-in-Chief Mariam Margvelashvili-Malament, DDS, MSC, PhD, Tufts University, Boston, MA, USA

Alexandru Eugen Petre, DDS, PhD, "Carol Davila" University of Medicine and Pharmacy Bucharest, Bucharest, Romania

ENGLISH LANGUAGE EDITOR-IN-CHIEF

Roxana-Cristina Petcu, Faculty of Foreign Languages, University of Bucharest, Bucharest, Romania

ENGLISH LANGUAGE EDITORS

Valeria Clucerescu, Biol., Bucharest, Romania

Diana Florea, Phil, PhD, Bucharest, Romania 
HONORARY STATISTICAL ADVISERS

Radu Burlacu, PhD, Bucharest, Romania

Amar Hassan Khamis Mohamed Omer, PhD, DEA

BOOKS REVIEWERS

Iulia Ciolachi, DMD, Bucharest, Romania

Florin-Eugen Constantinescu, DMD, PhD Student, Bucharest, Romania

JOURNAL MANAGER

loana Bălan, Maths, MSc, Bucharest, Romania

PROJECT EDITOR

Irina-Adriana Beuran, DMD, PhD, Bucharest, Romania

Carmen Liliana Defta, Biol, PhD, Bucharest, Romania

Alexandra Popa, Bucharest, Romania
TECHNICAL EDITORS

Gabriel Octavian Lazăr, Bucharest, Romania

Valentin Miroiu, Bucharest, Romania

Edgar Moraru, Bucharest, Romania

Edgar Moraru, Bucharest, Romania

Johannes Friedrich Carl Rohr, Riga,

DTP / GRAPHIC \& WEB DESIGNER

Valentin Miroiu, Bucharest, Romania

\section{EBSCO \\ $\theta$ \\ Academic \\ Search ${ }^{\text {TM }}$ \\ Ultimate \\ J-cate \\ I N DEXED \\ 5) WorldCat \\ Dimensions \\ KUDOS \\ Crossref \\ U. UNIVERSITY \\ "R OF WW YOMING

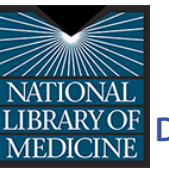 \\ $\mathrm{DQ} \widehat{A D} \equiv$ Google publons

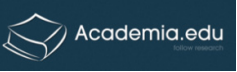 \\ 1) ICMJE \\ INTERNATONAL COMMIITTEE OS
MEDICAL JOUR NAL EDITORS \\ INFOBASE INDEX

The Stomatology Edu Journal (Stoma Edu J) is a scientific magazine of the Romanian Association of Oral Rehabilitation and Posturotherapy ROPOSTURO, a partner of the FDI regular member, the Romanian Society of Stomatology - RSS (founded in 1923) under the aegis of The Romanian Academy.

\section{Editor Office}

Stomatology Edu Journal, 102-104 Mihai Eminescust. $2^{\text {nd }}$ District, RO-020082 Bucharest, ROMANIA Tel/Fax: +40314327930

e-mail: stomatology.edu@gmail.com www.stomaeduj.com

\section{Editors-in-Chief}

Marco Ferrari, Constantinus Politis

Marian-Vladimir Constantinescu

\section{Managing Editor}

Florin-Eugen Constantinescu

\section{ROPOSTURO}

Romanian Association of Oral Rehabilitation and Posturotherapy

10, Ionel Perlea St., $1^{\text {st }}$ District

R0-010209 Bucharest, Romania

Tel: +4021 314 1062; Fax: +4021 3121357

e-mail: roposturo@gmail.com www.roposturo.ro

\section{Technical Editors}

Gabriel Octavian Lăzar

Valentin Miroiu

Edgar Moraru

Mirel Toma

\section{Project Editor}

Irina-Adriana Beuran

\section{Design Editor}

Ovidiu Zanfir

\section{Cover by}

Arch. Florin Adamescu

\section{Publisher Office}

Romanian Academy Publishing House

Calea 13 Septembrie, ${ }^{5^{\text {th }}}$ District

R0-050711 Bucharest, Romania

Tel: +40213188146

Fax: +40213182444

e-mail: edacad@ear.ro

www.ear.ro

\section{Technical Editor}

Doina Argeșanu

Editorial Assistant

Monica Stanciu

\section{Computer Editing}

Iolanda Povară

All the original content published is the sole responsibility of the authors. All the interviewed persons are responsible for their declaration and the advertisers are responsible for the information included in their commercials. 


\section{COVID-19 and academic publishing ranking}

Constantinus Politis

MD, DDS, MM, MHA, PhD

Professor \& Chairperson

Editor-in-Chief

Dear Readers,

In a section of Foreign Affairs (Volume 100, Number 5, 2021), Dr. Chonira Aturupane of Stanford University points out that during the COVID-19 pandemic a number of challenges stood in the way of effective policymaking: the prevalence of unreliable information; the degree to which uncertainty and unpredictable factors can derail the best-laid plans; the importance of comprehensive and feasible implementation plans. We will concentrate on the first issue, the importance of credible data.

Credible data, reliable information in science does not equal the absence of fake news. Credibility in scientific reporting requires at least the following dimensions to be assessed: method and data transparency; adequate sample size and power; validity of the data; adequate use of secondary data; analytic reproducibility and robustness; effect replicability; independent study sponsoring. Respecting all these requirements should lead to evidence-based data and evidence-based medicine (EBM).

Yet, on the reporting site in journals, the cornerstone of EBM has shifted far too much from original research towards the higher positioned systematic reviews and meta-analysis. Many thousands of pages have been filled with answering questions nobody was waiting for. Further on, unexperienced readers should not assume that level 1 evidence is always the best choice or appropriate for the research question. An item often overlooked is the natural history of a condition. For reviewers of most journals it is nearly impossible to adequately assess all items which define the quality of a study: randomization, blinding, a description of the randomization and blinding process, description of the number of subjects who withdrew or dropped out of the study; the confidence intervals around study estimates, and a description of the power analysis and the statistical methods used. Most reviewers are no statisticians.

This only can be solved if the number of journals is sufficiently reduced to allow for a thorough change of the review process. Before getting to the clinical reviewers, language experts should filter out inadequate manuscripts and trained statisticians should filter out studies which are underpowered, unvalidated or illdesigned. Only then should clinical reviewers assess the manuscript. This requires journals to be digital only with a well-developed staffing connected in the cloud and funded by independent academic consortia. The digital only version, and of course open access, allows for post-hoc comments or corrections to be added as a section to published papers.

As for systematic reviews and meta-analysis, these are very often conducted by PhD students or Master students in the fullfillment of a PhD or a Masters Program. It is cheap, fills pages, whether the question is relevant or not. It is very often easily accepted in high ranked journals, creating easily gained impact factors, citations and h-index points, and all of this usually at a young research age.

It is time to attach less importance to systematic reviews if the question they try to answer is not relevant. More is to be gained in well-conducted clinical research, but this is tedious work requiring resources and an experienced research team. In the clinical reality of surgical departments this is a rare phenomenon. The consequence of this surgical reality is that younger surgeons write manuscripts and publish articles and seasoned surgeons write book chapters or books or invited sessions in journals.

There is yet another way skilled surgeons can contribute to journals and science. Through their scientific societies, often in joined efforts with representatives of sister organisations, they can aim for concensus 
statements and guidelines. Professor Hendrik Terheyden, editor-in-chief of the International Journal of Implant Dentistry has guided the International Academy for Oral and Facial Rehabilitation (IAOFR) to work along these lines. The IAOFR, presided by Prof. Dr. Piet Haers, is an international group with more than 30 years of continuous history in the field of oral and facial rehabilitation of patients with innate or acquired tooth loss or defects of the jaws and the craniofacial region. This group has an international composition, high scientific expertise and independence. Consensus Statements and Guidelines can target a worldwide audience of practitioners, clinicians and patients. The methodology used is in accordance with the GIN-McMaster Guideline Development Checklist, the AWMF Guidance Manual and Rules for Guideline Development, and the policies of the Guidelines International Network. All this information is freely accessible on the internet. Consensus Statements and Guidelines allow for a corridor of accepted clinical treatment or pathways, excluding under-therapy, over-therapy, false therapy, obsolete therapy. Consensus Statements and Guidelines try to identify a standard of care and have the character of a recommendation to clinicians in standard clinical situations and a standard clinical environment without any legal force. Consequently, clinicians can deviate from recommendations in specific cases and situations. Consensus Statements and Guidelines can also be of help for informed patients for participative therapeutic decisions. Guidelines also provide tools for policymakers.

Conflicts of interest need to be addressed in a transparent way. The policy of an independent guideline group requires a declaration, evaluation and management of conflicts of interest of every participant of the guideline group because the guideline should not be vulnerable to competing interests of industry companies or competing societies afterwards. A listing of possible conflicts of interest of the participants should be forwarded to all participants in advance of the consensus meeting.

Since medicine is a quickly evolving field each statement and guideline expires 3 years after publication. The 'Terheyden-Haers doctrine' not only allows seasoned and skilled surgeons to combine surgical experience with common sense and scientific rigor but to translate the surgeon's group-knowledge into answers to questions which are relevant to patients and society at large.

Journals will remain necessary for those who pursue academic careers and are in need of citations, $\mathrm{h}$-index scores to advance in the academic ranking. The perverse side-effect however is that Universities and Academic Institutions in so-doing make publishers of scientific journals with paid 'open access' filthy rich, while at the same time depriving a mass of interested parties of scientific information. It is high time that universities embrace unpaid open access and look for alternatives beyond the $h$-indexes and citation indices to appreciate the scientific value of young academics.

Sincerely yours,

Constantinus Politis $[$ -

MD, DDS, MM, MHA, PhD

Professor \& Chairperson

Editor-in-Chief 


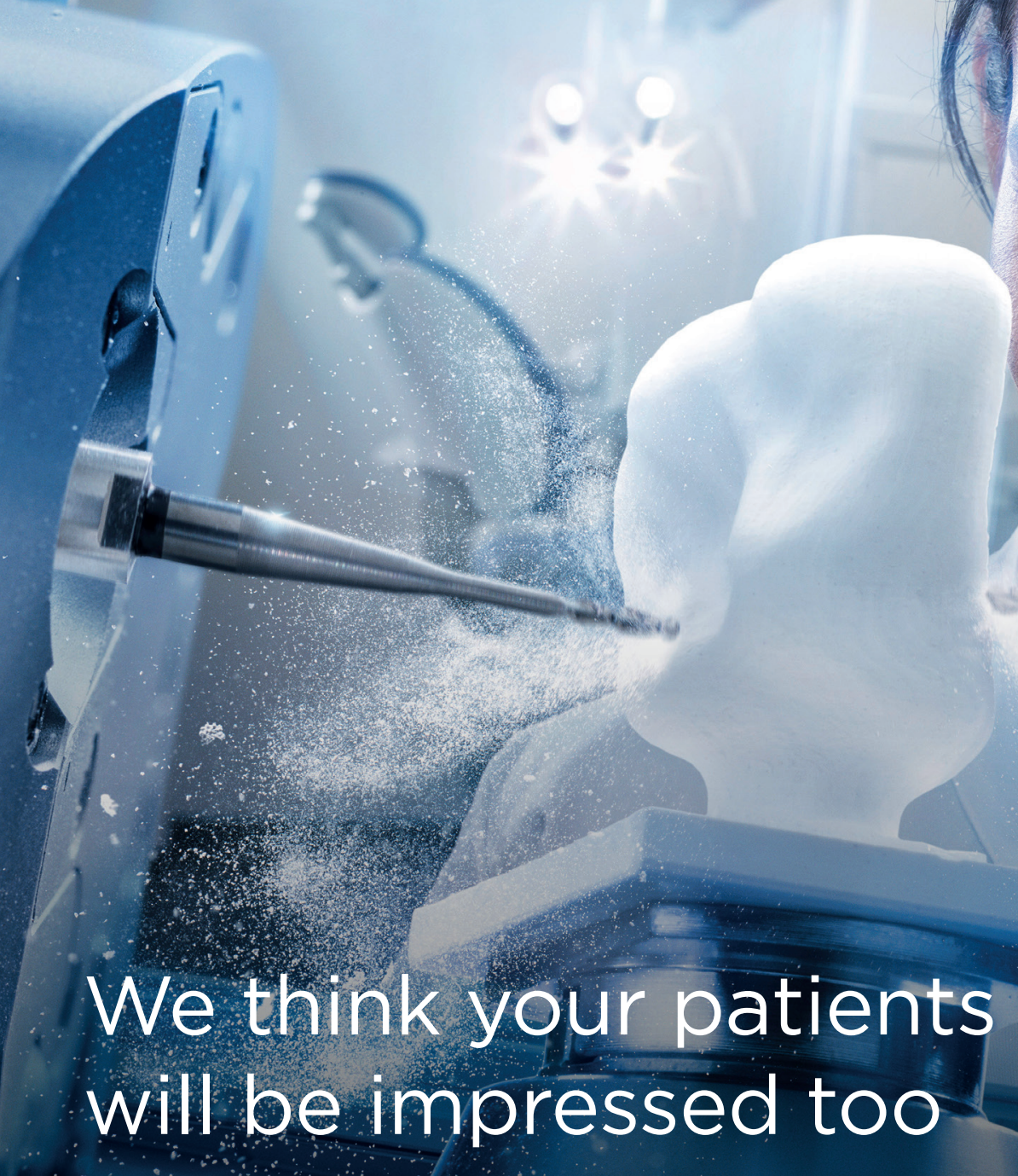

Speed, quality and efficiency. That's what CEREC is all about. The newly upgraded CEREC System raises digital chairside dentistry to unprecedented levels of predictability, performance, user-friendliness, and patient satisfaction. Now you can move from scanning to milling in just five clicks, and fit a new zirconia crown in around sixty minutes - all made possible through outstanding technology. And with our intuitive software operating across the whole system, you can maximise the benefits of automation. By integrating into your practice and workflows, CEREC combines all its expertise with yours, to help you achieve your best work every day.

CEREC: Where technology meets experience

Learn more at: dentsplysirona.com/cerec 


\section{Give your life some flow. We will fix it at work.}

Do something you love on your day off. It may lead you to a state of flow, where the difficult becomes easy and you can do anything-a wonderful and rewarding feeling.

Guess what? You can experience that at work too. Just tell us about your business needs, challenges and way of working. Based on that, we suggest solutions that save time and effort, while helping you achieve the best possible results for your patients.

Of course, anyone can promise this, but we are the ones who can really make your work flow.

\section{Find your flow \\ in implant dentistry}

dentsplysirona.com/makingyourworkflow 


\section{stomacduj}

Stoma Edu J. 2021;8(3):155

From The Journal of the American Dental Association

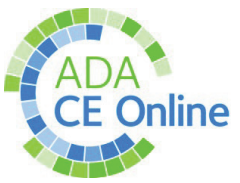

\section{JADA ONLINE CE EXAMS \\ http://jada.ada.org/ce/home \\ http://jada.ada.org/ceworksheets}

August 01, 2021

ANDREI CRISTIAN IONESCU, EUGENIO BRAMBILLA, LAMBERTO MANZOLI, GIOVANNA ORSINI, VALENTINA GENTILI, ROBERTA RIZZO

\section{EFFICACY OF PERSONAL PROTECTIVE EQUIPMENT AGAINST CORONAVIRUS TRANSMISSION VIA DENTAL HANDPIECES}

J Am Dent Assoc. 2021 AUG 01, 152 (8): 631-640.

Doi: https://doi.org/10.1016/j.adaj.2021.03.007

https://jada.ada.org/article/S0002-8177(21)00166-5/fulltext

This article has an accompanying online continuing education activity available at:

https://doi.org/10.1016/10.1016/j.adaj.2021.03.007

PMID: 34325779

PMCID: PMC7997726

DOI: https://doi.org/10.1016/j.adaj.2021.03.007

Copyright ๑ 2020 American Dental Association. Published by

Elsevier Inc. All rights reserved.

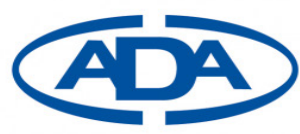

AUSTRALIAN DENTAL ASSOCIATION
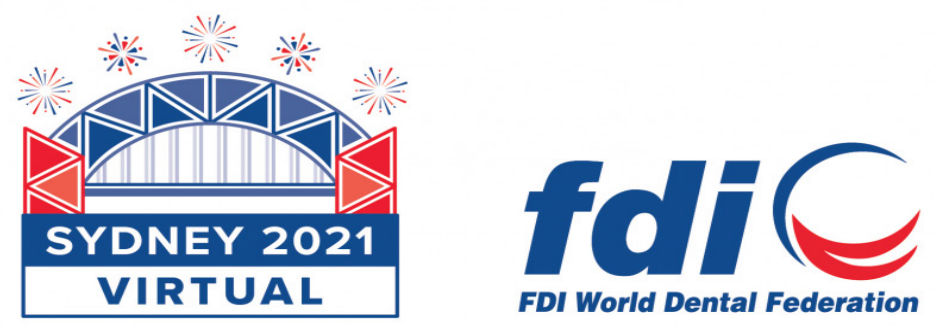

\section{World Dental Congress | Special Edition}

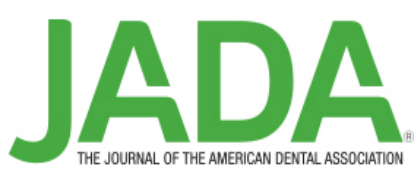




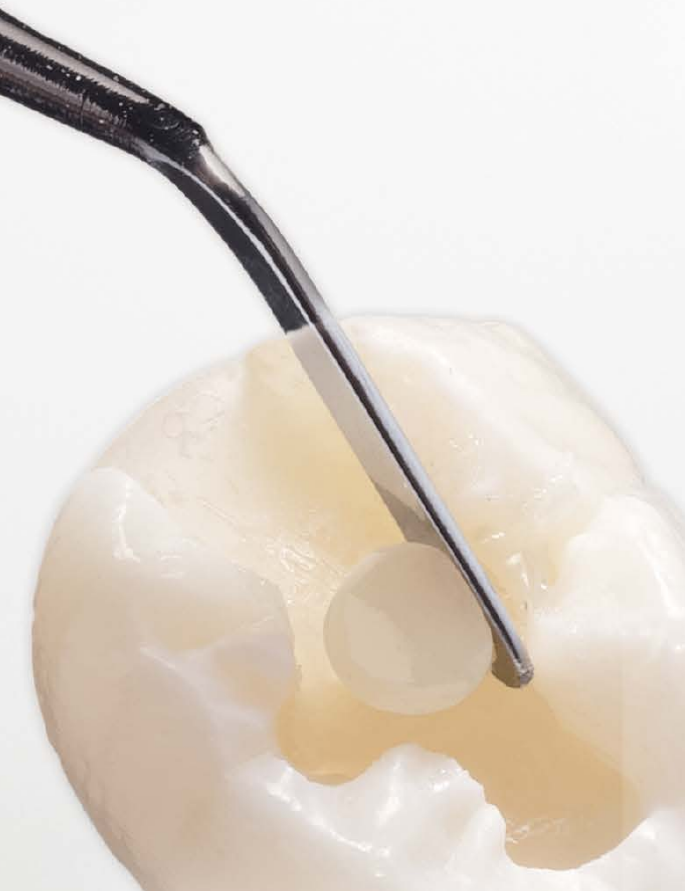

Neo Spectra ${ }^{\text {TM }}$ ST

Your most common cases, covered.
Neo Spectra ${ }^{\text {TM }}$ ST Effects

Complex anterior cases, simplified.

\section{New brand for ceram. $x^{\circ}$ SphereTEC $C^{T M}$ one composite}

\section{Efficient esthetics with \\ Neo Spectra ${ }^{\mathrm{TM}}$ ST Composites}

Our proven SphereTEC ${ }^{\circledast}$ formula now spans the full range, or 'Spectra', of shades and handling preferences, offering the perfect balance of everything that matters most to clinicians.

Easy adaptation \& handling

- Spherical filler shape produces a "ball bearing-like" effect

Ingenious simple shading system \& accurate shade match

$\rightarrow$ Chameleon effect from precise match of fillers to resin matrix

High strength \& outstanding gloss

$\Rightarrow$ Unique, pre-polymerized submicron glass filler particle structure

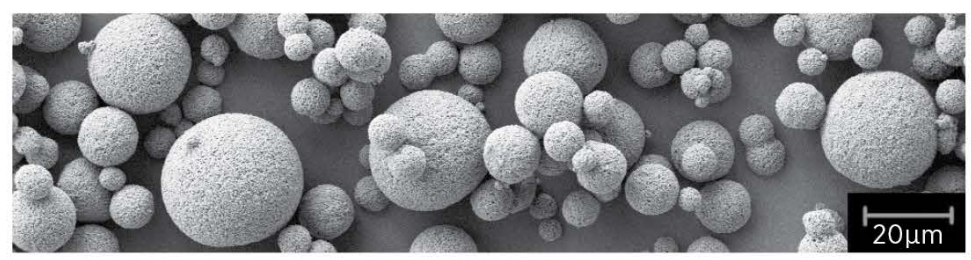

Made possible by

SphereTEC ${ }^{\circledast}$ Technology

SEM image of SphereTEC fillers 


\title{
MAXILLARY SINUS VOLUME IN CLEFT LIP AND PALATE PATIENTS WITH AND WITHOUT AN ORONASAL FISTULA USING CBCT
}

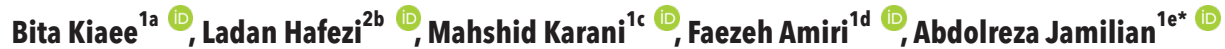 \\ 'Department of Orthodontic, Dental School, Tehran University of Medical Sciences, Tehran, Iran \\ ${ }^{2}$ Maxillofacial Radiology Department, Faculty of Dentistry, Tehran Medical Sciences, Islamic Azad University, Tehran, Iran \\ 'DDS, MS, Assistant Professor; e-mail: dr.bitakia@gmail.com; ORCIDiD: https://orcid.org/0000-0002-9117-3593 \\ bDS, MS, Assistant Professor; e-mail: Lhafezzi@yahoo.com; ORCIDiD: https://orcid.org/0000-0002-1727-2665 \\ 'DDS; e-mail: dr.mahkm96@gmail.com; ORCIDiD: https://orcid.org/0000-0002-8586-3846 \\ dDDS; e-mail: dr.faezehamiri1989@gmail.com; 0RCIDiD: https://orcid.org/ 0000-0003-0184-3061 \\ eDDS, MS, Professor; e-mail: info@jamilian.net; ORCIDiD: https://orcid.org/0000-0002-8841-0447
}

Introduction Formation of oronasal fistula is a common complication after surgical closure of cleft lip and palate (CLP). This study aimed to compare the maxillary sinus volume in 9-12-year-old CLP patients with and without an oronasal fistula who had undergone surgical closure of the cleft at 1 year of age, using conebeam computed tomography (CBCT).

Methodology This descriptive, cross-sectional, analytical study was conducted on CBCT scans of 50 patients with unilateral CLP who were between 9-12 years and had undergone surgical closure of the cleft at 1 year of age in two groups with and without an oronasal fistula $(n=50)$. The patients were selected among those presenting to a private orthodontic office between 2001-2009 and already had CBCT scans taken for orthodontic treatment. The 3D CBCT scans were reconstructed with Mimics software, and the volume of the maxillary sinuses was measured on the images. Data were compared using t-test.

Results The maxillary sinus volume was significantly smaller in patients with oronasal fistula compared with those without it $\left(9510.7 \pm 492 \mathrm{~mm}^{3}\right.$ vs. $\left.10278.2 \pm 512 \mathrm{~mm}^{3}, \mathrm{P}<0.000\right)$. The maxillary sinus of the affected side was smaller than that of the unaffected side in both groups of patients with and without an oronasal fistula $(\mathrm{P}<0.05)$.

Conclusion IImmature patients with unilateral CLP and oronasal fistula have a smaller maxillary sinus than unilateral CLP patients without an oronasal fistula, and may be at higher risk of respiratory infections.

\section{KEYWORDS}

Cone-Beam Computed Tomography; Orofacial Cleft; Fistula; Maxillary Sinus.

\section{INTRODUCTION}

The failed fusion of the medial nasal and maxillary processes would result in the occurrence of cleft lip while failed fusion of the palatine prominences would lead to the formation of a cleft palate [1,2]. Cleft lip and palate (CLP) has a prevalence of 1 per 500 live births [3]. Surgical management of CLP was first performed approximately 150 years ago [4]. At present, CLP patients often undergo surgery before the $1 \mathrm{st}$ year of age. However, an oronasal fistula may develop postoperatively due to the infection of the palate or tension of the flap, and cause problems for the patient [5]. The oronasal fistula is a common complication of surgical management of CLP with a prevalence rate of $9-50 \%$. The rate of recurrence of the fistula after surgery is as high as $35-70 \%[6,7]$.
Development of an oronasal fistula indicates failure of the surgical closure of the palate to obstruct the communication between the oral and the nasal cavity.

According to the classification by Pittsburg, seven types of fistula are present [8], which can be symptomatic or asymptomatic. Symptomatic fistula can cause several complications such as leakage of foods and drinks from the oral cavity into the nasal cavity, bad odor, rhinitis, impaired hearing, hypernasality, infection, and speech problems $[7,9,10]$.

CLP patients often suffer from decreased maxillary sinus volume and significant esthetic impairments due to the maxillary deficiency at the midface, where the maxillary sinuses are located. These patients often develop recurrent sinusitis for no clear reason. 
Also, they have smaller sinuses due to a different developmental process during the embryonic stage, surgical scars, recurrence of fistula, leakage of foods and liquids into the nasal cavity, frequent infections, and different pattern of air circulation in the nose and sinuses $[1,8,11-14]$.

Several studies have been conducted on CLP patients using 2D lateral cephalometry, which has high diagnostic accuracy for clinical applications, despite simplicity and low cost [15-20]. However, conebeam computed tomography (CBCT) has become increasingly popular in the recent years due to its higher accuracy at a comparable cost.

Controversy exists regarding the maxillary sinus volume in CLP patients such that some studies reported a significantly smaller volume of the maxillary sinuses in CLP patients compared with normal individuals [15,21-23] while some others found no significant difference in this respect $[8,11,24-26]$. Considering the existing controversy in this respect, and the gap of information regarding the maxillary sinus volume in patients who developed an oronasal fistula after surgery compared with those who did not, this study aimed to compare the maxillary sinus volume in 9-12-year-old CLP patients with and without an oronasal fistula who had undergone the surgical closure of the cleft at 1 year of age using CBCT. The null hypothesis was that no significant difference would be found in the maxillary sinus volume between CLP patients with and without oronasal fistula.

\section{MATERIALS AND METHODS}

This descriptive, cross-sectional, analytical study was conducted on 50 unilateral CLP patients between 9-12 years who had undergone surgical closure of the cleft at 1 year of age in two groups with and without oronasal fistula $(n=50)$. The patients were selected from among those presenting to a private orthodontic office in Tehran between 2010-2019 and who already had CBCT scans taken for orthodontic treatment. The study was approved by the ethics committee of School of Dentistry (IR.IAU.DENTAL. REC.1399.19).

The sample size was calculated to be 25 for each group according to the results of a pilot study on 10 patients from each group considering $\alpha=0.05, \beta=0.2$, mean maxillary sinus volume of $10671 \mathrm{~mm} 3$ and $10081 \mathrm{~mm} 3$ in the two groups and standard deviation of $715 \mathrm{~mm} 3$ using two-sample t-test, assuming equal variances in PASS 15.

The CBCT scans of unilateral CLP patients between 9-12 years who had undergone surgical closure of the cleft at 1 year of age were retrieved from the archives of a private orthodontic office from 2010-2019 by convenience sampling, and assigned to two groups with and without oronasal fistula.

The inclusion criteria were age between 9-12 years, history of surgical closure of the cleft before 1 year of aae. and cervical vertebral stage (CVS) 2 or 3 (on sagittal CBCT scans). The CVS of each patient was determined by two examiners after reaching a consensus.

The exclusion criteria were history of previous orthodontic treatment, orthognathic surgery, trauma, syndromes, frequent colds (more than 6 times in 1 year), medication intake at the time of $C B C T$, inflammatory diseases of the upper airways at the time of $C B C T$, and systemic conditions.

All CBCT images had been obtained in standard upright position with maximum intercuspation. Also, all images had been taken with NewTom 5G CBCT scanner (NEWTOM | CEFLA S.C., Imola, Italy) with a total scanning time of 14-18 s, $3.4 \mathrm{~s}$ exposure time, and $0.3 \mathrm{~mm} 3$ voxel size. Three-dimensional reconstruction of images was performed according to the Demirtas method [11].

After standardization of images, the maxillary sinus volume was quantified. For this purpose, first the skeletal borders adjacent to the sinus structure were were traced.
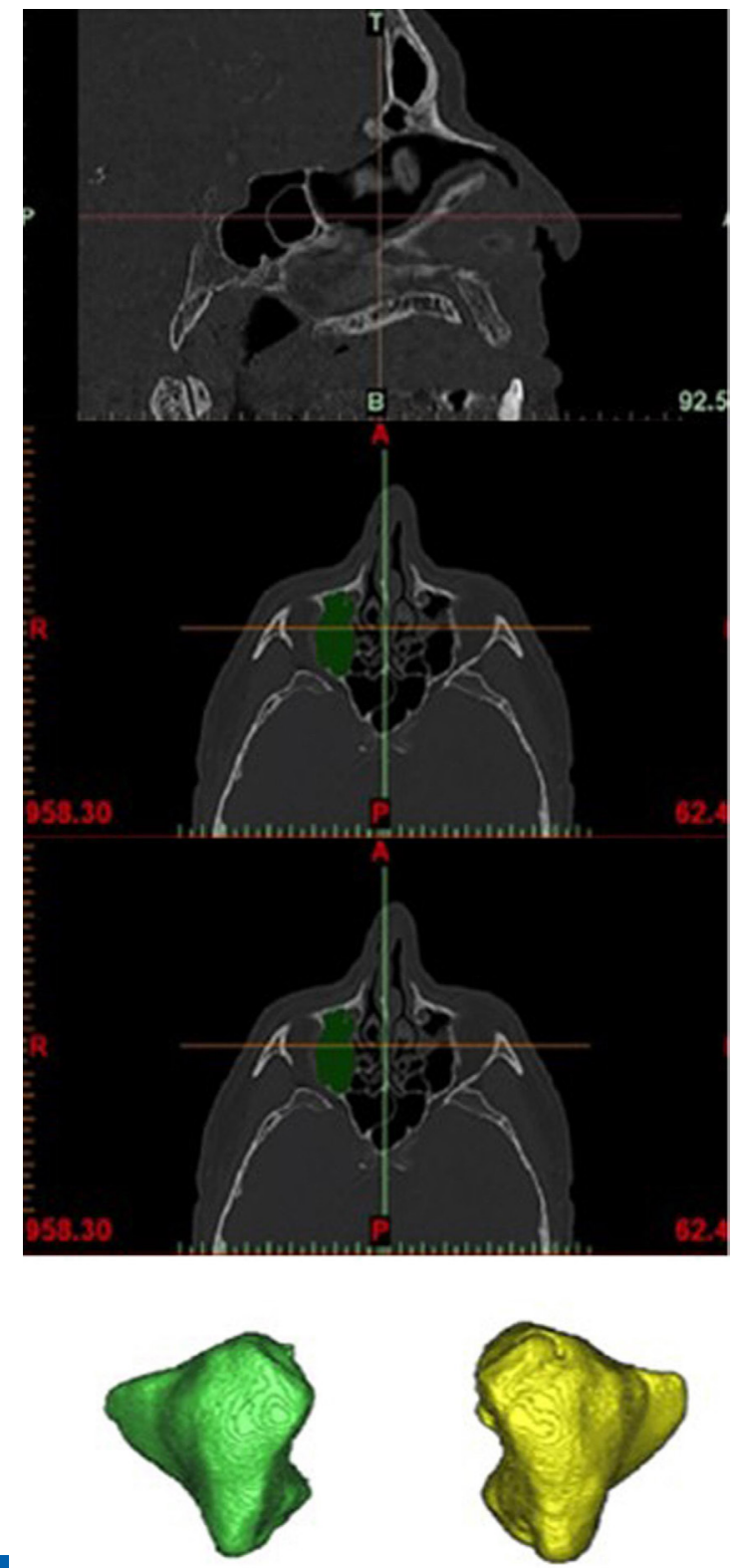

Figure 1. Quantification of the maxillary sinus volume on axial, sagittal and coronal $\mathrm{CBCT}$ sections using the Mimics software. 

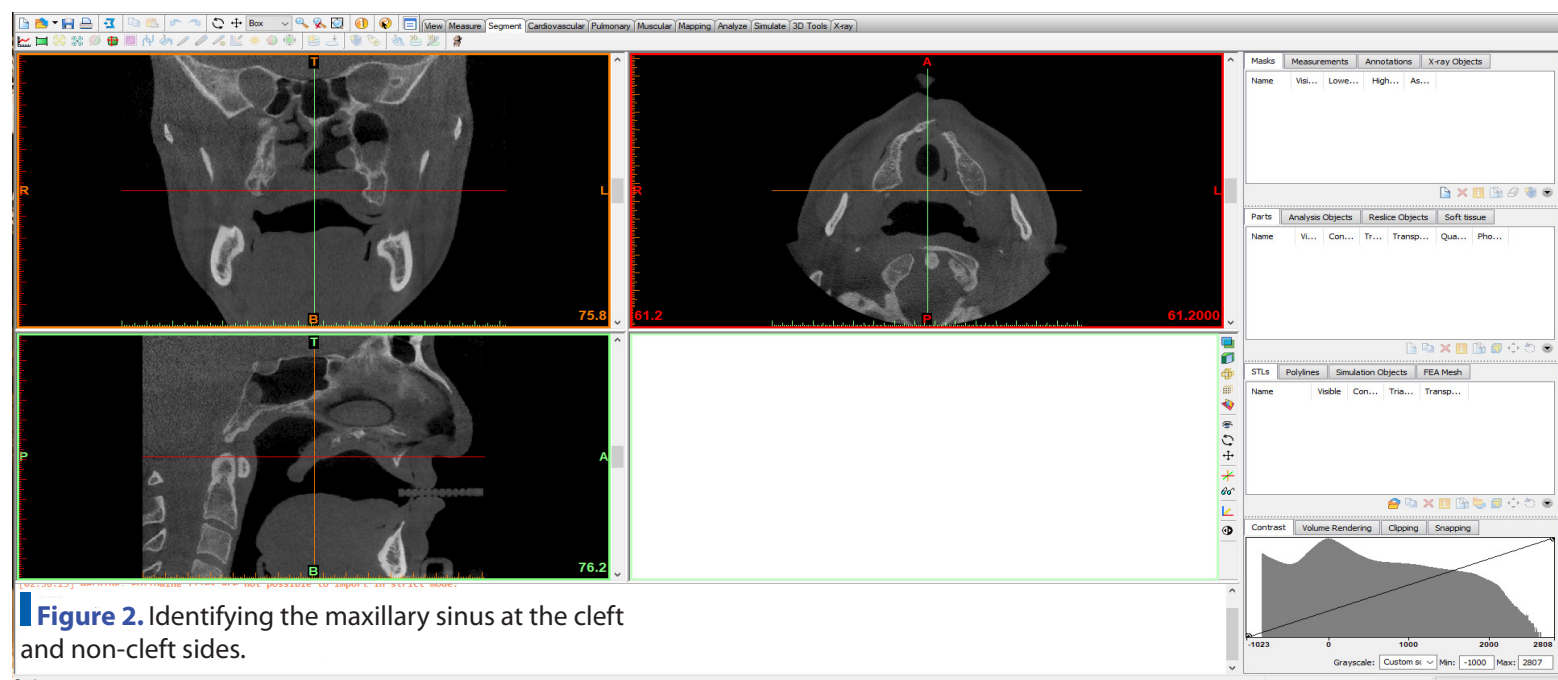

\section{and non-cleft sides.}

Figure 2. Identifying the maxillary sinus at the cleft

Next, the sinus area between the bones and the area between the infundibulum and the uncinate process was measured (Figs 1 and 2). Then, a 3D model was prepared to assess the sinus volume. After image reconstruction and standardization of orientation in axial, coronal and sagittal planes, the Mimics software suite-20 (Materialise, 3001 Leuven, Belgium) was used for the measurements.

The data were analyzed by SPSS version 22 using t-test. All measurements were repeated on 20 randomly selected $\mathrm{CBCT}$ scans after a 2 -week interval by another examiner, and the reliability of the measurements was ensured by test-retest reliability. Since $R$ was found to be $>0.8$, the results were found to be adequately reliable.

\section{RESULTS}

This study evaluated 50 patients including 25 with and 25 without oronasal fistula. The group with oronasal fistula included 17 females (66\%) and 8 males (34\%) with a mean age of $10 \pm 1$ years. Of all, 30 patients (80\%) were in CVS II (15 from each group) and 10 (20\%) were in CVS III (5 from each group). The control groups were matched with the test group in terms of age, CVS and gender.

Table 1 presents the mean maxillary sinus volume in the two groups of patients. As shown, the maxillary sinus volume at the cleft side of patients with oronasal fistula was significantly lower than that at the cleft side of patients without fistula $(P<0.000)$. The maxillary sinus volume at the non-cleft side of patients with oronasal fistula was also significantly lower than that at the non-cleft side of patients without fistula $(P<0.000)$. The maxillary sinus volume at the cleft side was significantly smaller than that at the non-cleft side in patients with $(P<0.000)$ and without $(P<0.000)$ oronasal fistula.

\section{DISCUSSION}

This study compared the maxillary sinus volume in 9-12-year-old CLP patients with and without oronasal fistula who had undergone surgical closure of the cleft at 1 year of age using CBCT. The null hypothesis was that no significant difference would be found in the maxillary sinus volume between CLP patients with and without oronasal fistula. The results showed that the maxillary sinus volume was significantly smaller in patients with oronasal fistula compared with those without it. Also, the maxillary sinus volume in the cleft side was significantly smaller than that in the non-cleft side in both groups. Thus, the null hypothesis of the study was rejected. The smaller size of the maxillary sinus at the cleft side can be due to different developmental processes during the embryonic stage, maxillary deficiency, surgical scars, recurrence of fistula, leakage of foods and liquids into the nasal cavity and frequent infections, and different patterns of air circulation in the nose and sinuses. The present results were in agreement with those of Demirtas et al [11]. Our methodology was also similar to that of Demirtas et al, [11] although they did not assess the effect of the presence of oronasal fistula on the maxillary sinus volume; however, they assessed patients with a mean age of 13.5 years while we evaluated patients between 9-12 years. The assessment of patients in this age range was an advantage since evidence shows airway growth and development in two periods of 6-9 and 12-15 years, with an interval between 9-12 years [27]. Also, CBCT images are not often obtained from patients younger than 9 years of age (CBCT is often first requested for grafting prior to canine eruption). Moreover, the soft tissue becomes more stable after 9 years of age. Erdura et al. [8] evaluated the maxillary sinus volume of

ITable 1. Mean maxillary sinus volume in the two groups of patients with and without oronasal fistula.

\begin{tabular}{|l|l|l|l|}
\hline Maxillary sinus volume & $\begin{array}{l}\text { Sinus volume at the } \\
\text { cleft side } \\
\text { Mean } \pm \text { std. deviation }\end{array}$ & $\begin{array}{l}\text { Cinus volume at the } \\
\text { non-cleft side } \\
\text { Mean } \pm \text { std. deviation }\end{array}$ & P value \\
\hline Oronasal fistula & $9510.78 \pm 492$ & $10282.8 \pm 483$ & $\mathrm{p}<0.0001$ \\
\hline Present $(n=5)$ & $10278.2 \pm 512$ & $10932.9 \pm 554$ & $\mathrm{p}<0.0001$ \\
\hline Absent $(\mathrm{n}=5)$ & $\mathrm{Fp}<0.0001$ & $\mathrm{Fp}<0.0001$ & \\
\hline FP value & & \\
\hline
\end{tabular}


unilateral CLP patients of approximately 13 years of age. They found no significant difference in the maxillary sinus volume between the cleft and noncleft sides, which was different from the present results, and may be attributed to the different age range of patients. Hikosaka et al. [18] measured the maxillary sinus volume in patients with CLP. They assessed the computed tomography (CT) scans of 109 CLP and 100 non-CLP patients and found no significant difference between the two groups, which was in contrast to our findings. Also, they found no significant difference in the maxillary sinus volume of the cleft and non-cleft sides, which was different from the present results. The difference between the two studies may be due to the use of different imaging modalities (CBCT vs. CT). Also, they did not specify the patients'age. Agarwal et al. [16] evaluated the differences in maxillary sinuses of the cleft and non-cleft sides. They made the measurements on the maxilla using a combination of reconstructed axial, coronal and lateral CT images. The maxillary sinus volume was calculated on $3 \mathrm{D}$ reconstructed images. They found significant reduction of length, width, height, depth and volume of the maxillary sinus at the cleft side, which supported the present results. However, they did not mention the patients' age range.

The assessment of patients between 9-12 years was a strength of this study since this age range is ideal for assessment of the size of maxillary sinuses [27]. The use of CBCT was another strength of this study since it provides highly accurate data regarding the dimensions of anatomical structures, and has high measurement accuracy. Also, the effect of the presence of the fistula on the maxillary sinus dimensions was evaluated in this study, which has not been addressed before.

Not evaluating bilateral CLP patients and small sample size were among the limitations of this study. Future studies with a larger sample size are required on bilateral CLP patients. Another limitation was that, patients evaluated in this study had been operated by different surgeons at 1 year of age, and different techniques had been used for cleft closure, which could have different effects. Due to the small number of patients, they could not be standardized in this respect. Future studies should address this topic and preferably enroll patients operated by the same surgeon and with the same surgical technique for cleft closure. Moreover, the effects of the surgical technique and time of surgery on the recurrence of the fistula are important topics that need to be scrutinized in further studies.

\section{CONCLUSION}

Immature patients with unilateral CLP and oronasal fistula have a smaller maxillary sinus than unilateral CLP patients without an oronasal fistula, and may be at higher risk of respiratory infections. Also, the maxillary sinus at the cleft side is smaller than that at the non-cleft side in unilateral CLP patients.

\section{ACKNOWLEDGMENTS}

None.

\section{AUTHOR CONTRIBUTIONS}

AJ: Study concept and design; critical revision of the manuscript for important intellectual content; administrative, technical, and material support; study supervision. LH: Acquisition of data. BK, AJ: Analysis and interpretation of data. FA: Drafting of the manuscript. MK: Statistical analysis.

\section{FUNDING}

This research did not receive any specific grant from funding agencies in the public, commercial, or not-for-profit sectors.

\section{COMPETING INTERESTS}

The authors declare that they have no competing interests.

\section{REFERENCES}

1. Jamilian A, Lucchese A, Darnahal A, et al. Cleft sidedness and congenitally missing teeth in patients with cleft lip and palate patients. Prog Orthod. 2016;17:14. doi: 10.1186/s40510-0160127-z. Epub 2016 May 9. PMID: 27135068; PMCID: PMC4864872. Full text links CrossRef PubMed Google Scholar Scopus WoS

2. Lawson W, Patel ZM, Lin FY. The development and pathologic processes that influence maxillary sinus pneumatization. Anat Rec (Hoboken). 2008;291(11):1554-1563. doi: 10.1002/ar.20774. PMID: 18951496.

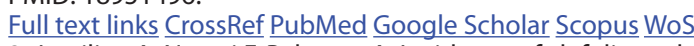
3. Jamilian A, Nayeri F, Babayan A. Incidence of cleft lip and palate in Tehran. J Indian Soc Pedod Prev Dent. 2007;25(4):174-176. doi: 10.4103/0970-4388.37013. PMID: 18007103.

PubMed Google Scholar Scopus

4. Salihu S, Krasniqi B, Sejfija O, et al. Analysis of potential oral cleft risk factors in the Kosovo population. Int Surg. 2014;99(2):161-165. doi: 10.9738/INTSURG-D-13-00089.1. PMID: 24670027; PMCID: PMC3968843.

Full text links CrossRef PubMed Google Scholar Scopus WoS 5. Tessier P. Anatomical classification facial, cranio-facial and latero-facial clefts. J Maxillofac Surg. 1976 Jun;4(2):69-92. doi: 10.1016/s0301-0503(76)80013-6. PMID: 820824.

PubMed Google Scholar Scopus
6. Costello BJ, Edwards SP, Clemens M. Fetal diagnosis and treatment of craniomaxillofacial anomalies. J Oral Maxillofac Surg. 2008 Oct;66(10):1985-1995. doi: 10.1016/j.joms.2008.01.042. PMID: 18848093.

Full text links CrossRef PubMed Google Scholar Scopus WoS

7. Sadhu P. Oronasal fistula in cleft palate surgery. Indian J Plast Surg. 2009 Oct;42 Suppl(Suppl):S123-S128. doi: 10.4103/09700358.57203. PMID: 19884667; PMCID: PMC2825081.

CrossRef Google Scholar

8. Erdur O, Ucar Fl, Sekerci AE, et al. Maxillary sinus volumes of patients with unilateral cleft lip and palate. Int J Pediatr Otorhinolaryngol. 2015 Oct;79(10):1741-1744. doi: 10.1016/j. ijporl.2015.08.003. Epub 2015 Aug 8. PMID: 26292906. Full text links PubMed Google Scholar Scopus WoS 9. Jamilian A, Showkatbakhsh R, Behnaz M, et al. Tooth-borne distraction osteogenesis versus conventional Le Fort I in maxillary advancement of cleft lip and palate patients. Minerva Stomatol. 2018 Jun;67(3):117-124. doi: 10.23736/S0026-4970.18.04121-3. Epub 2018 Jan 31. PMID: 29388417.

Full text links CrossRef PubMed Google Scholar Scopus WoS 10. Tahmasbi S, Jamilian A, Showkatbakhsh R, et al. Cephalometric changes in nasopharyngeal area after anterior maxillary segmental distraction versus Le Fort I osteotomy in patients with 
cleft lip and palate. Eur J Dent. 2018 Jul-Sep;12(3):393-397. doi: 10.4103/ejd.ejd_374_17. PMID: 30147405; PMCID: PMC6089043. Full text links CrossRef PubMed Google Scholar Scopus 11. Demirtas O, Kalabalik F, Dane A, et al. Does unilateral cleft lip and palate affect the maxillary sinus volume? Cleft Palate Craniofac J. 2018 Feb;55(2):168-172. doi: 10.1177/1055665617726991 Epub 2017 Dec 14. PMID: 29351024

Full text links CrossRef PubMed Google Schola

12. Jamilian A, Jamilian M, Darnahal A, et al. Hypodontia and supernumerary and impacted teeth in children with

various types of clefts. Am J Orthod Dentofacial Orthop. 2015 Feb;147(2):221-225. doi: 10.1016/j.ajodo.2014.10.024. PMID: 25636556.

Full text links CrossRef PubMed Google Scholar Scopus WoS 13. Jamilian A, Showkatbakhsh R, Boushehry MB. The effect of tongue appliance on the nasomaxillary complex in growing cleft lip and palate patients. J Indian Soc Pedod Prev Dent. 2006 Sep;24(3):136-139. doi: 10.4103/0970-4388.27893. PMID: 17065780

CrossRef PubMed Google Scholar Scopus

14. Showkatbakhsh R, Pourdanesh F, Jamilian A, et al. Hyrax application as a tooth-borne distractor for maxillary advancement. J Craniofac Surg. 2011 Jul;22(4):1361-1366. doi: 10.1097/SCS. 0b013e31821c93d8 PMID: 21772186.

Full text links CrossRef PubMed Google Scholar Scopus WoS 15. Lopes de Rezende Barbosa G, Pimenta LA, Pretti H, et al. Difference in maxillary sinus volumes of patients with cleft lip and palate. Int J Pediatr Otorhinolaryngol. 2014 Dec;78(12):22342236. doi: 10.1016/j.ijporl.2014.10.019. Epub 2014 Oct 25. PMID: 25458166.

Full text links PubMed Google Scholar Scopus WoS

16. Agarwal R, Parihar A, Mandhani PA, Chandra R. Three-dimensional computed tomographic analysis of the maxilla in unilatera cleft lip and palate: implications for rhinoplasty. J Craniofac Surg. 2012 Sep;23(5):1338-1342. doi: 10.1097/SCS.0b013e31826466d8 PMID: 22948621

Full text links PubMed Google Scholar Scopus WoS 17. Francis P, Raman R, Korula P, Korah I. Pneumatization of the paranasal sinuses (maxillary and frontal) in cleft lip and palate. Arch Otolaryngol Head Neck Surg. 1990 Aug;116(8):920-922. doi: 10.1001/archotol.1990.01870080042012. PMID: 2378718 Full text links PubMed Google Scholar WoS

18. Hikosaka M, Nagasao T, Ogata $\mathrm{H}$, et al. Evaluation of maxillary sinus volume in cleft alveolus patients using 3-dimensional computed tomography. J Craniofac Surg. 2013 Jan;24(1):e23-e26. doi: 10.1097/SCS.0b013e318267bdf3. PMID: 23348325. Full text links CrossRef PubMed Google Scholar Scopus WoS
19. Ishikawa Y, Kawano M, Honjo I, Amitani R. The cause of nasal sinusitis in patients with cleft palate. Arch Otolaryngol Head Neck Surg. 1989 Apr;115(4):442-446. doi: 10.1001/

archotol.1989.01860280040014. PMID: 2923687.

Full text links PubMed Google Scholar Scopus WoS

20. Ishikawa Y, Amitani R. Nasal and paranasal sinus disease in patients with congenital velopharyngeal insufficiency. Arch

Otolaryngol Head Neck Surg. 1994 Aug:120(8):861-865, doi: 10.1001/archotol.1994.01880320063014. PMID: 8049050. Full text links CrossRef PubMed Google Scholar Scopus WoS 21. Robinson HE, Zerlin GK, Passy V. Maxillary sinus development in patients with cleft palates as compared to those with normal palates. Laryngoscope. 1982 Feb;92(2):183-187. doi: 10.1002/ lary.1982.92.2.183. PMID: 7162315.

Full text links CrossRef PubMed Google Scholar Scopus WoS 22. Jamilian A, Sarkarat F, Jafari M, et al. Family history and risk factors for cleft lip and palate patients and their associated anomalies. Stomatologija. 2017:19(3):78-83. PMID: 29339670. Full text links PubMed Google Scholar Scopus

23. Suzuki H, Yamaguchi T, Furukawa M. Maxillary sinus development and sinusitis in patients with cleft lip and palate. Auris Nasus Larynx. 2000 Jul;27(3):253-256. doi: 10.1016/s03858146(99)00066-8. PMID: 10808114

Full text links CrossRef PubMed Google Scholar Scopus 24. Smith TD, Siegel MI, Mooney MP, et al. Formation and enlargement of the paranasal sinuses in normal and cleft lip and palate human fetuses. Cleft Palate Craniofac J. 1997 Nov;34(6):483-489. doi: 10.1597/1545-1569_1997_034_0483_ faeotp_2.3.co_2.PMID: 9431465.

Full text links CrossRef PubMed Google Scholar WoS

25. Schneiderman ED, Xu H, Salyer KE. Characterization of the maxillary complex in unilateral cleft lip and palate using conebeam computed tomography: a preliminary study. J Craniofac Surg. 2009 Sep;20 Suppl 2:1699-1710. doi: 10.1097/SCS.0b013e3181 b3eddf. PMID: 19816335.

Full text links CrossRef PubMed Google Scholar Scopus WoS 26. Guijarro-Martinez R, Swennen GR. Cone-beam computerized tomography imaging and analysis of the upper airway: a systematic review of the literature. Int J Oral Maxillofac Surg. 2011 Nov:40(11):1227-1237. doi: 10.1016/j.ijom.2011.06.017. Epub 2011 Jul 20. PMID: 21764260

Full text links PubMed Google Scholar Scopus WoS

27. Taylor M, Hans MG, Strohl KP, et al. Soft tissue growth of the oropharynx. Angle Orthod. 1996;66(5):393-400. doi: 10.1043/0003-3219(1996)066<0393:STGOTO>2.3.CO;2. PMID: 8893109.

Full text links PubMed Google Scholar Scopus WoS

\section{Bita KIAEE \\ DDS, MSc, Assistant Professor Department of Orthodontics Dental School Tehran University of Medical Sciences Tehran, Iran

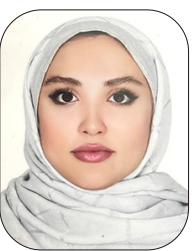
CV

Dr. Kiaee received her DDS (2013) and MSc in Orthodontics (2017) from Tehran University in Tehran, Iran. Since 2017, she has been working as an Assistant Professor at the Department of Orthodontics within the Faculty of Dentistry of Tehran University. Her research areas of interest are mostly clinical projects. 


\section{Ouestions}

\section{Which item was among the exclusion criteria stated in this article?}

$\square$ a. History of surgical closure of the cleft before 1 year of age;

ab. Orthognathic surgery;

口c. Cervical vertebral stage (CVS) 2 or 3;

$\square d$. Age between $9-12$ years.

\section{Which statement is NOT TRUE based on the findings of this article?}

$\square$ a. The maxillary sinus volume at the cleft side of patients with oronasal fistula was significantly lower than that at the cleft side of patients without fistula;

$\square$ b. The maxillary sinus volume at the non-cleft side of patients with oronasal fistula was significantly lower than that at the non-cleft side of patients without fistula;

$\square c$. The maxillary sinus volume at the cleft side was significantly smaller than that at the non-cleft side in patients with and without oronasal fistula;

$\square d$. The maxillary sinus volume at the cleft side of patients without oronasal fistula was significantly lower than that at the cleft side of patients with fistula.

\section{Which of the following statements is True based on the findings of this article?}

$\square$ a. Immature patients with unilateral CLP and oronasal fistula have a smaller maxillary sinus than unilateral CLP patients without an oronasal fistula;

$\square$ b. Immature patients with unilateral CLP and oronasal fistula may be at lower risk of respiratory infections; dc. The maxillary sinus at the non-cleft side is smaller than that at the cleft side in unilateral CLP patients; $\square$ d. Adult patients with bilateral CLP and oronasal fistula have a smaller maxillary sinus than unilateral CLP patients without an oronasal fistula.

\section{Which one is the prevalence of cleft lip and palate patients based on the present study?}

口a. 1 per 700 live births;

ab. 1 per 1000 live births;

ac. 1 per 500 live births;

dd. 2.3 per 1000 live births.

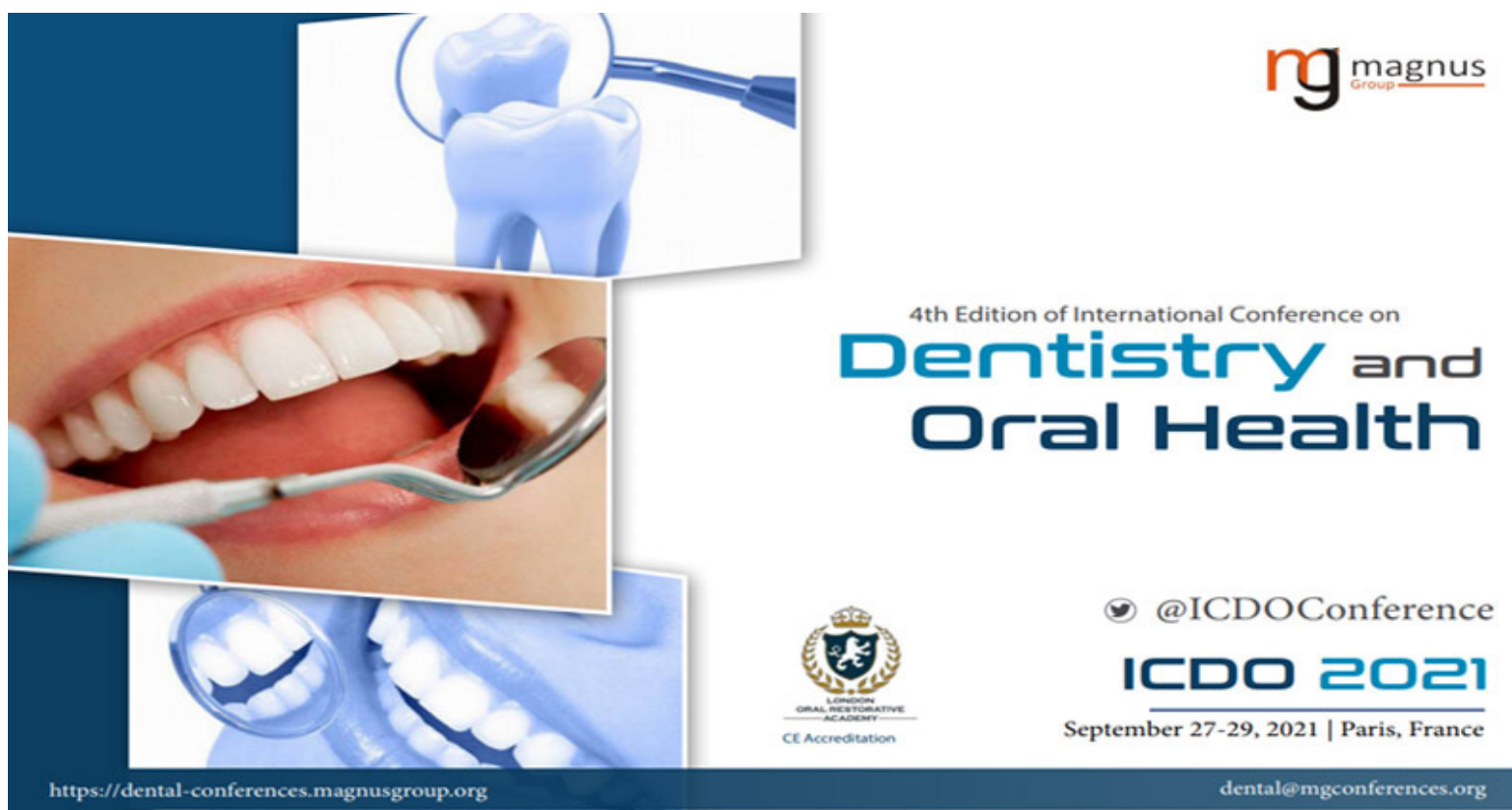




\title{
ON THE TRACK OF BRUXISM: QUANTITATIVE, QUALITATIVE AND INTRAINDIVIDUAL ANALYSES OF THE BRUXCHECKER ${ }^{\circledR}$ IN DAILY CLINICAL ROUTINE
}

\author{
Gregor Slavicek $^{1,2, a * \mathbb{1}}$, David Grimmer ${ }^{1,3}$, Anastasia Novitskaya ${ }^{1,4, b}{ }^{(1)}$, Florian Slavicek ${ }^{1,2, c}$ (1) \\ ${ }^{1}$ Steinbeis Transfer Institute Biomedical Interdisciplinary Dentistry, Steinbeis University Berlin, DE-12489 Berlin, Germany \\ ${ }^{2}$ Orehab Minds GmbH, DE-70567 Stuttgart, Germany \\ ZZahntechnik Baltz GbR, DE-73728 Esslingen am Neckar, Germany \\ ${ }^{4}$ Dental Clinic Smiletime, RU-14106 Podolsk, Podolsky District, Russia \\ a MD, DDS, MSc, Director and Head, CE0 and Head; e-mail: g.slavicek@orehab-minds.com; ORCIDiD: https://orcid.org/0000-0003-2454-4048 \\ bDS; e-mail: anastasia.novitskaya@gmail.com; ORCIDiD: https://orcid.org/0000-0003-3446-3866 \\ 'BSc; e-mail: f.slavicek@orehab-minds.com; ORCIDiD: https://orcid.org/0000-0003-4245-7829
}

\begin{abstract}
do) https://doi.org/10.25241/stomaeduj.2020.8(3).art.2

Introduction Bruxism is a relevant topic in daily dental routine. Bruxism has to be confirmed by instrumental procedures. The BruxChecker ${ }^{\circledast}(\mathrm{BC})$ is an inexpensive instrument that does not affect the stomatognathic system while used and is suitable for routine use in diagnostics and follow-ups. A novel digital approach for analyzing $B C$ is described, based on first standard values.

Material and Method Within this pilot study, 30 participants (15 males, 15 females) used an upper BC for one night and a lower $\mathrm{BC}$ during another night. A standardized digitalization process and a unique software application measured all Tooth Contact Areas (TCAs) on the BC: number and size of each TCAs for each occlusal segment.

Results The mean number of TCAs on upper BC is 28.17 (sd +/-7.84), for lower BC 27.70 (sd +/-7.41). The mean size $\left(\mathrm{mm}^{2}\right)$ of TCAs on upper BC is 71.81 (sd +/-51.27), for lower BC 68.11 (sd +/-42.64). There are only minor, not significant, gender differences regarding the number and size of TCAs. The transversal right-left TCAs distribution is almost symmetrical; a slightly increased difference can be observed for the size of TCAs right and left. The sagittal distribution of the TCAs shows the dominance of the posterior contacts, while the intermediate segments are least involved.

Conclusion Within the limits of this pilot study and based on the digital analyses of TCAs on BC, the paper presents first standard values and a two-step systematic individual BC analysis.
\end{abstract}

\section{KEYWORDS}

Bruxism; Occlusal Functions; Oral Rehabilitation; Parafunction; Tooth Contact Areas.

\section{INTRODUCTION}

$\mathrm{BC}$ visualizes the contacts between teeth that occur during unconscious teeth grinding or clenching during awake and sleep bruxism. The BC is fabricated for the individual patient using the pressure molding technique. Comparing the actual bruxing scheme on the $B C$ with a so-called optimal centric and eccentric occlusal situation is one suggested possibility to analyze the BC. However, understanding the optimal occlusion does not make it easier to work with the suggested classification scheme. In any case, the $\mathrm{BC}$ analyses must consider the laterotrusive and the mediotrusive side contacts during bruxing [1].

A paradigm shift in the assessment of sleep bruxism (SB) took place in recent years. SB is no longer understood solely as a harmful movement disorder.
But the majority of clinicians focus primarily on the possible negative consequences of bruxism: chipping, occlusal trauma, tooth migration, temporomandibular disorder [2]. The issue of the significance of teeth grinding in humans is controversially discussed in medicine. Is it an abnormal function, a movement disorder [3]? Or, in contrast, can SB be assessed as a relevant physiological occlusal function [4]? If one takes this view, then parafunction represents a secondary function beside primary occlusal functions. The increasing acceptance of considering SB as a physiologic function modifies the fundamental methodical approach. Today SB is graduated in possible (based on patient's self-reports), probable (determined by clinical inspection), and definite (verified by an instrumental analysis) [5].

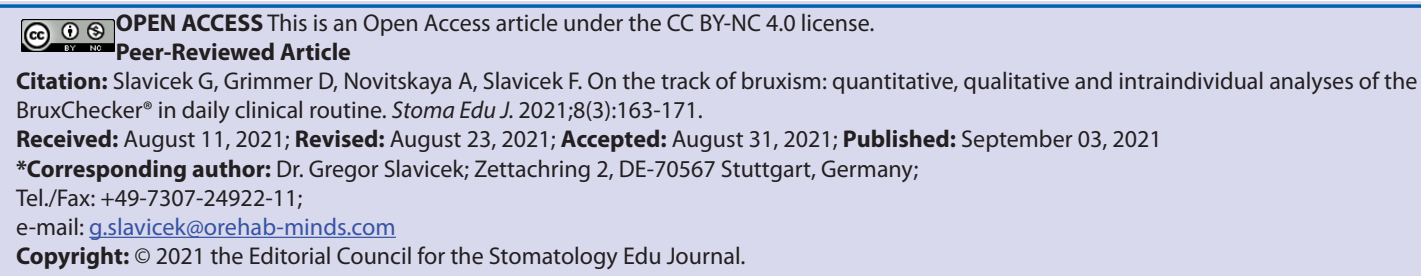


Dentists are interested in the best possible care for their (bruxing) patients. All diagnostics have impacts on the therapeutic decisions. Expert opinions regarding the best therapeutic concepts of SB differ substantially. Instead of the term "therapy" the phrase "management" is often utilized [6]; however, both terms exclusively refer to the negative consequences of teeth grinding. Based on today's knowledge, there is no indication to treat a most probably physiological oral function. Management recommendations include, among others, behavioral advice, medication, physiotherapy, or physical intervention [7]. The therapeutic goal of "stop bruxing" can never be achieved [8]. Such therapeutic concepts must be regarded as meaningless [9]. Dentists find themselves constricted between these points of view: is a management strategy necessary? Or are occlusal measures to influence/stop bruxism? Are occlusal therapeutic changes indicated or contraindicated in bruxing patients? It must be understood that awake and sleep bruxism will still be executed after occlusal therapy, but maybe with less muscular strength and minor eccentric mandibular movements. The ability and the necessity to influence bruxism by occlusal parameters is still a matter of controversy. Occlusal factors such as the inclination of occlusal guiding structures in the anterior and posterior occlusal segments seem to play an important role in muscle recruitment during bruxism [10]. In silico simulation demonstrated that both the direction and the size of the bruxing force vectors adapt and change due to the position and the inclination of occlusal guiding structures [10]. Grinding areas and occlusal parameters such as anterior occlusal plane and overbite are closely related [11]. The need of an oral Rehabilitation of bruxing patients is a common situation in daily dentistry. Patients present with impaired chewing surface morphology, the risk of increased mechanical and technical complications in prosthodontic Rehabilitation rises. Prosthetic intervention in a patient with (heavy) bruxism without taking into consideration heavy occlusal loading on materials and constructions will end in a breakdown. "Failure to do so may indicate earlier failure than is the norm." [12]. Successful oral Rehabilitation in patients with severely worn teeth seems to be independent of the materials of choice. Direct or indirect materials may be feasible options to restore severely worn teeth [13].

From a clinician's point of view, more clinical studies are required, with a clear focus on the clinical impact on oral structures of bruxism. The decision-making process for successful interventions in bruxing patients requires more detailed and focused studies [14]. As soon as patients recognize symptoms, they demand clarification. A link to awake or sleep bruxism is often not reported by the patient in this stage. The clarification of bruxism using instruments is required to confirm the subjective report of the patient [4]. The various uses of instrumental analysis are known in dentistry and are routine in many dental clinics. If, however, the use of instruments in bruxing subjects primarily refers to polysomnography [4], the immediate practical implementation is limited by apparent obstacles. Mobile devices that measure the muscle activity of selected masticatory muscles or record the forces on sensors in occlusal devices are available but elude clinical applicability due to missing cut-off values [15]. Devices measuring tooth contacts in centric and eccentric mandibular positions are available and successfully used in restorative dentistry. But such approaches are suitable only to a minimal extent for verifying awake or sleep bruxism, as the measurement takes place in a completely different setting: awake patients, sitting upright in a dental chair, with an invasive measuring instrument placed intraorally, performing artificial mandibular movements trying to simulate unconscious bruxing. The execution of so-called bruxing movements is very different from those performed in various sleeping postures with changing head positions. The $\mathrm{BC}$ is a device for such minimally invasive investigation of unconscious tooth contacts during sleep. A classifying evaluation of the BC enables an initial assessment [16]. But occlusion and occlusal structures are core elements in dentistry, and this can be rated as unique proposition of dental clinics. Occlusal Rehabilitation aims to maintain and re-establish oral function such as chewing and bruxing [17].

The BC visualizes functional TCAs. But the interpretation of the $B C$ remains challenging, and many dentists left the use of BC again after their initial enthusiasm. For this reason, the authors of this article suggest a different, systematic approach for the $\mathrm{BC}$ analysis based on numerical data. This pilot study aims to determine quantitative and qualitative data of occlusal contacts areas on BruxCheckers for sleep bruxism.

\section{MATERIAL AND METHOD}

60 already used BC from 30 subjects served as the data source in this exploratory study. Females and males participated in the study. The exclusion criteria comprise persons younger than 16 years and older than 35 years, participants with two or more missing teeth, removable (partial and total) and/or extensive fixed prosthodontic Rehabilitation. This manuscript did not require ethical approval. Each subject signed an informed consent after being informed about the study in detail. The use of the $\mathrm{BC}$ followed the guidelines and recommendations of the manufacturer (Scheu Dental, Iserlohn, Germany). The data analysis uses the BC used by the participants for one night; clinical intervention did not take place. Each participant used two BC for one night, but not simultaneously. Only sleep bruxism TCAs were analyzed in this pilot study. Before evaluation, white silicon reinforced the contrast of the TCAs against the red color of the $\mathrm{BC}$. 
A validated procedure was applied to digitize the $B C$. Reproducibility tests demonstrated the soundness of the digitizing process a priori - a series of 7 recordings of 16 BCs ( 8 upper and 8 lower BC) were included for that test. A password-protected zip folder guarded the data. Finally, the data set listed the automatically measured key figures number and area of TCAs for each BC. The calculation of the maximal differences and the standard deviations for the differences followed. The formula [means $+/-\left(s d^{*} 1.96\right)$ ] sets an upper and lower tolerance limit. Bland-Altman Diagrams visualized the results. If all means of record 1 to record 7 for all BC were within the upper and lower tolerance limits, adequate reproducibility can be derived (Fig. 1a,1b). For anonymization, a 7-digit unique identifier tags each BC. A short anonymous questionnaire collected information on gender, age, and subjective symptoms, possibly related to grinding and clenching. Table 1 presents the personal functional status of the study participants. In an automatic evaluation process, using a calibrated software (Orehab Minds $\mathrm{GmbH}$, Germany), the number and size of each TCAs were determined and assigned to a specific segment of the occlusion (right-anterior, left-anterior, right-intermediate, left-intermediate, right-posterior, left-posterior). For the statistical analysis, IBM SPSS Statistics 25 was used. The outcome measures are continuous data; a pretest served to estimate the expected standard deviation. The sample size for this pilot study $(n=30$ participants, $n=60 \mathrm{BC}$ ) was set on $20 \%$ of the sample size calculation for a planned clinical trial with relevant subgroups (e.g., dental status, gender, age, comorbidity, occlusal characteristics). One hundred fifty participants would still be sufficient to assign minor standardized differences in occlusal contact areas with a power of $80 \%$ for two-sided errors of type 1 (alpha) (two-sample t-test). Intra-individual

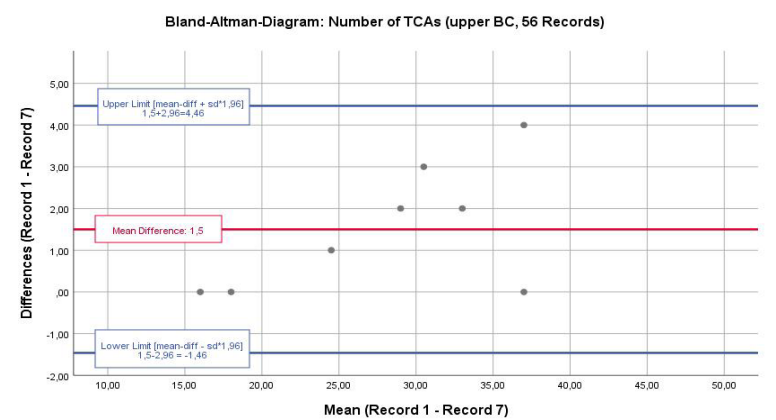

Figure 1a. Bland-Altman-Diagram to demonstrate the reproducibility of the analytic process for $\mathrm{BC}$. Here, the measurement parameter is the number of TCAs on upper BC. 8 BC were included; digitizing was repeated 7 times per BC (56 records in total). The mean difference $(1,5)$ and the tolerance limits (upper: 4,46 and lower: $-1,46$ ) were calculated. The mean differences per BC are indicated (•); all are located between the upper and lower limit. No outliers are detectable; the limits are not exceeded. A slight dependence on the number of TCAs may exist.

BC BruxChecker; TCAs Tooth Contact Areas. comparison (e.g., between lateral or sagittal distribution) could recognize an effect size of 0.2 with the same group size (paired t-test) [18].

After the study, all participants received a detailed report on their $\mathrm{BC}$ findings.

\section{RESULTS}

The mean age of all participants was 27 years (sd +/- 4.98 years). The female participants had an average age of 26 years with a sd of 5.3 years, the male study participants had an average age of 28 years (sd +/- 4.4 years). All participants had a natural occlusion with only minor restorations. 27 (80\%) had full dental arches, not considering wisdom teeth. In comparison, 14 (47\%) presented one or more of the following findings: lingual retainer of front teeth [4 (13\%) upper and 8 (26\%) lower]; missing teeth [3 (10\%) participant, one missing tooth 14 , one missing tooth 37 and one missing tooth 47].

Table 1 presents the subjective functional status of the study participants (personal self-assessment via VAS). The symptom pain for different locations appears with a minimum of 1 and a maximum of 4 on the VAS. The different localizations of the pain showed no noticeable deviations. However, the intensity of the pain, including its impact on activities of daily life (AoDL), individual stress levels, and the reported quality of sleep, are widely spread. Although this pilot study aimed not to identify associations between TCAs and symptoms, the collected data will serve as a basis for further studies to determine whether TCAs' number, size, or distribution are equally related to patients' symptoms.

All 60 BC (30 upper and 30 lower) from 30 individuals are analyzed. The mean value of the number of TCAs for the upper occlusion is $n=28.2(\mathrm{sd}+/-7.8)$ with a minimum number of 11 and a maximum number of 39 TCAs (Fig. 2a). The mean value of the number of TCAs for the lower occlusion is 27.7 (sd +/- 7.4), with

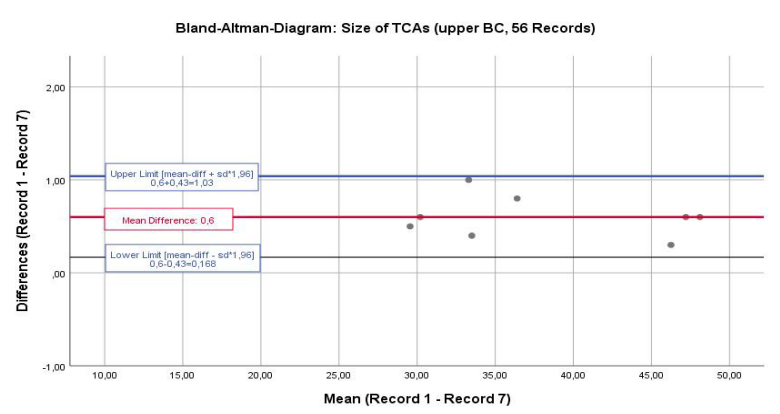

Figure 1b. Bland-Altman-Diagram to demonstrate the reproducibility of the analytic process for $\mathrm{BC}$. Here, the measurement parameter is size of TCAs on upper $\mathrm{BC}$. $8 \mathrm{BC}$ were included; digitizing was repeated 7 times per $\mathrm{BC}$ ( 56 records in total). The mean difference $(0,6)$ and the tolerance limits (upper: 1,03 and lower: 0,168) were calculated. The mean differences per $\mathrm{BC}$ are indicated (•); all are located between the upper and lower limit. No outliers are detectable; the limits are not exceeded. A slight dependence on the number of TCAs may exist.

BC BruxChecker; TCAs Tooth Contact Areas. 


\begin{tabular}{|c|c|c|c|c|}
\hline $\begin{array}{c}\text { Parameter } \\
\text { VAS 0-10 }\end{array}$ & Mean & sd & min & max \\
\hline tooth_ache* $^{*}$ & 3.77 & 0.68 & 1 & 4 \\
\hline headache* $^{*}$ & 3.67 & 0.55 & 2 & 4 \\
\hline backpain* $^{*}$ & 3.30 & 0.70 & 1 & 4 \\
\hline facialpain* $^{*}$ & 3.93 & 0.37 & 2 & 4 \\
\hline temporal_pain* $^{*}$ & 3.90 & 0.40 & 2 & 4 \\
\hline ear_tmj_pain* $^{*}$ & 3.77 & 0.57 & 2 & 4 \\
\hline pain_mouth_open* $^{*}$ & 3.83 & 0.46 & 2 & 4 \\
\hline pain_mastication* $^{*}$ & 3.87 & 0.43 & 2 & 4 \\
\hline AoDL_influenced* & 3.10 & 1.73 & 1 & 8 \\
\hline overal_pain_intensity* $^{*}$ & 3.00 & 1.64 & 1 & 8 \\
\hline sleep_quality* & 7.00 & 1.80 & 4 & 10 \\
\hline stress_level* $^{*}$ & 5.80 & 1.77 & 2 & 9 \\
\hline
\end{tabular}

Table 1. Overview: reported symptoms of the participants. These data were not collected to analyze correlations of TCAs (number and/or size) with subjective complaints but to check the sample for consistency and to support future sample size calculations.

TCAs Tooth Contact Areas; sd standard deviation, min minimum; max maximum, AoDLActivities of Daily Living, VAS Visual Analog Scale..

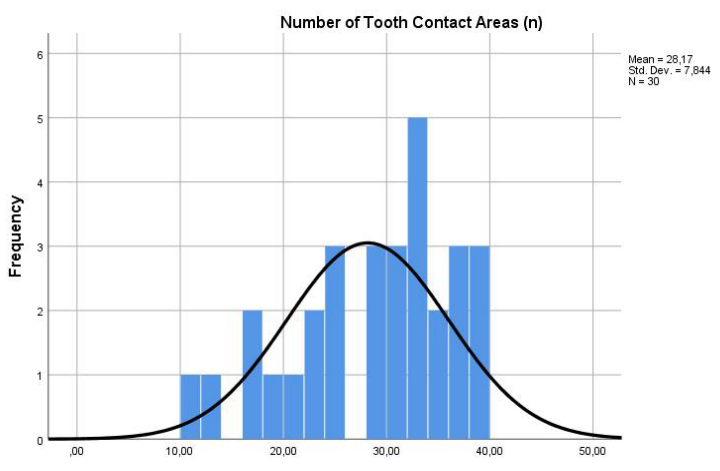

Upper BruxChecker®, males and females

IFigure 2a. Histogram to show the distribution of the number of TCAs for all upper BC, females and males. The mean number of TCAs is 28.17 with a sd of 7.844 and a range of 28 (minimum 11, maximum 39). Based on this sample, a normal distribution cannot be assumed (KS Test, $\mathrm{p}=0.019$ ). BC BruxChecker; TCAs Tooth Contact Areas; KS test Kolmogorov-Smirnov Test

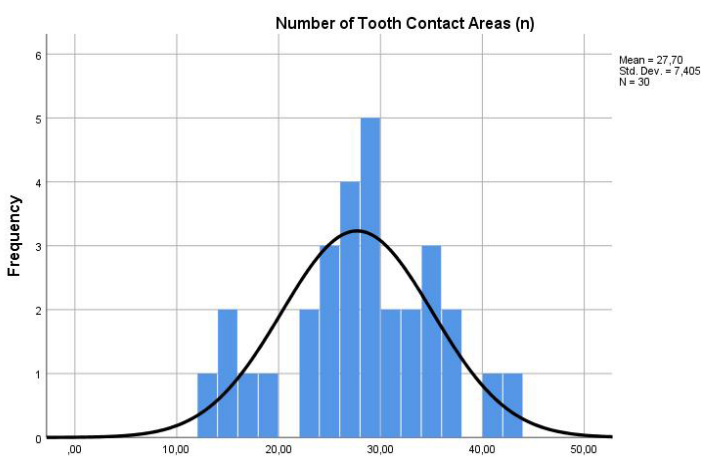

Lower BruxChecker®, males and females

Figure $\mathbf{2 b}$. Histogram to show the distribution of the number of TCAs for all lower BC, females and males. The mean number of TCAs is 27.7 with a sd of 7.405 and a range of 30 (minimum 13, maximum 43). Based on this sample, a normal distribution can be assumed (KS Test, $\mathrm{p}=0.2$ ). BC BruxChecker; TCAs Tooth Contact Areas; KS test Kolmogorov-Smimov Test.

a minimum number of 13 and a maximum number of 43 (Fig. 2b). The mean size of TCAs is $71.8 \mathrm{~mm}^{2}$ ( $\mathrm{sd}$ $\left.+/-51.3 \mathrm{~mm}^{2}\right)$ for the upper occlusion and $68.1 \mathrm{~mm}^{2}$ (sd $+/-42.6 \mathrm{~mm}^{2}$ ) for the lower occlusion. The range of TCAs size for upper occlusion encompasses a span from $13 \mathrm{~mm}^{2}$ to $224 \mathrm{~mm}^{2}$ or from $11 \mathrm{~mm}^{2}$ to

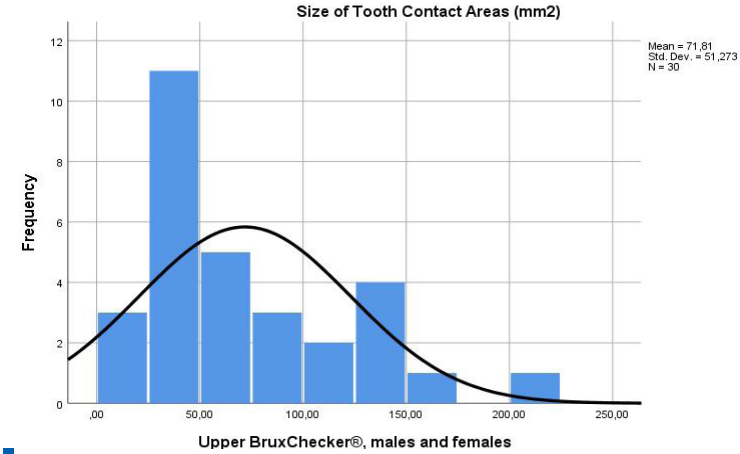

Figure 2c. Histogram to show the distribution of the size of TCAs for all upper BC, females and males. The mean number of TCAs is 71.81 with a sd of 51.273 and a range of 211 (minimum 13, maximum 224). Based on this sample, a normal distribution cannot be assumed (KS Test, $\mathrm{p}=0,021$ ). Measurements in $\mathrm{mm}^{2}$.

BC BruxChecker; TCAs Tooth Contact Areas; KS test Kolmogorov-Smirnov Test.

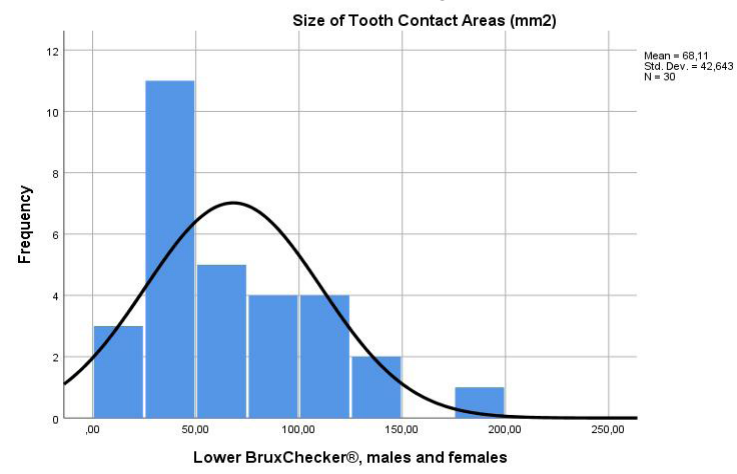

Figure 2d. Histogram to show the distribution of the size of TCAs for all lower BC, females and males. The mean number of TCAs is 68.11 with a sd of 42.643 and a range of 183.5 (minimum 11, maximum 194.5). Based on this sample, a normal distribution cannot be assumed (KS Test, $\mathrm{p}=0.047$ ). Measurements in $\mathrm{mm}^{2}$.

BC BruxChecker; TCAs Tooth Contact Areas; KS test Kolmogorov-Smirnov Test.

$194.5 \mathrm{~mm}^{2}$ for the inferior occlusion (Fig. 2c, 2d), respectively. Table $2 \mathrm{a}$ and $2 \mathrm{~b}$ summarizes these results. Kolmogorov-Smirnov Tests (KS test) tested the null hypotheses "Within this sample, number and size of TCAs are normal-distributed." For the upper $\mathrm{BC}$, a normal distribution for both number (KS test, $p=0.019$ ) and size (KS test, $p=0.021$ ) of TCAs cannot be assumed; for the lower $\mathrm{BC}$, a normal distribution cannot be assumed for size (KS test, $p=0.047$ ), but for the number of TCAs (KS test, $p=0.2$ ).

The comparison between females and males shows only minor, not significant differences for number of TCAs: for the males, an average of 29.13 (sd +/- 8.55) TCAs for the upper occlusion; for the females, 27.2 (sd +/- 7.25); for the lower occlusion, an average of 27.13 (sd +/- 6.01) TCAs for males, for the females 28.26 ( $\mathrm{sd}+/-8.77$ ), respectively. The following data can be described for the size of TCAs: males, upper occlusion: $87.27 \mathrm{~mm}^{2}$ (sd +/$57.88 \mathrm{~mm}^{2}$ ), females, upper occlusion: $56.35 \mathrm{~mm}^{2}$ (sd +/-39.79 $\mathrm{mm}^{2}$ ); males, lower occlusion: $80.38 \mathrm{~mm}^{2}$ (sd $+/-46.11 \mathrm{~mm}^{2}$ ), females, lower occlusion: $55.83 \mathrm{~mm}^{2}$ $\left(\mathrm{sd}+/-36.29 \mathrm{~mm}^{2}\right)$ (Tab. 3). The minimal differences between women and men related to TCAs also appear in the direct comparison (Fig. 3a, 3b) [MannWhitney $U$ test for size of TCAs: upper $B C p=0.09$; lower $B C p=0.08$; Mann-Whitney $U$ test for number of upper BC: $p=0.37$; independent samples t-test for number of lower $B C: p=0.6]$. 


\begin{tabular}{|l|c|c|}
\hline $\begin{array}{c}\text { Upper } \\
\text { BruxChecker }\end{array}$ & $\begin{array}{c}\text { Number of Tooth } \\
\text { Contact Areas }(\mathbf{n})\end{array}$ & $\begin{array}{c}\text { Size of Tooth } \\
\text { Contact Areas } \\
\left.\mathbf{( m m}^{\mathbf{2}}\right)\end{array}$ \\
\hline $\mathrm{N}$ & 30 & 30 \\
\hline Mean & 28.1667 & 71.81 \\
\hline sd & 7.84366 & 51.27321 \\
\hline Minimum & 11.00 & 13.00 \\
\hline Maximum & 39.00 & 224.20 \\
\hline
\end{tabular}

Table 2a. Key figures for number and size of TCAs of upper BC, male and female participants.

TCAs Tooth Contact Areas; BC BruxChecker; sd standard deviation.

\begin{tabular}{|l|c|c|}
\hline $\begin{array}{c}\text { Lower } \\
\text { BruxChecker }\end{array}$ & $\begin{array}{c}\text { Number of Tooth } \\
\text { Contact Areas }(\mathbf{n})\end{array}$ & $\begin{array}{c}\text { Size of Tooth } \\
\text { Contact Areas } \\
\left(\mathbf{m m}^{\mathbf{2}}\right)\end{array}$ \\
\hline $\mathrm{N}$ & 30 & 30 \\
\hline Mean & 27.7000 & 68.1067 \\
\hline $\mathrm{sd}$ & 7.40526 & 42.64273 \\
\hline Minimum & 13.00 & 11.00 \\
\hline Maximum & 43.00 & 194.50 \\
\hline
\end{tabular}

Table $\mathbf{2 b}$. Key figures for number and size of TCAs of lower BC, male and female participants.

TCAs Tooth Contact Areas; BC BruxChecker; sd standard deviation.

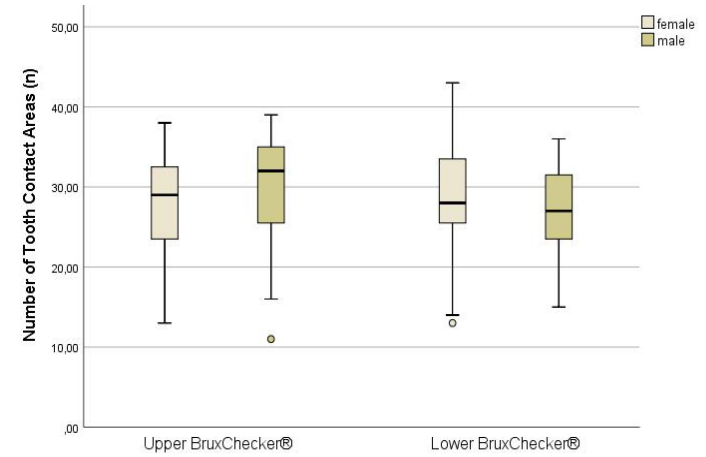

I Figure 3a. Comparison of number of TCAs for females and males, shown for upper and lower BC. Boxes indicate the IQR [Q3-Q1], the lines (-) indicate the median (Q2). The whiskers are limited by minimum and maximum. Outliers (o) are identified if the distance to Q1 or Q3 is bigger than IQR multiplied by 1.5. In such cases, the whiskers are limited by the value that just does not represent an outlier.

TCAs Tooth Contact Areas; IQR Interquartile Range; Q1 First Quartile, Q2 Second Quartile, Q3 Third Quartile.

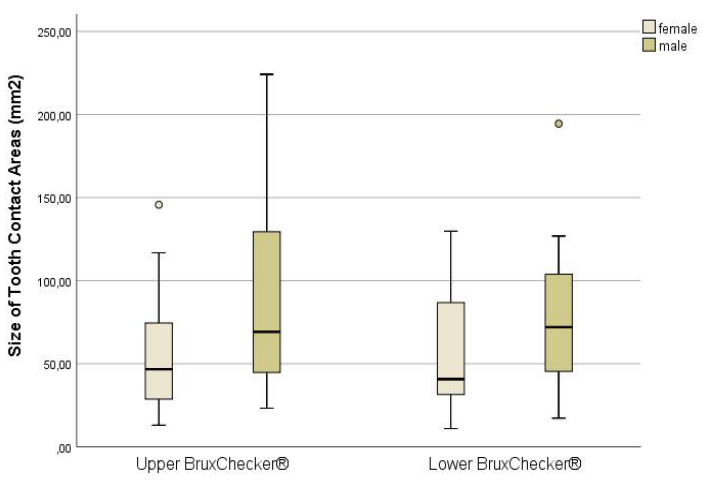

Figure 3b. Comparison of size of TCAs for females and males, shown for upper and lower BC. Boxes indicates the IQR [Q3-Q1], the lines (-) indicate the median (Q2). The whiskers are limited by minimum and maximum. Outliers ( $\mathbf{0}$ ) are identified as such if the distance to Q1 or Q3 is bigger than IQR multiplied by 1.5. In such cases, the whiskers are limited by the value that just does not represent an outlier.

TCAs Tooth Contact Areas; IQR Interquartile Range; Q1 First Quartile, Q2 Second Quartile, Q3 Third Quartile.

\begin{tabular}{|c|c|c|c|}
\hline \multicolumn{2}{|c|}{ Females } & $\begin{array}{c}\text { Number of Tooth } \\
\text { Contact Areas }\end{array}$ & $\begin{array}{c}\text { Size of Tooth } \\
\text { Contact Areas }\end{array}$ \\
\hline $\begin{array}{c}\text { Upper } \\
\text { BruxChecker }\end{array}$ & Mean & 27.2000 & 56.3533 \\
\cline { 2 - 4 } $15 B C$ analysed & sd & 7.24273 & 39.79228 \\
\hline $\begin{array}{c}\text { Lower } \\
\text { BruxChecker }\end{array}$ & Mean & 28.2667 & 55.8333 \\
\cline { 2 - 4 } & sd & 8.76247 & 36.29183 \\
\hline
\end{tabular}

Table 3a. Key figures for number and size ofTCAs of upper and lower BC, female participants.

TCAs Tooth Contact Areas; BC BruxChecker; sd standard deviation.

\begin{tabular}{|c|c|c|c|}
\hline \multicolumn{2}{|c|}{ Males } & $\begin{array}{c}\text { Number of Tooth } \\
\text { Contact Areas }\end{array}$ & $\begin{array}{c}\text { Size of Tooth } \\
\text { Contact Areas }\end{array}$ \\
\hline $\begin{array}{c}\text { Upper } \\
\text { BruxChecker }\end{array}$ & Mean & 29.1333 & 87.2667 \\
\cline { 2 - 4 } $15 B C$ analysed & sd & 8.54289 & 57.88172 \\
\hline $\begin{array}{c}\text { Lower } \\
\text { BruxChecker } \\
15 B C \text { analysed }\end{array}$ & Mean & 27.1333 & 80.3800 \\
\cline { 2 - 4 } & sd & 6.01031 & 46.11729 \\
\hline
\end{tabular}

Table 3a. Key figures for number and size of TCAs of upper and lower BC, male participants.

TCAs Tooth Contact Areas; BC BruxChecker; sd standard deviation.

Further attention during the analyses of $B C$ has to be paid to the distribution of TCAs right and left, the transversal (lateral) distribution. The number of TCAs is almost identical on the right and left sides (Fig. 4a). There are minor differences in the distribution of the size of TCAs on the right and left (Fig. 4b). Tab. 4a and $4 \mathrm{~b}$ present these results. The transversal (lateral) distribution seems to be regardless of the number or the size of TCAs (Fig. 4c, 4d). The evaluation of the sagittal distribution weighs three sections: anterior (corresponds largely to anterior teeth including the canine), intermediate (corresponds largely to the premolar region), and posterior (corresponds largely to the molar region). The sagittal distribution of TCAs in the upper jaw is 8.2 (sd +/- 3.3) anterior, 7.5 (sd +/- 2.5) intermediate, and 12.5 (sd +/- 4.8) posterior. The sagittal distribution of TCAs in the lower jaw is 8.3 (sd +/- 3.1) anterior, 6.6 (sd +/- 2.1) intermediate, and 12.8 (sd +/- 4.6) posterior. The following values describe the mean size of TCAs: for the upper occlusion $28.2 \mathrm{~mm}^{2}$ (sd +/- 23.7mm²) anterior, $13.9 \mathrm{~mm}^{2}$ (sd $+/-10.8 \mathrm{~mm}^{2}$ ) intermediate

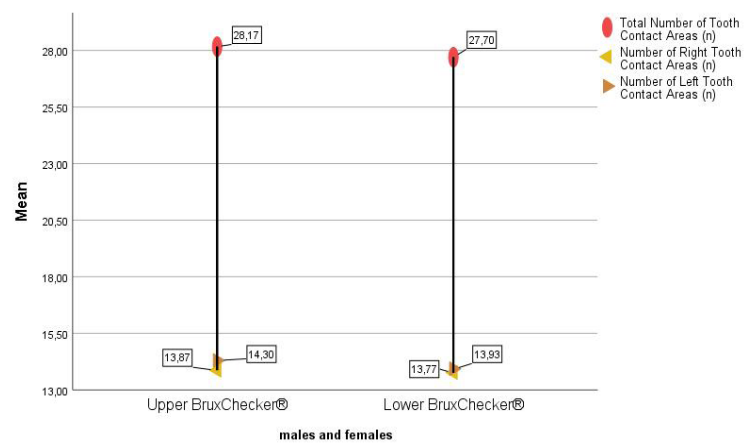

Figure 4a. Comparison of the transversal (lateral) distribution of number of TCAs for total vs. right vs. left. Total ( $\square)$, right $(\triangleleft)$, and left $(\triangleright)$ TCAs are shown for upper and lower BC (males and females). TCAs Tooth Contact Areas, BC BruxChecker. 


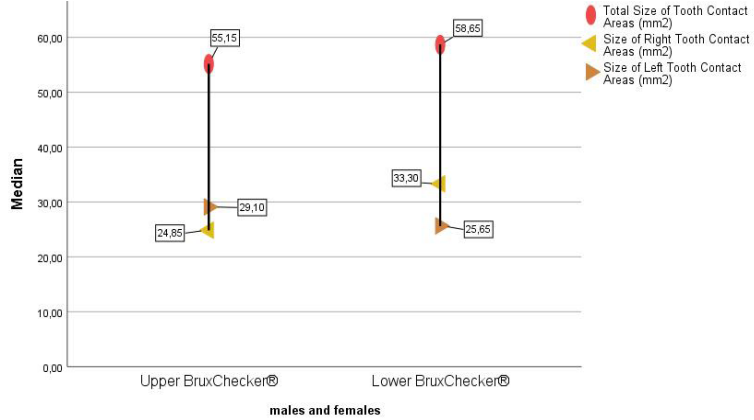

Figure 4b. Comparison of the transversal (lateral) distribution of size of TCAs for total vs. right vs. left. Total ( $($ ), right $(\varangle)$, and left $(\square)$ TCAs are shown for upper and lower BC (males and females).

TCAs Tooth Contact Areas, BC BruxChecker.

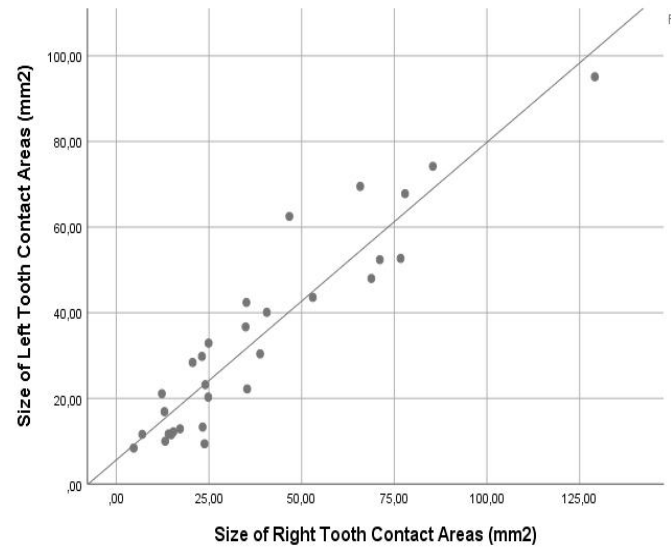

Figure 4c. Scatter plot for size of right vs. left TCAs for the upper BC (males and females). The R2 value of 0,873 shows a tendency towards a symmetrical lateral distribution of the number of TCAs.

TCAs Tooth Contact Areas; BC BruxChecker; R2 coefficient of determination.

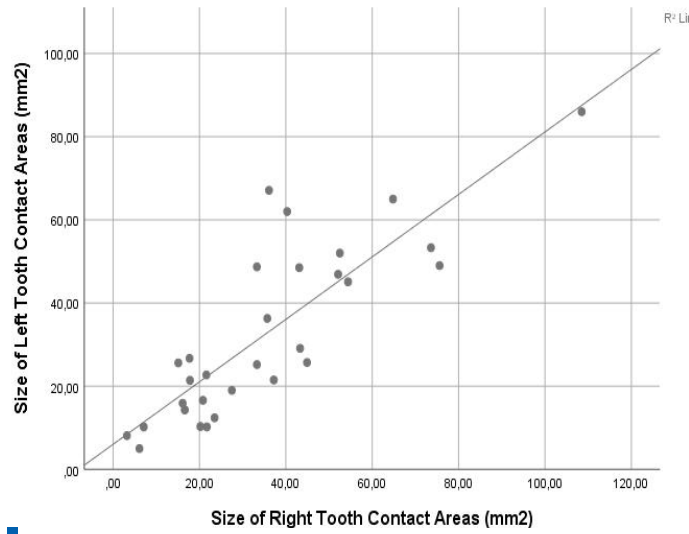

Figure 4d. Scatter plot for size of right vs. left TCAs for the lower BC (males and females). The R2 Value of 0,704 shows a tendency towards a symmetrical lateral distribution of the size of TCAs.

TCAs Tooth Contact Areas; BC BruxChecker:R2 coefficient of determination.

and $29.7 \mathrm{~mm}^{2}$ (sd +/- $24.9 \mathrm{~mm}^{2}$ ) posterior; for the lower occlusion: $23.7 \mathrm{~mm}^{2}$ (sd +/- $17.2 \mathrm{~mm}^{2}$ ) anterior, $12.3 \mathrm{~mm}^{2}\left(\mathrm{sd}+/-8.8 \mathrm{~mm}^{2}\right)$ intermediate and posterior $32.2 \mathrm{~mm}^{2}$ (sd $+/-24.5 \mathrm{~mm}^{2}$ ) posterior. The results are summarized in Tables $5 \mathrm{a}$ and $5 \mathrm{~b}$ and shown in Figures $5 \mathrm{a}$ and $5 \mathrm{~b}$. A TCAs may exceed the midline (right-left) or the boundaries between sections (anterior-intermediate or intermediate-posterior). In such situations, TCAs are split up and allocated proportionally to both sides of the adjacent sections. The areas are measured per TCAs and summed up for each segment. Rounding errors can lead to minimal inaccuracies in the automatic summation in the decimal places.

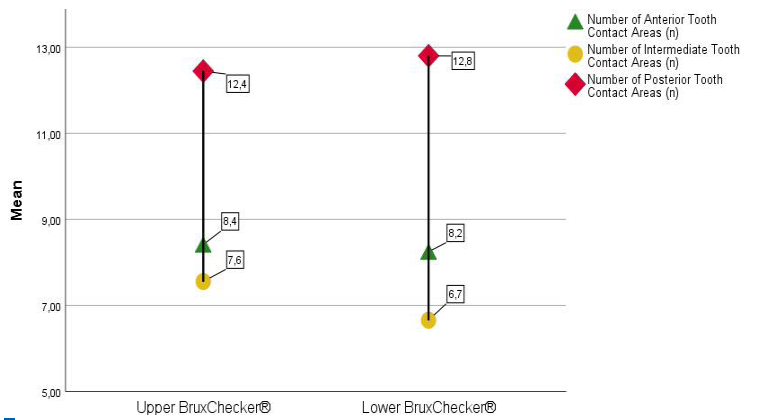

Figure 5a. Comparison of the sagittal distribution of the number of TCAs for anterior vs. intermediate vs. posterior. Anterior $(\boldsymbol{\Delta})$, intermediate $(\bullet)$, and posterior $(\bullet)$ number of TCAs are shown for upper and lower BC (males and females). Posterior sections are dominantly involved, while the intermediate sections have the lowest number of TCAs. Similar distributions are shown for upper and lower BC

TCAs Tooth Contact Areas; BC BruxChecker.

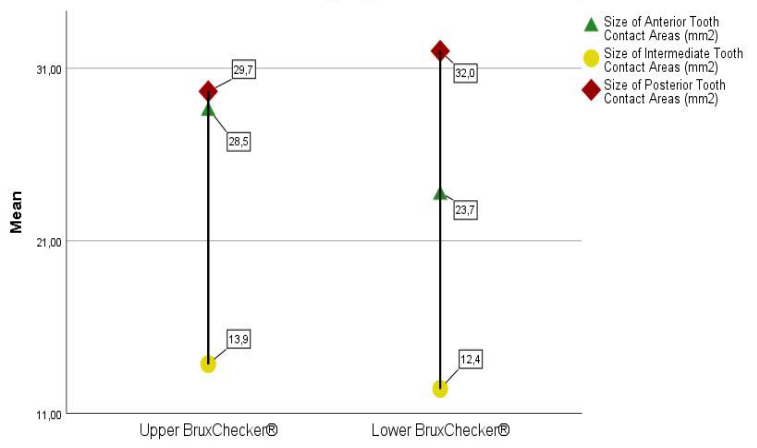

Figure 5b. Comparison of the sagittal distribution of the size of TCAs for anterior vs. intermediate vs. posterior. Anterior $(\boldsymbol{\Delta})$, intermediate $(\bullet)$, and posterior $(\boldsymbol{\bullet})$ size of TCAs are shown for upper and lower BC (males and females). The dominance of posterior sections can only be seen for lower $\mathrm{BC}$, while the anterior and posterior sections of the upper BC are almost equally involved. The intermediate sections show the smallest sizes of TCAs.

TCAs Tooth Contact Areas; BC BruxChecker.

Based on this pilot study, the authors recommend a two-step procedure for the systematic BC analysis: Step 1 - Quantitative analysis; Step 2 - Qualitative Analysis. In the future, an option of a third step (intraindividual analysis) for individual occlusal planning exists.

\section{Step 1 - Quantitative analysis}

The quantitative analysis of a BC: based on the measured critical numbers for number and size; the extent to which the individual uses occlusion when bruxing during sleep, compared to average values (Fig. 6)

\section{Step 2 - Qualitative analysis}

Understand the distribution of TCAs on the BC is a crucial element in occlusal functional analysis. The following assumptions facilitate the qualitative analysis of a BC: involvement of all occlusal sections; symmetric transversal distribution; the sagittal distribution shows the dominance of the posterior occlusal segments, both for the number and the size of TCAs, followed by the anterior segments. The intermediate section shows the least participation (Fig. 7).

Typically, the dental focus is on "large" and "eyecatching" grinding spots. However, such a focus inhibits a deeper understanding of the involved 
occlusion. It is essential to pay attention to those occlusal sections not used in bruxing. In addition, it might be helpful to superimpose the visible TCAs on the $\mathrm{BC}$ and the functional structures of the occlusal morphology (Fig. 8).

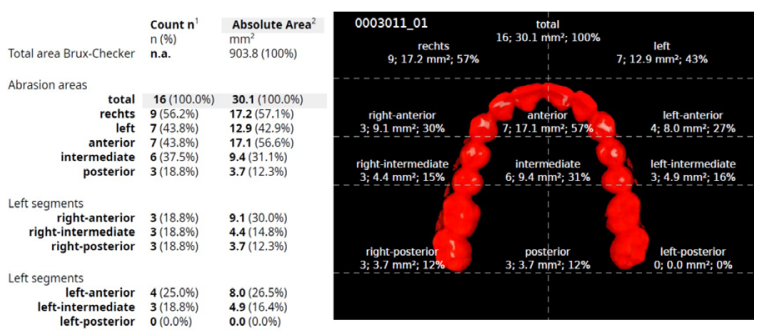

Figure 6. The quantitative analysis of an individual $B C$ based on the measured key numbers for number and size of TCAs; value table and graphical overview.

TCAs Tooth Contact Areas; BC BruxChecker.
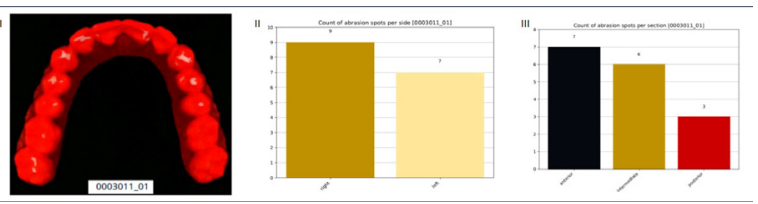

Figure 7. The qualitative analysis of an individual $\mathrm{BC}$ based on the bar charts to point out the transversal and sagittal distribution of TCAs.

TCAs Tooth Contact Areas; BC BruxChecker.

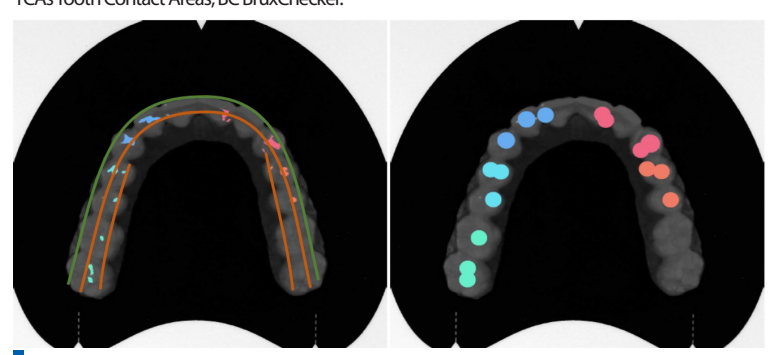

Figure 8. An additional opportunity to use an individual BC is the intraindividual occlusal analysis in comparing the distribution of actual and expected TCAs within the dental arches.

TCAs Tooth Contact Areas; BC BruxChecker.

\section{DISCUSSION}

From the authors' point of view, the quantitative approach is an advantage to understand the $B C$, and thus for tooth grinding pattern of the individual patient. The claim for instrumental confirmation by the SB is fulfilled [4]. The key figures support the possibility to compare the individual situation with standard values and expectations for optimized occlusion $[3,16,17,19]$. The distribution of TCAs for the upper and lower occlusion is symmetric for the transversal (lateral) distribution and well-adjusted in the sagittal distribution. The following concepts may explain the quantitative differences between upper and lower BC: a) different nights: bruxing activity varies from night to night; b) The lower dental arch is smaller than the upper dental arch. c) grinding of teeth has different effects on the upper and lower teeth, especially on anterior teeth: while the lower front teeth will contact with a relatively small area during the entire bruxing movement, the upper front teeth will be "used" widely - from centric occlusion contact points up to the incisal edge. In the premolar and molar regions, these differences are less significant.
This quantitative approach to $\mathrm{BC}$ enables the clinician not only to focus on adverse effects $[1,6,8$, $12,13]$ but instead on therapeutic aspects - which occlusal parameters to be changed $[10,11,17]$. It seems possible to change the muscle recruitment during bruxing activity by modifying occlusal structures $[10,11]$, based on an increased alertness of dentists for TCA's and their distribution by BC visualization and numerical analyses. In addition, it appears reasonable to alter bruxing patterns by the design of occlusal parameters such as canine guidance concerning the temporomandibular joint movement pattern [17].

The BC constitutes a clinically suitable instrument for long-time observation and a functional recall after Rehabilitation. It is up to the supervising team whether other diagnostic methods should be used $[1,2,4,11]$.

Missing teeth may influence the quantitative analysis of a BC. The number of the OCA's on the upper $\mathrm{BC}$ of participant with missing teeth are close to the sample mean (missing first premolar: 36 TCAs; missing first lower molar: 29 TCAs; missing second lower molar: 30 TCAs). The size of the OCA's on the upper $B C$ of these participant are close to the sample mean (missing first premolar: $96.7 \mathrm{~mm}^{2} \mathrm{TCAs}$; missing first lower molar: $69.2 \mathrm{~mm}^{2}$ TCAs; missing second lower molar: $80.82 \mathrm{~mm}^{2}$ TCAs). The number of the OCA's on the lower BC of these participant are close to the sample mean (missing first premolar: 36 TCAs; missing first lower molar: 22 TCAs; missing second lower molar: 15 TCAs). The size of the OCA's on the upper BC of these participant are still high and close to the sample mean (missing first premolar: $92.4 \mathrm{~mm}^{2}$ TCAs; missing first lower molar: $63.2 \mathrm{~mm}^{2}$ TCAs; missing second lower molar: $\left.38.9 \mathrm{~mm}^{2} \mathrm{TCAs}\right)$. Missing teeth have to be considered in the $B C$ analyses. The effect of absent teeth on the key figures of $B C$ analysis has to be evaluated in future studies

\section{CONCLUSION}

- The average size of TCAs in this study population shows a high variance $\left(72 \mathrm{~mm}^{2}+/-51 \mathrm{~mm}^{2}\right)$.

-The average number of TCAs in this study population is 28 with a sd of $+/-8$.

- There is only a not significant gender-specific difference.

- The lateral distribution of TCAs is symmetrical for both number and size.

- The sagittal distribution shows a dominance of the posterior occlusion.

- Based on the quantitative analysis, the clinician has the option to assess occlusion with the number and size of TCAs and thus perform a functional-occlusal analysis: all sections of occlusal seems to be involved in bruxing.

- In the future, dentists' attention can be focused more on the number of TCAs in combination with the size of TCAs: few but large TCAs should be seen differently compared to many but small TCAs. 
- Occlusal segments without any TCAs have to be seen as critical as those with huge TCAs

- Based on the knowledge of the distribution of number and size of TCAs, a qualitative analysis of the $B C$ serves as a valuable element in the functional assessment of the individual occlusion.

\section{AUTHOR CONTRIBUTIONS}

GS: contributed to the concept, protocol, data gathering and analysis, their interpretation and critically revising the manuscript. DG: contributed to the concept, protocol, data gathering and analysis and critically revising the manuscript. AN: contributed to the gathering and analysis, their interpretation and critically revising the manuscript. FS: contributed to the data analysis, their interpretation and critically revising the manuscript.

\section{ACKNOWLEDGMENTS}

None.

\section{CONFLICT OF INTEREST}

Gregor Slavicek and Florian Slavicek are CEO's of Orehab Minds GmbH, DE-70567 Stuttgart, Germany.

\section{REFERENCES}

1. Greven M, Onodera K, Sato S. The use of the BruxChecker in the evaluation and treatment of bruxism. J Craniomandib Funct. 2015;7(3):249-259.

Full text links CrossRef PubMed Google Scholar Scopus WoS 2. Onodera K, Kawagoe T, Sasaguri K, et al. The use of a bruxchecker in the evaluation of different grinding patterns during sleep bruxism. Cranio. 2006 Oct;24(4):292-299. doi: 10.1179/ crn.2006.045. PMID: 17086859.

Full text links CrossRef PubMed Google Scholar Scopus WoS 3. Sateia MJ. International classification of sleep disorders-third edition: highlights and modifications. Chest. 2014 Nov;146(5):1387-1394. doi: 10.1378/chest.14-0970. PMID: 25367475.

Full text links CrossRef PubMed Google Scholar Scopus WoS 4. Sato S, Slavicek R. The masticatory organ and stress management. J. Stomat. Occ. Med. 2008;1(1):51-57.

PubMed Google Scholar

5. Lobbezoo F, Ahlberg J, Raphael KG, et al. International consensus on the assessment of bruxism: Report of a work in progress. J Oral Rehabil. 2018 Nov;45(11):837-844. doi: 10.1111/joor.12663. Epub 2018 Jun 21. PMID: 29926505; PMCID: PMC6287494. Full text links CrossRef PubMed Google Scholar Scopus WoS 6. Bussadori SK, Motta LJ, Horliana ACRT, et al. The current trend in management of bruxism and chronic pain: an overview of systematic reviews. J Pain Res. 2020 Sep 30;13:2413-2421. doi: 10.2147/JPR.S268114. PMID: 33061557; PMCID: PMC7533232. Full text links CrossRef PubMed Google Scholar Scopus WoS 7. Lobbezoo F, van der Zaag J, van Selms MK, et al. Principles for the management of bruxism. J Oral Rehabil. 2008 Jul:35(7):509523. doi: 10.1111/j.1365-2842.2008.01853.x. PMID: 18557917. Full text links CrossRef PubMed Google Scholar Scopus 8. Yap AU, Chua AP. Sleep bruxism: Current knowledge and contemporary management. J Conserv Dent. 2016 SepOct;19(5):383-389. doi: 10.4103/0972-0707.190007. PMID: 27656052; PMCID: PMC5026093.

Full text links CrossRef PubMed Google Scholar Scopus 9. Beddis H, Pemberton M, Davies S. Sleep bruxism: an overview for clinicians. Br Dent J. 2018 Sep 28;225(6):497-501. doi: 10.1038/ sj.bdj.2018.757. Epub 2018 Sep 21. PMID: 30237554 Full text links CrossRef PubMed Google Scholar Scopus 10. Sagl B, Schmid-Schwap M, Piehslinger E, et al. Effect of facet inclination and location on TMJ loading during bruxism: An

in-silico study. J Adv Res. 2021 Apr 29. https://doi.org/10.1016/j. jare.2021.04.009

Google Scholar

11. Tago C, Aoki S, Sato S. Status of occlusal contact during sleep bruxism in patients who visited dental clinics - A study using a Bruxchecker ${ }^{\circledast}$. Cranio. 2018 May;36(3):167-173. doi: 10.1080/08869634.2017.1295125. Epub 2017 Feb 24. PMID: 28234550.

Full text links CrossRef PubMed Google Scholar Scopus WoS 12. Johansson A, Omar R, Carlsson GE. Bruxism and prosthetic treatment: a critical review. J Prosthodont Res. 2011 Jul;55(3):127136. doi: 10.1016/j.jpor.2011.02.004. Epub 2011 May 18. PMID: 21596648.

Full text links PubMed Google Scholar Scopus WoS

13. Mesko ME, Sarkis-Onofre R, et al. Rehabilitation of severely worn teeth: A systematic review. J Dent. 2016 May;48:9-15. doi: 10.1016/j.jdent.2016.03.003. Epub 2016 Mar 7. PMID: 26965079 Full text links CrossRef PubMed Google Scholar Scopus WoS 14. Koyano K, Tsukiyama Y, Ichiki R, Kuwata T. Assessment of bruxism in the clinic. J Oral Rehabil. 2008 Jul;35(7):495-508. doi: 10.1111/j.1365-2842.2008.01880.x. PMID: 18557916.

Full text links CrossRef PubMed Google Scholar Scopus WoS 15. Yamaguchi T, Mikami S, Maeda M, Saito T, Nakajima T, Yachida W, Gotouda A. Portable and wearable electromyographic devices for the assessment of sleep bruxism and awake bruxism: A literature review. Cranio. 2020 Sep 1:1-9. doi: 10.1080/08869634.2020.1815392. Epub ahead of print. PMID: 32870753.

Full text links CrossRef PubMed Google Scholar Scopus WoS 16. Sato S. ATLAS Occlusion Diagnosis by BC http://products scheu-dental.com/documents/5000/1-DOC/0/0/0/0/5/BRUX CHECKER_Sato_ATLAS_Occlusion_Diagnosis_07 13_GB Original 5505.pdf

17. Slavicek $G$. The influence of occlusion on masticatory efficiency considering relevant influencing factors. Stoma Edu J. 2020;7(3):197-207. https://doi.org/10.25241/stomaeduj.2020.7(3). art.6

18. Machin D, Campbell MJ, Tan SB, Tan SH. Sample size tables for clinical studies. 3rd ed. Chichester, West Sussex, UK; Hoboken, NJ: Wiley, 2011 ISBN 978-1-4051-4650-0

Google Scholar

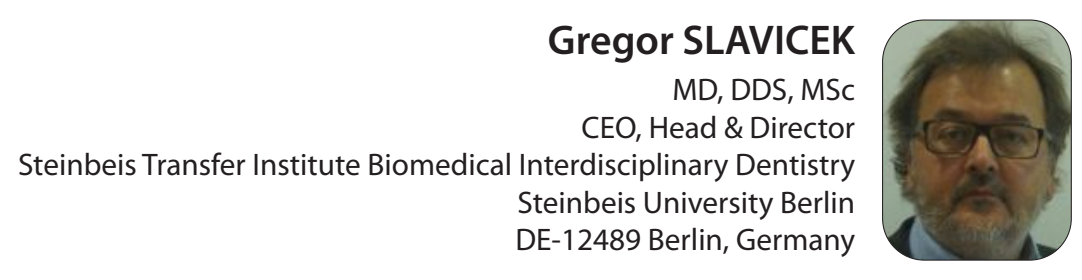

Dr. Slavicek is an MD, specialized in Dentistry. He is currently Director of the Steinbeis Transfer Institute Biomedical Interdisciplinary Dentistry, Steinbeis University Berlin. Since 2019, he has been CEO of Orehab Minds GmbH in Stuttgart, Germany. He graduated from the University Vienna (medicine and dentistry), also specializing in Clinical Research at the same university (Master of Science). He attended additional postgraduate orthodontic training at University Aarhus (Denmark), Prof. B. Melsen, and postgraduate gnathological training at University of Florida (USA), Prof. H. Lundeen and Prof. C. Gibbs. He is an honorary member of the Italian Gnathological Society. He was awarded an honorary professorship by the Ukrainian Dental Society. He was visiting professor at the first medical state University in Moscow Sechenov (2014-2018). 


\section{Ouestions}

\section{How can bruxism be graduated according to the actual international consensus?}

Da. Possible, confirmed, severe;

ub. Possible, probable, definite;

ac. Confirmed and not definite;

ad. Possible, harmless, sometimes.

\section{Which number of tooth contact areas to expect on an upper BruxCheckers ${ }^{\circledR}$ (males and} females)?

Da. Number: $8+/-2$

ab. Number: $71+/-51$;

uc. Number: $28+/-8$;

ud. Number: $101+/-51$.

\section{Which size of tooth contact areas to expect on an upper BruxCheckers ${ }^{\circledR}$ (males and} females)?

口a. Size: $71 \mathrm{~mm}^{2}+/-51 \mathrm{~mm}^{2}$

ab. Size: $7,1 \mathrm{~mm}^{2}+/-5,1 \mathrm{~mm}^{2}$

ac. Size: $17 \mathrm{~mm} 2+/-15 \mathrm{~mm}^{2}$.

ad. Size: $171 \mathrm{~mm} 2+/-151 \mathrm{~mm}^{2}$.

\section{Which answer is correct?}

$\square$ a. The lateral distribution of tooth contact areas on BruxCheckers ${ }^{\circledast}$ is almost symmetrical;

$\square$ b. The posterior segments are dominant in the sagittal distribution of tooth contact areas on BruxCheckers ${ }^{\oplus}$; $\square$ c. There are only minor differences between females and males regarding tooth contact areas;

d. Answers 1-3 are correct.

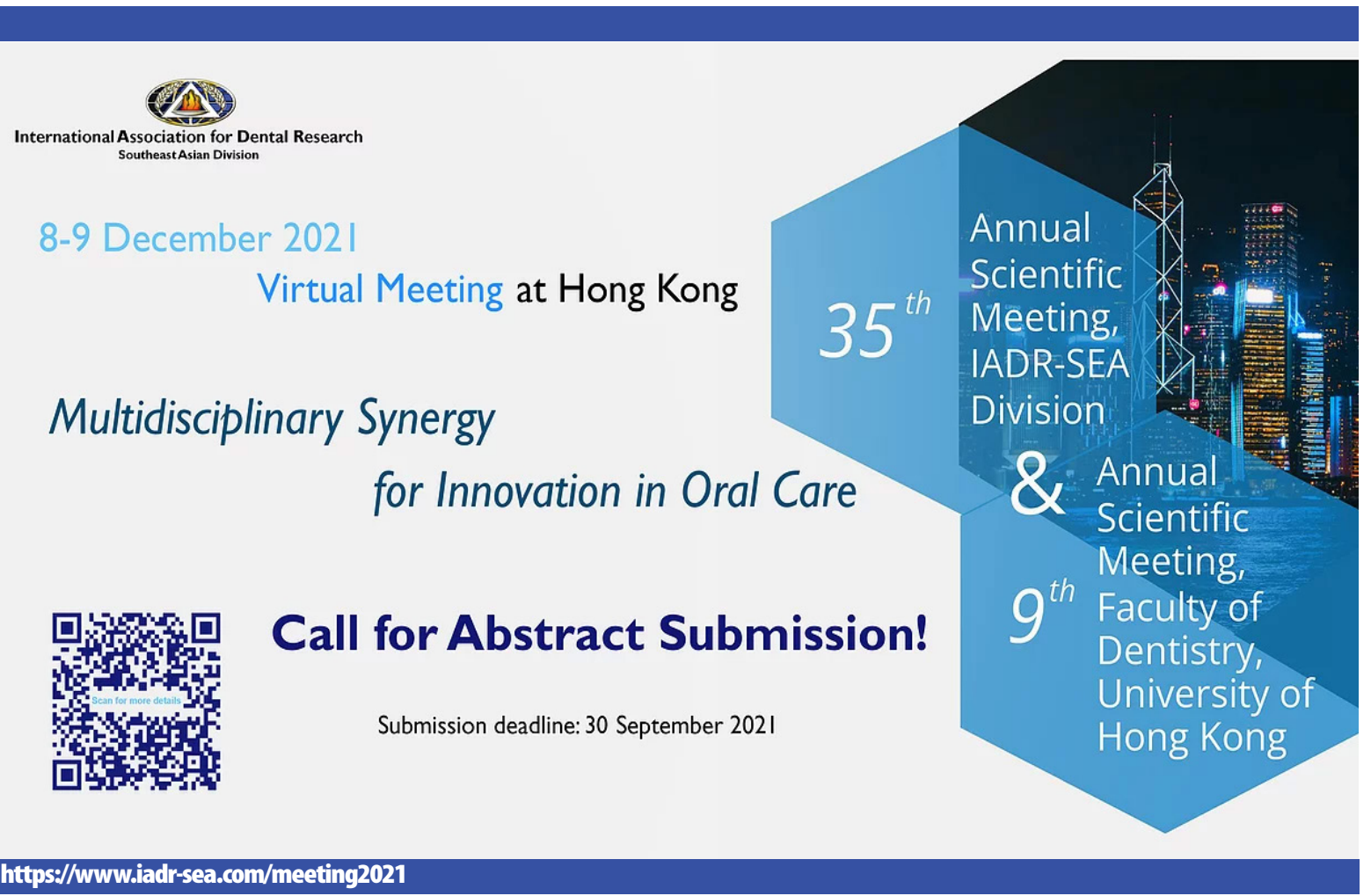




\section{ProTaper Next ${ }^{\circledast}$ \\ Flexible performance}

Dentsply Sirona Endodontics advocates medical standard care by packaging ProTaper Next ${ }^{\oplus}$ files in pre-sterilised blister packs for single patient use. Using two to three ProTaper Next ${ }^{\circledast}$ shaping files for each clinical procedure, instead of four to five previously, makes it affordable for the practitioner to implement a single use policy for endodontic instruments with numerous advantages, namely:

(2) Ergonomics

- Reduced risk of file breakage

\&) Optimal cutting efficiency

(8) No risk for cross contamination
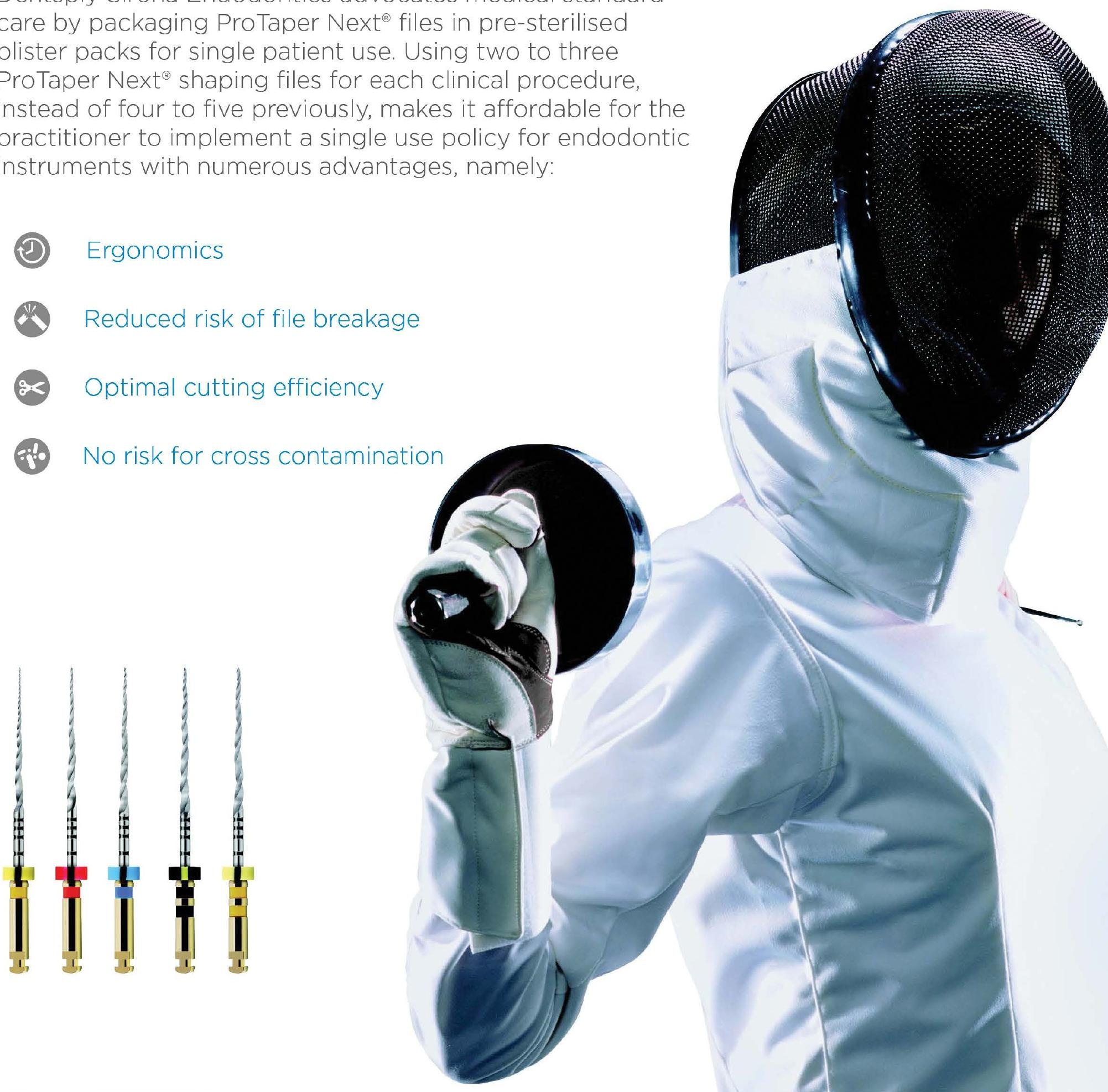


\title{
THE USE OF ER:YAG LASER FOR DENTAL CARIES REMOVAL
}

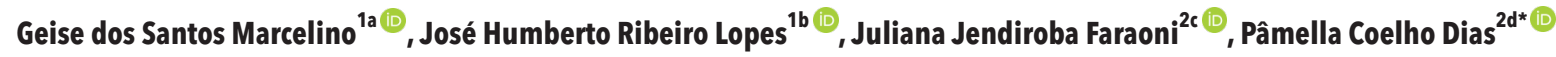 \\ 'School of Dentistry, Faculdade Morgana Potrich (FAMP), Mineiros, Goiás, Brazil \\ ${ }^{2}$ Restorative Dentistry Department, School of Dentistry, University of São Paulo (USP), Ribeirão Preto, São Paulo, Brazil \\ aDDS, General Dentist; email: hisy74@gmail.com; ORCID-iD: https://orcid.org/0000-0003-0056-1580 \\ bDSS, General Dentist; email: zehumbert096@gmail.com; ORCID-iD: https://orcid.org/0000-0001-5028-4425 \\ 'DDS, PhD, Researcher; email: jujfaraoni@yahoo.com.br; ORCID-iD: https://orcid.org/0000-0003-0945-4028 \\ dDDS, MSc, PhD student; email: pamellacdias@hotmail.com; ORCID-iD: https://orcid.org/0000-0003-4886-3940
}

\begin{abstract}
di) https://doi.org/10.25241/stomaeduj.2021.8(3).art.3
\end{abstract}

Background Carious tissue removal in enamel and dentin requires the use of sharp and resistant instruments. New tools have appeared to optimize/facilitate dental treatment, among them the laser. Regarding laser application for dental caries removal, the use of erbium laser doped with yttrium, aluminum, and garnet (Er:YAG) stands out. The Er:YAG laser is excellent for hard tissues ablation since its wavelength of 2.940nm is highly absorbed by water and hydroxyapatite.

Objective To review the application of the Er:YAG laser in dental caries removal, to present its advantages and limitations in clinical practice, as well as to describe its action mechanism, and to compare its effectiveness with different methods used to remove caries.

Data sources The search for articles to compose this literature review was carried out in the PubMed and Embase databases.

Study selection Articles in English published between 2006 and 2021. The manual search included additional articles and books; a total of 39 references were selected.

Data extraction Information from studies that evaluated the use of the Er:YAG laser to remove caries or related this type of laser to other methods. Articles that evaluated characteristics of the dental structure, or the influence of restorative materials after caries removal with the Er:YAG laser, were also considered.

Study selection Based on studies results, the Er:YAG laser presents itself as an alternative for caries removal since it can remove demineralized tissue (selective ablation) without causing damage to the dental element.

\section{KEYWORDS}

Cariology; Dental Caries; Dental Caries Removal; Dentin; Lasers.

\section{INTRODUCTION}

Contemporary dentistry is based on early diagnosis, adequacy of the oral environment, and prevention of oral diseases. In recent years, new tools have emerged to optimize/facilitate dental treatment, including laser. Studies carried out over the years have proven the effectiveness of laser therapy for hard and soft tissues manipulation [1-3].

The word LASER comes from the English acronym Light Amplification by Stimulated Emission of Radiation. Its mechanism of action is based on the emission of a collimated light beam of high energy intensity and can be stimulated by solid, liquid, or gaseous active medium. Lasers have different wavelengths, and this implies the variable phenomena that they can present: absorption, penetration, transmission, and diffusion. In dentistry, the most desirable phenomenon is absorption, as it will interact with living tissue, effectively exercising its different functions [4].
Lasers can be classified, according to their application, in low and high-power lasers [4]. Lowpower lasers can aid analgesia, reduce inflammation and stimulate tissue repair [3,5], while high-powered ones are used in surgery, ablation of decayed tissue, and orthodontics $[2,4,5]$. There are also lasers used for photodynamic therapy and tissue fluorescence diagnosis [4].

Regarding the application of laser for dental caries removal, the use of erbium-doped yttrium, aluminum, and garnet laser (Er:YAG laser) stands out. This laser operates in a pulsed mode, and the handpiece includes a spray of water to prevent tissue dryness and heat build-up, allowing energy to be absorbed efficiently [6].

Several types of research have evaluated the use of lasers in dentistry, highlighting the erbium laser in hard tissues $[1,2,7,8]$. This study aimed to perform a literature review about the application of the Er:YAG laser in dental caries removal and to present its advantages and limitations in clinical practice.

(c) (1) \&) OPEN ACCESS This is an Open Access article under the CC BY-NC 4.0 license

(c) (1) () OPEN ACCESS This is an

Citation: Marcelino GDS, Lopes JHR, Faraoni JJ, Dias PC. The use of Er:YAG laser for dental caries removal. Stoma Edu J. 2021;8(3):173-183. Received: August 17, 2021; Revised: September 11, 2021; Accepted: September 27, 2021; Published: September 28, 2021

*Corresponding author: Pâmella Coelho Dias, DDS, MSc, PhD student; Department of Restorative Dentistry, School of Dentistry, University of São

Paulo, Avenida do Café, s/n, 14040-904, Ribeirão Preto, SP, Brazil; Tel./Fax: +55 16 3315-4016; e-mail: pamellacdias@hotmail.com

Copyright: $\odot 2021$ the Editorial Council for the Stomatology Edu Journal. 


\section{METHODOLOGY}

The article search for this literature review utilized the PubMed and Embase databases, and the selection included articles published between 2006 and 2021. The terms used were "Er:YAG laser" AND "dental caries removal". The inclusion criteria included articles in English published between 2006 and 2021 that evaluated the use of the Er:YAG laser to remove caries or related this type of laser to other methods. Articles that evaluated characteristics of the dental structure, or the influence of restorative materials after removal of caries with Er:YAG laser, were also considered. The search excluded: literature reviews, monographs, case reports, studies with bovine teeth, and studies with artificial or induced demineralization. The manual search included ten studies: three books, four original articles, and three reviews as they contained viable information to structure this literature review. Figure 1 shows the flowchart detailing the selection of articles. In total, this review included 39 references.

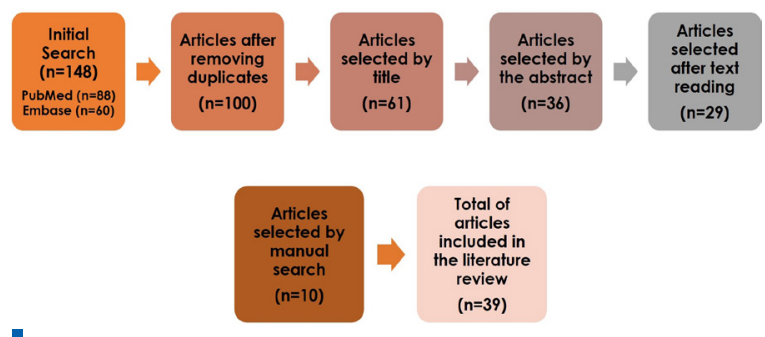

Figure 1. Flowchart of the article selection process.

\section{LITERATURE REVIEW}

Dental caries is described in the literature as a multifactorial disease influenced by genetic, environmental, and behavioral characteristics, being a complex disease resulting from the accumulation of specific acidogenic bacterial colonies present in the dental biofilm, capable of adhering to the tooth. These, in turn, produce acids from their metabolism using fermentable carbohydrates responsible for decreasing the $\mathrm{pH}$ on the dental surface, promoting the reduction of hydroxyapatite crystals and the widening of the intercrystalline spaces, leading to an increase in porosity and, consequently, the emergence of the disease [9].

Clinically, the active initial caries lesion appears on enamel as a white spot with a rough and opaque appearance. With the progression of demineralization, this lesion forms a cavity that can progress to reach the dentin, which then starts to show generally a yellow color, moist aspect, and softened consistency [9].

The removal of decayed enamel and dentin tissue requires the use of strong and sharp instruments to allow the proper preparation of the cavity. There are several instruments used for cavity preparation, such as hand instruments (chisels, dentin scoop) and rotary instruments (carbide burs with different types of active tip, diamond tips) [10]. Previous studies have shown that chemical-mechanical methods like Carisolv ${ }^{\circledR}$ and Papacarie $^{\circledR}$ are also effective in removing caries $[11,12]$.

The laser is another alternative that has been used in the dental field as an effective method for removing decayed tissue, being considered a conservative method since such removal is selective. Besides, laser treatment promotes greater comfort during the surgical procedure and without causing pulpal damage [13-15]. The type of laser most used for this purpose is the yttrium-aluminum-garnet erbium laser (Er:YAG).

The Er:YAG laser is excellent for the ablation of hard tissues, as it has a wavelength of $2.940 \mathrm{~nm}$, which is highly absorbed in water and hydroxyapatite. The erbium laser creates microexplosions in the hydroxyapatite by vaporizing the water molecules present in the hard tissues, which leads to the breakdown of this tissue during the ablation process. This laser operates in a pulsed mode, and the handpiece includes a spray of water to prevent tissue dryness and heat accumulation, allowing the energy to be absorbed efficiently. Thus, its action occurs without tissue carbonization and with minimal generation of heat [6]. Its use was approved for these purposes by the Food and Drug Administration (FDA) in May 1997 [14].

Research that used scanning electron microscopy (SEM) and thermographic study to evaluate the pulp temperature during the use of Er:YAG laser in deciduous and permanent teeth showed that in the same pulse of energy, ablation in dentin was more effective than in enamel and that ablation and caries removal values were significantly higher in primary teeth when comparing to permanent teeth, but without exceeding the temperature of $5.5^{\circ} \mathrm{C}$ [7].

Eberhard et al. (2008) analyzed extracted decayed permanent molars in which they were sectioned and treated with fluorescence-feedback controlled (FFC) Er:YAG laser or diamond tips. The use of the FCC Er:YAG laser at a threshold of $7 U$ (units) resulted in less dentin loss when compared to the use of diamond tips [16].

A randomized clinical trial compared the efficacy of the fluorescence-controlled Er:YAG laser and the low-speed bur in removing decayed tissue in adults. The results showed that the use of the FCC laser at a threshold of 7 and $8 \mathrm{U}$ promotes the same effectiveness of the bur, presenting insignificant numbers of remaining bacteria [17].

One research evaluated different techniques for caries removal and found no selectivity for demineralized tissue using the Er:YAG laser. In this study, the laser showed significant variability in the results, where several samples remained with amounts of remaining caries and others had tooth structure removed in excess [18].

A study evaluating the rate of ablation and selectivity of healthy and demineralized enamel and dentin promoted by a 30W (watts) diode-pumped Er:YAG

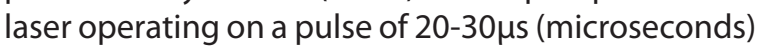


showed that this laser has considerable potential for selective removal of dental caries [19].

Analysis of the removal of demineralized dentin using the FFC Er:YAG laser showed that dentin ablation occurred effectively at fluorescence control values between $6 \mathrm{U}$ and $7 \mathrm{U}$ when measured by microCT (computed microtomography). While at a value greater than $8 \mathrm{U}$, the removal of decayed dentin was unsatisfactory [20].

Kornblit et al. (2008) evaluated the effectiveness of the Er:YAG laser in removing caries in deciduous and permanent molars and observed that ablation in areas infected by caries promoted maximum maintenance of the remaining structure. According to these authors, the laser provided decontamination of the affected area and improved retention of the composite resin to the surface prepared with laser, promoting better marginal enamel sealing [2].

Yonemoto et al. (2006) evaluated the DIAGNOdent ${ }^{\circledR}$ as a guide for caries removal using the Er:YAG laser. Values set at 11-20 were able to remove caries preserving the affected dentin in vitro [21].

An in vivo study used 120 primary teeth from children aged 5 to 9 years, divided into four groups: air rotor, Carisolv ${ }^{\circledR}$, Papacarie $^{\circledR}$, and Er:YAG laser. The results were visually and tactile observed, besides having the values of the DIAGNOdent ${ }^{\circledR}$ pen and the FLACC scale (Face, Legs, Activity, Cry, Consolability) to measure pain during the procedure. Air rotor and laser were the most effective and efficient methods, and laser and chemical-mechanical methods were considered more comfortable [13].

Another in vivo study evaluated the FFC Er:YAG laser for caries removal in pediatric patients. S. mutans and or Lactobacilli were found in $33.33 \%$ of the lesions. In a total of 79 lesions, 14 contained S. mutans and 15 contained Lactobacilli. The average log of colonyforming units (CFU) per sample was 0 for S. mutans and Lactobacilli. The average time to perform the procedure was $2.3 \pm 1.2 \mathrm{~min}$. Regarding pain, $93.8 \%$ of children considered laser usage comfortable [15]. One research biochemically analyzed decayed and healthy teeth treated by the fluorescence-controlled Er:YAG laser, where a layer of dentin was removed from the bottom of the preparation to determine the presence of hydroxylysylpyridinoline (HP) and lysylpyridinoline (LP) collagen cross-links using high-performance liquid chromatography. 100\% HP and LP were found in decayed dentin and $0.33 \%$ HP and $0.68 \%$ LP in healthy dentin. After caries removal, $0.84 \% \mathrm{HP}$ and $1.26 \% \mathrm{LP}$ were found at the $5 \mathrm{U}$ fluorescence-control threshold and $1.56 \% \mathrm{HP}$ and $2.48 \% \mathrm{LP}$ at $10 \mathrm{U}$. The Er:YAG laser proved to be a viable method for removing the irreversibly denatured collagen present in decayed dentin [1]. Scanning electron microscope was used to investigate the morphological changes in the hard dental tissues after caries removal and cavity preparation using different methods: Er:YAG laser, Carisolv $^{\circledR}$ gel, high-speed diamond burs, and lowspeed micromotor steel burs. The dental surface after using the laser remained highly retentive, without smear layer residues and with the presence of exposed dentinal tubules. The samples treated with Carisolv $^{\circledR}$ gel presented a rough retentive surface and some dentinal tubules obliterated by denatured collagen and surface contaminants; surfaces prepared with low and high-speed burs showed a thick smear layer and no micro retentions [22].

An in vitro study evaluated marginal microleakage of cavities restored with glass ionomer, comparing Er:YAG laser with Apacaries gel and atraumatic restorative technique (ART), and found a higher level of infiltration with the use of the laser to remove caries compared to the other methods [23].

Studies show that different techniques for removing decayed tissue influence the bond strength of adhesive systems [24-27]. The study of Yildiz et al. (2013) concluded that the chemical-mechanical method or use of burs at low rotation compared to the Er:YAG laser show better results in terms of bond strength for both self-etch and total-etch adhesives [27]. In another study, using a 2-step selfetch adhesive system, the dentin surface prepared by the Er:YAG laser showed lower micro-tensile bond strength ( $\mu \mathrm{TBS})$ values compared to healthy dentin [24]. In the study of Sattabanasuk et al. (2006), the bond strength values of a total-etch adhesive system were similar for the Er:YAG laser and steel bur [25].

Sirin Karaarslan et al. (2012) evaluated the microtensile bond strength of 3 types of adhesive systems - Clearfil ${ }^{\otimes}$ SE Bond (2-step self-etch), G-Bond ${ }^{\circledR}$ (singlestep self-etch), and Adper ${ }^{\circledR}$ Single Bond 2 (2-step total-etch) after caries removal using a spherical steel bur at low-speed, Carisolv ${ }^{\circledR}$ gel or the Er:YAG laser. Based on the results, the techniques used to remove decayed tissue showed significant differences in bond strength between the adhesive systems. There was no significant difference in the bond strength of total-etch adhesive systems comparing laser and bur groups. Using the laser, Adper ${ }^{\oplus}$ Single Bond 2 was superior to the other adhesive systems, indicating that total-etch adhesives are the best option in this type of caries removal method [26].

The microhardness and chemical composition of dentin vary according to the applied caries removal method. The chemical-mechanical technique $\left(\right.$ Carisolv $\left.^{\circledR}\right)$ showed lower microhardness of the remaining dentin and a considerable number of samples with residual caries (20\%) when compared to the carbide bur and the Er:YAG laser (both 5\%). There was no significant difference in calcium and phosphorus rates of the three evaluated groups [28]. A comparative clinical study between the bur and the Er:YAG laser to remove caries from primary molars showed that the laser was less efficient than the bur to remove caries. Regarding effectiveness, the two treatments were similar to remove caries in the pulp wall, and the bur was better in the surrounding walls. The composite resin restorations for both groups remained satisfactory after one year of treatment [8]. A double-blind clinical study, performed in children aged 7-10 years, evaluated composite resin restorations in primary teeth performed after selective removal of necrotic dentin using an Er:YAG laser and a carbide bur. Adhesive restorations did not suffer laser interference, and the SEM analysis showed that laser group restorations showed a $10 \%$ gap in its extension, and the group treated with a bur showed 
a $20 \%$ gap in the cavosurface margin after 12 months of follow-up [29].

A longitudinal clinical study with four years of follow-up evaluated the clinical longevity of composite resin restorations after selective caries removal in permanent molars using the Er:YAG laser or bur preparation with chlorhexidine as dentin biomodifier. The Er:YAG laser group biomodified with chlorhexidine presented a statistically significant difference for marginal adaptation criteria compared to the other groups; for secondary caries criteria and clinical and radiographic evaluation of pulp vitality, there was no statistically significant difference between the evaluated groups. The authors concluded that the method of caries removal and dentin biomodification did not influence the survival rate of composite resin restorations [30].

Prabhakar et al. (2018) evaluated morphological changes and the presence of bacterial deposits in primary decayed molars submitted to carious tissue removal by Carie-Care (chemical-mechanical method), Er:YAG laser, and tungsten carbide spherical bur. The results showed that the laser group was the most effective of the three, with fewer bacterial deposits and no smear layer formation [31]. A meta-analysis evaluated the Er:YAG laser to remove caries and for cavity preparation in children compared to the traditional mechanical method. This study evaluated seven randomized clinical trials and found that the laser requires more operative time but is less painful. There were no statistically significant differences between the two types of treatment concerning retention, marginal adaptation, and marginal discoloration of restorations [32].

$A$ recent systematic review showed that the use of burs, chemomechanical method, and the Er:YAG laser are efficient for caries removal, reduction of bacteria in the tooth cavity, and do not compromise the clinical performance of restorations [33].

An in vitro study compared the FFC Er:YAG laser with the Er:YAG laser in three different pulses (super short, medium short, and short pulse) regarding the efficiency of removing cariogenic bacteria and carious dentin and dentin temperature during ablation. The results showed that no experimental group had bacterial contamination after treatment. In the groups with varied pulses of laser energy, the dentin temperature was significantly higher than the FFC laser [34].

A study that evaluated and compared the Er:YAG laser, the tungsten bur, and the polymer bur in caries removal showed no difference between the treatment time comparing the three methods. Histological analysis showed that all groups effectively removed the infected dentin and the laser group showed a regular $5 \mu \mathrm{m}$ thick layer of denatured collagen. The group treated by the tungsten bur presented a smear layer, and the polymer bur group showed an affected dentin surface layer [35].

Matsumoto et al. (2007) clinically evaluated the applicability of the Er:YAG laser on 95 decayed teeth from 45 patients. No adverse reactions and no or little pain were reported in most treated teeth (89.5\%). Tooth preparation was successfully performed exclusively by laser in $94.7 \%$ of the cases, and the operative time was on average 49 seconds [36].

\section{DISCUSSION}

The Er:YAG laser to remove caries has been widely studied in recent years, showing that it is a safe and comfortable method for the patient, minimizing the use of local anesthesia and maintaining pulp vitality $[2,7,13,17]$.

Studies comparing different methods of caries removal found that the Er:YAG laser, together with the chemical-mechanical method, provided greater comfort and satisfaction for both the operator and the patient as they were less traumatic [13]. According to a systematic review, chemomechanical methods are the best option for a minimally invasive treatment [33]. In an in vitro study, the hand excavator was the most effective technique to remove caries in deciduous teeth [37].

Comparing caries removal effectiveness (capacity) between laser and carbide bur at low rotation, the results of the two methods were similar for removing caries from the pulpal wall; the bur was more effective on the surrounding walls of primary molars [8]. Both techniques showed similar results regarding the presence of residual caries [28].

The adjusted value in lasers with fluorescencefeedback control influenced selectivity for carious tissue in the studies evaluated in this literature review. Schwass et al. (2013) showed that the Er:YAG laser with fluorescence control selected between $7 \mathrm{U}$ and $8 \mathrm{U}$ was effective for removing demineralized dentin [20], as well as studies by Dommisch et al. (2008) [17] and Eberhard et al. (2008) [16], where the Er:YAG laser with fluorescence control at levels of $7 \mathrm{U}$ and $8 \mathrm{U}$ promoted caries removal similar to that obtained with the conventional bur, generating greater comfort and wellness to the patient. The use of a laser with fluorescence control set to $9 \mathrm{U}$ and $10 \mathrm{U}$ did not remove all decayed tissue [17]. Contrasting these results, Neves et al. (2011) did not find selectivity when analyzing samples prepared with the FFC Er:YAG laser at the threshold of $7 \mathrm{U}$, where some specimens were overprepared, and others continued with decayed tissue. In this study, the laser was the evaluated method that presented the least minimally invasive potential [18].

Regarding the morphological changes generated on the treated dental surface, the laser did not promote thermal damage and also left the surface highly retentive and without the presence of a smear layer; while the use of burs in both high and low rotation promoted surfaces with a thick smear layer and absence of microretentions; the use of polymer burs left an affected dentin layer [22,35].

Despite the advantages of using laser as a method of removing decayed tissue, clinical studies have 
shown variation in clinical time, with laser consuming about $3 x$ more time than the use of burs [17] with an average treatment duration of $2.3 \pm 1.2 \mathrm{~min}$ [15]. Other studies have also shown a longer average treatment time with the use of laser, but with a minor difference: 110s [8] or 49s [36] for the Er:YAG laser and 55s [8] for the low-speed carbide bur. Another disadvantage found in one of the selected studies was the presence of marginal infiltration in decayed teeth ablated by laser and restored with glass ionomer [23].

The bond strength of adhesive systems influenced the method used to remove caries [26]. According to the results, the authors suggest choosing a conventional adhesive system after caries removal by the Er:YAG laser and a self-etch adhesive system after using a chemical-mechanical method. These results corroborate the study by Neves et al. (2011) that found lower micro-tensile bond strength using a 2-step self-etch adhesive after caries removal by the Er:YAG laser compared to the chemical-mechanical method and the use of conventional burs [24]. In another study, the use of a chemical-mechanical technique or usage of burs at low-speed compared to Er:YAG laser showed better results in terms of bond strength for both self-etch and total-etch adhesive systems [27]. Other studies showed that the Er:YAG does not influence the bond strength value of a total-etch adhesive system $[25,38]$; however, the study of Sattabanasuk et al. (2006) showed higher bond strength values for Er:YAG laser compared to steel bur evaluating a self-etch adhesive system (Clearfil Protect Bond) [25].
A 12-month follow-up of a randomized clinical trial with a split-mouth design showed that teeth with decayed tissue removed by both laser and bur and restored with a 2-step total-etch adhesive system and composite resin maintained satisfactory restorative treatment [8]. In a double-blind clinical study, the restorations of the laser group showed a lower percentage of a gap than the group treated by bur in the analysis performed by SEM at the same follow-up time [29].

In a biochemical analysis of dentin collagen on decayed surfaces treated with erbium laser through SEM, the percentage of dehydrated collagen and decayed dentin reduced after laser treatment, becoming similar to healthy dentin [1]. In the study of Krause et al. (2008), 42.9\% of the samples had bacterial residues, but in only $7.1 \%$, the bacterial count was greater than 100 CFU (colony forming units) [15].

The pulp response to the application of external heat was evaluated in an in vivo study using rhesus monkeys [39]. The results showed that a temperature increase of $2.2^{\circ} \mathrm{C}$ does not cause pulp changes and that increase of $5.5^{\circ} \mathrm{C}$ allowed pulp repair for most specimens (75\%). In several studies, the use of the Er:YAG laser has proven not to generate thermal damage to the dental structure, not exceeding the temperature increase above the threshold tolerated by the dental pulp $[2,7,19,34]$.

Table 1 summarizes the 29 studies selected by Pubmed and Embase.

\begin{tabular}{|c|c|c|c|c|c|}
\hline Author (Year) & Substrate & $\begin{array}{l}\text { Type of } \\
\text { study }\end{array}$ & $\begin{array}{c}\text { Evaluated } \\
\text { parameters }\end{array}$ & $\begin{array}{l}\text { Er:YAG laser } \\
\text { specifications }\end{array}$ & Conclusion \\
\hline $\begin{array}{l}\text { Al-Batayneh et } \\
\text { al. (2014) [7] }\end{array}$ & $\begin{array}{l}\text { Sound and carious } \\
\text { enamel and dentin } \\
\text { from } 40 \text { primary e } \\
40 \text { permanent } \\
\text { extracted teeth }\end{array}$ & $\begin{array}{l}\text { In vitro } \\
\text { comparative } \\
\text { study }\end{array}$ & $\begin{array}{l}\text { - Laser ablation in } \\
\text { sound enamel and } \\
\text { dentin } \\
\text { - Comparison } \\
\text { between the Er:YAG } \\
\text { laser and the rotary } \\
\text { bur for carious } \\
\text { removal } \\
\text { - Surfaces changes } \\
\text { through SEM }\end{array}$ & $\begin{array}{l}\text { - Wavelength: } 2.94 \mu \mathrm{m} \\
\text { - Pulse energy: } 200 \mathrm{~mJ} \\
\text { - Pulse duration: } 250 \mu \mathrm{s} \\
\text { - Frequency: } 10 \mathrm{~Hz} \\
\text { - Power output: } 6 \mathrm{~W}\end{array}$ & $\begin{array}{l}\text { - Laser creates greater crater } \\
\text { depths in dentin than enamel } \\
\text { for both types of teeth } \\
\text { - Laser is more efficient than } \\
\text { the rotary bur to remove } \\
\text { caries in primary teeth } \\
\text { - There was no significant } \\
\text { difference between } \\
\text { both methods regarding } \\
\text { permanent teeth } \\
\text { - Dental ablation did not } \\
\text { exceed } 5.5^{\circ} \mathrm{C} \\
\text { - SEM: dentin ablation with } \\
\text { no smear layer }\end{array}$ \\
\hline $\begin{array}{l}\text { Baraba et al. } \\
\text { (2018) [34] }\end{array}$ & $\begin{array}{l}60 \text { teeth with } \\
\text { dentin caries and } \\
12 \text { teeth without } \\
\text { caries lesion. }\end{array}$ & $\begin{array}{l}\text { In vitro } \\
\text { comparative } \\
\text { study }\end{array}$ & $\begin{array}{l}\text { Caries removal } \\
\text { efficiency of the FFC } \\
\text { Er:YAG laser and } \\
\text { different pulses of } \\
\text { the Er:YAG laser } \\
\text {-PCR analysis } \\
\text {-Thermal alterations }\end{array}$ & $\begin{array}{l}\text { FCC laser: } \\
\text {-Pulse energy: } 350 \mathrm{~mJ} \\
\text { (enamel) and } 250 \mathrm{~mJ} \\
\text { (dentin) } \\
\text {-Pulse duration: } 400 \mu \mathrm{s} \\
\text {-Frequency: } 4 \mathrm{~Hz} \\
\text {-Threshold: } 7 \mathrm{U} \\
\text { Laser with different } \\
\text { pulses: } \\
\text {-Pulses: } 50 \mu \mathrm{s}, 100 \mu \mathrm{s}, \\
\text { and } 300 \mu \mathrm{s} \\
\text {-Pulse energy: } 350 \mathrm{~mJ} \\
\text { (enamel) and } 250 \mathrm{~mJ} \\
\text { (dentin) } \\
\text {-Frequency: } 10 \mathrm{~Hz} \\
\text {-Non-contact mode } \\
\text {-Distance: } 7 \mathrm{~mm}\end{array}$ & $\begin{array}{l}\text {-Ablated specimens were } \\
\text { bacteria-free } \\
\text {-All laser evaluated were } \\
\text { efficient for caries removal } \\
\text {-FCC laser group presented } \\
\text { the lowest average } \\
\text { temperature }\end{array}$ \\
\hline
\end{tabular}




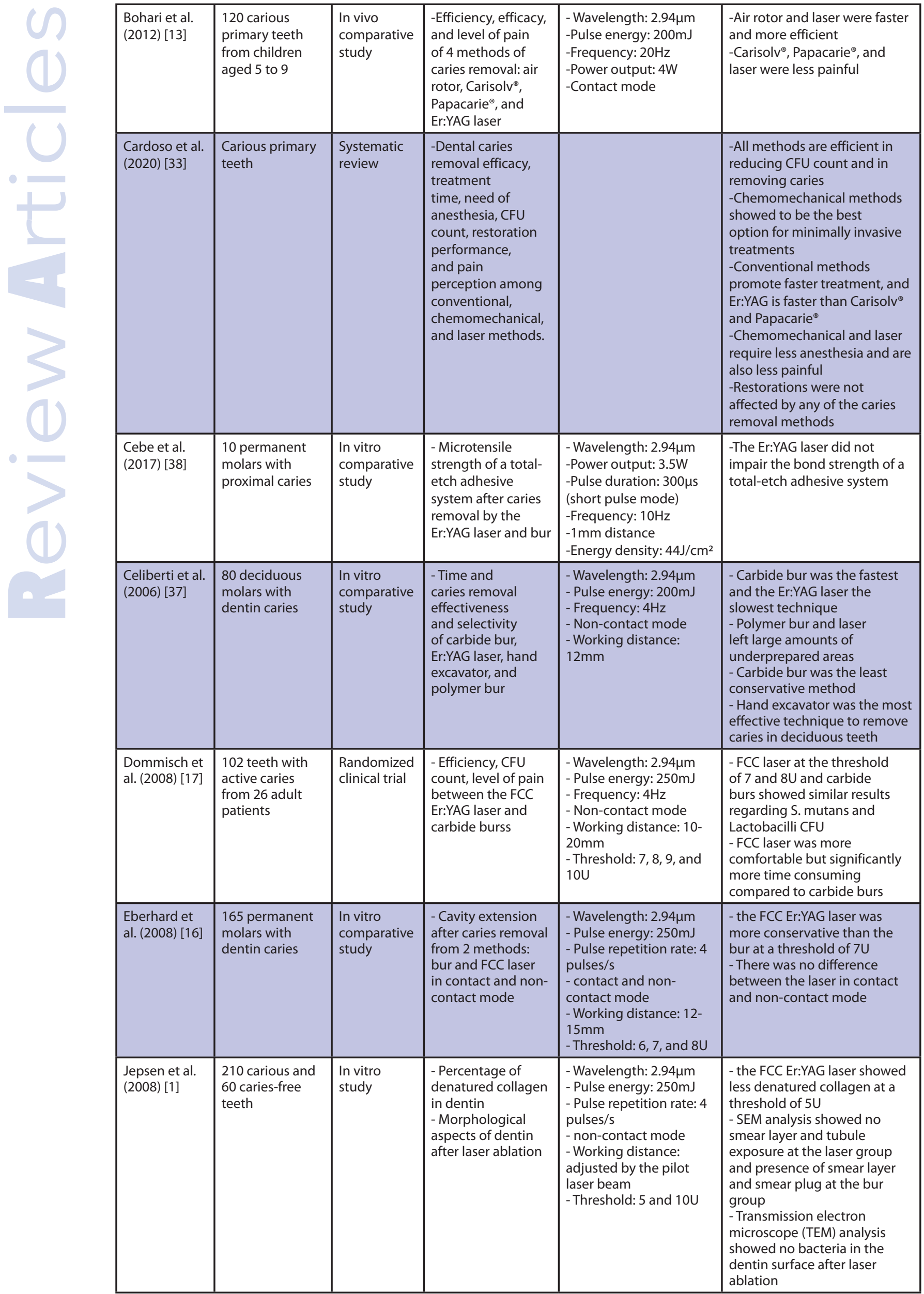




\begin{tabular}{|c|c|c|c|c|c|}
\hline $\begin{array}{l}\text { Juntavee } \\
\text { et al. (2013) } \\
{[23]}\end{array}$ & $\begin{array}{l}\text { Primary second } \\
\text { molars with } \\
\text { occlusal caries }\end{array}$ & $\begin{array}{l}\text { In vitro } \\
\text { comparative } \\
\text { study }\end{array}$ & $\begin{array}{l}\text { - Influence of } \\
\text { Apacaries gel, } \\
\text { Er:YAG laser, and } \\
\text { spoon excavator } \\
\text { as caries removal } \\
\text { methods in } \\
\text { the marginal } \\
\text { microleakage of } \\
\text { glass ionomer } \\
\text { restorations } \\
\end{array}$ & $\begin{array}{l}\text { - Pulse energy: } 260 \mathrm{~mJ} \\
\text { - Frequency: } 30 \mathrm{~Hz} \\
\text { - Pulse mode }\end{array}$ & $\begin{array}{l}\text { - the Er:YAG laser promoted } \\
\text { significant higher microleakage } \\
\text { than Apacaries and spoon } \\
\text { excavator in ionomer } \\
\text { restorations }\end{array}$ \\
\hline $\begin{array}{l}\text { Katirci et al. } \\
\text { (2016) [28] }\end{array}$ & $\begin{array}{l}\text { Permanent molars } \\
\text { with occlusal } \\
\text { caries }\end{array}$ & $\begin{array}{l}\text { In vitro } \\
\text { comparative } \\
\text { study }\end{array}$ & $\begin{array}{l}\text { - Effectiveness } \\
\text { of three caries } \\
\text { removal methods by } \\
\text { stereomicroscopic } \\
\text { observations and } \\
\text { microindentation } \\
\text { hardness } \\
\text { measurement } \\
\text { - Chemical } \\
\text { composition of the } \\
\text { residual dentin }\end{array}$ & $\begin{array}{l}\text { - Pulse energy: } 250 \mathrm{~mJ} \\
\text { - Frequency: } 4 \mathrm{~Hz} \\
\text { - Non-contact mode } \\
\text { - Working distance: } \\
\text { 10mm }\end{array}$ & $\begin{array}{l}\text { - Carbide bur and Er:YAG } \\
\text { laser had a similar outcome } \\
\text { regarding caries removal } \\
\text { - Carisolv }{ }^{\oplus} \text { was less effective } \\
\text { than the carbide bur and the } \\
\text { Er:YAG laser and presented } \\
\text { remaining dentin with a lower } \\
\text { hardness compared to the } \\
\text { other methods } \\
\text { - There were no differences in } \\
\text { the calcium and phosphate } \\
\text { ratio among the three methods }\end{array}$ \\
\hline $\begin{array}{l}\text { Kornblit et } \\
\text { al. (2008) } \\
\text { [2] }\end{array}$ & $\begin{array}{l}30 \text { carious teeth } \\
\text { from children aged } \\
4 \text { to } 12 \mathrm{~s}\end{array}$ & Clinical trial & $\begin{array}{l}\text { - Possible } \\
\text { postoperative } \\
\text { complications after } \\
\text { caries removal with } \\
\text { the Er:YAG laser }\end{array}$ & $\begin{array}{l}\text { - Wavelength: } 2.94 \mu \mathrm{m} \\
\text { - Pulse duration: } 140 \mu \mathrm{s} \\
\text { - Pulse energy: } 120 \text { to } \\
200 \mathrm{~mJ} \\
\text { - Frequency: } 2 \text { to } 20 \mathrm{~Hz} \\
\text { - focus mode } \\
\text { - Working distance: } 0.8 \\
\text { to } 1 \mathrm{~cm}\end{array}$ & $\begin{array}{l}\text { - Children treated with Er:YAG } \\
\text { did not show any pain or } \\
\text { sensitivity } 7 \text { and } 28 \text { days after } \\
\text { the treatment }\end{array}$ \\
\hline $\begin{array}{l}\text { Krause et } \\
\text { al. (2008) } \\
{[15]}\end{array}$ & $\begin{array}{l}79 \text { carious lesions } \\
\text { from children aged } \\
3 \text { to } 12\end{array}$ & Clinical trial & $\begin{array}{l}\text { - Efficacy of the FCC } \\
\text { Er:YAG laser } \\
\text { - CFU count after } \\
\text { laser treatment } \\
\text { - Children } \\
\text { perceptions during } \\
\text { treatment }\end{array}$ & $\begin{array}{l}\text { - Wavelength: } 2.94 \mu \mathrm{m} \\
\text { - Pulse duration: } 400 \mu \mathrm{s} \\
\text { - Pulse energy: } 250 \mathrm{~mJ} \\
\text { - Frequency: } 4 \mathrm{~Hz} \\
\text { - non-contact mode } \\
\text { - Working distance: } \\
12 \mathrm{~cm} \\
\text { - Threshold: } 7 \mathrm{U}\end{array}$ & $\begin{array}{l}\text { - Treatment duration was } \\
2.3 \pm 1.2 \text { min } \\
-93.8 \% \text { of the children } \\
\text { considered the laser treatment } \\
\text { comfortable } \\
\text { - After laser ablation, } 42.9 \% \text { of } \\
\text { the samples showed residual } \\
\text { bacteria; however, only } 7.1 \% \\
\text { presented more than } 100 \mathrm{CFU} / \\
\text { sample }\end{array}$ \\
\hline $\begin{array}{l}\text { Li et al. } \\
\text { (2019) [32] }\end{array}$ & $\begin{array}{l}\text { Carious teeth from } \\
\text { children }\end{array}$ & $\begin{array}{l}\text { Meta- } \\
\text { analysis }\end{array}$ & $\begin{array}{l}\text { - Duration of } \\
\text { treatment } \\
\text { - Pain perception } \\
\text { - Success of } \\
\text { restorations }\end{array}$ & & $\begin{array}{l}\text { - Caries removal with laser is } \\
\text { more time consuming than the } \\
\text { use of bur } \\
\text { - the Er:YAG laser is less painful } \\
\text { than -the bur } \\
\text { - There were no statistical } \\
\text { differences in complete } \\
\text { restoration retention, marginal } \\
\text { discoloration, and marginal } \\
\text { adaptation between Er:YAG } \\
\text { laser and bur }\end{array}$ \\
\hline $\begin{array}{l}\text { Matsumoto } \\
\text { et al. (2007) } \\
{[36]}\end{array}$ & $\begin{array}{l}\text { Carious teeth from } \\
\text { adults }\end{array}$ & Clinical trial & $\begin{array}{l}\text { - Pain, discomfort, } \\
\text { assessment during } \\
\text { cavity preparation, } \\
\text { prognosis factor, } \\
\text { and overall clinical } \\
\text { evaluation }\end{array}$ & $\begin{array}{l}\text { - Wavelength: } 2.94 \mu \mathrm{m} \\
\text { - Pulse energy: } 700 \mathrm{~mJ} \\
\text { - Frequency: } 8 \mathrm{~Hz}\end{array}$ & $\begin{array}{l}\text { - Laser showed: low rate of } \\
\text { pain during treatment, no } \\
\text { discomfort, ample efficacy, } \\
\text { substantial efficiency, good } \\
\text { prognosis after three months } \\
\text { of follow-up, and mean of } \\
\text { treatment duration of } 49 \mathrm{~s}\end{array}$ \\
\hline $\begin{array}{l}\text { Medioni et } \\
\text { al. (2016) } \\
\text { [35] }\end{array}$ & $\begin{array}{l}\text { Carious molars } \\
\text { and premolars }\end{array}$ & $\begin{array}{l}\text { In vitro } \\
\text { comparative } \\
\text { study }\end{array}$ & $\begin{array}{l}\text { - Effectiveness of } \\
\text { - the Er:YAG laser, } \\
\text { carbide bur, and } \\
\text { polymer bur for } \\
\text { caries removal }\end{array}$ & $\begin{array}{l}\text { - Wavelength: } 2.94 \mu \mathrm{m} \\
\text { - Pulse energy: } 375 \mathrm{~mJ} \\
\text { - Pulse duration: } 50 \mu \mathrm{s} \\
\text { - Frequency: } 10 \mathrm{~Hz} \\
\text { - Quasi-contact mode }\end{array}$ & $\begin{array}{l}\text { - Procedure time was similar for } \\
\text { all the three methods } \\
\text { - Histological analysis showed } \\
\text { smear layer in the specimens } \\
\text { treated with carbide bur, } \\
\text { denatured collagen in the laser } \\
\text { group, and a layer of affected } \\
\text { dentin in the polymer bur } \\
\text { group } \\
\text { - All methods removed the } \\
\text { infected dentin }\end{array}$ \\
\hline $\begin{array}{l}\text { Neves et al. } \\
\text { (2011) [24] }\end{array}$ & Carious molarss & $\begin{array}{l}\text { In vitro } \\
\text { comparative } \\
\text { study }\end{array}$ & $\begin{array}{l}\text { - Influence of the } 7 \\
\text { methods for caries } \\
\text { removal in the } \\
\text { bonding capacity } \\
\text { of the remaining } \\
\text { dentin }\end{array}$ & $\begin{array}{l}\text { - Pulse energy: } 250 \mathrm{~mJ} \\
\text { - Pulse repetition rate: } \\
4 \text { pulses/s } \\
\text { - Non-contact mode } \\
\text { - Threshold: } 7 U\end{array}$ & $\begin{array}{l}\text { - Remaining denting from the } \\
\text { FCC Er:YAG laser group showed } \\
\text { lower } \mu \text { TBS values } \\
\text { - Carisolv showed the best } \\
\text { results regarding } \mu \text { TBS, } \\
\text { followed by carbide bur + caries } \\
\text { detector }\end{array}$ \\
\hline
\end{tabular}




\begin{tabular}{|c|c|c|c|c|c|}
\hline $\begin{array}{l}\text { Neves et al. } \\
\text { (2011) [18] }\end{array}$ & Carious molars & $\begin{array}{l}\text { In vitro } \\
\text { comparative } \\
\text { study }\end{array}$ & $\begin{array}{l}\text { - Caries removal } \\
\text { effectiveness and } \\
\text { minimally invasive } \\
\text { potential of } 9 \\
\text { methods for caries } \\
\text { removal by microCT }\end{array}$ & $\begin{array}{l}\text { - Pulse energy: } 250 \mathrm{~mJ} \\
\text { - Pulse repetition rate: } \\
4 \text { pulses/s } \\
\text { - Non-contact mode } \\
\text { - Threshold: } 7 U\end{array}$ & $\begin{array}{l}\text { - Chemomechanical methods } \\
\text { + metal excavators showed the } \\
\text { best results } \\
\text { - the FCC Er:YAG laser showed } \\
\text { the most variable results: } \\
\text { specimens with over and others } \\
\text { with under preparation } \\
\text { - the FCC Er:YAG laser did not } \\
\text { prove to be a selective method } \\
\text { for caries removal }\end{array}$ \\
\hline $\begin{array}{l}\text { Polizeli et al. } \\
\text { (2019) [29] }\end{array}$ & $\begin{array}{l}48 \text { primary } \\
\text { molars with } \\
\text { occlusal and } \\
\text { proximal caries } \\
\text { from children } \\
\text { aged } 7 \text { to } 10\end{array}$ & $\begin{array}{l}\text { Double- } \\
\text { blind, } \\
\text { randomized } \\
\text { clinical trial }\end{array}$ & $\begin{array}{l}\text { - Salivary cortisol } \\
\text { levels and clinical } \\
\text { performance of } \\
\text { restorations after } \\
\text { caries removal by } \\
\text { the Er:YAG laser } \\
\text { compared to } \\
\text { carbide bur }\end{array}$ & $\begin{array}{l}\text { - Medium short pulse } \\
\text { mode } \\
\text { - Pulse energy: } 250 \mathrm{~mJ} \\
\text { - Frequency: } 4 \mathrm{~Hz} \\
\text { - non-contact mode } \\
\text { - Working distance: } \\
7 \mathrm{~cm}\end{array}$ & $\begin{array}{l}\text { - Salivary cortisol levels were } \\
\text { similar for laser and bur } \\
\text { - There was no difference } \\
\text { regarding marginal adaptation, } \\
\text { retention, discoloration, } \\
\text { and secondary caries for } \\
\text { restorations from both groups } \\
\text { after one year of follow-up }\end{array}$ \\
\hline $\begin{array}{l}\text { Prabhakar et } \\
\text { al. (2018) [31] }\end{array}$ & $\begin{array}{l}\text { Carious primary } \\
\text { molars }\end{array}$ & $\begin{array}{l}\text { In vitro } \\
\text { comparative } \\
\text { study }\end{array}$ & $\begin{array}{l}\text { - Morphological } \\
\text { changes } \\
\text {-Bacterial deposits }\end{array}$ & $\begin{array}{l}\text { - Wavelength: } 2.94 \mu \mathrm{m} \\
\text { - Pulse energy: } 200 \mathrm{~mJ} \\
\text { - Energy density: } 22.5 \mathrm{~J} / \\
\mathrm{cm}^{2} \text { for } 10 \text { pulse/s } \\
\text { - Non-contact mode }\end{array}$ & $\begin{array}{l}\text { - the Er:YAG laser showed a } \\
\text { minor quantity of bacterial } \\
\text { deposits compared to } \\
\text { Carie-Carie and carbide bur; } \\
\text { Carie-Carie presented greatly } \\
\text { bacterial deposits } \\
\text { - Morphological changes: } \\
\text { Carbide bur - thin smear layer } \\
\text { and few open tubules; Er:YAG } \\
\text { laser: irregular rugged surface, } \\
\text { no smear layer, opened tubules; } \\
\text { Carie-Carie - rough surface, } \\
\text { smear layer, obliterated tubules }\end{array}$ \\
\hline $\begin{array}{l}\text { Sattabanasuk } \\
\text { et al. (2006) } \\
{[25]}\end{array}$ & $\begin{array}{l}\text { Carious third } \\
\text { molars }\end{array}$ & $\begin{array}{l}\text { In vitro } \\
\text { comparative } \\
\text { study }\end{array}$ & $\begin{array}{l}\text { - Influence of } 3 \\
\text { methods for caries } \\
\text { removal and two } \\
\text { types of adhesive } \\
\text { systems in the } \\
\text { bonding capacity } \\
\text { of the remaining } \\
\text { dentin }\end{array}$ & $\begin{array}{l}\text { - Pulse energy: } 180 \mathrm{~mJ} \\
\text { - Frequency: } 2 \mathrm{~Hz} \\
\text { - Non-contact mode }\end{array}$ & $\begin{array}{l}\text { - The total-etch adhesive } \\
\text { system (OptiBond Solo Plus) } \\
\text { showed similar results in all } \\
\text { groups (steel bur, laser, and SiC } \\
\text { paper) } \\
\text { - The self-etch adhesive system } \\
\text { (Clearfil Protect Bond) showed } \\
\text { lower bond strength in dentin } \\
\text { treated with steel bur } \\
\text {-Only the laser group showed } \\
\text { similar bond strength for the } \\
\text { two tested adhesive systems }\end{array}$ \\
\hline $\begin{array}{l}\text { Schwass et al. } \\
\text { (2013) [20] }\end{array}$ & $\begin{array}{l}\text { Teeth with } \\
\text { proximal dentin } \\
\text { caries }\end{array}$ & $\begin{array}{l}\text { In vitro } \\
\text { comparative } \\
\text { study }\end{array}$ & $\begin{array}{l}\text { - Different } \\
\text { thresholds of } \\
\text { FCC Er:YAG in the } \\
\text { selectivity of caries } \\
\text { removal }\end{array}$ & $\begin{array}{l}\text { - Pulse energy: } 600 \mathrm{~mJ} \\
\text { (enamel) and } 250 \mathrm{~mJ} \\
\text { (dentin) } \\
\text { - Frequency: } 10 \mathrm{~Hz} \\
\text { (enamel) and } 4 \mathrm{~Hz} \\
\text { (dentin) } \\
\text { - Pulse duration: } 400 \mu \mathrm{s} \\
\text { - Threshold: } 4,5,6,7,8 \text {, } \\
9,10,12,16, \text { and } 20 \mathrm{U} \\
\text { - Non-contact mode }\end{array}$ & $\begin{array}{l}\text { - Feedback control values } \\
\text { higher than } 8 U \text { did not remove } \\
\text { infected caries efficiently } \\
\text { - Threshold for conservative } \\
\text { caries removal lies between } 7 \\
\text { and } 8 U\end{array}$ \\
\hline $\begin{array}{l}\text { Sirin } \\
\text { Karaarslan et } \\
\text { al. (2012) [26] }\end{array}$ & Carious molars & $\begin{array}{l}\text { In vitro } \\
\text { comparative } \\
\text { study }\end{array}$ & $\begin{array}{l}\text { - Influence of } 3 \\
\text { methods for caries } \\
\text { removal and three } \\
\text { adhesive systems } \\
\text { in the bonding } \\
\text { capacity of the } \\
\text { remaining dentin }\end{array}$ & $\begin{array}{l}\text { - Wavelength: } 2.94 \mu \mathrm{m} \\
\text { - Power output: } 3.5 \mathrm{~W} \\
\text { - Pulse duration: } 300 \mu \mathrm{s} \\
\text { (short pulse mode) } \\
\text { - Frequency: } 10 \mathrm{~Hz} \\
\text { - 1mm distance } \\
\text { - Energy density: } 44 \mathrm{~J} / \\
\mathrm{cm}^{2}\end{array}$ & $\begin{array}{l}\text { - The total-etch adhesive } \\
\text { system: similar bond strength } \\
\text { values for steel bur and laser } \\
\text { and lower for Carisolv } \\
\text { - One-step and two-step self- } \\
\text { etch adhesive systems: similar } \\
\text { bond strength values for all } \\
\text { three methods } \\
\text { - the bur group: all adhesive } \\
\text { systems had the same behavior } \\
\text { - the laser group: total-etch } \\
\text { adhesive showed the higher } \\
\mu \text { TBS values } \\
\text {-Carisolv }{ }^{\circledast} \text { : two-step self-etch } \\
\text { adhesive showed the best } \\
\text { results }\end{array}$ \\
\hline
\end{tabular}




\begin{tabular}{|c|c|c|c|c|c|}
\hline $\begin{array}{l}\text { Tsanova } \\
\text { \& Tomov } \\
\text { (2010) [22] }\end{array}$ & $\begin{array}{l}\text { Carious teeth } \\
\text { from adults }\end{array}$ & $\begin{array}{l}\text { In vitro } \\
\text { comparative } \\
\text { study }\end{array}$ & $\begin{array}{l}\text { - Ultrastructural } \\
\text { changes in substrates } \\
\text { treated with Er:YAG } \\
\text { laser, Carisolv }^{\circledR} \\
\text { diamond bur, steel } \\
\text { bur }\end{array}$ & $\begin{array}{l}\text { - Pulse energy: } 400 \mathrm{~mJ} \\
\text { - Frequency: } 20 \mathrm{~Hz} \\
\text { - Power output: } 8 \mathrm{~W}\end{array}$ & $\begin{array}{l}\text { - Er:YAG laser: irregular and } \\
\text { rough dentin surface with no } \\
\text { smear layer, exposed tubules; } \\
\text { retentive enamel } \\
\text { - Carisolv }: \text { dentin with rough } \\
\text { and granular aspect, retentive } \\
\text { surface } \\
\text { The diamond bur: thin and } \\
\text { smooth smear layer in most } \\
\text { regions and absence in a few } \\
\text { others, opened tubules } \\
\text { The steel bur: smear layer and } \\
\text { obliterated tubules }\end{array}$ \\
\hline $\begin{array}{l}\text { Valério et } \\
\text { al. (2016) } \\
\text { [8] }\end{array}$ & $\begin{array}{l}\text { Carious } \\
\text { primary } \\
\text { molars from } \\
\text { children aged } \\
6 \text { to } 10\end{array}$ & $\begin{array}{l}\text { Split-mouth } \\
\text { randomized } \\
\text { clinical trial }\end{array}$ & $\begin{array}{l}\text { - Er:YAG laser } \\
\text { effectiveness } \\
\text { compared to carbide } \\
\text { bur } \\
\text { - CFU count } \\
\text { - Restoration } \\
\text { longevity }\end{array}$ & $\begin{array}{l}\text { - Pulse energy: } 250 \mathrm{~mJ} \\
\text { - Frequency: } 4 \mathrm{~Hz} \\
\text { - Non-contact mode } \\
\text { - } 7 \mathrm{~mm} \text { distance } \\
\text { - Energy density: } 39 \mathrm{~J} / \mathrm{cm}^{2}\end{array}$ & $\begin{array}{l}\text { - The carbide bur is faster and } \\
\text { more effective to remove caries } \\
\text { in the surrounding walls than } \\
\text { Er:YAG laser } \\
\text { - CFU for S. mutans and } \\
\text { Lactobacilli sp. was similar for } \\
\text { both methods } \\
\text { - One-year follow-up showed } \\
\text { no differences in restoration } \\
\text { longevity for both groups }\end{array}$ \\
\hline $\begin{array}{l}\text { Valério et } \\
\text { al. (2020) } \\
{[30]}\end{array}$ & $\begin{array}{l}\text { Carious } \\
\text { molars from } \\
\text { children aged } \\
8 \text { to } 12\end{array}$ & $\begin{array}{l}\text { Longitudinal } \\
\text { clinical trial }\end{array}$ & $\begin{array}{l}\text { - Influence of Er:YAG } \\
\text { and carbide bur } \\
\text { associated with } \\
\text { chlorhexidine at the } \\
\text { longevity of adhesive } \\
\text { restorations after four } \\
\text { years of follow-up }\end{array}$ & $\begin{array}{l}\text { - Medium short pulse } \\
\text { mode } \\
\text { - Pulse energy: } 260 \mathrm{~mJ} \\
\text { - Frequency: } 4 \mathrm{~Hz} \\
\text { - Non-contact mode } \\
\text {-12mm distance } \\
\text { - Energy density: } 41 \mathrm{~J} / \mathrm{cm}^{2}\end{array}$ & $\begin{array}{l}\text { - The clinical longevity of the } \\
\text { restorations was affected } \\
\text { neither by the method for } \\
\text { caries removal nor by the } \\
\text { dentin biomodification with } \\
\text { chlorhexidine at four years of } \\
\text { follow-up }\end{array}$ \\
\hline $\begin{array}{l}\text { Yan et al. } \\
\text { (2015) [19] }\end{array}$ & $\begin{array}{l}\text { Teeth with } \\
\text { occlusal caries }\end{array}$ & In vitro study & $\begin{array}{l}\text { - Potential of a diode } \\
\text { pumped solid-state } \\
\text { (DPSS) Er:YAG laser for } \\
\text { caries removal }\end{array}$ & $\begin{array}{l}\text { - Pulse duration: } 20-30 \mu \mathrm{s} \\
\text { - Frequency: } 500 \mathrm{~Hz} \\
\text { - Power output: } 30 \mathrm{~W}\end{array}$ & $\begin{array}{l}\text { - Ablation with minor thermal } \\
\text { damage } \\
\text { - Higher ablation rate in } \\
\text { demineralized surfaces } \\
\text { compared to the sound ones }\end{array}$ \\
\hline $\begin{array}{l}\text { Yildiz et al. } \\
\text { (2013) [27] }\end{array}$ & $\begin{array}{l}\text { Carious } \\
\text { primary molar } \\
\text { teeth }\end{array}$ & $\begin{array}{l}\text { In vitro } \\
\text { comparative } \\
\text { study }\end{array}$ & $\begin{array}{l}\text { - Influence of } 3 \\
\text { methods for caries } \\
\text { removal and two } \\
\text { adhesive systems in } \\
\text { the bonding capacity } \\
\text { of the remaining } \\
\text { dentin }\end{array}$ & $\begin{array}{l}\text { - Wavelength: } 2.94 \mu \mathrm{m} \\
\text { - Power output: } 3.5 \mathrm{~W} \\
\text { - Pulse duration: } 300 \mu \mathrm{s} \\
\text { (short pulse mode) } \\
\text { - Frequency: } 10 \mathrm{~Hz} \\
\text { - 1mm distance } \\
\text { - Energy density: } 44 \mathrm{~J} / \mathrm{cm}^{2}\end{array}$ & $\begin{array}{l}\text { - Laser presented lower } \mu \text { TBS } \\
\text { values than carbide bur and } \\
\text { Carisolv } v^{\circledR} \text { groups regardless of } \\
\text { the adhesive system used } \\
\text { (one-step self-etch and two- } \\
\text { step total-etch) } \\
\text { - Bur and Carisolv }{ }^{\circledR} \text { presented } \\
\text { the best results for both types } \\
\text { of adhesive systems }\end{array}$ \\
\hline $\begin{array}{l}\text { Yonemoto } \\
\text { et al. (2006) } \\
\text { [21] }\end{array}$ & $\begin{array}{l}\text { Molars with } \\
\text { occlusal } \\
\text { dentin caries }\end{array}$ & In vitro study & $\begin{array}{l}\text { - Values of } \\
\text { DIAGNOdent }{ }^{\oplus} \text { that } \\
\text { could be used as a } \\
\text { guide for the removal } \\
\text { of the outer layer of } \\
\text { carious dentin with } \\
\text { Er:YAG laser }\end{array}$ & $\begin{array}{l}\text { - Pulse energy: } 150-200 \mathrm{~mJ} \\
\text { (enamel) and } 50-150 \mathrm{~mJ} \\
\text { (dentin) } \\
\text { - Pulse duration: } 200 \mu \mathrm{s} \\
\text { Frequency: } 10,20,25 \text { or } \\
30 \mathrm{~Hz}\end{array}$ & 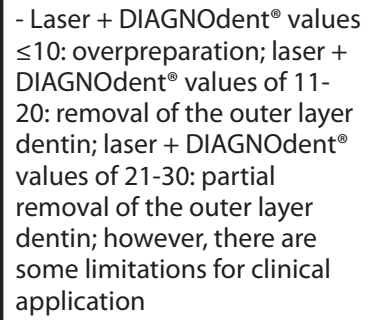 \\
\hline
\end{tabular}

Table 1. Summary of the selected articles.

\section{CONCLUSION}

The Er:YAG laser is a viable alternative for the treatment of caries since it can remove demineralized tissue without causing damage to the dental element, in addition to providing greater comfort for the patient due to the absence of noise, vibrations, and pressures during removal of decayed tissue and less need for anesthetic administration in most cases.

\section{REFERENCES}

1. Jepsen S, Acil Y, Peschel T, et al. Biochemical and morphological analysis of dentin following selective caries removal with a fluorescence-controlled Er:YAG laser. Lasers Surg Med. 2008 Jul;40(5):350-357. doi: 10.1002/lsm.20631. PMID: 18563782 CrossRef PubMed Google Scholar Scopus WoS
Despite the advantages, its use requires more clinical time compared to the use of burs. Furthermore, the cost of the equipment, despite not having been addressed in the review, can also be considered a limiting factor. In general, the Er:YAG laser is as effective as the conventional and chemicalmechanical methods for selective caries removal.

\section{ACKNOWLEDGMENTS}

None.

2. Kornblit R, Trapani D, Bossù M, et al. The use of Erbium:YAG laser for caries removal in paediatric patients following Minimally Invasive Dentistry concepts. Eur J Paediatr Dent. 2008 Jun;9(2):81-87. PMID: 18605890.

Full text link PubMed Google Scholar Scopus WoS 
3. Parker S, Cronshaw M, Anagnostaki E, et al. Current concepts of laser-oral tissue interaction. Dent J (Basel). 2020 Jun 28;8(3):61. doi: 10.3390/dj8030061. PMID: 32605215; PMCID: PMC7558496.2020;8(3):61.

CrossRef PubMed Google Scholar Scopus WoS

4. Jorge ACT, Cassoni A, Rodrigues JA. [Applications of highintensity lasers in dentistry]. Portuguese. Rev Saúde - UNG.

2010;4(3):25-33.

Full text link Google Scholar

5. Neves LS, Silva CMS, Henriques JFC, et al. [The use of laser in orthodontics]. Portuguese. Rev Dent Press Orthodon Orthoped Facial. 2005;10(5):149-156. https://doi.org/10.1590/S141554192005000500015

CrossRef Google Scholar

6. Convissar RA. Principles and Practice of Laser Dentistry. 2nd Edition. St Louis, Ml: Elsevier; 2016. ISBN: 9780323297622

7. Al-Batayneh OB, Seow WK, Walsh LJ. Assessment of Er:YAG laser for cavity preparation in primary and permanent teeth: a scanning electron microscopy and thermographic study. Pediatr Dent. 2014 May-Jun;36(3):90-94. PMID: 24960377.

Full text link PubMed Google Scholar Scopus

8. Valério RA, Borsatto MC, Serra MC, et al. Caries removal in deciduous teeth using an Er:YAG laser: a randomized split-mouth clinical trial. Clin Oral Investig. 2016 Jan;20(1):65-73. doi: 10.1007/ s00784-015-1470-z. Epub 2015 Apr 17. PMID: 25877234. CrossRef PubMed Google Scholar Scopus WoS

9. Maltz M. [Cariology: Basic Concepts, Diagnosis and NonRestorative Treatment]. Portuguese. São Paulo: Artes Médicas; 2016. ISBN: 978-8536702629.

10. Baratieri LN, Júnior SM. [Restorative Dentistry - Fundamentals and Possibilities]. 2nd Edition. Portuguese. São Paulo: Santos; 2015. ISBN: 978-8541203173

11. Kavvadia K, Karagianni V, Polychronopoulou A, Papagiannouli L. Primary teeth caries removal using the Carisolv chemomechanical method: a clinical trial. Pediatr Dent. 2004 Jan-Feb;26(1):23-8. PMID: 15080354.

Full text link PubMed Google Scholar Scopus WoS

12. Kotb RMS, Abdella AA, El Kateb MA, Ahmed AM. Clinical evaluation of Papacarie in primary teeth. J Clin Pediatr Dent. 2009 Winter;34(2):117-123. doi: 10.17796/

jcpd.34.2.f312p36g18463716. PMID: 20297701

CrossRef PubMed Google Scholar Scopus WoS

13. Bohari MR, Chunawalla YK, Ahmed BMN. Clinical

evaluation of caries removal in primary teethusing

conventional, chemomechanical and laser technique: an in vivo

study. J Contemp Dent Pract. 2012 Jan 1;13(1):40-47. doi: 10.5005/ jp-journals-10024-1093. PMID: 22430692.

CrossRef PubMed Google Scholar

14. Cozean C, Arcoria CJ, Pelagalli J, Powell GL. Dentistry for the 21st century? Erbium:YAG laser for teeth. J Am Dent Assoc. 1997 Aug;128(8):1080-1087. doi: 10.14219/jada.archive.1997.0364. PMID: 9260417.

CrossRef PubMed Google Scholar

15. Krause F, Braun A, Lotz G, et al. Evaluation of selective caries re moval in deciduous teeth by a fluorescence feedback-controlled

Er:YAG laser in vivo. Clin Oral Investig. 2008 Sep;12(3):209-215. doi: 10.1007/s00784-007-0169-1. Epub 2008 Jan 26. PMID: 18224360. CrossRef PubMed Google Scholar Scopus WoS

16. Eberhard J, Bode K, Hedderich J, Jepsen S. Cavity size difference after caries removal by a fluorescence-controlled Er:YAG laser and by conventional bur treatment. Clin Oral Investig. 2008 Sep;12(3):209-215. doi: 10.1007/s00784-007-0169-1. Epub 2008 Jan 26. PMID: 18224360.

CrossRef PubMed Google Scholar Scopus WoS

17. Dommisch H, Peus K, Kneist S, et al. Fluorescence-controlled Er:YAG laser for caries removal in permanent teeth: a randomized clinical trial. Eur J Oral Sci. 2008 Apr;116(2):170-176. doi: 10.1111/j.1600-0722.2008.00521.x. PMID: 18353012. CrossRef PubMed Google Scholar Scopus WoS

18. Neves AA, Coutinho E, De Munck J, Van Meerbeek B. Cariesremoval effectiveness and minimal-invasiveness potential of caries-excavation techniques: a micro-CT investigation. J Dent. 2011 Feb;39(2):154-162. doi: 10.1016/j.jdent.2010.11.006. Epub 2010 Nov 25. PMID: 21111770.

CrossRef PubMed Google Scholar Scopus WoS

19. Yan $\mathrm{R}$, Chan $\mathrm{KH}$, Tom $\mathrm{H}$, et al. Selective removal of dental caries with a diode-pumped Er:YAG laser. Proc SPIE Int Soc Opt Eng. 2015 Feb 24;9306:930600. doi: 10.1117/12.2083653. PMID: 25914496; PMCID: PMC4405669.

CrossRef PubMed Google Scholar Scopus WoS

20. Schwass DR, Leichter JW, Purton DG, Swain MV. Evaluating the efficiency of caries removal using an Er: YAG laser driven by fluorescence feedback control. Arch Oral Biol. 2013 Jun;58(6):603610. doi: 10.1016/j.archoralbio.2012.09.017. Epub 2012 Nov 1. PMID: 23123070.

CrossRef PubMed Google Scholar Scopus WoS
21. Yonemoto K, Eguro T, Maeda T, Tanaka H. Application of DIAGNOdent ${ }^{\circledR}$ as a guide for removing carious dentin with Er:YAG laser. J Dent. 2006 Apr;34(4):269-76. doi: 10.1016/j.jdent.2005.07.001. Epub 2005 Sep 8. PMID: 16153765.

CrossRef PubMed Google Scholar Scopus WoS

22. Tsanova S, Tomov G. Morphological changes in hard dental tissues prepared by Er:YAG laser (LiteTouch, Syneron), Carisolv and rotary instruments. A scanning electron microscopy evaluation. Folia Med. (Plovdiv). 2010 Jul-Sep;52(3):46-55. doi: 10.2478/v10153-010-0006-1. PMID: 21053673. CrossRef PubMed Google Scholar

23. Juntavee A, Juntavee N, Peerapattana J, et al. Comparison of marginal microleakage of glass ionomer restorations in primary molars prepared by chemo-mechanical caries removal (CMCR), Erbium:Yttrium Aluminum-Garnet (Er:YAG) laser and atraumatic restorative technique (ART). Int J Clin Pediatr Dent. 2013;6(2):75-79. doi: 10.5005/jp-journals-10005-1193. Epub 2013 Aug 26. PMID: 25206196; PMCID: PMC4086587.

CrossRef PubMed Google Scholar

24. Neves AA, Coutinho E, Cardoso MV, et al. Micro-tensile bond strength and interfacial characterization of an adhesive bonded to dentin prepared by contemporary caries-excavation

techniques. Dent Mater. 2011 Jun;27(6):552-562. doi: 10.1016/j.dental.2011.02.008. Epub 2011 Apr 13. PMID: 21489617

CrossRef PubMed Google Scholar Scopus WoS

25. Sattabanasuk V, Burrow M, Shimada Y, Tagami J. Resin

adhesion to caries-affected dentine after different removal methods. Aust Dent J. 2006 Jun;51(2):162-9. doi: 10.1111/j.1834-7819.2006. tb00421.x. PMID: 16848265 .

CrossRef PubMed Google Scholar Scopus WoS

26. Sirin Karaarslan E, Yildiz E, Cebe M, et al. Evaluation of

micro-tensile bond strength of caries-affected human dentine

after three different caries removal techniques. J Dent. 2012

Oct:40(10):793-801. doi: 10.1016/j.jdent.2012.05.013. Epub 2012 Jun 9. PMID: 22687577.

CrossRef PubMed Google Scholar Scopus WoS

27. Yildiz E, Sirin Karaarslan E, Yegin Z, et al. Effect of caries removal

techniques on the bond strength of adhesives to caries-affected primary dentin in vitro. Eur J Paediatr Dent. 2013 Sep;14(3):209-214 PMID: 24295006.

Full text link PubMed Google Scholar Scopus WoS

28. Katirci G, Ermis RB. Microindentation hardness and calcium phosphorus ratio of dentin following excavation of dental caries lesions with different techniques. Springerplus. 2016 Sep 22.5(1):1641 doi: 10.1186/s40064-016-3289-8. PMID: 27722059.

PMCID: PMC5031566.

CrossRef PubMed Google Scholar Scopus WoS

29. Polizeli SAF, Curylofo-Zotti FA, Valerio RA, et al. Selective removal of necrotic dentin in primary teeth using laser irradiation: one-year clinical evaluation of composite restorations. J Lasers Med Sci. 2019 Spring;10(2):108-116. doi: 10.15171/jlms.2019.18. Epub 2019 Feb 25. PMID: 31360379; PMCID: PMC6499567.

CrossRef PubMed Google Scholar

30. Valério RA, Galo R, Galafassi D, et al. Four-year clinical prospective follow-up of resin composite restoration after selective caries removal using Er:YAG laser. Clin Oral Investig. 2020 Jul; 24(7):22712283. doi: 10.1007/s00784-019-03082-w. Epub 2019 Nov 4. PMID: 31686235.

CrossRef PubMed Google Scholar

31. Prabhakar A, Lokeshwari M, Naik SV, Yavagal C. Efficacy of caries removal by Carie-Care and Erbium-doped Yttrium Aluminum Garnet laser in primary molars: a scanning electron microscope study. Int J Clin Pediatr Dent. 2018 Jul-Aug;11(4):323-329. doi: 10.5005/jp-journals-10005-1533. Epub 2018 Aug 1. PMID: 30397377; PMCID: PMC6212662.

CrossRef PubMed Google Scholar

32. Li T, Zhang X, Shi H, et al. Er:YAG laser application in caries removal and cavity preparation in children: a meta-analysis. Lasers Med Sci. 2019 Mar;34(2):273-280. doi: 10.1007/s10103-018-2582-x. Epub 2018 Jul 12. PMID: 30003427

CrossRef PubMed Google Scholar Scopus WoS 33. Cardoso M, Coelho A, Lima R, et al. Efficacy and patient's acceptance of alternative methods for caries removal - a systematic review. J Clin Med. 2020 Oct 23;9(11):3407. doi: 10.3390/jcm9113407. PMID: 33114249; PMCID: PMC7690910.

CrossRef PubMed Google Scholar Scopus WoS

34. Baraba A, Kqiku L, Gabric D, et al. Efficacy of removal of cariogenic bacteria and carious dentin by ablation using different modes of Er:YAG lasers. Braz J Med Biol Res. 2018 Jan 11;51(3):e6872. doi: 10.1590/1414-431X20176872. PMID: 29340524; PMCID: PMC5769758.

CrossRef PubMed Google Scholar Scopus WoS

35. Medioni E, Rocca JP, Fornaini C, Merigo E. Histological evaluation of three techniques for caries removal. J Oral Sci. 2016;58(4):583-589. doi: 10.2334/josnusd.16-0225. PMID: 28025444.

CrossRef PubMed Google Scholar 
36. Matsumoto K, Wang X, Zhang C, Kinoshita J. Effect of a novel Er:YAG laser in caries removal and cavity preparation: a clinical observation. Photomed Laser Surg. 2007 Feb;25(1):8-13. doi: 10.1089/ pho.2006.2020. PMID: 17352631.

CrossRef PubMed Google Scholar

37. Celiberti P, Francescut P, Lussi A. Performance of four dentine excavation methods in deciduous teeth. Caries Res. 2006;40(2):117

123. doi: 10.1159/000091057. PMID: 16508268.

CrossRef PubMed Google Scholar Scopus WoS
38. Cebe F, Bulbul M, Simsek I, et al. Effect of Erbium: yttrium aluminum garnet laser on bond strength of a total-etch adhesive system to caries-affected dentin on gingival wall. Niger J Clin Pract. 2017 Jun;20(6):734-740. doi: 10.4103/1119-3077.181321. PMID: 28656929. CrossRef PubMed Google Scholar Scopus WoS

39. Zach L, Cohen G. Pulp response to externally applied heat. Oral Surg Oral Med Oral Pathol. 1965 Apr;19:515-530. doi: 10.1016/00304220(65)90015-0. PMID: 14263662.

CrossRef PubMed Google Scholar Scopus

\section{Geise dos Santos MARCELINO}

DDS, General Dentist

Department of Restorative Dentistry

School of Dentistry

Faculdade Morgana Potrich (FAMP)

Mineiros, Goiás, Brazi

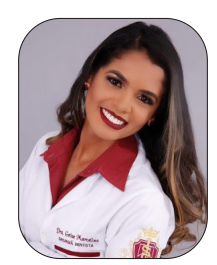

Geise dos Santos Marcelino graduated from FAMP, Mineiros, Goiás, Brazil, and is a student of the Specialization course in Orthodontics at the Graduate Center in Dentistry - CIOG, Goiânia, Goiás. Her academic interests include Hospital Dentistry and Pediatric Dentistry. She works as a general dentist in a private practice in Senador Canedo, Goiás and at the PSF in Taquaral de Goiás, Goiás, Brazil.

\section{Ouestions}

\section{Which caries removal method is the least conservative?}

a. Mechanical removal with dentin scoop;

ab. Diamond tips and air rotor;

ac. Er:YAG laser;

d. Use of a chemical-mechanical method.

\section{Which is the Er:YAG laser wavelength?}

口a. 2.940nm;

ab. $2.840 \mathrm{~nm}$;

口c. $2.490 \mathrm{~nm}$;

ad. $2.480 \mathrm{~nm}$

\section{Which sentence is correct?}

口a. Er:YAG is a selective method for caries removal;

$\square$ b. Chemical-mechanical methods cause more pain for the patients;

口. Er:YAG can affect pulp vitality;

$\square d$. Carbide burs cannot be used in children.

\section{In dentistry, which one is the most desirable phenomenon of the laser?}

a. Diffusion;

b. Transmission;

ac. Absorption;

ad. Penetration. 


\title{
CONTRIBUTION OF PIEZOCISION IN ORAL SURGERY: THE EXAMPLE OF THE ACCELERATION OF ORTHODONTIC MOVEMENTS
}

\author{
Thonnart François $^{1 \mathrm{a}^{*}}$, Systermans $\operatorname{Simon}^{2 \mathrm{~b}}$, $_{\text {, Gilon Yves }}^{2 c}$ (B) \\ ${ }^{1}$ Department of Plastic and Maxillofacial Surgery, CHU Liège, Belgium \\ ${ }^{2}$ Department of Maxillofacial Surgery, ZOL Genk, Belgium \\ ${ }^{a}$ MD, DDS, Maxillofacial Surgery Resident; e-mail: francois-thonnart@hotmail.com; ORCIDiD: https://orcid.org/0000-0001-9382-8699 \\ ${ }^{b}$ MD, DDS, PhD, Professor, Maxillofacial Surgeon; e-mail: yves.gilon@chuliege.be; ORCIDiD: https://orcid.org/0000-0002-1991-5951 \\ 'MD, DDS, Maxillofacial Surgery Resident; e-mail: simon.systermans@chuliege.be; ORCIDiD: https://orcid.org/ 0000-0002-6740-8372
}

\begin{abstract}
do) https://doi.org/10.25241/stomaeduj.2021.8(3).art.4

Introduction Patients are more demanding of short or less invasive interventions. Piezocision responds well to this demand, particularly in the case of piezo-guided corticotomy to accelerate orthodontic movements. Different surgical approaches are described to shorten orthodontic procedures. Corticotomy is a surgical process where osteotomies are realized at the level of the cortical part of the bone.

Objective The aim of this work is to review the contribution of piezocision in oral surgery, using as example a review over the current results of piezocision on the acceleration of orthodontic movements.

Data sources The articles referenced and used in this article come from the PubMed database. The searched keywords were "piezocision" alone or in combination with "orthodontics".

Study selection This search resulted in 44 available articles. Subsequently, 6 randomized controlled trials were selected based on relevance, journal, and publication date. Four Randomized Controlled Trials and two Controlled Clinical Trials were studied.

Data extraction The reviewer assessed each article for their relevance and methodology. The 6 studies compared the time savings between conventional orthodontic treatment (control group) and orthodontic treatment combined with piezocision surgery (test group).

Data synthesis Piezocision corticotomy reduces the operation and the postoperative period and increases the acceptance of corticotomies and their indications.
\end{abstract}

\section{KEYWORDS}

Piezocision ; Orthodontics ; Corticotomy ; Oral Surgery ; Minimally Invasive.

\section{INTRODUCTION}

Originally, piezosurgery was developed to allow cutting hard structures without affecting soft structures, with an ultrasound instrumentation. Bone cutting is performed by high frequency micromovements generated by the piezoelectric handpiece, the piezotome. The back and forth motion transmitted to a cutting insert creates a cutting effect. Over the past decades, numerous scientific articles have illustrated the numerous indications of piezocision in oral surgery, implant surgery, cranio-maxillofacial surgery and other surgical disciplines. The main advantages and characteristics of piezocision are the selective cutting of the bone without damaging adjacent soft tissues such as vessels, nerves, mucous membranes, but also to reach difficult access areas via angled inserts compared to conventional instrumentation, and to cut without generating signifi- cant exothermic reaction. The use of angled inserts improves the visibility of the operating field. Therefore, piezoelectric surgery is a safe, precise and atraumatic technique.

In our oral and maxillofacial surgery practice, the piezotome is currently taking an important place. It is particularly used in our department in preimplant surgery for maxillary ridge expansion, opening the bone windows during the sinus lift, during ramic, symphyseal, tuberosal or cranial parietal harvesting and during the lateralization surgery of the inferior alveolar nerve. The piezotome is also used in maxi-llofacial surgery for mandibulectomy and costochondral harvesting (temporomandibular ankylosis treatment, rhinoplasties), and for free fibula flaps. It is also used for condylectomies and complicated mandibular sagittal osteotomies with malposition of the inferior alveolar nerve. In oral surgery, the piezotome is used in our practice for retrograde 
endodontic surgeries, cyst removal but also to accelerate orthodontic movements.

Orthodontics is a dental discipline that aims to correct the dental occlusion and/or the positioning of the jaws and teeth, using various removable or fixed devices. The long duration of orthodontic treatments is one of the most common complaints of patients undergoing orthodontic treatment. In addition, longer treatments can increase the risk of complications such as caries, periodontal problems and root resorption.

Various surgical approaches have been described to accelerate tooth movement. Invasive procedures such as corticotomies with periodontal flaps have shown good results in decreasing treatment times in orthodontics [1-2].

To reduce the invasiveness of corticotomies, a minimally invasive surgical procedure has been introduced. This consists of making transmucosal cortical incisions without flaps using a piezotome. This technique involves micro-incisions and small corticotomies. Localized decortication induces a demineralization-remineralization process described as regional acceleratory phenomenon (RAP). The induced corticotomy at the bone level is followed by an increase in bone turnover and a decrease in bone mineral.

The aim of this work is to explain the contribution of piezocision in oral surgery through piezocision corticotomy.

\section{MATERIALS AND METHODS}

The articles referenced and used in this article come from the Pubmed database. The searched keywords were "piezocision" alone or in combination with "orthodontics". This search resulted in 44 available articles. Subsequently, 6 randomized controlled trials were selected based on relevance, journal, and publication date. Each study was conducted on healthy patients and analyzed the effectiveness of piezocision on accelerating orthodontic movements.

\section{RESULTS}

Four Randomized Controlled Trials and two Controlled Clinical Trials were studied. The 6 studies compared the time savings between conventional orthodontic treatment (control group) and orthodontic treatment combined with piezocision surgery (test group).

\subsection{Characteristics of the studies}

The general information from the studies is summarized in Table 1. Of the 6 articles, 4 are RCT [3-4-6-8] and 2 are CCT [5-7]. All studies included 131 patients. Each study presented a group treated with electric piezocision and another "control" group with conventional orthodontic movement. One study [5] compared the efficacy of conventional corticotomy to piezocision. The studies by Uribe, Gibreal, and Charavet focus on tooth alignment, while the studies by Abbas and Aksakalli investigate canine distalization in premolar extraction.

\subsection{Orthondontic movements}

The study by Charavet et al [6] showed a decrease of $43 \%$ in orthodontic time in the piezocision group compared to the control group, compared to $59 \%$ in the study [4]. The differences between the two groups in study [6] increased in time until full alignment but decreased for final adjustments.

Study [3] showed no significant difference between the two groups. The duration of canine distalization in study [7] is reduced in the piezocision group.

In addition, the study by Abbas et al [5] found a higher rate of movement in the corticotomy group compared with the piezocision group during weeks $2,4,10,12$ after surgery. The 2019 study by Charavet et al [8] shows a $36 \%$ acceleration of treatment for the piezocision group compared with the control group.

\begin{tabular}{|c|c|c|c|c|c|c|}
\hline Study name & $\begin{array}{l}\text { Study } \\
\text { type }\end{array}$ & Number & Group & Intervention type & $\begin{array}{l}\text { Type of orthodontic } \\
\text { movements }\end{array}$ & Origins \\
\hline Uribe (2013) [8] & $\mathrm{RCT}$ & $n=29$ & $\begin{array}{l}\text { Piezocision: M:6; W:10; age: } 30 \\
\text { Control: M:6; W:7; age } 29.4\end{array}$ & $\begin{array}{l}\text { Piezocision: piezocision + orthodontic movement } \\
\text { Control: Orthodontic movement only }\end{array}$ & $\begin{array}{l}\text { Anterior alignment due to } \\
\text { crowding of the maxilla ( } 3 \text { to } 3 \text { ) }\end{array}$ & USA \\
\hline Gibreal (2019) [4] & $\mathrm{RCT}$ & $n=34$ & $\begin{array}{l}\text { Piezocision: } n=17 \\
\text { Control: } n=17\end{array}$ & $\begin{array}{l}\text { Piezocision: piezocision + orthodontic movement } \\
\text { Control: Orthodontic movement only }\end{array}$ & $\begin{array}{l}\text { Anterior alignment due to } \\
\text { crowding of the maxilla ( } 3 \text { to } 3 \text { ) }\end{array}$ & Syria \\
\hline Abbas (2016) [5] & $\mathrm{CCT}$ & $n=20$ & $\begin{array}{l}\text { Group } 1: n=10 \\
\text { Group 2: } n=10\end{array}$ & $\begin{array}{l}\text { Group 1: one-sided corticotomy with } \\
\text { contralateral control group } \\
\text { Group 2: one-sided piezocision with contralateral } \\
\text { control group }\end{array}$ & Distalization of a maxillary canine & Egypt \\
\hline Charavet (2016) [6] & $\mathrm{RCT}$ & $n=24$ & $\begin{array}{l}\text { Piezocision: } n=12 \\
\text { Control: } n=12\end{array}$ & $\begin{array}{l}\text { Piezocision: piezocision + orthodontic movement } \\
\text { Control : Orthodontic movement only }\end{array}$ & $\begin{array}{l}\text { Anterior alignment due to } \\
\text { crowding of the upper and lower } \\
\text { jaws ( } 3 \text { to } 3 \text { ) }\end{array}$ & Belgium \\
\hline Aksakalli (2016) [7] & $\mathrm{CCT}$ & $n=10$ & / & $\begin{array}{l}\text { Piezocision: piezocision + orthodontic movement } \\
\text { Control : Orthodontic movement only }\end{array}$ & Distalization of a maxillary canine & Turkey \\
\hline Charavet (2019) [8] & $\mathrm{RCT}$ & $n=24$ & $\begin{array}{l}\text { Piezocision: } n=12 \\
\text { Control: } n=12\end{array}$ & $\begin{array}{l}\text { Piezocision: piezocision + orthodontic movement } \\
\text { Control: Orthodontic movement only }\end{array}$ & $\begin{array}{l}\text { Anterior alignment due to } \\
\text { crowding of the upper and lower } \\
\text { jaws ( } 3 \text { to } 3 \text { ) }\end{array}$ & Belgium \\
\hline
\end{tabular}

Table 3. Studies descriptions. 
A summary table (Table 2) compares the time gains for the test groups versus the control groups.

\begin{tabular}{|l|c|c|}
\hline \multicolumn{1}{|c|}{ Studies } & N & Saves time in orthodontic treatment (\%) \\
\hline Uribe, et al. 2017 [3] & 41 & Not significant \\
\hline Gibreal, et al. 2019 [4] & 36 & $59 \%$ \\
\hline Charavet, et al. 2019 [8] & 24 & $43 \%$ \\
\hline Charavet, et al. 2016 [6] & 24 & $36 \%$ \\
\hline Abbas, et al. 2016 [5] & 20 & $/$ \\
\hline Aksakalli, et al 2016 [7] & 10 & $63 \%$ \\
\hline
\end{tabular}

ITable 2. Comparison of time savings according to the analyzed studies.

\subsection{Surgical approach}

The surgical protocol is based on a flapless piezocision procedure. This technique consists in making vertical interproximal microincisions $4 \mathrm{~mm}$ above each papilla. The length of the incisions varies according to the studies from 5 to $8 \mathrm{~mm}$ [6-8] and $4 \mathrm{~mm}$ [3]. After the incisions, the gingiva is elevated to visua-lize the bone and adjacent roots. A corticotomy line is then made with a piezoelectric instrument. The line also varies according to the studies, from $5 \mathrm{~mm}$ long and $3 \mathrm{~mm}$ deep for Charavet et al. [6-8] and $1 \mathrm{~mm}$ deep for Uribe et Al [3]. The incisions are sutured with absorbable suture.

\subsection{Periodontal parameters}

All periodontal parameters were comparable between the piezocision and test groups at the end of the treatment in the studies[5-6-7-8].

For 3 patients ( 2 in the control group and 1 in the test group) in the study [6], a non-significant increase in recession was observed between the interval at the beginning of the treatment and the end of the treatment.

The studies by Charavet et al [6-8] investigated the visibility of vertical scars in the piezocision groups. Study [6] observed persistent scarring in $50 \%$ of patients with piezocision. In $33 \%$ of cases, the scar was as a punt and in $17 \%$ of cases, in the form of a line. The 2019 study shows a visible scar in $66 \%$ of the patients treated with piezocision.

\subsection{Root resorptions}

Abbas et al [5] showed that there were no differences in root resorptions between the corticotomy group and the piezocision group. However, the contralateral control group shows greater root resorptions of the canine than the experimental groups (piezocision and corticotomy).

Studies [6-8] do not show an increase in root resorptions in each group.

\subsection{Patient-centered outcomes}

Study [6] did not show any significant differences between the two groups consumption of paracetamol. The level of satisfaction was significantly higher in the piezocision group compared to the control group.

\section{DISCUSSION}

The analysis of the results shows an acceleration of orthodontic treatment in 5 of the 6 clinical trials analyzed, ranging from 36 to $63 \%$ (Table 2). According to Uribe et al. [3], the results of his study do not show a significant difference in the time required to correct a mandibular anterior crowding between the two groups.

The lack of significant time savings in orthodontic treatment in the Uribe et al. [3] study is probably related to the surgical technique. Indeed, the corticotomy is only $1 \mathrm{~mm}$ deep and $3 \mathrm{~mm}$ high, compared to the $3 \mathrm{~mm}$ and $5 \mathrm{~mm}$ found in the studies of Charavet [6-8] and Gibreal [4].

In addition, the studies by Charavet et al. and Gibreal et al. perform 5 vertical incisions up to the canine-premolar interdental space while Uribe et al. perform 3 vertical incisions, stopping between the canine and lateral incisor. The difference between the two RCTs by Charavet et al. may be explained by the use of different Brackets system, CAD/CAM for the 2019 study.

The study by Gibreal et al. shows a greater time gain than the 2 studies by Charavet et al. The improvement in time gain for orthodontic tooth movements observed is probably related to the severity of the anterior crowding. In the Gibreal et al. study, severe anterior crowding required prior extraction, which probably increased the RAP effect.

Based on the results of the studies above and the literature cited above, the effectiveness of bone decortication in accelerating tooth movement is progressive and effective for 3 months after surgery, with greater effectiveness in the maxilla. This effectiveness of piezocision is observed when the first arch is placed 1 to 2 weeks before surgery and when the corticotomy is at least $3 \mathrm{~mm}$ deep and 5 to $8 \mathrm{~mm}$ long. In addition, the patient should be recalled every 2 weeks to activate the fixed appliance if possible because of the limited effect of the RAP [4]. A review of the literature by Mertens et al. [9] shows interesting results of corticotomies depending on the indications. All of them seem to go in the direction of an acceleration of dental movements. However, few studies have been performed with a control group treated with fixed orthodontics, without surgery. Therefore, the number of reviews supporting that the use of corticotomies reduces orthodontic treatment time is limited.

According to Charavet et al. [6-8], there is a visible scar (either punctiform or linear) in 50 to $66 \%$ of the subjects who have undergone piezocision. Therefore, upper jaw piezocision is not recommended for patients with a gummy smile.

Furthermore, an interradicular proximity of less than $2 \mathrm{~mm}$ is a contraindication to corticotomy6. Means such as CBCT, surgical guides [10] or retroalveolar radiographs with opaque interradicular wires can be used to avoid root effraction. These tools can also be 
used to prevent damage to anatomical structures such as the maxillary sinus or the mental foramen. All periodontal parameters appeared to be stable in the different studies. However, 3 patients with pre-existing oral recessions showed an increase in recessions [8]. Therefore, mucogingival techniques combined or not with piezocision may be interesting to prevent gingival recession. A bone grafting technique associated with piezocision was performed in a study by Charavet and Lecloux [11]. This technique has allowed a thickening of the vestibular bone in a class II patient and thus prevented the aggravation of bone dehiscence and the appearance of gingival recession.

According to the study by Angelo Troedban [12], the use of surgical ultrasound devices in reduction rhinoplasty has shown a decrease in postsurgical morbidity and significantly increases overall patient satisfaction. Piezotome rhinoplasty could reduce the need for secondary corrective rhinoplasties, and piezotomes could be the surgical instrument of choice in facial hard tissue cosmetic surgery as they already are in oral surgery.

Relating to preimplant sinus surgery, numerous studies [13-14] have shown a lower rate of Schneider's sinus membrane perforation using piezoelectric instruments compared with conventional rotary instrumentation.

In orthognathic surgery, most surgical trauma occurs especially during osteotomy. Therefore, any surgical tool such as the piezotome that can provide a safe and precise cut is an excellent option. It has several disadvantages: reduced ability to cut dense bone, increased time to perform an osteotomy [15] and additional cost [16]. The neurosensory effect of the piezotome is the main factor studied by several authors [16], especially on the inferior alveolar nerve during sagittal osteotomy of the lower jaw. Most studies report little or no nerve damage using piezotomy surgery. Only one comparative study finds less nerve disruption after inferior sagittal osteotomy using conventional rotary handpiece instrumentation [16].

\section{CONCLUSION}

Piezocision corticotomy seems to be an attractive technique to reduce the time of orthodontic treatments. Compared to corticotomies, it reduces the operation and the postoperative period and increases the acceptance of corticotomies and their indications.

However, given the presence of vertical scars in more than $50 \%$ of cases, it remains contraindicated in patients with a gummy smile.

These examples confirm the interest of piezosurgery in oral and maxillofacial surgery, at a time when the demand for less invasive treatments is growing. The indications for the piezotome are becoming more and more extensive, which makes it an instrument of choice, indispensable in our practice.

\section{ACKNOWLEDGMENTS}

There are no conflicts of interest and no financial interests to be disclosed.

\section{AUTHOR CONTRIBUTIONS}

FT, SS: wrote the manuscript in consultation with YG. All authors provided critical feedback and helped shape the research and the manuscript. YG: aided in interpreting the results.

\section{REFERENCES}

1. Gkantidis N, Mistakidis I, Kouskoura T, Pandis N. Effectiveness of non-conventional methods for accelerated orthodontic tooth movement: a systematic review and meta-analysis. J Dent. 2014 Oct;42(10):1300-19. doi: 10.1016/j.jdent.2014.07.013. Epub 2014 Jul 27. PMID: 25072362.

Full text link PubMed Google Scholar Scopus

2. Patterson BM, Dalci O, Darendeliler MA, Papadopoulou AK. Corticotomies and orthodontic tooth movement: A systematic review. J Oral Maxillofac Surg. 2016 Mar;74(3):453-73. doi: 10.1016/j.joms.2015.10.011. Epub 2015 Oct 24. PMID: 26608454. Full text link PubMed Google Scholar CrossRef WoS 3. Uribe F, Davoody L, Mehr R, et al. Efficiency of piezotomecorticision assisted orthodontics in alleviating mandibular anterior crowding-a randomized clinical trial. Eur J Orthod. 2017 Nov 30;39(6):595-600. doi: 10.1093/ejo/cjw091. PMID: 28371882. Full text link PubMed Google Scholar Scopus WoS

4. Gibreal O, Hajeer MY, Brad B. Efficacy of piezocision-based flapless corticotomy in the orthodontic correction of severely crowded lower anterior teeth: a randomized controlled trial. Eur J Orthod. 2019 Mar 29;41(2):188-195. doi: 10.1093/ejo/cjy042. PMID: 29931294.

Full text link PubMed Google Scholar Scopus WoS

5. Abbas NH, Sabet NE, Hassan IT. Evaluation of corticotomy-facilitated orthodontics and piezocision in rapid canine retraction. Am J Orthod Dentofacial Orthop. 2016 Apr;149(4):473-80. doi: 10.1016/j.ajodo.2015.09.029. PMID: 27021451.

Full text link PubMed Google Scholar Scopus WoS
6. Charavet C, Lecloux G, Bruwier A, et al. Localized piezoelectric alveolar decortication for orthodontic treatment in adults: A Randomized Controlled Trial. J Dent Res. 2016 Aug;95(9):10039. doi: 10.1177/0022034516645066. Epub 2016 Apr 29. PMID: 27129491.

Full text link PubMed Google Scholar

7. Aksakalli S, Calik B, Kara B, Ezirganli S. Accelerated tooth movement with piezocision and its periodontal-transversal effects in patients with Class II malocclusion. Angle Orthod. 2016 Jan; 86(1):59-65. doi: 10.2319/012215-49.1. Epub 2015 May 19. PMID: 25989211.

Full text link PubMed Google Scholar WoS

8. Charavet C, Lecloux G, Jackers N, et al. Piezocision-assisted orthodontic treatment using CAD/CAM customized orthodontic appliances: a randomized controlled trial in adults. Eur J Orthod. 2019 Sep 21;41(5):495-501. doi: 10.1093/ejo/cjy082. PMID: 30649257.

Full text link PubMed Google Scholar

9. Mertens B, Angioni C, Orti V, Canal P. Collaboration between periodontics and orthodontics: interest of alveolar corticotomies and piezocision. Review of literature]. Orthod Fr. 2017 Jun;88(2):179-191. French. doi: 10.1051/orthodfr/2017010. Epub 2017 Jun 9. PMID: 28597838

Full text link PubMed Google Scholar

10. Strippoli J, Durand R, Schmittbuhl M, et al. Pain and quality of life in patients undergoing guided piezocorticision- assisted orthodontic treatment. J Clin Orthod. 2017 Dec;51(12):792-799. PMID: 29364825.

PubMed Google Scholar $\underline{\text { Scopus }}$ 
11. Charavet C, Lecloux G, Bruwier A, et al. Selective piezocision-assisted orthodontic treatment combined with minimally invasive alveolar bone regeneration: A proof-of-concept. Int Orthod. 2018 Dec;16(4):652-664. doi: 10.1016/j.ortho.2018.09.021.

Epub 2018 Nov 1. PMID: 30391131 . Full text link PubMed Google Scholar Scopus WoS

12. Troedhan A. Piezotome rhinoplasty reduces postsurgical morbidity and enhances patient satisfaction: A multidisciplinary clinical Study. J Oral Maxillofac Surg. 2016 Aug;74(8):1659.e11659.e11. doi: 10.1016/j.joms.2016.04.013. Epub 2016 Apr 23. PMID: 27186871.

PubMed Google Scholar

13. Wallace SS, Mazor Z, Froum SJ, et al. Schneiderian membrane perforation rate during sinus elevation using piezosurgery: clinical results of 100 consecutive cases. Int J Periodontics Restorative Dent. 2007 Oct;27(5):413-419. PMID: 17990437. Full text link PubMed Google Scholar Scopus WoS

14. Testori T, Wallace SS, Del Fabbro M, et al. Repair of large sinus membrane perforations using stabilized collagen barrier membranes: surgical techniques with histologic and radiogra- phic evidence of success. Int J Periodontics Restorative Dent. 2008 Feb;28(1):9-17. PMID: 18351198

Full text link PubMed Google Scholar Scopus WoS

15. Bianchi A, Badiali G, Piersanti L, Marchetti C. Computerassisted piezoelectric surgery: a navigated approach toward performance of craniomaxillofacial osteotomies. J Craniofac Surg. 2015 May;26(3):867-872. doi: 10.1097/SCS.0000000000001360. PMID: 25915675.

Full text link PubMed Google Scholar Scopus WoS

16. AlAsseri N, Swennen G. Minimally invasive orthognathic surgery: a systematic review. Int J Oral Maxillofac Surg. 2018 Oct;47(10):1299-1310. doi: 10.1016/j.ijom.2018.04.017. Epub 2018 May 29. PMID: 29857982.

Full text link PubMed Google Scholar Scopus WoS

17. Shirota T, Kamatani T, Yamaguchi T, et al. Effectiveness of piezoelectric surgery in reducing surgical complications after bilateral sagittal split osteotomy. Br J Oral Maxillofac Surg. 2014 Mar;52(3):219-222. doi: 10.1016/j.bjoms.2013.11.015. Epub 2014 Jan 3. PMID: 24388635.

Full text link PubMed Google Scholar Scopus WoS

\section{François THONNART}

MD, DDS, Maxillofacial Surgery Resident Department of Maxillofacial Surgery ZOL Genk, Belgium

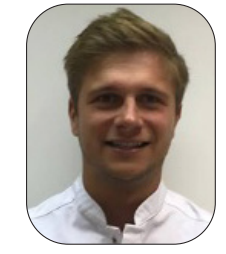

Dr. François Thonnart is a resident in Oral and Maxillofacial Surgery at the University of Liège, Liège, Belgium. He has a clinical focus on the head and neck oncology, orthognatic and dento-alveolar surgery. He currently works as resident in Ziekenhuis Oost Limburg in Genk, Limburg, Belgium.

\section{Questions}

\section{The effectiveness of piezocision is observed when:}

$\square$ a. The first arch is placed 3 weeks after the surgery;

b. The corticotomy is $3-4 \mathrm{~mm}$ long;

ac. The corticotomy is minimum $3 \mathrm{~mm}$ deep;

$\square$ d. The corticotomy is $1-2 \mathrm{~mm}$ deep.

\section{In Charavet's study, there is a visible scar after piezocision in:}

口a. 50 to $66 \%$;

ab. 35 to $45 \%$;

ac. 0 to $10 \%$;

ad. 95 to $100 \%$.

\section{The use of surgical ultrasound devices has shown:}

$\square$ a. A higher rate of Schneider's sinus membrane perforation;

b. No increase in patient satisfaction for rhinoplasty;

ac. A decrease in postsurgical morbidity;

$\square d$. It can increase the need for secondary corrective rhinoplasties.

\section{Piezotome:}

$\square$ a. Is not able to cut dense bone;

$\square$ b. Reduces the risk of nerve damage;

ac. Decreases the time to perform an osteotomy;

$\square \mathrm{d}$. Increases the time of orthodontic treatments. 


\title{
SELECTING AN APPROPRIATE OCCLUSAL SCHEME WHEN FABRICATING IMPLANT-SUPPORTED FIXED DENTAL PROSTHESES: A SYSTEMATIC REVIEW
}

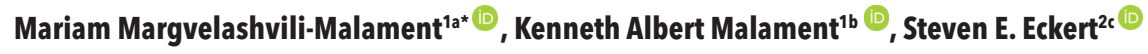 \\ 'Department of Prosthodontics' School of Dental Medicine, Tufts University, Boston, MA, USA \\ ${ }^{2}$ College of Medicine, Mayo Clinic, Rochester, MN, USA \\ aDMD, MSc, PhD, Assistant Professor; e-mail: mariam.malament@tufts.edu; ORCIDiD: https://orcid.org/0000-0002-3751-0675 \\ bDS, MSCD, Clinical Professor; e-mail: kenneth.malament@tufts.edu; ORCIDiD: https://orcid.org/0000-0002-7144-5643 \\ 'DDS, MS, Professor Emeritus; e-mail: seeckert@me.com; ORCIDiD: https://orcid.org/0000-0001-9382-7135
}

Background Dental implants are ankylosed in the bone without a periodontal ligament resulting in a lack of micro-mobility during chewing. Consequently, occlusion with dental implants may be at greater risk, specifically when the teeth come into contact in lateral excursive movements.

Objective A systematic review of the literature was performed to identify occlusal concepts that were most favorable for implant-retained fixed restorations.

Data Sources A search of the literature was conducted using PubMed and EndNote literature online software databases. Keywords were used to assist in the identification of the literature.

Study Selection The literature search identified 49 articles using PubMed and 33 articles using the authorcreated EndNote database.

Data Extraction Two occlusal concepts were identified, namely mutually protected occlusion and group function unilateral occlusion. None of the articles demonstrated clear scientific evidence to identify superiority of one concept over the other.

Data Synthesis Based upon the systematic review of the literature, no scientific evidence was identified favoring any specific occlusal concept.

\section{KEYWORDS}

Occlusion; Dental Implants; Implant Supported Fixed Restoration; Mutually Protected; Group Function.

\section{INTRODUCTION}

The primary purpose of teeth is to prepare food for ingestion. Processing food demands the actions of trituration, manipulation, and deglutition. When teeth are lost, the function is compromised [1]. The replacement of missing teeth is accomplished using dental prostheses. These prostheses may be used to replace all the teeth with complete dental prostheses, or some of the teeth with partial dental prostheses. Replacement teeth may gain support using remaining natural teeth, dental implants, residual alveolar ridges, or a combination of these structures. Studies clearly indicate that removable prostheses are not as effective in restoring function, esthetics, and patient self-esteem. In fact, multiple nutritional deficiencies, associated comorbidities, and loss of self-confidence have been reported with removable prostheses [2-4]. Implants may provide single tooth replacement, or they could support the entire dentition with fixed dental prostheses. Although natural teeth and dental implants may provide similar support for dental prostheses, there are substantial differences between the two. The implant is an alloplastic device that replaces the natural tooth root and supports the prosthesis. Although implants may provide aesthetic and comfortable tooth replacement, there are characteristics associated with the use of dental implants that must be considered [5]. Perhaps the most obvious is the lack of a periodontal ligament around implants and thus a lack of micro-mobility during chewing. Consequently, occlusion with dental implants may be at greater risk, especially when teeth contact in lateral excursions [6].

The aim of this review was to identify the most harmonious relationship of prosthetic teeth when supported by dental implants and describe occlusal theories using a systematic review.

Received: July 17, 20211; Revised: August 05, 2021; Accepted: September 03, 2021; Published: September 07, 2021

*Corresponding author: Dr. Mariam Margvelashvili-Malament, Assistant Professor

Department of Prosthodontics, School of Dental Medicine, Tufts University, 1 Kneeland Street, Boston MA 02111, USA

Tel: +1 (617) 636-7000; Fax: +1 (617) 636-6583; e-mail: mariam.malamet@tufts.edu

Copyright: $\odot 2021$ the Editorial Council for the Stomatology Edu Journal. 


\section{MATERIALS AND METHODS}

The research question for this review was formulated following the Preferred Reporting Items for Systematic Reviews and Meta-Analyses (PRISMA) guidelines using the Population, Intervention, Comparison and Outcome (PICO) tool.

POPULATION: The patient group receiving fixed dental prostheses supported by implants.

INTERVENTION: The patient group receiving a specific form of treatment. Unilateral group function lateral occlusion with multiple posterior teeth guiding lateral movements.

COMPARISON: The patient group receiving an alternative form of treatment. Mutual protection placing lateral contacts on anterior teeth thereby separating the posterior teeth during mandibular movements.

OUTCOME: The results obtained from the two compared treatments.

In partially and/or completely edentulous patients restored with implant-supported fixed dental prostheses either a mutually protected occlusion, whereby the anterior teeth separate the posterior teeth in laterotrusion, or a group function occlusion, where the anterior and posterior teeth contact simultaneously on the working side result in fewer complications? The dental literature was to be evaluated to determine the relative superiority of one occlusal scheme over the other to answer the PICO question.

An electronic search was conducted utilizing the following database and Software: PubMed and EndNote using the search strategy "(dental implants OR implants) AND Occlusion AND implant restoration AND "dental implants"[Mesh]" and "Dental Occlusion and Dental Implant and Fixed Prosthesis or Occlusion or Group Function and Mutually Protected" respectively. No language or journal type restrictions were applied to the search. A supplemental hand search was also conducted. Search strategy and outcomes for each source are provided in Table 1.

To meet the eligibility requirements, the selected studies had to meet the following inclusion criteria:

1. Human studies.

2. Randomized controlled clinical trials (RCT), clinical trials, systematic reviews.

3. If multiple publications on the same cohort to be found, only the publication with the longest followup time was included.

The exclusion criteria included the following:

1. Not meeting inclusion criteria.

2. Duplicate publications.

3. Full-text not available in English.

4. Full-text unavailable.

5. No information available about occlusal concepts applied.

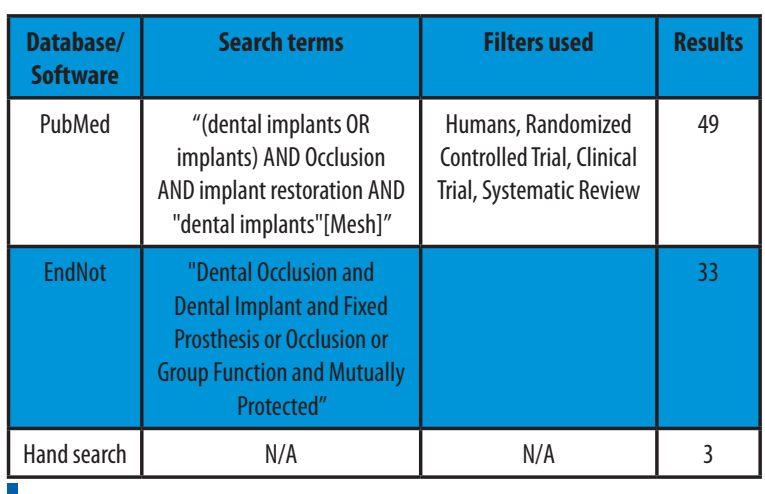

Table 1. Search strategy.

\subsection{Screening Process}

A total of 49 (PubMed) and 33 (EndNote) articles were selected by two of the authors (M.M.M. and S.E) as being of potential interest to the reader on the topic of dental occlusion. These articles were assessed by reviewing the titles and then by reading the abstracts. Any disagreement regarding the quality of the article was managed through discussion and eventually by the inclusion of the third author (K.A.M) if necessary.

The authors, after compilation and assessment of the articles, extracted the available data from the articles and compiled the gathered data. The articles were evaluated relative to the use of natural tooth support or dental implant support of the final prostheses.

\section{RESULTS}

Using the literature search described, no studies were identified to answer the PICO question. There were subjective descriptions of different techniques that were used in the management of clinical patients relative to the posterior fixed occlusal scheme. The PubMed search was linked with 49 articles. After screening the titles, 39 were assessed as irrelevant, 7 as potentially relevant, 2 as hypothetical designs and 1 as relevant. The EndNote search was linked with 33 articles, 23 were reviewed as irrelevant, 7 potentially relevant, 3 represented hypothetical designs (Fig. 1).

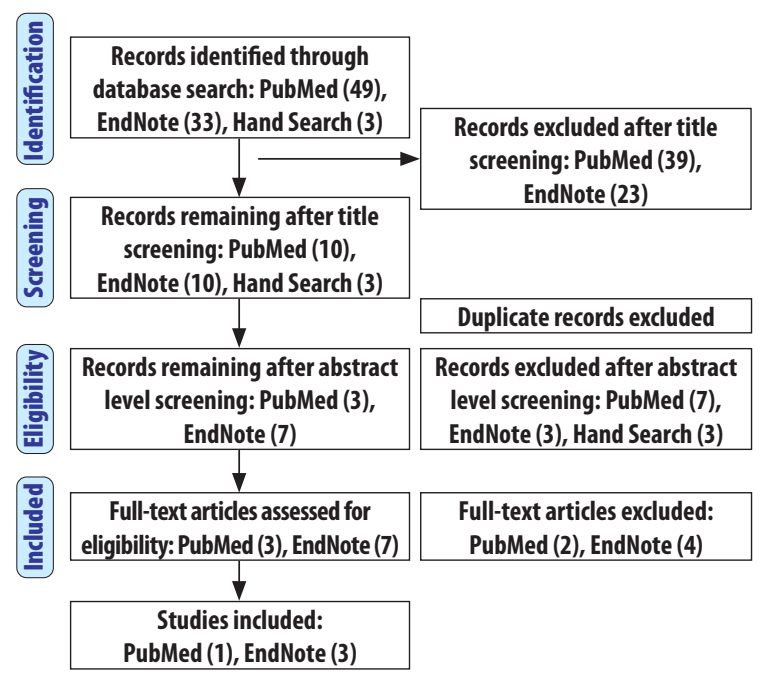

Figure 1. Screening process. 
Dental occlusion described as mutually protected occlusion was identified as the most common method of management of lateral articulation of the teeth. Group function was identified in three articles, although no scientific studies were performed. Due to an inability to identify a study, or studies, that answer the PICO question or provided conceptual homogeneity, no Meta-Analysis or risk of bias assessment could be conducted. The following opinion-based and clinical articles were identified and are summarized in Table 2.

Wismeijer et al. [7] described implant reconstruction in the edentulous mandibular arch opposing an edentulous maxilla as being treated using bilateral balanced occlusion. Mutually protected occlusion or group function was suggested when the maxilla was dentate. In an article that was primarily describing the use of short implants in the posterior areas, Misch et al [8] suggested that cantilevers should be eliminated, and the patient should be restored with a mutually protected or canine guided occlusal concept.

In 2016, Sheridan et al. [9] performed a systematic review that failed to identify evidence in favor of any specific occlusal management. Once again, these authors suggested mutually protected occlusion with anterior guidance with wide freedom in centric and avoidance of cantilevers. Considering the descriptors, specifically with "wide freedom in centric," the readers may have interpreted the terms as fulfilling the description of group function.

Esquivel-Upshaw et al [10] studied the effect of direction and magnitude of occlusal loading on implant supported FDPs. The authors provided group function to the treated patients and identified these lateral excursive contacts as not being associated with a higher fracture occurrence. Conversely, the strong centric contacts resulted in higher porcelain fracture rate. None of the treated patients received mutually protected occlusion. The authors suggested that due to the absence of a periodontal ligament, implant supported fixed dental prostheses should have lighter maximum intercuspation contacts.

\section{DISCUSSION}

This systematic review of the literature failed to identify randomized controlled clinical trials or cohort studies that would promote one specific occlusal design concept over another. Even from the standpoint of descriptive studies there is no clear recommendation. The lack of a periodontal ligament limits the micromotion and proprioceptive capability of implant-supported fixed restorations making them potentially more succeptible to technical complica-tions. Therefore, it is of paramount importance to provide optimal occlusion to hopefully generate higher survival rates for implant-supported fixed restorations. However, the question remains as to what is the optimal occlusal scheme. Although this systematic review failed to identify studies that would answer the question directly, suggestions dervied from the included articles as well as the factors that may be considered confounding variables are further discussed.

Two occlusal concepts that are currently applied to fixed restorations on implants are: group function occlusion and mutually protected occlusion.

Both occlusal approaches share the concept of simultaneous, bilateral contact of posterior teeth when the jaws are in maximum intercuspation. The concepts differ in the way that occlusion of the anterior teeth is described with group function exhibiting very light contact of the anterior teeth while mutual protection entails anterior teeth contact in all excursive movements thereby separating the posterior teeth.

Mutually protected occlusion is considered by many to be the ideal occlusal scheme for the natural dentition. D'Amico described the size and innervation of the canine tooth as a way to explain the rationale for embracing the mutual protection concept [11-13]. Conversely, group function exhibits unilateral, simultaneous anterior and posterior tooth contact as the jaws move laterally from maximum intercuspation. Primary support for the concept of group function is seen when the dentition exhibits abrasive wear after years of function [14-18].

Although without clear scientific or clinical evidence, three of the selected four studies recommended mutually protected occlusion for implant-supported fixed restorations.

Most of the authors highlight the complexity of biomechanics with implant-supported fixed dental prostheses. Misch et al. suggested decreasing stress through a biomechanical approach, namely: splinting implants and avoiding cantilevers, applying

\begin{tabular}{|c|c|c|c|c|c|c|c|}
\hline Author/Year & Journal & $\begin{array}{c}\text { Study } \\
\text { Design }\end{array}$ & $\begin{array}{c}\text { Sample Size } \\
\text { (number of FDPs }\end{array}$ & $\begin{array}{c}\text { Occlusal } \\
\text { Concept Used }\end{array}$ & $\begin{array}{c}\text { Observation } \\
\text { Time }\end{array}$ & $\begin{array}{c}\text { Prostheses' } \\
\text { Survival Rate (\%) }\end{array}$ & Results \\
\hline $\begin{array}{c}\text { Wismeijer, D. et } \\
\text { al 1995 }\end{array}$ & $\begin{array}{c}\text { Journal of } \\
\text { Prosthetic Dentistry }\end{array}$ & Review & N/A & N/A & N/A & N/A & $\begin{array}{c}\text { Recommends mutually protected } \\
\text { occlusion }\end{array}$ \\
\hline $\begin{array}{c}\text { Misch, C. E. } \\
\text { et al 2006 }\end{array}$ & $\begin{array}{c}\text { Journal of } \\
\text { Periodontology }\end{array}$ & $\begin{array}{c}\text { Retrospective } \\
\text { Case Series }\end{array}$ & 338 & $\begin{array}{c}\text { Mutually } \\
\text { protected }\end{array}$ & Up to 6 years & N 98.9\% & $\begin{array}{c}\text { Recommends methods to decrease } \\
\text { biomechanical stress (including } \\
\text { mutually protected occlusion) }\end{array}$ \\
\hline $\begin{array}{c}\text { Sheridan, R. A. } \\
\text { et al 2016 }\end{array}$ & Implant Dentistry & Review & N/A & N/A & N/A & N/A & $\begin{array}{c}\text { Recommends mutually protected } \\
\text { occlusion }\end{array}$ \\
\hline $\begin{array}{c}\text { Esquivel-Upshaw, } \\
\text { F. H. et al 20146 }\end{array}$ & Journal of Dentistry & RCT & 89 & Group Function & 3 years & $85 \%$ & Recommends light centric contacts \\
\hline
\end{tabular}

Table 2. Included studies. 
a mutually protected occlusal concept, and selecting an implant design to increase bone-to-implant contact area. Unfortunately, this study lacked a control group utilizing an alternative occlusal concept. Mutually protected occlusion resulted in high survival rates, yet the study does not answer the PICO question of current systematic review. It shows successful application of this occlusal concept but fails to demonstrate its superiority [8].

Esquivel-Upshaw, et al. showed no risk of higher fracture of implant-supported fixed dental prosthesis in excursive contacts (group function). This was true for both metal-ceramic and ceramic-ceramic restorations. However, similarly to Misch there was no control group of the alternative occlusal concept group. Regardless, the authors recommend hypoocclusion in maximum intercuspation on implant-supported fixed restorations [10].

Another concept that should be mentioned is bilateral balanced occlusion. Unlike mutually protected occlusion and group function, bilateral balance provides bilateral contacts in eccentric movements. While this occlusal concept is popular in complete denture prosthodontics, it should also be considered when a fixed restoration opposes a removable complete denture. When a prosthodontist considers the alternative occlusal concepts for treating edentulous pateints with fixed prostheses, the decision is often made based upon clincal experience and personal and laboratory preferences. However, another important aspect that should be considered is the type of restorative material being used. Normally the material choices are acrylic resin, cast metal, metal-ceramic, and milled or pressed ceramic materials. Over time, the use of acrylic resin has diminished because of unfavorable wear characteristics. Although acrylic resin prostheses usually have a supporting metal substructure, the wear characteristics of acrylic or composite materials as an occlusal material demonstrate moderate to severe wear in a relatively short period of time. The prostheses can be removed and the surface veneering material replaced, but this will require a number of appointments that will incur some cost. In addition, the customization of the occlusal surface of the prosthesis may create an occlusal awareness for the patient that could be unfavorable.

Full cast metal restorations could certainly be considered. The advantage of cast metal is that most cast materials exhibit a hardness and a wear pattern similar to that seen with natural dentition. The disadvantage of cast metal is the appearance and the relatively high cost associated with such a prostheses. In today's esthetically conscious society, full cast metal restorations are unlikely to prove acceptable. Metal ceramic restorations have been one of the most popular choices for restorative material for more than 50 years. Metal ceramic is relatively stable over time although it is somewhat prone to chipping and fracture of the veneering ceramic material. The restoration, because of the fabrication process, is built up incrementally. The ability to duplicate a prosthesis sometime after it was made originally will provide a cosmetic benefit for the patient but in terms of full functional replacement, the incremental stacking of porcelain will never be so accurate that it could be used without adjustment. In addition to the abrasive nature of metal ceramic restorations there is also a tendency for the material to lose surface detail over time. The cost of metal ceramic is dependent upon the type of metal alloy that is used. This is a material that was quite popular through the first decades of implant dentistry but it appears to have lost much of the previous popularity of this material.

The use of milled, or pressed, all ceramic materials has demonstrated a number of advantages. Since the design of such a prosthesis (milled) can be saved digitally, any future damage in the form of breakage, could be easily restored as long as the fixed dental prosthesis is retrievable. Perhaps a more important advantage is that monolithic all ceramic materials exhibit very little, if any, discernible wear over time. With the advent of lithium disilicate and zirconia materials the aesthetic replacement of posterior teeth should be easy to achieve and reliable and predictable into the future. Assuming that the choice of material will be that of a milled all ceramic material, it is important to remember the unique characteristics of the dental implant that must be duplicated or compensated for in the final prosthesis. Perhaps the most critical factor as it relates to implants is the relative immobility of the individual implants. Unlike natural teeth that exhibit physiologic mobility, implants are, for all intents and purposes, rigid within bone. This rigid device must have a carefully controlled occlusal relationship with the opposing teeth. The patient can advise the clinician of the presence of high occlusal contacts but it is very hard to communicate to the patient the more important factor related to lateral motions and how those must be compensated in the prosthetic design.

\section{CONCLUSIONS}

Within the limitations of this systematic review the authors agreed on the following conclusions:

- There is lack of information as to which occlusal scheme, mutually protected or group function, is more favorable.

- Based upon clinical preference and experience, group function or mutually protected occlusion, both appear to be acceptable occlusal schemes for implant supported fixed dental prostheses.

- Future clinical studies are needed to assess scientific and clinical evidence of the superiority of one occlusal scheme over other.

\section{AUTHOR CONTRIBUTIONS}

MM-M: was responsible for the conceptualization, design, data analyses and writing the manuscript. SE: was responsible for the conceptualization, design, and data analyses, and editing the manuscript. KM: was responsible for editing the manuscript. All the authors gave their final approval and agreed to be accountable for all aspects of the work. 


\section{REFERENCES}

1. Curtis DA, Plesh O, Miller AJ, et al. A comparison of masticatory function in patients with or without reconstruction of the mandible. Head Neck. 1997 Jul;19(4):287-296. doi: 10.1002/ (sici) 1097-0347(199707)19:4<287:aid-hed7>3.0.co;2-x. PMID: 9213107.

CrossRef PubMed Google Scholar Scopus

2. Felton DA. The ACP's evidence-based guidelines for the care and maintenance of complete dentures. J Prosthodont. 2010 Dec;19(8):591. doi: 10.1111/j.1532-849X.2010.00662.x. PMID: 21129079.

Full text links CrossRef PubMed Google Scholar Scopus

3. Felton DA. Edentulism and comorbid factors. Tex Dent J. 2010

Apr;127(4):389-401. PMID: 20446489.

Full text links CrossRef PubMed Google Scholar Scopus WoS

4. Felton DA. Complete edentulism and comorbid diseases: an update. J Prosthodont. 2016 Jan;25(1):5-20. doi: 10.1111/ jopr.12350. Epub 2015 Sep 15. PMID: 26371954.

Full text links CrossRef PubMed Google Scholar Scopus WoS 5. Buser D, Sennerby L, De Bruyn H. Modern implant dentistry based on osseointegration: 50 years of progress, current trends and open questions. Periodontol 2000. 2017 Feb;73(1):7-21. doi: 10.1111/prd.12185. PMID: 28000280.

Full text links CrossRef PubMed Google Scholar Scopus WoS 6. Koyano K, Esaki D. Occlusion on oral implants: current clinical guidelines. J Oral Rehabil. 2015 Feb;42(2):153-161. doi: 10.1111/ joor.12239. Epub 2014 Oct 6. PMID: 25284468.

Full text links CrossRef PubMed Google Scholar Scopus WoS 7. Wismeijer D, van Waas MA, Kalk W. Factors to consider in selecting an occlusal concept for patients with implants in the edentulous mandible. J Prosthet Dent. 1995 Oct;74(4):380-384. doi: 10.1016/s0022-3913(05)80378-6. PMID: 8531156. Full text links CrossRef PubMed Google Scholar Scopus WoS 8. Misch CE, Steignga J, Barboza E, et al. Short dental implants in posterior partial edentulism: a multicenter retrospective 6-year case series study. J Periodontol. 2006 Aug;77(8):1340-1347. doi: 10.1902/jop.2006.050402. PMID: 16937587.

Full text links CrossRef PubMed Google Scholar Scopus WoS 9. Sheridan RA, Decker AM, Plonka AB, Wang HL. The role of occlusion in implant therapy: a comprehensive updated review. Implant Dent. 2016 Dec;25(6):829-838. doi: 10.1097/ ID.0000000000000488. PMID: 27749518.

Full text links PubMed Google Scholar Scopus WoS
10. Esquivel-Upshaw JF, Mehler A, Clark AE, et al. Fracture analysis of randomized implant-supported fixed dental prostheses. J Dent. 2014 Oct;42(10):1335-1342. doi: 10.1016/j. jdent.2014.07.001. Epub 2014 Jul 9. PMID: 25016139; PMCID: PMC4169735.

Full text links CrossRef PubMed Google Scholar Scopus WoS 11. Alexander PC. The periodontium and the canine function theory. J Prosthet Dent. 1967 Dec;18(6):571-578. doi: 10.1016/0022-3913(67)90223-5. PMID: 5234942.

Full text links CrossRef PubMed Google Scholar Scopus

12. D'Amico A. The canine teeth-normal functional relation of the natural teeth of man. J South Calif Dent Assoc. 1958;26(1):6-23. Google Scholar

13. D'Amico A. Functional occlusion of the natural teeth of man. J Prosthet Dent. 1961;11(5):899-915. https://doi. org/10.1016/0022-3913(61)90148-2

Google Scholar Scopus

14. Becker CM, Kaiser DA. Evolution of occlusion and occlusal instruments. J Prosthodont. 1993 Mar;2(1):33-43. doi: 10.1111/j.1532-849x.1993.tb00379.x. PMID: 8374710.

Full text links CrossRef PubMed Google Scholar Scopus

15. Jemt T, Lundquist S, Hedegard B. Group function or canine protection. J Prosthet Dent. 1982 Dec;48(6):719-724. doi: 10.1016/ s0022-3913(82)80036-x. PMID: 6961212.

Google Scholar

16. Schwartz H. Occlusal variations for reconstructing the natural dentition. J Prosthet Dent. 1986 Jan;55(1):101-105. doi: 10.1016/0022-3913(86)90084-3. PMID: 3511222.

Full text links CrossRef PubMed Google Scholar Scopus WoS 17. Thornton LJ. Anterior guidance: group function/canine guidance. A literature review. J Prosthet Dent. 1990 Oct;64(4):479482. doi: 10.1016/0022-3913(90)90048-h. PMID: 2231460. Full text links PubMed Google Scholar Scopus

18. O'Leary TJ, Shanley DB, Drake RB. Tooth mobility in cuspidprotected and group-function occlusions. J Prosthet Dent. 1972 Jan;27(1):21-25. doi: 10.1016/0022-3913(72)90169-2. PMID: 4550061 .

Full text links PubMed Google Scholar Scopus

\section{Mariam MARGVELASHVILI-MALAMENT}

DMD, MSc, PhD, Assistant Professor Department of Prosthodontics School of Dental Medicine Tufts University - TUSDM Boston, MA, USA

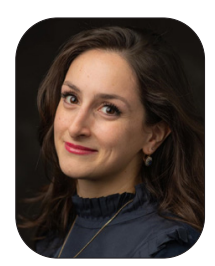

Dr. Margvelashvili-Malament is an Assistant Professor in the Department of Prosthodontics at Tufts University School of Dental Medicine (TUSDM). She is a Diplomate of the American Board of Prosthodontics and Fellow of the American College of Prosthodontics.

She received her DMD from the Tbilisi State University in Georgia, Master of Science and PhD Degrees in Dental Materials from the University of Siena, Italy. She is a co-author of the national residency program in Prosthodontics in Georgia. She was also the Founding Chair of the International Dental Program at the University of Georgia.

She is the recipient of an ITI Scholarship. She completed her Advanced Graduate training in Prosthodontics at TUSDM with high honors. She has lectured internationally and published numerous scientific articles and she also serves as a reviewer for international journals. 


\section{Questions}

\section{How can mutually protected occlusal concept be described?}

$\square$ a. An occlusal scheme in which the posterior teeth prevent excessive contact of the anterior teeth in maximal intercuspal position, and anterior teeth disengage the posterior teeth in all mandibular excursive movements;

Db. An occlusal scheme in which multiple posterior teeth contact in all mandibular excursive movements on the working side to distribute occlusal forces;

Dc. An occlusal scheme in which the buccal and lingual cusps of the maxillary posterior teeth on working and balancing side contact buccal and lingual cusps of mandibular posterior teeth in all mandibular excursive movements;

$\square$ d. None of the above.

\section{How can group function occlusal concept be described?}

$\square$ a. An occlusal scheme in which the posterior teeth prevent excessive contact of the anterior teeth in maximal intercuspal position, and anterior teeth disengage the posterior teeth in all mandibular excursive movements;

Db. An occlusal scheme in which multiple posterior teeth contact in all mandibular excursive movements on the working side to distribute occlusal forces;

口c. An occlusal scheme in which the buccal and lingual cusps of the maxillary posterior teeth on working and balancing side contact buccal and lingual cusps of mandibular posterior teeth in all mandibular excursive movements;

$\square d$. None of the above.

\section{Slightly hypo-occlusion in maximal intercuspal contacts is recommended for implant-supported fixed restorations because:}

$\square$ a. The lack of a periodontal ligament limits the micromotion;

ab. The lack of a proprioceptive capability of implant-supported fixed restorations;

$\square$ c. Both a. and b. are correct;

$\square$ d. None of the above.

\section{Based on the findings of this systematic review, the following is correct:}

$\square$ a. There is a lack of information as to which occlusal scheme, mutually protected or group function, is more favorable for implant-supported fixed restorations. Group function or mutually protected occlusion, both appear to be acceptable occlusal schemes;

$\square$ b. There is strong scientific evidence that suggests the use of group function occlusal concept for implant-supported fixed restorations;

$\square$ c. There is strong scientific evidence that suggests the use of mutually protected occlusal concept for implant-supported fixed restorations;

$\square$ d. None of the above. 


\title{
MECHANISMS LINKING ORAL HEALTH AND FRAILTY IN OLDER ADULTS: A NARRATIVE REVIEW
}

\author{
Kalliopi Konstantopoulou ${ }^{1 \mathrm{a}^{*}(\mathbb{C})}$, Anastassia Kossioni ${ }^{1 \mathrm{~b}}$ (]) \\ 'Department of Prostho ${ }^{\circ}$ ntics, Dental School, National and Ka $p^{0}$ distrian University of Athens, Athens, Greece \\ 'DaDDS, MSc; e-mail: kakonsta@dent.uoa.gr; ORCIDiD: https://orcid.org/0000-0002-4314-9222 \\ bDDS, MSc, PhD, Professor; e-mail: akossion@dent.uoa.gr; ORCIDiD: https://orcid.org/0000-0003-0610-6984
}

do) https://doi.org/10.25241/stomaeduj.2021.8(3).art.6

Background Frailty is a geriatric syndrome in which multiple systems lose their physiological reserves resulting in increased vulnerability to stressors and risk of adverse health-related outcomes. There is an increasing number of studies discussing the association of oral health with frailty through several pathways. Objective The aim of this review was to describe the possible mechanisms linking oral health and frailty. Data Sources A narrative review was performed with literature search in PubMed, Google Scholar and ScienceDirect electronic databases. Reference lists from relevant studies and cited papers were also investigated.

Study Selection The review included full papers of any study design, published in peer-reviewed journals in English until July 2021.

Data Extraction Current literature indicates four possible mechanisms linking oral health and frailty.

Data Synthesis The first mechanism refers to the nutritional pathway. It is reported that poor oral health negatively affects protein and vitamins intake. Malnutrition and decreased energy intake have a dominant role in frailty onset. Inflammation is another mechanism. Periodontal disease causes a systemic increase of pro-inflammatory biomarkers which in turn may lead to muscle strength deterioration. Furthermore, oral health can be related to frailty through neural mechanisms. Specifically, occlusion and proprioception from the periodontal ligament contribute to the control of body balance. Finally, the mechanisms include the psychological pathway, since poor oral health may lead to social isolation and depression which increase the risk of negative general health outcomes. More studies are necessary to clarify the previous associations and reveal any causative effects.

\section{KEYWORDS}

Oral Health; Frailty; Malnutrition; Inflammation; Depression.

\section{INTRODUCTION}

One of the dominant characteristics of the older population is heterogeneity, therefore overall health and function can vary substantially among individuals of the same chronological age. The concept of frailty has come to the forefront of research interest in Geriatric Medicine as a geriatric syndrome characterized by multiple functional impairments trying to explain this diversity among older people $[1,2,3]$. Frailty is defined as a clinical state of increased vulnerability related to ageing in which multiple systems lose their physiological reserves and the homeostatic balance is disrupted, resulting in an increased risk of adverse health-related outcomes, including functional impairment, dependency, hospital admission, institutionalization, reduced quality of life and mortality, even after exposure to a minor stressor, such as a viral infection or the use of a new drug $[2,4]$. The most common clinical manifestations of frailty are falls, confusion, functional decline and several non-specific signs and symptoms, such as unintentional weight loss, extreme fatigue and frequent infections. Genetic and environmental factors combined with epigenetic mechanisms are closely associated to the cumulative molecular and cellular damage, and pathophysiology of frailty.

As frailty is considered a dynamic and modifiable condition exercise (aerobic, balance and resistancebased), caloric and protein support, vitamin D intake and reducing polypharmacy seem to be effective strategies in its prevention or even reversion [4].

Prevalence of frailty among community-dwelling older adults and nursing home residents is estimated to be approximately $16.7 \%$ [5] and $52.3 \%$ respectively [6]. Regarding the assessment of frailty, a total of 67 instruments are available in the literature [7]. The Physical Frailty Phenotype has been identified as the most widely used instrument [7]. 
According to this instrument, frailty is diagnosed when at least three of the following components are met: unintentional weight loss, self-reported exhaustion, low physical activity, weak hand grip strength and slow gait speed, while pre-frailty is defined by the presence of one or two of these criteria [8]. Moreover, the Clinical Frailty Scale and the Frailty Index of Accumulative Deficits are among the nine most-referenced frailty instruments [7]. It was developed as a 7-point ordinal scale and has been modified as a 9-point scale from one (very fit) to nine (terminally ill with a life expectancy of less than six months) based on information about health status derived from medical history and clinical examination; a score of 5 or more indicates frailty [9]. The Frailty Index of Accumulative Deficits is based on the multi-dimensional nature of frailty and is expressed as a ratio of various accumulated health deficits [10].

Frailty has come to the forefront of the research interest in the dental field as well. Poor oral health has a high prevalence among older adults and there is an increasing number of studies which demonstrate cross-sectional, as well as longitudinal associations of oral health indicators with frailty or its components through several suggested pathways [11-13]. A systematic review showed a relationship between aspects of oral health, such as number of teeth, need for and use of dental prostheses, and frailty or pre-frailty, and suggested the existence of various mediators of this association which should be further investigated [11]. In a systematic review of longitudinal studies, the number of teeth, oral function, accumulation of oral health problems and number of dry mouth symptoms were identified as predictors of frailty [12]. The evident associations between oral health and frailty status among older people suggest that the integration of frailty assessment into dental treatment planning might be useful in providing the most appropriate dental care and preventive strategies to older adults who are at a state of increasing vulnerability [13]. Moreover, oral health, and particularly occlusal force and mastication, have been associated with sarcopenia [14], a muscle disease characterized by decreased muscle strength and muscle mass, and/ or reduced physical performance, which has many mutual clinical features with frailty and may serve as a precursor of frailty $[15,16]$.

Apart from the various individual oral health indicators that have been investigated in relation to frailty, the term "oral frailty" has been introduced by the Japanese Society describing a condition of decreased articulation, slight choking, or spillage while eating and increased number of unchewable foods [17]. A longitudinal study in Japanese community-dwelling older adults, describing oral frailty as the presence of at least three of the following parameters: less than 21 natural teeth, decreased masticatory performance, decreased oral diadochokinesis for the syllable "ta", decreased tongue pressure, subjective difficulties in eating tough foods and swallowing tea or soup showed that it may predict new onsets of frailty as defined by the Physical Frailty Phenotype and mortality [18].

As an increasing number of studies has shown an association between oral health and frailty, the purpose of the present narrative review was to describe the possible linking mechanisms.

\section{METHODOLOGY}

A literature search in PubMed, Google Scholar and ScienceDirect electronic databases was performed. The following keywords were used: (oral health OR oral function) AND (frailty) AND (linking mechanisms OR linking pathways). In addition, reference lists from relevant studies and cited papers were investigated. The titles and abstracts of the retrieved articles were screened to decide whether full-text reading was required, and full texts were retrieved for the selected articles. Included studies should have been published in peer-reviewed journals in English language, while no limits were set on the study design and the year of publication. Articles published until July 2021 were included in the present review.

\section{RESULTS}

Current literature indicates four possible mechanisms through which oral health is associated to frailty: a) nutritional pathway, b) inflammation, c) neural mechanisms and d) psychological pathway (Fig. 1).

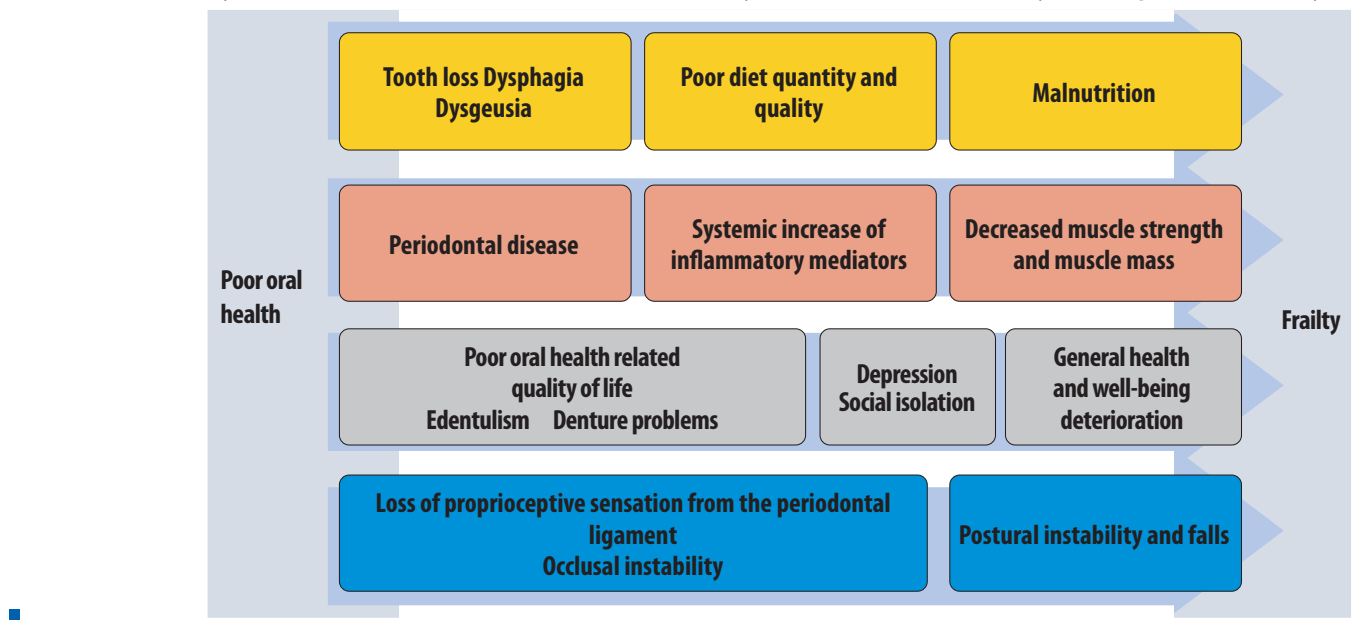

Figure 1. Screening process. 


\subsection{Nutritional pathway}

The first linking mechanism refers to the nutritional pathway and there is an interesting discussion on the association between oral health and nutrition.

Malnutrition is associated with frailty $[19,20]$. A metaanalysis revealed that a total of $68 \%$ of communitydwelling older adults with malnutrition had frailty [21].

Another meta-analysis demonstrated the substantial association between malnutrition and frailty or sarcopenia, with the co-occurrence of two or all the afore-mentioned conditions in about $50 \%$ of the hospitalized older adults [22].

There are indications that energy intake, as well as nutrient quality have an important role in the onset of frailty and the pathogenesis of sarcopenia [23]. Deficiencies in nutrients have been associated with mitochondrial dysfunction which in turn may cause fatigue and weakness, two elements of Physical Frailty Phenotype [24,25]. Furthermore, a decreased amount of protein intake possibly contributes to the pathogenesis of frailty findings, based on a meta-analysis of observational studies suggesting an association between an increased intake of dietary protein and a lower prevalence of frailty $(O R=0.67)$ [26]. In addition to the quantity of proteins, other parameters, such as protein source and protein distribution across meals, may also have an impact on the development and progression of frailty in older people [18].

Diet quality overall has been associated with a lower incidence of frailty in older adults $[27,28]$. Regarding the eating patterns in older adults, higher adherence to the Mediterranean Diet, which is characterized by a high intake of plant foods and olive oil and low consumption of red meats, have been inversely correlated to the loss of muscle mass, sarcopenia and frailty [29]; a meta-analysis demonstrated the protective role of the Mediterranean Diet against physical disability $(\mathrm{OR}=0.75)$ and frailty $(\mathrm{OR}=0.42)$ [30]. It is hypothesized that the Mediterranean Diet has a protective action on skeletal muscle health (myoprotective effect), since it is regarded as a source of bioactive nutrients and has anti-oxidative and anti-inflammatory properties [31]. On the other hand, Westernised dietary patterns, characterized by high consumption of refined cereals, whole dairy products, and processed meat, have a direct relationship with the increased risk of developing several components of physical frailty phenotype, namely weight loss and slow gait speed [32].

Poor dentition, dysphagia and dysgeusia are considered to be among the nine common risk factors (the nine d's) of malnutrition in older adults [33], but more research is necessary to clarify any causative effects and the role of individual contributors.

Edentulism and the presence of less than 21 natural teeth have been associated with the decreased intake of fruits, vegetables and proteins and the increased consumption of carbohydrates [34]. A meta-analysis showed that a lower number of remaining teeth was associated with poorer nutritional status, while edentulism and the presence of a prosthesis were not found to have a statistically significant effect on malnutrition in older adults [35].

However, a systematic review of longitudinal studies has shown that the evidence of a causative effect between tooth loss and nutritional status and nutrient intake was minor [36]. Also, the results of a randomized controlled trial indicated that both removable partial dental prostheses and the shortened dental arch concept generated equal improvement in partially dentate older adults' masticatory performance, but the masticatory performance could not predict nutritional status, due to their weak association [37]. Impaired masticatory performance in older adults is affected by a variety of factors and may lead to alteration of dietary choices and, subsequently, to malnutrition [38]. Better masticatory performance among functionally independent older adults, was independently associated with higher adherence to the Mediterranean Diet, in contrast to other dental indicators such as the number of natural teeth and use of removable prostheses [39], while older Greeks were more adherent to the components of the Mediterranean Diet compared to younger ones disregarding their dental status [40]. The enhancement of the maximum bite force and masticatory performance has been viewed as a prerequisite for a normal nutritional status in older people $[41,42]$. Nevertheless, the prosthetic rehabilitation of missing teeth does not seem sufficient for the treatment of malnutrition, and should be accompanied by nutritional advice, as this combination has been shown to lead to alterations in the food intake such as fruits and vegetables and to improvement of older adults' nutritional status [41-44].

Regarding dysgeusia, taste alteration leads to a diminution of food enjoyment, which in turn may decrease appetite and result in malnutrition [45]. Dysphagia (swallowing problems), which is highly prevalent in older individuals, can alter the oral intake of foods and liquids and, thus, serves as a risk factor of malnutrition [46-48]. According to a systematic review, chewing and swallowing problems were among the factors which were consistently associated with poor nutrition in nursing home residents $[31,49]$. Furthermore, high Xerostomia Index scores in older adults have been associated with the selective avoidance of foods including raw carrots, whole apples and nuts, lettuce, corn and grilled or fried meats [50].

In a cross-sectional study, community dwelling older adults with oral frailty (based on the definition proposed by Tanaka et al.) were found to have a greater possibility of more severe malnutrition assessed using the Mini Nutritional Assessment - Short Form $(\mathrm{OR}=2.17)$ and the level of serum albumin $(\mathrm{OR}=1.59)$ [51].

Also, a two-year longitudinal study demonstrated that oral frailty was associated with an increased risk of deterioration of nutritional status $(O R=2.24)$ [52]. 
There are indications that oral health status is independently associated with malnutrition [53]. However, the findings of a systematic review of prospective studies regarding dental status and swallowing function as determinants of malnutrition in older adults were inconsistent, while moderate quality evidence proposed that periodontal diseases, oral pain and difficulties in mastication are not determinants of malnutrition [54]. Therefore, mastication seems to explain only part of variance in the intake of food and/or nutrients in independent older adults [41], and more high-quality studies are necessary.

\subsection{Inflammation}

The term "inflammaging" describes an agerelated state of low-grade chronic inflammation. It is characterized by both increased levels of proinflammatory cytokines, such as CRP and IL- 6 and acute phase proteins, such as CRP, and decreased concentrations of IL-10, which lead to deterioration of immunological homeostasis [55, 56]. Thus, inflammaging has been assumed as an underlying mechanism of frailty. Proinflammatory biomarkers, principally interleukin 6 (IL-6) and tumor necrosis factor-a (TNF-a) can have an effect on the onset of frailty [57]. The results of a meta-analysis demonstrated a cross-sectional association between higher concentrations of CRP and IL-6, and frailty and pre-frailty, while no statistically significant longitudinal relationship emerged [58]. Another meta-analysis revealed a cross-sectional quantitative relationship between immunological biomarkers and frailty among older adults assessed with Physical Frailty Phenotype, which was stronger for CRP and IL-6 and weaker for TNF-a [56].

In a prospective cohort study, elevated serum levels of IL-6 acted as a predictor of walking speed decline among community-dwelling older adults [59]. Also, the findings of a meta-analysis suggested that higher levels of circulating CRP, IL- 6 and TNF-a were significantly associated with lower handgrip strength and knee extension strength, and CRP levels were significantly inversely correlated to skeletal muscle mass [60]. A meta-analysis of cross-sectional studies showed that serum levels of CRP were elevated in people with sarcopenia compared to controls, while no statistically significant associations were found between serum IL- 6 levels and TNF-a levels, and sarcopenia [61].

There is evolving evidence of strong associations between periodontitis, low-grade inflammation and systemic health. The accumulation of periodontopathogenic bacteria into the gingival sulcus stimulates a local inflammatory response and pro-inflammatory mediators such as interleukin 6 (IL6) and tumor necrosis factor a (TNF-a) are produced in periodontal lesions, which may move into the systemic circulation. Also, serum levels of C-reactive protein (CRP), an acute phase reactant produced mainly in the liver in various inflammatory cytokines, are elevated in patients with periodontitis [62].

\subsection{Psychological pathway}

Late-life depression and frailty have been described as comorbid geriatric syndromes [63]. A metaanalysis supported a reciprocal relationship between depression and frailty in older adults [64]. A systematic review suggested the strong prospective relationship between the presence of depression and greater risk of incident frailty among community-dwelling older adults [65]. Also, a strong correlation between depression and risk of frailty was found in a meta-analysis and this risk was higher for older men compared to older women (OR=4.76 and $O R=2.25$ respectively) [66]. The findings of another meta-analysis revealed a weak negative correlation between depressive symptomatology and handgrip strength [67]. Furthermore, the results of a longitudinal study demonstrated that both loneliness and social isolation were independently associated with incident frailty [68]. Another prospective cohort study showed a negative association between frequency of laughter and risk of functional disability among older individuals [69].

On the other hand, a longitudinal study showed that high levels of loneliness were associated with increased risk of incident physical frailty, but no relationship was found between loneliness and social isolation, and rate of change in frailty index [70]. Also, the results of a population-based cohort study suggested that depression does not act as a risk factor for the onset of frailty in older people [71]. The bidirectional association between depression and frailty is questioned, but it is indicated that they share some common risk factors in the short and long term [72].

Oral health has an effect on various aspects of older adults' quality of life among which are appearance and socializing [73]. Poor oral health may have negative consequences on social interaction and self-esteem and may lead to depression, which has an adverse effect on general health and wellbeing $[74,75]$. Cross-sectional as well as longitudinal associations between oral health related quality of life and loneliness in older adults have been identified [76].

Tooth loss can negatively affect speech and appearance, while denture problems may result in embarrassment due to dislodgement, pain and discomfort [38,77]. Older adults with fewer natural teeth and those who do not use dentures may have a greater possibility of social isolation [78]. In addition, tooth loss and selfreported dry mouth were found to be associated with a higher risk of developing depression among older adults in a longitudinal study [79]. Tooth loss and selfreported oral health problems, such as difficulty in chewing tough foods, may be longitudinally correlated to development or worsening of depression in older adults [80]. 
Also, a significant association was found between lower GOHAI (Geriatric Oral Health Assessment Index) scores and depression in Greek community-dwelling older adults [81]. A meta-analysis revealed a positive association of edentulism (OR=1.28) and periodontal disease $(H R=1.73)$ with depression in adults and older people [82].

A population-based cross-sectional study indicated a bidirectional association between the number of remaining teeth and the frequency of laughter among community-dwelling older adults [83].

Moreover, the results of a nationwide populationbased cohort study demonstrated that periodontitis was associated with the increased risk of subsequent depression [84].

On the other hand, a study in older Greeks has shown that the frequency of eating out was not affected by the dental status, but other biological and social factors played a more significant role indicating the multifactorial nature of human behaviour [85].

\subsection{Neural mechanisms}

The deterioration of body balance control is one of the most common causes of falls among older people [86]. Evidence has shown the existence of a positive association between postural instability and frailty or pre-frailty $[87,88]$. In a meta-analysis, an association between falls and frailty $(\mathrm{OR}=1.80)$ was found [89]. Moreover, a systematic review and metaanalysis provided a significant association between frailty and the future risk of falls among communitydwelling older adults, greater in males [90]. Another systematic review and meta-analysis with similar findings showed that community-dwelling older adults with frailty and prefrailty were at higher risk for falls and, also, those with frailty were more prone to recurrent falls [91].

Oral health may be related to postural stability through neural mechanisms. The stomatognathic system plays a role in the control of body posture [92]. Dental occlusion, trigeminal afferents and proprioception from the periodontal ligament may contribute to the control of postural stability, therefore tooth loss is a possible risk factor for postural instability $[92,93]$.

A case-control study showed that edentulous older adults had statistically significantly less body balance activity and higher body oscillation compared to those who maintained their dentition, while the use of complete denture(s) was not associated with body balance control [93]. However, in another study, complete dentures were found to have a positive effect on static and dynamic stability among edentulous older individuals [94]. In a longitudinal study, the complete loss of occlusion with natural teeth (Eichner index $\mathrm{C}$ ) was associated with decreased one-leg standing time with eyes open ( $\mathrm{OR}=4.27)$ [95]. Furthermore, a prospective study disclosed an independent association of maximum occlusal force with one-leg standing time among men aged 85 and older [96]. The results of a cohort study showed a strong relationship between occlusal status and postural stability [97]. According to a prospective cohort study, older adults with fewer than 20 teeth and those not using dentures were at higher risk for incident falls (OR=2.5) [98].

Also, the presence of teeth $(\mathrm{OR}=0.59)$ and dentures $(\mathrm{OR}=0.66)$ was significantly associated with decreased risk of falls in older adults with dementia [99]. On the other hand, the findings of a crosssectional study demonstrated that the use of dentures was correlated to decreased balance in both static and dynamic conditions and the duration of denture use was negatively asso-ciated with dynamic balance [100].

\section{DISCUSSION}

Current evidence supports both the cross-sectional and the longitudinal association between oral health and frailty [11-13], but more studies are necessary to confirm the evidence and clarify any causative effects. The majority of studies investigating this relationship were conducted in community dwelling older adults in Japan and the most commonly used frailty assessment instrument was the Physical Frailty Phenotype. This review has also identified four potential pathways which may link oral health and frailty that also need further investigation: the nutritional pathway, inflammation, the psychological pathway and neural mechanisms.

Oral health indicators, such as the number of teeth, masticatory performance, swallowing problems and dysgeusia seem to contribute to the nutritional status in older adults [33-35,38,45-52]. However, robust evidence on the association between oral health and malnutrition is still lacking as various confounding factors are implicated $[41,42,54]$. Malnutrition and decreased energy intake, in turn, are considered to have a dominant role in the onset of frailty and the pathogenesis of sarcopenia [23-26]. The multifactorial nature of nutritional status and food choices has been acknowledged, therefore, the interdisciplinary collaboration between dental professionals, dietetics practitioners, and primary care providers is necessary for treatment and prevention of malnutrition [42].

Regarding the pathway of inflammation, periodontitis may lead to systemic increase of inflammatory mediators, which may serve as an underlying mechanism of frailty. Nevertheless, the findings regarding the association of periodontitis with frailty are contradictory and evidence which supports inflammation as a linking mechanism between oral health and frailty is weak [12].

There are indications that poor oral health, namely tooth loss, periodontitis and self-assessed oral health status negatively influences older adults' quality of life and is associated with an increased risk of depression in older adults $[78-82,84]$. 
Reciprocal, as well as prospective associations between depre-ssive symptomatology and frailty in older adults havebeen reported $[64,65]$, while it is suggested that depression and frailty are affected by common causes such as biological, psychosocial, behavioral, and environmental factors [72].

As far as the neural mechanisms are concerned, the literature supports the existence of a relationship between the stomatognathic system and body posture; the loss of proprioception from periodontal ligament may have a negative impact on the head position and contribute to postural instability [92,93]. posture; the loss of proprioception from periodontal ligament may have a negative impact on the head position and contribute to postural instability [92,93]. Deterioration in control of body balance is one of the leading causes of falls in older people [86]. Falls, in turn, are associated with frailty [87-89] and are among the most common clinical manifestations of frailty [90,91]. This narrative review has revealed the need for further research including case-control and randomized controlled trials to thoroughly explore the association between oral health and frailty and also the specific role of oral health as a predictor

\section{REFERENCES}

1. Ahmed N, Mandel R, Fain MJ. Frailty: an emerging geriatric syndrome. Am J Med. 2007;120(9):748-753. doi: 10.1016/j. amjmed.2006.10.018. PMID: 17765039.

Full text links PubMed Google Scholar

2. Clegg A, Young J, Iliffe S, Rikkert MO, Rockwood K. Frailty in elderly people. Lancet. 2013;381(9868):752-762. doi: 10.1016/ S0140-6736(12)62167-9 PMID: 23395245; PMCID: PMC4098658. Free PMC article PubMed Google Scholar WoS

3. Mitnitski AB, Graham JE, Mogilner AJ, Rockwood K. Frailty, fitness and late-life mortality in relation to chronological and biological age. BMC Geriatr. 2002;2:1. doi: 10.1186/1471-2318-2-1. PMID: 11897015; PMCID: PMC88955.

Full text links Free PMC article PubMed Google Scholar WoS 4. Morley JE, Vellas B, van Kan GA, et al. Frailty consensus: a call to action. J Am Med Dir Assoc. 2013;14(6):392-397. doi: 10.1016/j. jamda.2013.03.022. PMID: 23764209; PMCID: PMC4084863 Full text links Free PMC article PubMed Google Scholar WoS 5. Ofori-Asenso R, Chin KL, Mazidi M, et al. Global incidence of frailty and prefrailty among community-dwelling older adults: a systematic review and meta-analysis. JAMA Netw Open. 2019;2(8):e198398. doi: 10.1001/jamanetworkopen.2019.8398. PMID: 31373653; PMCID: PMC6681553.

Full Text links Free PMC article PubMed Google Scholar WoS 6. Kojima G. Prevalence of Frailty in Nursing Homes: A systematic review and meta-analysis. J Am Med Dir Assoc. 2015;16(11):940945. doi: 10.1016/j.jamda.2015.06.025. PMID: 26255709. Full text links PubMed Google Scholar WoS

7. Buta BJ, Walston JD, Godino JG, et al. Frailty assessment instruments: systematic characterization of the uses and contexts of highly-cited instruments. Ageing Res Rev. 2016;26:53-61. doi: 10.1016/j.arr.2015.12.003. PMID: 26674984; PMCID: PMC4806795. Full text links Free PMC article PubMed Google Scholar WoS 8. Fried LP, Tangen CM, Walston J, et al. Frailty in older adults: evidence for a phenotype. J Gerontol A Biol Sci Med Sci. 2001;56(3):M146-M156. doi: 10.1093/gerona/56.3.m146. PMID: 11253156.

Full text links PubMed Google Scholar WoS

9. Moorhouse P, Rockwood K. Frailty and its quantitative clinical evaluation. J R Coll Physicians Edinb. 2012;42(4):333-340. doi: 10.4997/JRCPE.2012.412. PMID: 23240122.

Full text links PubMed Google Scholar WoS

10. Mitnitski AB, Mogilner AJ, Rockwood K. Accumulation of deficits as a proxy measure of aging. Sci. World J. 2001;1:323-336. doi: 10.1100/tsw.2001.58. PMID: 12806071; PMCID: PMC6084020. Full text links $\underline{\text { Free PMC article PubMed Google Scholar WoS }}$ and marker of frailty. Moreover, more studies are necessary to explore the potential linking mechanisms including nutrition, inflammation, psychological and neural pathways. Studies in community-dwelling older individuals and nursing home residents should also examine the possible protective effect of systematic oral care provision against frailty. Statistically significant results on these parameters may lead to the integration of markers of oral health in the frailty assessment instruments and to the development of appropriate preventive strategies in the context of oral health promotion.

\section{CONCLUSIONS}

Oral health and frailty may be linked through nutritional, inflammatory, psychological and neural mechanisms. Further studies are necessary to thoroughly elucidate the role of these pathways as mediators of the latter association and, subsequently, to determine the most effective preventive strategies.

\section{AUTHOR CONTRIBUTIONS}

KK: protocol, data gathering, data analysis, authoring the draft. AK: concept, protocol, critically revising the manuscript.

11. Tôrres LH, Tellez M, Hilgert JB, et al. Frailty, Frailty components, and oral health: a systematic review. J Am Geriatr Soc. 2015;63(12):2555-2562. doi: 10.1111/jgs.13826. PMID: 26563844.

Full text links PubMed Google Scholar WoS

12. Hakeem FF, Bernabé E, Sabbah W. Association between oral health and frailty: a systematic review of longitudinal studies. Gerodontology. 2019;36(3):205-215. doi: 10.1111/ger.12406. PMID: 31025772.

Full text links PubMed Google Scholar WoS

13. Slashcheva LD, Karjalahti E, Hassett LC, et al. A systematic review and gap analysis of frailty and oral health characteristics in older adults: a call for clinical translation. Gerodontology. 2021;10.1111/ger.12577. doi: 10.1111/ger.12577. PMID: 34331353.

Full text links PubMed Google Scholar

14. Hatta K, Ikebe K. Association between oral health and sarcopenia: a literature review. J Prosthodont Res. 2021;65(2):131136. doi: 10.2186/jpr.JPOR_2019_567. PMID: 32938852. Full text links PubMed Google Scholar 15. Cruz-Jentoft AJ, Bahat G, Bauer J, et al. Sarcopenia: revised European consensus on definition and diagnosis [published correction appears in Age Ageing. 2019 Jul 1;48(4):601]. Age Ageing. 2019;48(1):16-31. doi:10.1093/ageing/afy169. Full text links Free PMC article PubMed Google Scholar WoS 16. Coelho-Junior HJ, Marzetti E, Picca A, et al. Protein intake and frailty: a matter of quantity, quality, and timing. Nutrients. 2020;12(10):2915. doi: 10.3390/nu12102915. PMID: 32977714; PMCID: PMC7598653.

Full text links Free PMC article PubMed Google Scholar WoS 17. Minakuchi S, Tsuga K, Ikebe K, et al. Oral hypofunction in the older population: position paper of the Japanese Society of Gerodontology in 2016. Gerodontology. 2018;35(4):317-324. doi: 10.1111/ger.12347. PMID: 29882364.

Full text links PubMed Google Scholar

18. Tanaka T, Takahashi $\mathrm{K}$, Hirano $\mathrm{H}$, et al. Oral frailty as a risk factor for physical frailty and mortality in community-dwelling elderly. J Gerontol A Biol Sci Med Sci. 2018;73(12):1661-1667. doi: 10.1093/gerona/glx225. PMID: 29161342.

Full text links PubMed Google Scholar WoS

19. Artaza-Artabe I, Sáez-López P, Sánchez-Hernández N, et al. The relationship between nutrition and frailty: effects of protein intake, nutritional supplementation, vitamin $D$ and exercise on muscle metabolism in the elderly. A systematic review. Maturitas. 2016;93:89-99. doi: 10.1016/j.maturitas.2016.04.009. PMID: 27125943.

Full text links PubMed Google Scholar WoS 
20. Wei K, Nyunt MSZ, Gao Q, et al. Frailty and malnutrition: related and distinct syndrome prevalence and association among community-dwelling older adults: Singapore longitudinal ageing studies. J Am Med Dir Assoc. 2017;18(12):1019-1028. doi: 10.1016/j.jamda.2017.06.017. PMID: 28804010. Full text links PubMed Google Scholar WoS 21. Verlaan S, Ligthart-Melis GC, Wijers SLJ, et al. High prevalence of physical frailty among community-dwelling malnourished older adults - a systematic review and meta-analysis. J Am Med Dir Assoc. 2017;18(5):374-382. doi: 10.1016/j.jamda.2016.12.074. PMID: 28238676.

Full text links PubMed Google Scholar WoS 22. Ligthart-Melis GC, Luiking YC, Kakourou A, et al. Frailty, sarcopenia, and malnutrition frequently (co-)occur in

hospitalized older adults: a systematic review and meta-analysis. J Am Med Dir Assoc. 2020;21(9):1216-1228. doi: 10.1016/j. jamda.2020.03.006. PMID: 32327302

Full text links PubMed Google Scholar WoS

23. Lorenzo-López L, Maseda A, de Labra C, et al. Nutritional determinants of frailty in older adults: a systematic review. BMC Geriatr. 2017;17(1):108. Published 2017 May 15. doi: 10.1186/ s12877-017-0496-2. PMID: 28506216; PMCID: PMC5433026. Full text links Free PMC article PubMed Google Scholar WoS 24. Yannakoulia M, Ntanasi E, Anastasiou CA, Scarmeas N. Frailty and nutrition: from epidemiological and clinical evidence to potential mechanisms. Metabolism. 2017;68:64-76. doi: 10.1016/j. metabol.2016.12.005. PMID: 28183454.

Full text links PubMed Google Scholar WoS

25. Filler K, Lyon D, Bennett J, et al. Association of mitochondrial dysfunction and fatigue: a review of the literature. BBA Clin. 2014;1:12-23. doi: 10.1016/j.bbacli.2014.04.001. PMCID: PMC4136529.

Full text links Free PMC article PubMed Google Scholar WoS 26. Coelho-Júnior HJ, Rodrigues B, Uchida M, Marzetti E. Low protein intake is associated with frailty in older adults: a systematic review and meta-analysis of observational studies. Nutrients. 2018;10(9):1334. doi: 10.3390/nu10091334. PMID: 30235893; PMCID: PMC6165078.

Full text links Free PMC article PubMed Google Scholar WoS 27. Shikany JM, Barrett-Connor E, Ensrud KE, et al.

Macronutrients, diet quality, and frailty in older men. J Gerontol $A$ Biol Sci Med Sci. 2014;69(6):695-701. doi: 10.1093/gerona/glt196. PMID: 24304504; PMCID: PMC4022097.

Full text links Free PMC article PubMed Google Scholar WoS 28. Chan R, Leung J, Woo J. Dietary patterns and risk of frailty in Chinese community-dwelling older people in Hong Kong: a prospective cohort study. Nutrients. 2015:7(8):7070-7084 doi: 10.3390/nu7085326. PMID: 26305253; PMCID: PMC4555165. Full text links Free PMC article PubMed Google Scholar WoS 29. Ganapathy A, Nieves JW. Nutrition and sarcopenia-what do we know? Nutrients. 2020;12(6):1755. doi: 10.3390/nu12061755. PMID: 32545408; PMCID: PMC7353446.

Full text links Free PMC article PubMed Google Scholar WoS 30. Silva R, Pizato N, da Mata F, et al. Mediterranean diet and musculoskeletal-functional outcomes in community-dwelling older people: a systematic review and meta-analysis. J Nutr Health Aging. 2018;22(6):655-663. doi: 10.1007/s12603-017-0993 1. PMID: 29806854.

Full text links PubMed Google Scholar WoS

31. Granic A, Sayer AA, Robinson SM. Dietary patterns, skeletal muscle health, and sarcopenia in older adults. Nutrients. 2019;11(4):745. doi: 10.3390/nu1 1040745. PMCID: PMC6521630. Full text links Free PMC article PubMed Google Scholar WoS 32. León-Muñoz LM, García-Esquinas E, López-García E, et al. Major dietary patterns and risk of frailty in older adults: a prospective cohort study. BMC Med. 2015;13:11. doi: 10.1186/ s12916-014-0255-6. PMID: 25601152; PMCID: PMC4298966. Full text links Free PMC article PubMed Google Scholar WoS 33. Agarwal $E$, Miller M, Yaxley A, Isenring E. Malnutrition in the elderly: a narrative review. Maturitas. 2013;76(4):296-302. doi: 10.1016/j.maturitas.2013.07.013. PMID: 23958435. Full text links PubMed Google Scholar WoS 34. Zhu Y, Hollis JH. Tooth loss and its association with dietary intake and diet quality in American adults. J Dent. 2014;42(11):1428-1435. doi: 10.1016/j.jdent.2014.08.012. PMID 25174947.

Full text links PubMed Google Scholar WoS 35. Toniazzo MP, Amorim PS, Muniz FWMG, Weidlich P. Relationship of nutritional status and oral health in elderly: systematic review with meta-analysis. Clin Nutr. 2018;37(3):824 830. doi: 10.1016/j.clnu.2017.03.014. PMID: 28392164. Full text links Google Scholar WoS

36. Gaewkhiew P, Sabbah W, Bernabé E. Does tooth loss affect dietary intake and nutritional status? A systematic review of longitudinal studies. J Dent. 2017;67:1-8. doi: 10.1016/j. jdent.2017.10.012. PMID: 29097121.

Full text links PubMed Google Scholar Wos

37. Wallace S, Samietz S, Abbas M, et al. Impact of prosthodontic rehabilitation on the masticatory performance of partially dentate older patients: can it predict nutritional state? Results from a RCT. J Dent. 2018;68:66-71. doi: 10.1016/j. jdent.2017.11.003. PMID: 29129784

Full text links PubMed Google Scholar WoS

38. Anastassiadou V. Dietary habits, nutrition and oral health. In: Kossioni A, ed. Gerodontology essentials for health care professionals. Springer Nature; 2020

Full text links Google Scholar

39. Bousiou A, Konstantopoulou K, Martimianaki G, et al. Oral factors and adherence to Mediterranean diet in an older Greek population. Aging Clin Exp Res. 2021;10.1007/s40520-021-018618. doi: 10.1007/s40520-021-01861-8. PMID: 33893988

Full text links PubMed Google Scholar WoS

40. Kossioni A, Bellou O. Eating habits in older people in Greece: the role of age, dental status and chewing difficulties. Arch Gerontol Geriatr. 2011;52(2):197-201. doi: 10.1016/j. archger.2010.03.017. PMID: 20399518.

Full text links PubMed Google Scholar WoS

41. Schimmel M, Genton L, McKenna G. Masticatory function and nutritional status: considerations for an ageing population. In Oral rehabilitation for compromised and elderly patients. Springer, Cham; 2019

Full text links Google Scholar WoS

42. Schimmel M, Katsoulis J, Genton L, Müller F. Masticatory function and nutrition in old age. Swiss Dent J. 2015;125(4):449454. https://www.sso.ch/fileadmin/upload sso/2 Zahnaerzte/2 SDJ/SDJ_2015/SDJ_Pubmed_2015/sdj-2015-04-04.pdf. PMID:26169366.

Full text links PubMed Google Scholar WoS

43. Tada A, Miura H. Systematic review of the association of mastication with food and nutrient intake in the independent elderly. Arch Gerontol Geriatr. 2014;59(3):497-505. doi: 10.1016/j. archger.2014.08.005. PMID: 25179444.

Full text links PubMed Google Scholar WoS

44. Kossioni AE. The association of poor oral health parameters with malnutrition in older adults: a review considering the potential implications for cognitive impairment. Nutrients. 2018;10(11):1709. doi: 10.3390/nu10111709

Full text links Free PMC article PubMed Google Scholar WoS 45. Laguna $L$, Chen J. The eating capability: constituents and assessments. Food Qual Prefer. 2016;48:345-358. https://www. sciencedirect.com/science/article/pii/S0950329315000683?casa token=3Fri168jMxQAAAAA:L2vGSJSOAgsfDNBBxt1wtKozOf9sLH OuGKVrHNBGKqdO-6AaQKUVH3X-ppo4BV5xC3WC8o Full text links Google Scholar WoS

46. Sura L, Madhavan A, Carnaby G, Crary MA. Dysphagia in the elderly: management and nutritional considerations. Clin Interv Aging. 2012;7:287-298. doi: 10.2147/CIA.S23404. PMID:22956864. Full text links Free PMC article PubMed Google Scholar WoS 47. Serra-Prat M, Palomera M, Gomez C, et al. Oropharyngeal dysphagia as a risk factor for malnutrition and lower respiratory tract infection in independently living older persons: a population-based prospective study. Age Ageing. 2012;41(3):376381. doi: 10.1093/ageing/afs006. PMID: 22311895.

Full text links PubMed Google Scholar WoS

48. Fávaro-Moreira NC, Krausch-Hofmann S, Matthys C, et al. Risk factors for malnutrition in older adults: a systematic review of the literature based on longitudinal data. Adv Nutr. 2016;7(3):507522. doi: 10.3945/an.115.011254. PMID: 27184278.

Full text links Free PMC article PubMed Google Scholar WoS 49. Tamura BK, Bell CL, Masaki KH, Amella EJ. Factors associated with weight loss, low BMI, and malnutrition among nursing home patients: a systematic review of the literature. J Am Med Dir Assoc. 2013;14(9):649-655. doi: 10.1016/j.jamda.2013.02.022. PMID: 23639716

Full text links PubMed Google Scholar WoS

50. Quandt SA, Savoca MR, Leng X, et al. Dry mouth and dietary quality in older adults in North Carolina. J Am Geriatr Soc. 2011;59(3):439-445. doi: 10.1111/j.1532-5415.2010.03309.x. PMID: 21391935; PMCID: PMC3096847.

Full text links PMC free article PubMed Google Scholar WoS 51. Iwasaki M, Motokawa K, Watanabe Y, et al. Association between oral frailty and nutritional status among communitydwelling older adults: the Takashimadaira study. J Nutr Health Aging. 2020;24(9):1003-1010. doi: 10.1007/s12603-020-1433-1. PMID: 33155629.

Full text links $\underline{\text { PubMed Google Scholar WoS }}$ 
52. Iwasaki M, Motokawa K, Watanabe Y, et al. A two-year longitudinal study of the association between oral frailty and deteriorating nutritional status among community-dwelling older adults. Int J Environ Res Public Health. 2020;18(1):213. Published 2020 Dec 30. doi: 10.3390/ijerph18010213. PMID: 33396639; PMCID: PMC7796237.

Full text links Free PMC article PubMed Google Scholar WoS 53. Van Lancker A, Verhaeghe S, Van Hecke A, et al. The association between malnutrition and oral health status in elderly in long-term care facilities: a systematic review. Int J Nurs Stud. 2012;49(12):1568-1581. doi: 10.1016/j.ijnurstu.2012.04.001. PMID: 22542267

Full text links PubMed Google Scholar WoS

54. O'Keeffe M, Kelly M, O'Herlihy E, et al. Potentially modifiable determinants of malnutrition in older adults: a systematic review. Clin Nutr. 2019;38(6):2477-2498. doi: 10.1016/j.clnu.2018.12.007. PMID: 30685297.

Full text links PubMed Google Scholar WoS

55. Franceschi C, Campisi J. Chronic inflammation (inflammaging) and its potential contribution to age-associated diseases. $J$ Gerontol A Biol Sci Med Sci. 2014;69 Suppl 1:S4-S9. doi: 10.1093/ gerona/glu057. PMID: 24833586.

Full text links PubMed Google Scholar WoS

56. Marcos-Pérez D, Sánchez-Flores M, Proietti S, et al. Association of inflammatory mediators with frailty status in older adults: results from a systematic review and meta-analysis. Geroscience. 2020;42(6):1451-1473. doi:10.1007/s11357-020-00247-4. PMID: 32803650; PMCID: PMC7732924.

Full text links Free PMC article PubMed Google Scholar WoS 57. Michaud M, Balardy L, Moulis G, et al. Proinflammatory cytokines, aging, and age-related diseases. J Am Med Dir Assoc. 2013;14(12):877-882. doi: 10.1016/j.jamda.2013.05.009. PMID: 23792036

Full text links PubMed Google Scholar WoS

58. Soysal $P$, Stubbs B, Lucato $P$, et al. Inflammation and frailty in the elderly: a systematic review and meta-analysis. Ageing Res Rev. 2016;31:1-8. doi: 10.1016/j.arr.2016.08.006. PMID: 27592340. Full text links PubMed Google Scholar WoS

59. Verghese J, Holtzer R, Oh-Park M, et al. Inflammatory markers and gait speed decline in older adults. J Gerontol A Biol Sci Med Sci. 2011;66(10):1083-1089. doi: 10.1093/gerona/glr099. PMID: 21719612: PMCID: PMC3202897.

Full text links PubMed Free PMC article Google Scholar WoS 60. Tuttle CSL, Thang LAN, Maier AB. Markers of inflammation and their association with muscle strength and mass: a systematic review and meta-analysis. Ageing Res Rev. 2020;64:101185. doi: 10.1016/j.arr.2020.101185. PMID: 32992047.

Full text links PubMed Google Scholar WoS

61. Bano G, Trevisan C, Carraro S, et al. Inflammation and sarcopenia: a systematic review and meta-analysis. Maturitas. 2017;96:10 15. doi: 10.1016/j.maturitas.2016.11.006. PMID: 28041587. Full text links PubMed Google Scholar WoS 62. Cecoro G, Annunziata M, luorio MT, et al. Periodontitis, lowgrade inflammation and systemic health: a scoping review. Medicina (Kaunas). 2020;56(6):272. doi: 10.3390/medicina56060272. PMID: 32486269; PMCID: PMC7353850. Full text links Free PMC article PubMed Google Scholar WoS 63. Buigues C, Padilla-Sánchez C, Garrido JF, et al. The relationship between depression and frailty syndrome: a systematic review. Aging Ment Health. 2015;19(9):762-772. doi: 10.1080/13607863.2014.967174. PMID: 25319638.

Full text links PubMed Google Scholar WoS

64. Soysal P, Veronese $N$, Thompson T, et al. Relationship between depression and frailty in older adults: a systematic review and meta-analysis. Ageing Res Rev. 2017;36:78-87. doi: 10.1016/j. arr.2017.03.005. PMID: 28366616.

Full text links PubMed Google Scholar WoS

65. Vaughan L, Corbin AL, Goveas JS. Depression and frailty in later life: a systematic review. Clin Interv Aging. 2015:10:1947-1958. doi: 10.2147/CIA.S69632. PMID: 26719681; PMCID: PMC4687619. Free PMC article PubMed Google Scholar WoS

66. Chu W, Chang SF, Ho HY, Lin HC. The relationship between depression and frailty in community-dwelling older people: a systematic review and meta-analysis of 84,351 older adults. J Nurs Scholarsh. 2019;51(5):547-559. doi: 10.1111/jnu.12501. PMID: 31328878.

Full text links PubMed Google Scholar WoS

67. Zasadzka E, Pieczyńska A, Trzmiel T, et al. Correlation between handgrip strength and depression in older adults-a systematic review and a meta-analysis. Int J Environ Res Public Health. 2021;18(9):4823. doi: 10.3390/ijerph18094823. PMID: 33946502; PMCID: PMC8124581.

Full text links Free PMC article PubMed Google Scholar WoS
68. Davies K, Maharani A, Chandola T, et al. The longitudinal relationship between loneliness, social isolation, and frailty in older adults in England: a prospective analysis. Lancet Healthy Longev. 2021;2(2):70-77. https://www.sciencedirect.com/science/ article/pii/S2666756820300386.

Full text links Google Scholar

69. Tamada Y, Takeuchi K, Yamaguchi C, et al. Does laughter predict onset of functional disability and mortality among older Japanese adults? The JAGES prospective cohort study.

J Epidemiol. 2021;31(5):301-307. doi: 10.2188/jea.JE20200051. PMID: 32418940; PMCID: PMC8021882.

Full text link Free PMC article PubMed Google Scholar WoS

70. Gale CR, Westbury L, Cooper C. Social isolation and loneliness as risk factors for the progression of frailty: the English longitudinal study of ageing. Age Ageing. 2018;47(3):392-397. doi: 10.1093/ ageing/afx188. PMID: 29309502; PMCID: PMC5920346.

Full text article Free PMC article PubMed Google Scholar WoS 71. Da Mata FAF, Miranda Forte Gomes M, Lício Ferreira Santos J, et al. Depression and frailty in older adults: a population-based cohort study. PLoS One. 2021;16(3):e0247766. doi: 10.1371/journal.pone.0247766. MID: 33662006; PMCID: PMC7932072. Full text links Free PMC article PubMed Google Scholar WoS 72. Mayerl H, Stolz E, FreidI W. Frailty and depression: reciprocal influences or common causes? Soc Sci Med. 2020;263:113273. doi: 10.1016/j.socscimed.2020.113273. PMID: 32810695.

Full text links PubMed Google Scholar WoS

73. Kossioni AE, Dontas AS. The stomatognathic system in the elderly. Useful information for the medical practitioner. Clin Interv Aging. 2007;2(4):591-597. doi: 10.2147/cia.s1596. MID: 18225459; PMCID: PMC2686331.

Full text links Free PMC article PubMed Google Scholar 74. Kisely S, Sawyer E, Siskind D, Lalloo R. The oral health of people with anxiety and depressive disorders - a systematic review and meta-analysis. J Affect Disord. 2016;200:119-132. doi: 10.1016/j.jad.2016.04.040. PMID: 27130961.

Full text links PubMed Google Scholar WoS

75. Kandelman D, Petersen PE, Ueda H. Oral health, general health, and quality of life in older people. Spec Care Dentist. 2008;28(6):224-236. doi: 10.1111/j.1754-4505.2008.00045.x. PMID: 19068063

Full text links PubMed Google Scholar WoS

76. Rouxel $P$, Heilmann A, Demakakos $P$, et al. Oral health-related quality of life and loneliness among older adults. Eur J Ageing. 2016:14(2):101-109 doi: 10.1007/s10433-016-0392-1. PMID: 28579932; PMCID: PMC5435788.

Full text links Free PMC article PubMed Google Scholar WoS 77. Niesten D, van Mourik K, van der Sanden W. The impact of having natural teeth on the QoL of frail dentulous older people. A qualitative study. BMC Public Health. 2012;12:839. doi: 10.1186/1471-2458-12-839. PMID: 23031489; PMCID: PMC3524040.

Full text links Free PMC article PubMed Google Scholar WoS 78. Koyama S, Saito M, Cable N, et al. Examining the associations between oral health and social isolation: a cross-national comparative study between Japan and England. Soc Sci Med. 2021;277:113895. doi: 10.1016/j.socscimed.2021.113895. PMID: 33882441.

Full text links PubMed Google Scholar

79. Kunrath I, Silva AER. Oral health and depressive symptoms among older adults: Iongitudinal study. Aging Ment Health. 2020;1-7. doi: 10.1080/13607863.2020.1855104. PMID: 33291966. Full text links PubMed Google Scholar WoS

80. Yamamoto T, Aida J, Kondo K, et al. Oral health and incident depressive symptoms: JAGES project longitudinal study in older Japanese. J Am Geriatr Soc. 2017;65(5):1079-1084. doi: 10.1111/ jgs.14777. PMID: 28165614

Full text links PubMed Google Scholar WoS

81. Gkavela G, Kossioni A, Lyrakos G, et al. Oral health related quality of life in older people: preliminary validation of the Greek version of the Geriatric Oral Health Assessment Index (GOHAI). Eur Geriatr Med. 2015;6(3):245-250. https://www.sciencedirect. $\mathrm{com} /$ science/article/pii/S1878764915000030?casa_token=jriqF tyLf_kAAAAA:6EwCjjZ8Lz_IDjmy76clg4xk3QaGmn1L0ZIG7V76EXkYpjgbk4NF7o52B4VWMIHVNFN0yiM.

Full text links Google Scholar WoS

82. Cademartori MG, Gastal MT, Nascimento GG, et al. Is depression associated with oral health outcomes in adults and elders? A systematic review and meta-analysis. Clin Oral Investig. 2018;22(8):2685-2702. doi: 10.1007/s00784-018-2611-y. PMID: 30191327

Full text links $\underline{\text { PubMed Google Scholar WoS }}$ 
83. Hirosaki M, Ohira T, Shirai K, et al. Association between frequency of laughter and oral health among community-dwelling older adults: a population-based cross-sectional study in Japan. Qual Life Res. 2021;30(6):1561-1569. doi: 10.1007/s11136-020-

02752-7. PMID: 33432445.

Full text links PubMed Google Scholar WoS

84. Hsu CC, Hsu YC, Chen $\mathrm{HJ}$, et al. Association of periodontitis and subsequent depression: a nationwide population-based study. Medicine (Baltimore). 2015;94(51):e2347. doi: 10.1097/ MD.0000000000002347. PMID: 26705230; PMCID: PMC4697996. Free PMC article PubMed Google Scholar WoS

85. Kossioni A, Bellou O. The effect of aging and dental status on the frequency of eating out. Arch Gerontol Geriatr. 2012;54(2):e130-e133. doi: 10.1016/j.archger.2011.10.016. PMID: 22088937.

Full text links PubMed Google Scholar WoS

86. Cuevas-Trisan R. Balance problems and fall risks in the elderly. Phys Med Rehabil Clin N Am. 2017;28(4):727-737. doi: 10.1016/j. pmr.2017.06.006. PMID: 29031339.

Full text links PubMed Google Scholar WoS

87. Chkeir A, Safieddine D, Bera D, et al. Balance quality assess-

ment as an early indicator of physical frailty in older people. Annu Int Conf IEEE Eng Med Biol Soc. 2016;2016:5368-5371. doi: 10.1109/ EMBC.2016.7591940. PMID: 28325024.

Full text links PubMed Google Scholar WoS

88. Moraes DC, Lenardt MH, Seima MD, et al. Postural instability and the condition of physical frailty in the elderly. Rev Lat Am Enfermagem. 2019;27:e3146. doi: 10.1590/1518-8345.2655-3146. PMID: 31038639; PMCID: PMC6528635.

Full text links Free PMC article PubMed Google Scholar WoS 89. Fhon JR, Rodrigues RA, Neira WF, et al. Fall and its association with the frailty syndrome in the elderly: systematic review with meta-analysis. Rev ESC Enferm USP. 2016;50(6):1005-1013. doi: 10.1590/S0080-623420160000700018. PMID: 28198967. Full text links PubMed Google Scholar WoS

90. Kojima G. Frailty as a predictor of future falls among commu nity-dwelling older people: a systematic review and meta-analysis. J Am Med Dir Assoc. 2015;16(12):1027-1033. doi: 10.1016/j. jamda.2015.06.018. PMID: 26255098.

Full text links PubMed Google Scholar WoS

91. Cheng $\mathrm{MH}$, Chang SF. Frailty as a risk factor for falls among community dwelling people: evidence from a meta-analysis.

J Nurs Scholarsh. 2017;49(5):529-536. doi: 10.1111/jnu.12322.

PMID: 28755453.

Full text links PubMed Google Scholar WoS

92. Cuccia A, Caradonna C. The relationship between the stomatognathic system and body posture. Clinics (Sao Paulo). 2009;64(1):61-66. doi: 10.1590/s1807-59322009000100011. PMID: 19142553; PMCID: PMC2671973.

Full text links Free PMC article PubMed Google Scholar WoS
93. Yoshida M, Kikutani T, Okada G, et al. The effect of tooth loss on body balance control among community-dwelling elderly persons. Int J Prosthodont. 2009;22(2):136-

139. https://web.b.ebscohost.com/abstract?direct=true\&profile $=$ ehost\&scope $=$ site\&authtype $=$ crawler\&jrnI=08932174\&AN=43288454\&h=Ap2\%2fiS9jqUyBz2CIFIrliR7Q4Egb5WqHg348oyjgEicKoBGtgm0TB0prjNnQfDGVr-

MgEe8WfY8fs9QjBvx\%2bGlg\%3d\%3d\&crl=c\&resultNs=AdminWebAuth\&resultLocal=ErrCrINo-

tAuth\&crlhashurl=login.aspx\%3fdirect $\% 3$ dtrue $\% 26$ pro-

file $\% 3 d$ ehost $\% 26$ scope $\% 3 d$ site $\% 26$ authtype $\% 3 d$ crawler $\% 26 j r n-$ \%3d08932174\%26AN\%3d43288454. PMID: 19418857.

Full text links PubMed Google Scholar WoS

94. Okubo M, Fujinami Y, Minakuchi S. Effect of complete dentures on body balance during standing and walking in elderly people. J Prosthodont Res. 2010;54(1):42-47. doi: 10.1016/j. jpor.2009.09.002. PMID: 19819207.

Full text links PubMed Google Scholar

95. Okuyama N, Yamaga T, Yoshihara A, et al. Influence of dental occlusion on physical fitness decline in a healthy Japanese elderly population. Arch Gerontol Geriatr. 2011;52(2):172-176. doi: 10.1016/j.archger.2010.03.011. PMID: 20378189.

Full text links PubMed Google Scholar PubMed

96. linuma T, Arai Y, Fukumoto M, et al. Maximum occlusal force and physical performance in the oldest old: the Tokyo oldest old survey on total health. J Am Geriatr Soc. 2012;60(1):68-76. doi:10.1111/j.1532-5415.2011.03780.x

Full text links PubMed Google Scholar

97. Song-Yu X, Rodis OM, Ogata S, et al. Postural stability and occlusal status among Japanese elderly. Gerodontology.

2012;29(2):e988-e997. doi:10.1111/j.1741-2358.2011.00596.x

Full text links PubMed Google Scholar

98. Yamamoto T, Kondo K, Misawa J, et al. Dental status and incident falls among older Japanese: a prospective cohort study. BMJ Open. 2012;2(4):e001262. doi: 10.1136/bmjopen-2012-001262. PMID: 22855628; PMCID: PMC4400665.

Full text links Free PMC article PubMed Google Scholar WoS 99. Eshkoor SA, Hamid TA, Nudin SS, Mun CY. Association between dentures and the rate of falls in dementia. Med Devices (Auckl). 2014;7:225-230. Published 2014 Jun 20. doi:10.2147/ MDER.S63220

Full text links Free PMC article PubMed Google Scholar 100. Bae Y, Park Y. Head posture and postural balance in community-dwelling older adults who use dentures. Medicina (Kaunas). 2020;56(10):529. Published 2020 Oct 12. doi:10.3390/medicina56100529

Full text links Free PMC article PubMed Google Scholar

\title{
Kalliopi KONSTANTOPOULOU
}

\author{
DDS, MSc \\ Department of Prosthodontics \\ School of Dentistry \\ National and Kapodistrian University of Athens \\ Athens, Greece
}

Kalliopi Konstantopoulou graduated from the Dental School of National and Kapodistrian University of Athens, Athens, Greece in 2016. In 2019, she obtained her master's degree in Health Promotion and Education from the Medical School of National and Kapodistrian University of Athens and is currently a postgraduate student at the Department of Prosthodontics, Dental School, National and Kapodistrian University of Athens, Athens, Greece. She is also a Board member at the European College of Gerodontology. 


\title{
Questions
}

\author{
1. The most widely used instrument to assess frailty is: \\ $\square$ a. Physical Frailty Phenotype; \\ ab. Frailty Index; \\ Dc. Clinical Frailty Scale; \\ Dd. Short Physical Performance Battery.
}

\section{Oral health is linked to frailty through:}

a. Nutrition;

Db. Inflammation;

ac. Psychological and neural pathways;

$\square$ d. All of the above are correct.

\section{Which of the following sentences is correct?}

$\square$ a. Oral health is the dominant determinant of malnutrition;

ab. Nutritional status and food selection have a multifactorial nature;

口c. Malnutrition can be reversed solely by prosthodontic rehabilitation;

$\square$ d. Westernized dietary patterns may prevent frailty.

\section{Which of the following sentences is correct?}

$\square$ a. No prospective associations exist between depression and frailty;

$\square$ b. No reciprocal associations exist between depression and frailty;

D. Depression and frailty seem to be affected by common causes;

Dd. None of the above.

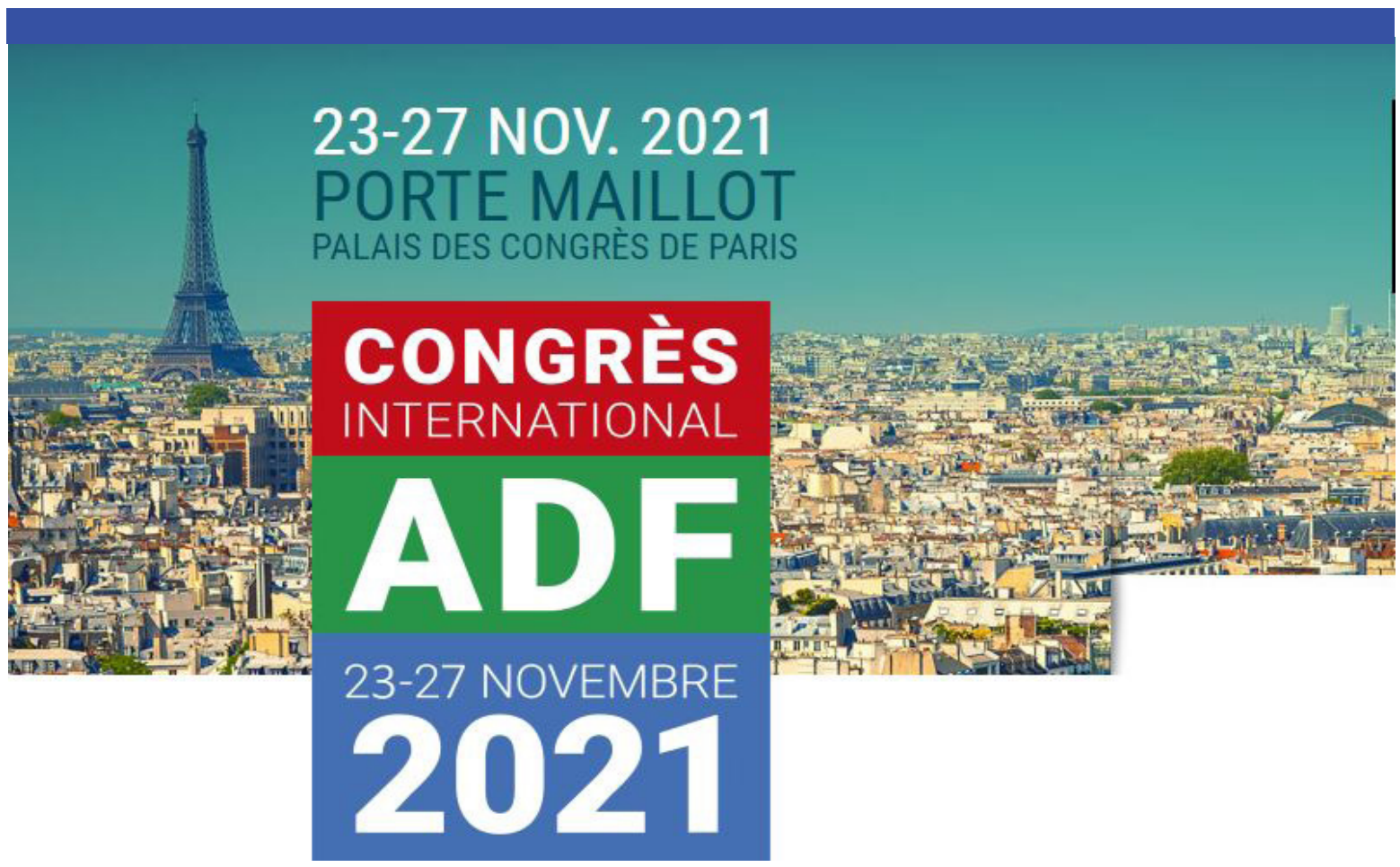




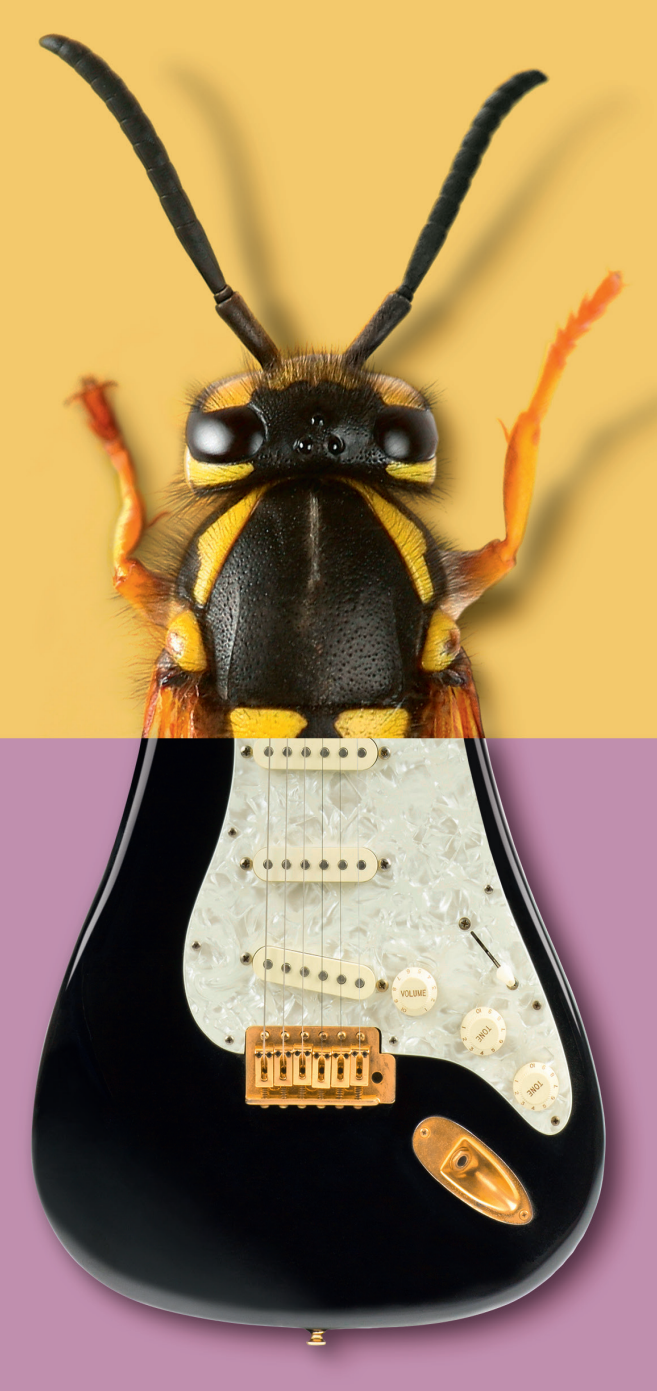

DAC Universal S Hazards turned harmless.

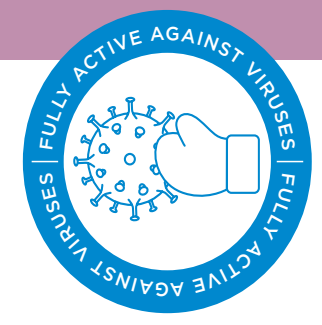

You think you will never win the fi ght against germs but Dentsply Sirona turns hygiene risks into manageable maintenance. With DAC Universal S you'll benefi t from an automated and quick way of cleaning, lubricating and sterilizing dental instruments. The process takes approx. 21 minutes making it possible to comply with hygiene requirements by simply pressing a button. Your patients and your team can fully rely on our comprehensive protection against hazards.

Find out more at dentsplysirona.com/safehygiene

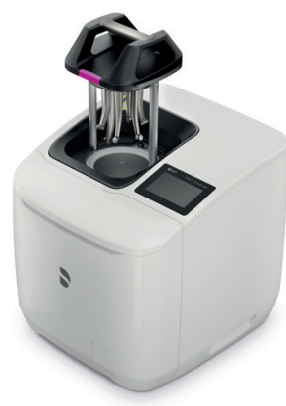




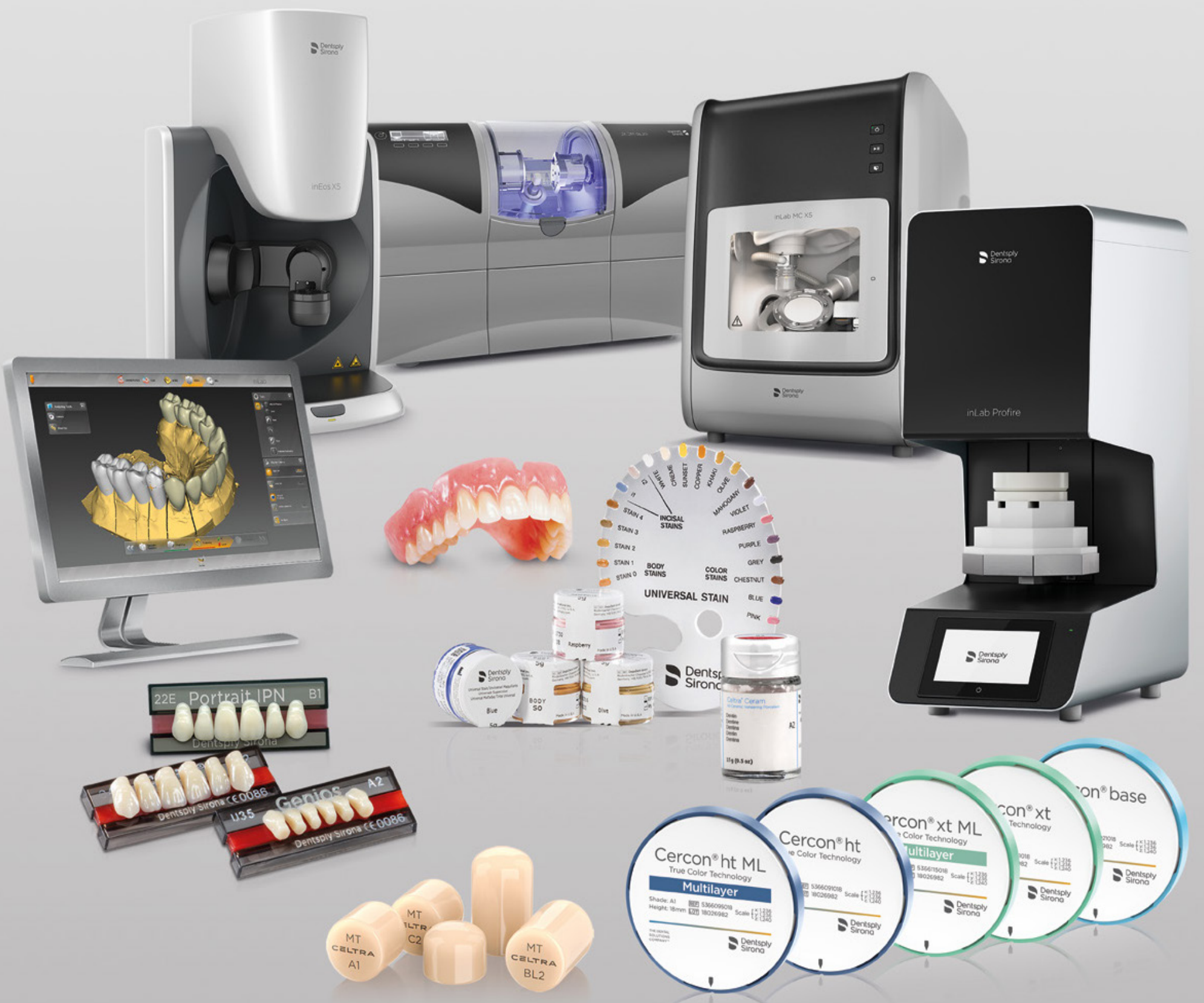

The family products for Dental Labs from Dentsply Sirona

Dentsply Sirona Lab offers you a comprehensive range of materials tailored specifically to the inLab design software and production units - in a variety that leaves nothing to be desired. Our product portfolio eliminates the trade-off between efficiency and aesthetics with simpler to use CAD/CAM materials that produce high-quality outcomes at a pace and workflow that keeps your business successful. 


\title{
A MULTIDISCIPLINARY APPROACH FOR THE REHABILITATION OF A PATIENT WITH CHONDROSARCOMA: PROSTHETICALLY-DRIVEN DIGITAL WORKFLOW FOR MAXILLARY RECONSTRUCTION AND IMPLANT TREATMENT
}

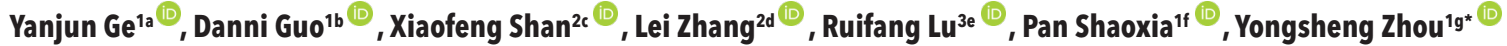 \\ 'Department of Prosthodontics, Peking University School and Hospital of Stomatology \& National Center of Stomatology \& National Clinical \\ Research Center for Oral Diseases \& National Engineering Laboratory for Digital and Material Technology of Stomatology \& Beijing Key \\ Laboratory of Digital Stomatology \& Research Center of Engineering and Technology for Computerized Dentistry Ministry of Health \& NMPA \\ Key Laboratory for Dental Materials, Beijing 100081, China \\ ${ }^{2}$ Department of Oral-Maxillofacial Surgery, Peking University School and Hospital of Stomatology \& National Center of Stomatology \& \\ National Clinical Research Center for Oral Diseases \& National Engineering Laboratory for Digital and Material Technology of Stomatology, \\ Beijing 100081, China \\ ${ }^{3}$ Department of Periodontology, Peking University School and Hospital of Stomatology \& National Center of Stomatology \& National Clinical \\ Research Center for Oral Diseases \& National Engineering Laboratory for Digital and Material Technology of Stomatology \& Beijing Key \\ Laboratory of Digital Stomatology \& Research Center of Engineering and Technology for Computerized Dentistry Ministry of Health \& NMPA \\ Key Laboratory for Dental Materials, Beijing 100081, China
}

aDDS, PhD; e-mail:yanjun ge@163.com; ORCIDiD: https://orcid.org/0000-0003-2853-8657
'DDS; e-mail: gdnsunshine@163.com; ORCIDiD: https://orcid.org/0000-0001-8190-0972
'DDS, PhD; e-mail: kqsxf@263.net; ORCIDiD: https://orcid.org/0000-0002-2126-8052
dDDS, PhD; e-mail:zhlei doctor@sina.com; ORCIDiD: https://orcid.org/0000-0001-8251-6032
e DDS, PhD; e-mail: kgrflu@bjmu.edu.cn; ORCIDiD: https://orcid.org/0000-0002-9581-508X
'DDS, PhD; e-mail: panshaoxia@vip.163.com; ORCID: https://orcid.org/0000-0002-3808-9499
'DDS, PhD, Professor and Head; e-mail: kqzhouysh@hsc.pku.edu.cn; ORCID: $\underline{\text { https://orcid.org/0000-0002-4332-0878 }}$

d) https://doi.org/10.25241/stomaeduj.2021.8(3).art.7

ABSTRACT

Aim To describe a comprehensive digital therapy oriented towards the final restoration for treating an oral maxillofacial defect caused by maxillary chondrosarcoma.

Summary The prosthetically-driven multidisciplinary approach was applied to achieve perfectly functionalaesthetic reconstruction for a male patient with maxillary chondrosarcoma. The complete tumor resection was ensured by the design of virtual osteotomy and surgical guide plate. A reverse engineering technique was used to reconstruct the bone defect in the maxillary aesthetic area, which offered reference for a threedimensional printing guide plate to shape and fix the free vascularized iliac bone flap. On the solid basis of previous treatment, the implant placement was performed under the guidance of the prosthetic-driven implant plate. Vestibular extension and tissue graft were performed to increase keratinized gingiva width to improve implant-supported fixed prosthesis effect.

Key learning points 1. A multidisciplinary approach including maxillofacial surgery, prosthodontic and periodontal treatment can provide better esthetic and functional results for complex rehabilitation of a patient with oral maxillofacial defect. 2. Predictability of maxillary reconstruction and implant restoration can be increased with prosthetic-driven treatment plan. 3. Applying preoperative virtual design and personalized guide plate is beneficial to achieve an ideal outline of reconstructed upper jaw. 4. Obtaining comprehensive aesthetic parameters of the expected restoration is one of the key principles of upper anterior teeth rehabilitation. 5. Digital technology provides an opportunity for consistency between the primary treatment design and the final restoration outcome.

\section{KEYWORDS}

Digital; Surgical guide; Implant supported restoration; Oral-maxillofacial defect; Multidisciplinary approach

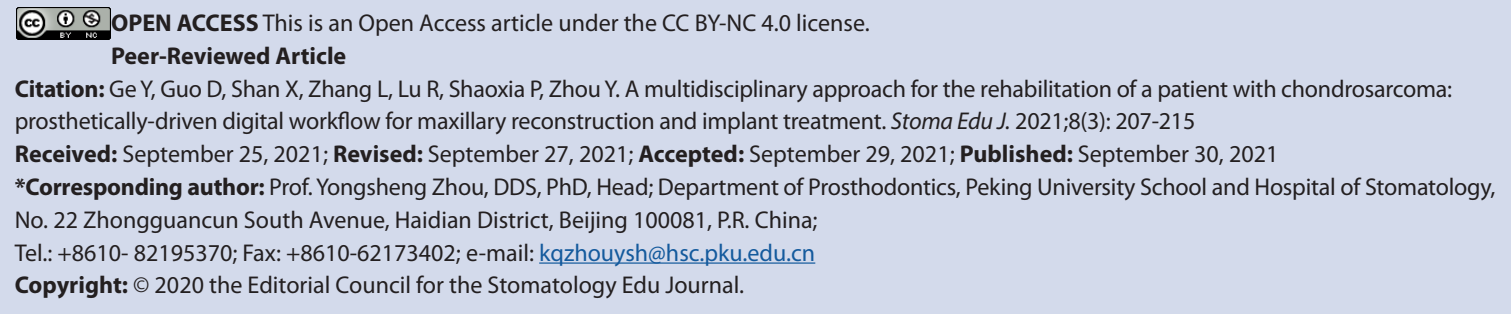




\section{INTRODUCTION}

Tumors, trauma or congenital factors mostly lead to an oral-maxillofacial defect. The maxillary defect, especially in the anterior teeth area, has a serious impact on patients from both physiological and psychological aspects, including bite, pronunciation and aesthetic functions $[1,2]$. Therefore, as a complex functional and aesthetic reconstruction, the multidisciplinary approach is urgently needed to make a comprehensive diagnosis and optimal treatment plan, which may consist in periodontal, prosthodontic, maxillofacial and implant treatment [3].

Conventional rehabilitation workflow for patients with oral cancer completes the following steps in sequence [4]. Surgery is performed to remove the affected area. The bone defect is reconstructed with a bone flap or prosthesis. When feasible, the implant and fixed restoration are used to improve the effect. Obviously, there are disadvantages of the conventional workflow to be optimized. Discontinuous procedures are difficult to ensure the treatment consistency. The diagnosis and treatment standards of different specialties are diversified and rely heavily on their experience. In summary, the complex treatment process reduces the predictability of the rehabilitation [5].

The development of digital technology provides a variety of means for the optimization of the oralmaxillofacial defect treatment, such as virtual surgery, personalized model made by rapid prototyping technique, static plate or dynamic navigation-guided surgery [6]. The application of the novel digital technology can achieve higher time efficiency and better quality of outcomes for prosthetic treatment [7]. The implant guide plate significantly reduces the error of implant surgery [8]. Precious registration of multi-source data can realize virtual aesthetic design before surgery. Most of the current scientific evidence of applying digital technique for oral-maxillofacial rehabilitation focuses on mandible reconstruction and shaping of vascularized fibular flap [5,9-12]. Literature on maxillary reconstruction in aesthetic high-risk area rehabilitated with a free vascularized iliac bone flap assisted by digital technique was rare.

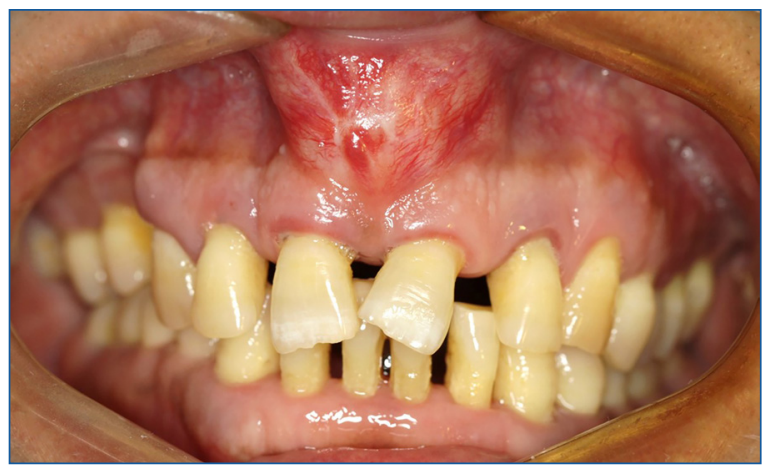

IFigure 1. A maxillary tumor with a diameter of about $3 \mathrm{~cm}$ and smooth surface on the labial side of the upper anterior teeth.
In this article, a maxillary chondrosarcoma case is reported to propose a multidisciplinary approach and prosthetically-driven digital workflow for the oral-maxillofacial rehabilitation.

\section{CASE PRESENTATION}

A 46-year-old male patient required examination and treatment with the chief complaint of a mass on the front of the maxillary and accompanied by loose upper anterior teeth for several months, and he had no relevant medical history. The general examination showed no abnormalities. The patient visited the Department of Prosthodontics, Peking University School and Hospital of Stomatology in February 2018.

There was a tough mass with a diameter of about $3 \mathrm{~cm}$ and smooth surface on the labial side of the maxilla central and lateral incisors (Fig. 1). The vestibular sulcus was swollen without bleeding and tenderness. Intraoral examination revealed tooth space among upper anterior teeth, which were I degree loose and drifted towards the mesial direction. Deep overjet and overbite were shown on anterior teeth. The first and second right maxilla premolars were missing. The relative position of the upper and lower jaws was basically normal. This patient had lots of dental calculus and poor oral hygiene. The contour of the nasal base and upper lip was obviously raised, the skin color of the lesion looking normal. There were no abnormalities in the region of the neurological lymph nodes and bilateral temporomandibular joint.

Cone beam computed tomography (CBCT) showed one circular area in the maxilla with reduced bone density and unclear boundaries closely adhering to the anterior teeth. The range of this lesion was about $5 \mathrm{~cm} \times 4 \mathrm{~cm} \times 3 \mathrm{~cm}$, in which spot and flakelike calcification were visible. The radiographic film revealed neither root canal treatment nor peri-apical resorption of upper anterior teeth (Fig. 2).

According to the clinical and radiographic examination, multidisciplinary experts consulted and gave a comprehensive diagnosis and sequential treatment plan. Firstly, the systematic periodontal treatment was performed by the periodontist.

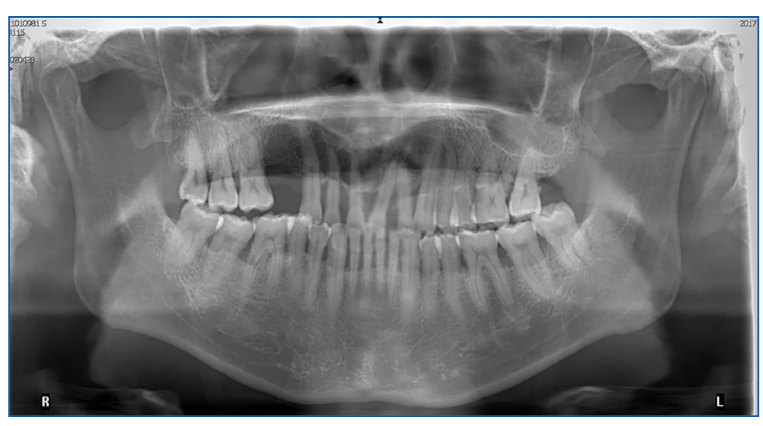

Figure 2. Pre-operative panoramic radiograph indicating the maxilla with reduced bone density and unclear boundaries lesion close to the anterior teeth. Neither root canal treatment nor peri-apical resorption of upper anterior teeth were noted. 
The oral and maxillofacial surgeons would remove the maxillary tumor and reconstruct the maxilla for implant restoration. Free gingival grafts would be performed where required. Subsequently, implant-supported fixed partial denture would be accomplished.

The current condition, treatment plan, cost and prognosis were communicated in detail to the patient. Signed informed consent, with the aid of digital technique, virtual surgical planning (VSP) and rapid prototyping technology (RP) were applied for maxillary chondrosarcoma resection and reconstruction. The free vascularized iliac bone graft surgery was performed. The CT dataset of maxillofacial and iliac were used to simulate the osteotomy operation and construct a three-dimensional maxillary defect model through reverse engineering software. Based on digital design, surgical guide plates and personalized models were made to assist in the osteotomy operation and flap fixation (Fig. 3). A full-thickness flap was raised through intraoral incision under general anesthesia. The toothsupported maxillary surgical guide was completed in place. According to the preoperative design, the maxillary lesion was excised (Fig. 4). Taking pathology analysis and examination together, the results confirmed the diagnosis of well-differentiated chondrosarcoma. According to the pathological results of frozen sections, there wereas no tumor cells at the margin. The free vascularized iliac bone flap was prepared and shaped under the guidance of the personalized plate and maxillary model. The bone flap was adequately positioned at the maxillary defect area and firmly fixed by titanium nails and plate. A vascular anastomosis was completed under the microscope for the successful reconstruction (Fig. 5). One week, three months and twelve months after surgery, a clinical examination was performed at each follow-up visit. Panoramic radiograph and CBCT showed no recurrence (Fig. 6).

After healing, plaster models were made from primary impressions. A characteristic occlusal rim was made to record the maxillo-mandibular relationship and key aesthetic parameters with radiopaque material. The Digital Imaging and Communications in Medicine (DICOM) data from CBCT and model scanning data were registered accurately. Based on the aesthetic principle, the expected restoration and implant treatment were virtually designed (Fig. 7). An implant surgical guide supported by natural teeth and lateral retention nails was made through the RP technique. A full-thickness flap was raised under local anesthesia (Primacaine adrenaline 1:100,000, Dentaires Pierre Rolland), and four implants (15,13 NobelActive ${ }^{\circledR}$ RP, 11,21 NobelActive ${ }^{\oplus}$ NP, Institut Nobel Biocare AG) were inserted with the guidance of the template (Fig. 8). Before suturing, the healing screws were connected to the implant. Ten days after surgery, the sutures were removed. The examination revealed a favorable healing process of the implant and soft tissue.

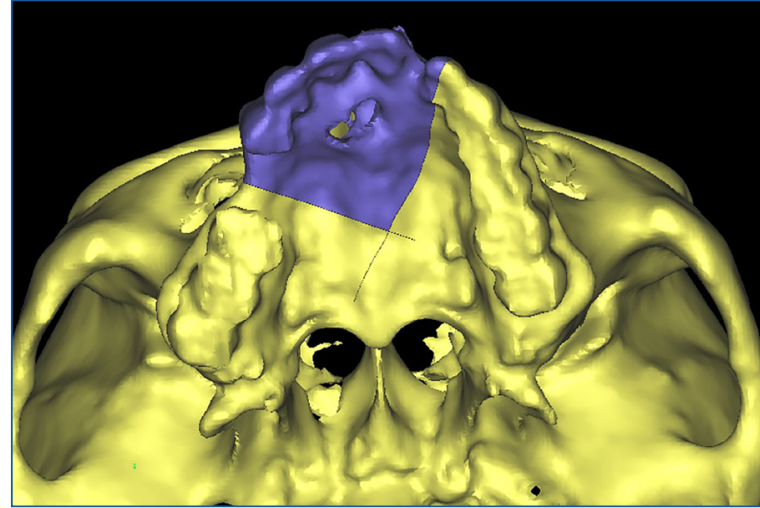

IFigure 3. (a)

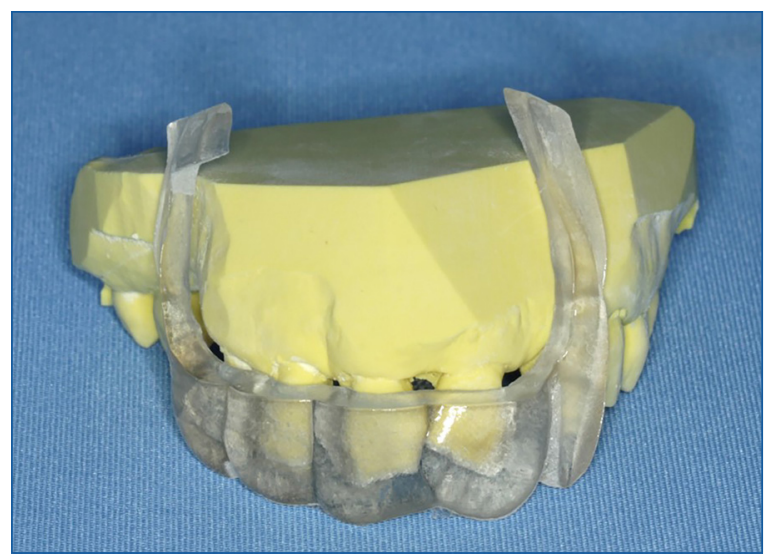

IFigure 3.(b)

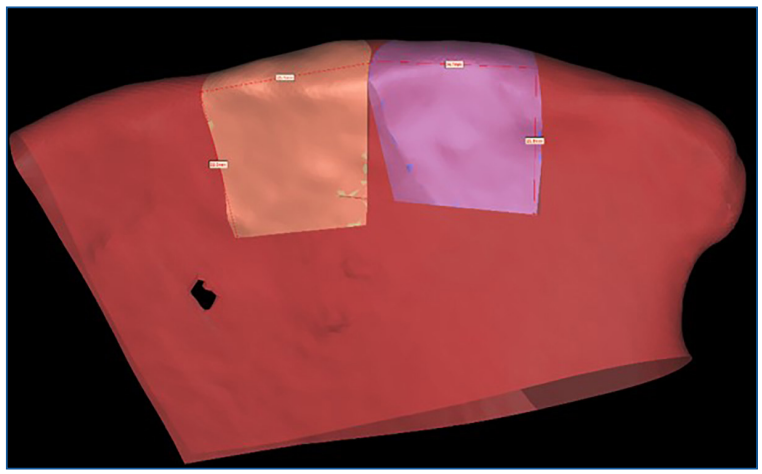

IFigure 3. (c)

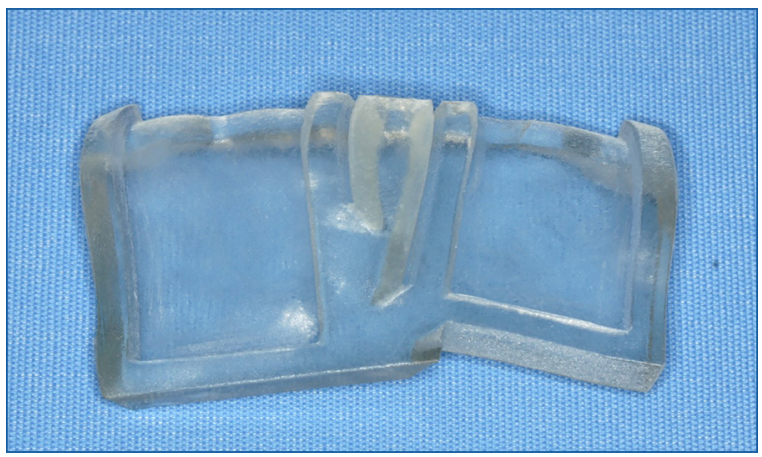

IFigure 3.(d)

I Figure 3. Virtual surgical planning (VSP) and rapid prototyping technology (RP) applying for maxillary chondrosarcoma resection and reconstruction. (a) Virtual osteotomy operation was performed using digital technique. (b) 3D printed surgical plate for radical resection of maxillary chondrosarcoma. (c) The iliac CT data were used to simulate maxillary defect reconstruction. (d) A guide plate for free vascularized iliac bone graft surgery. 


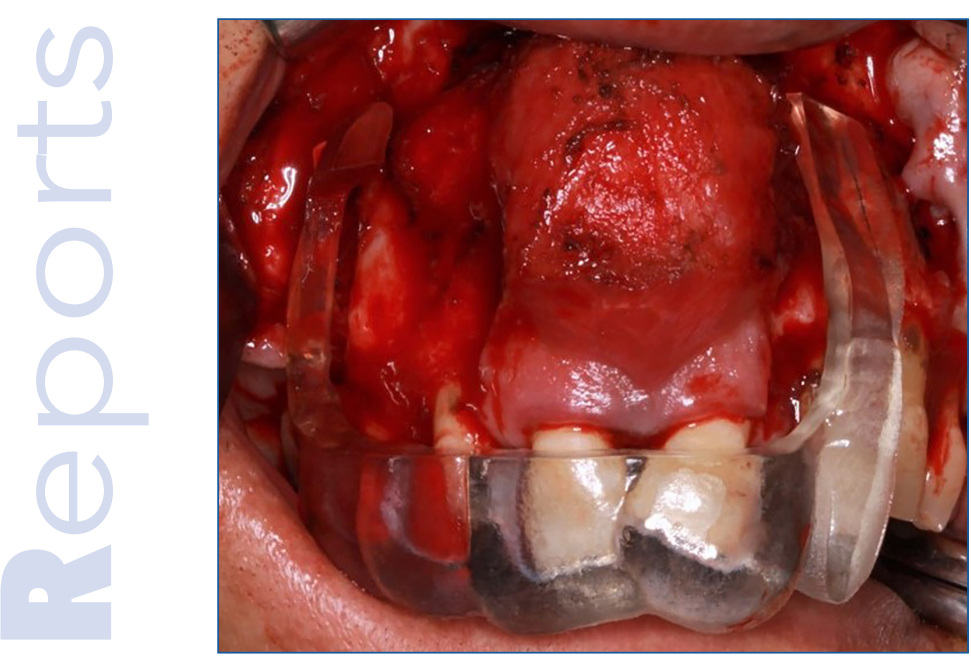

IFigure 4. (a)

I Figure 4. Resection of maxillary chondrosarcoma with the guidance of tooth-supported surgical guide. (a) The surgical guide plate was in place. (b) The maxillary lesion was excised as pre-operative design. (c) The maxillary defect after maxillofacial surgery.

I Figure 5. Maxillary reconstruction with vascularized iliac bone flap graft surgery. (a) Preparation of free vascularized iliac bone flap. (b) Shaping and fixation of flap with the personalized 3D printed model as reference. (c) The bone flap was adequately positioned at the maxillary defect area and firmly fixed. (d) Completion of vascular anastomosis.

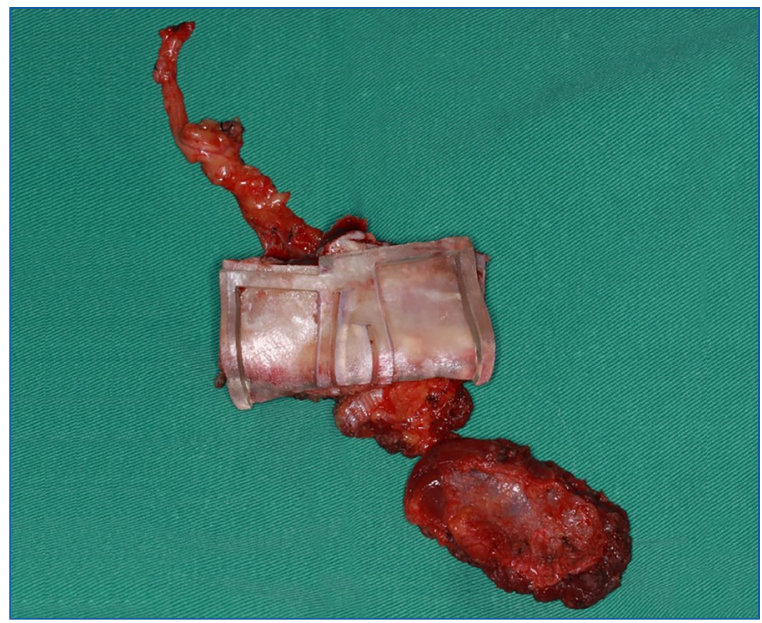

IFigure 5.(a)

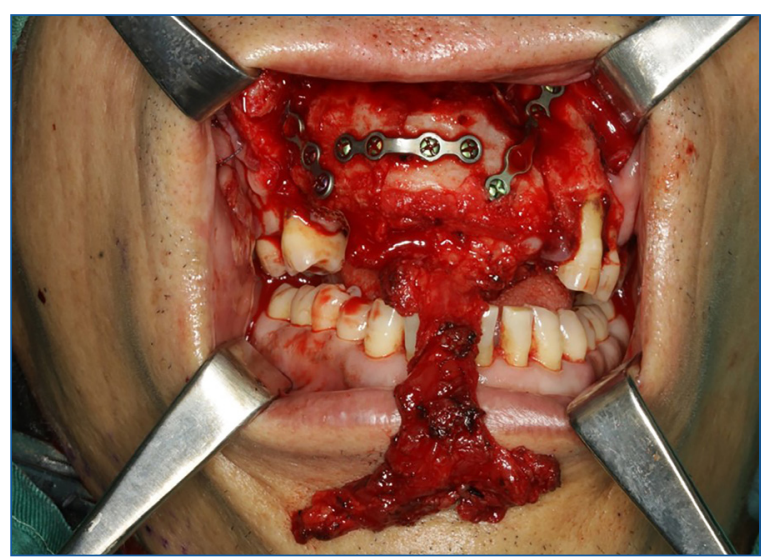

IFigure 5. (c)

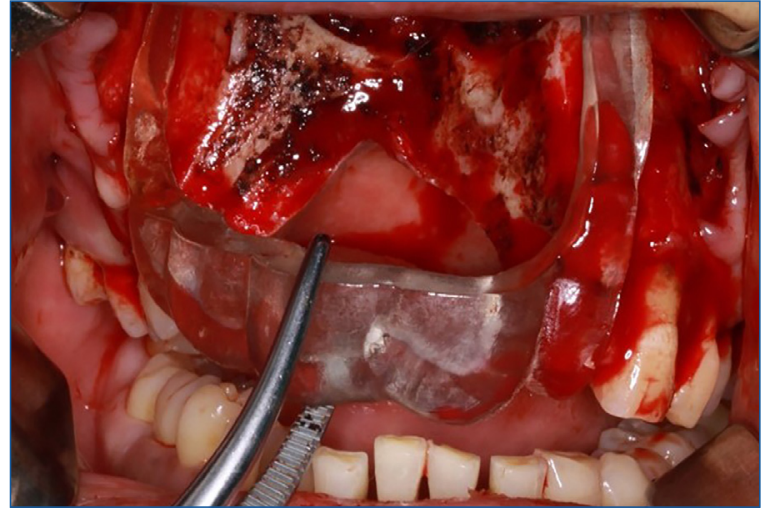

IFigure 4. (b)

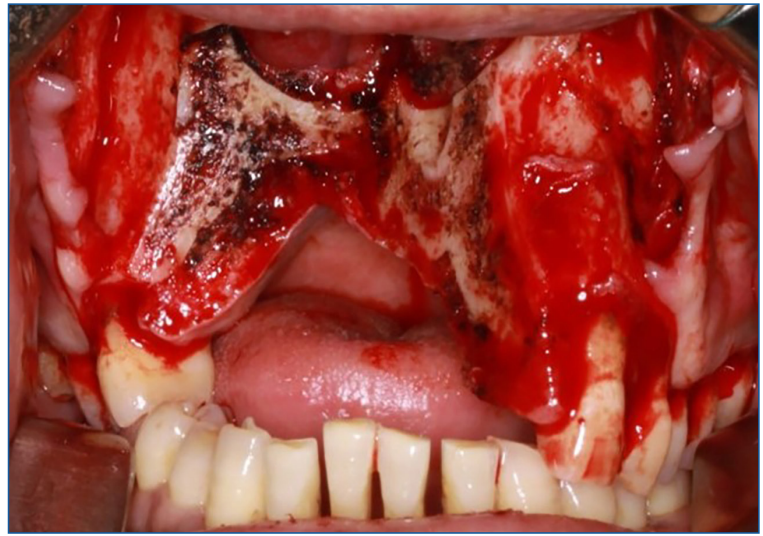

IFigure 4. (c)

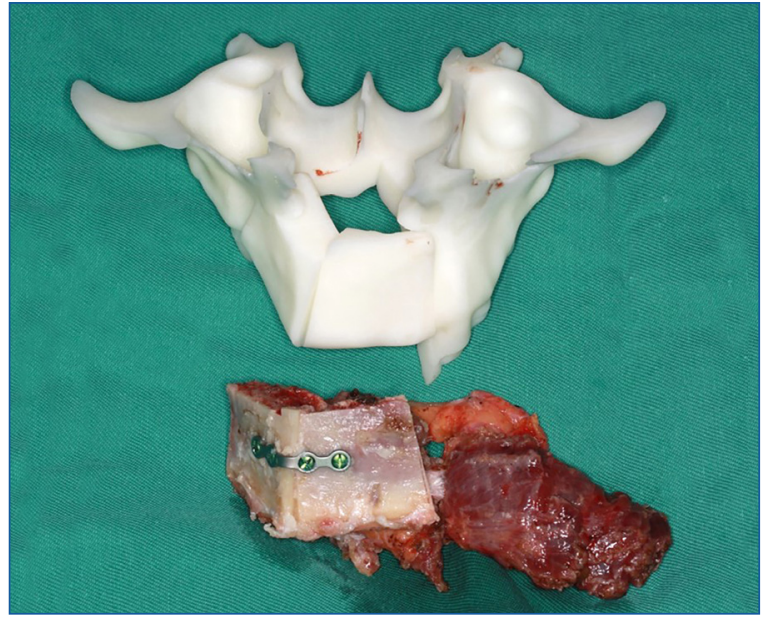

IFigure 5.(b)

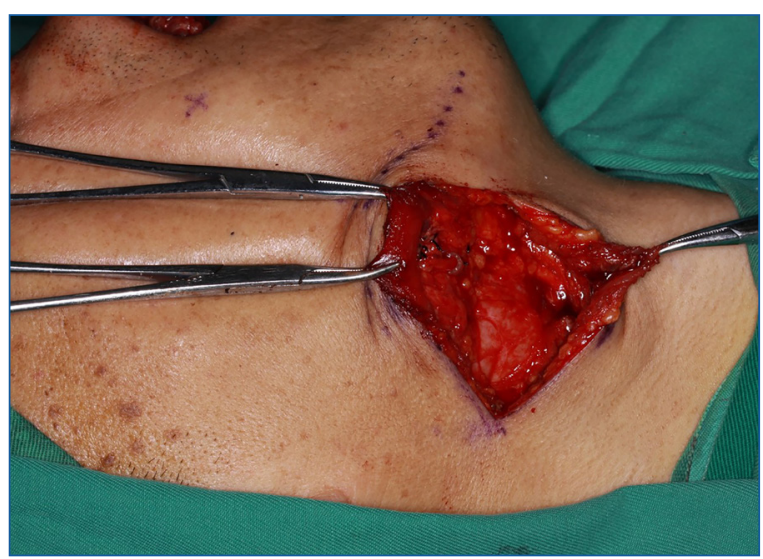

IFigure 5.(d) 


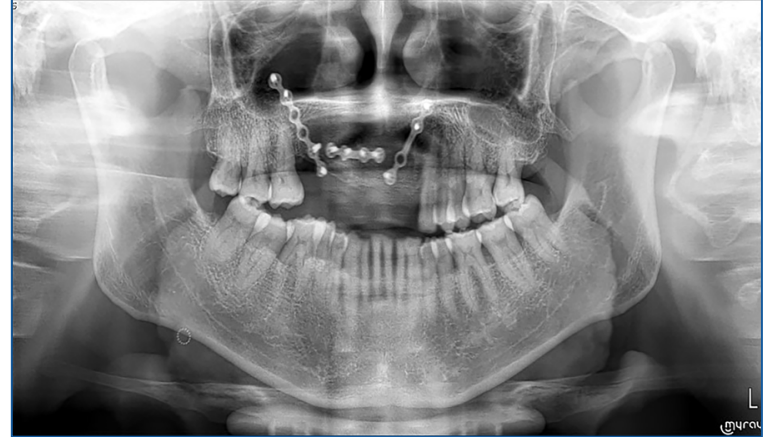

I Figure 6. Panoramic radiograph showed adequate bone for implant placement.

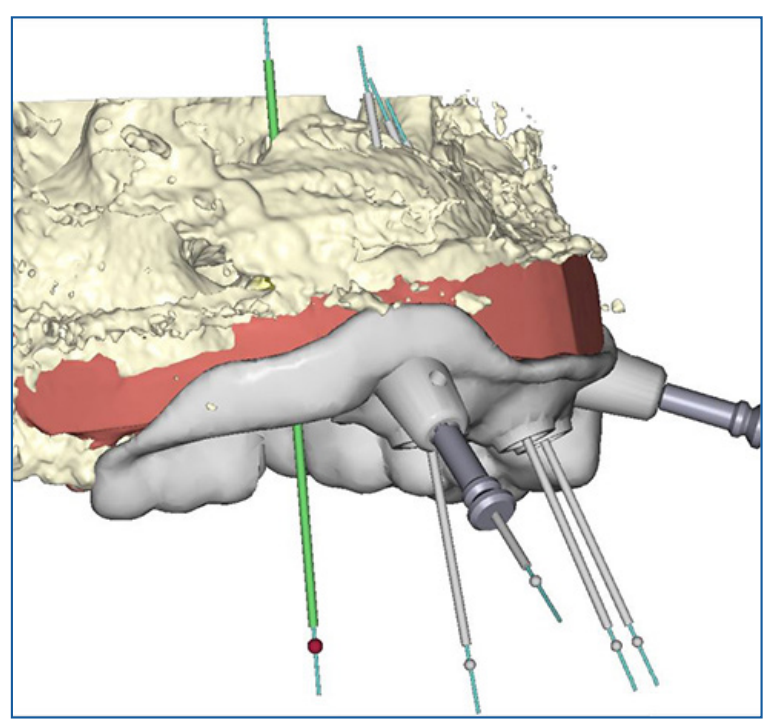

IFigure 7.(a)

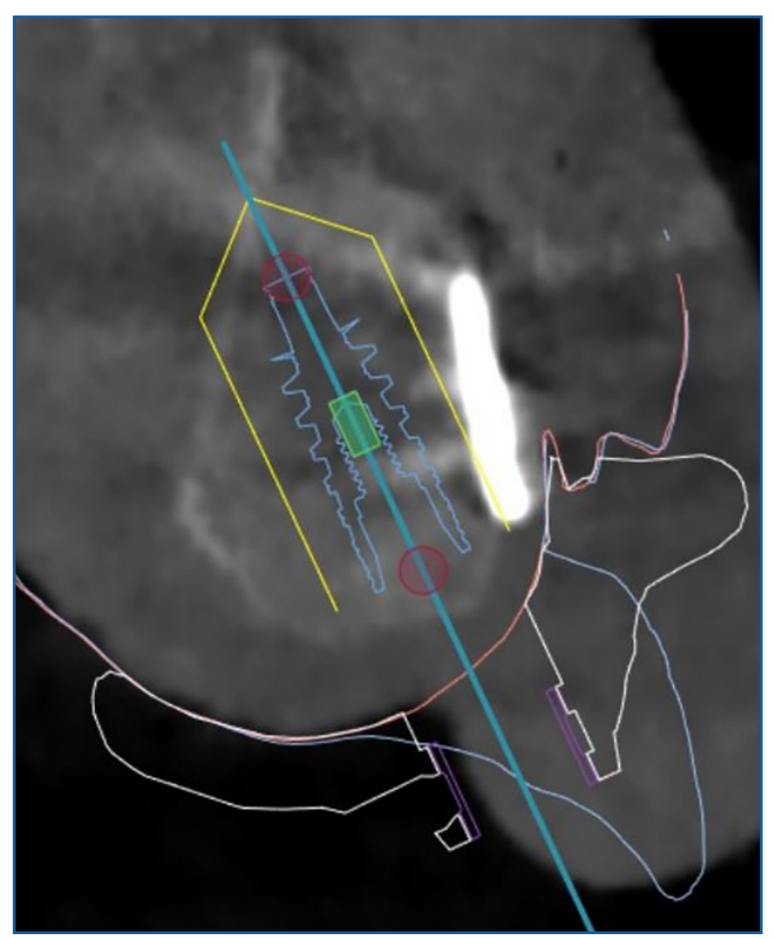

IFigure 7.(b)

I Figure 7. A prosthetically-driven virtual design for implant placement. (a) Registration of multi-source data. (b) Implant type and position were virtually designed according to the optimal restoration.

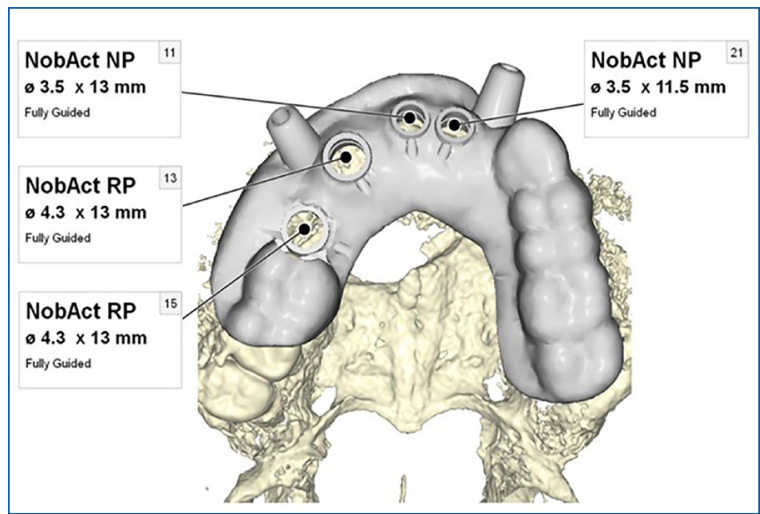

IFigure 8. (a)

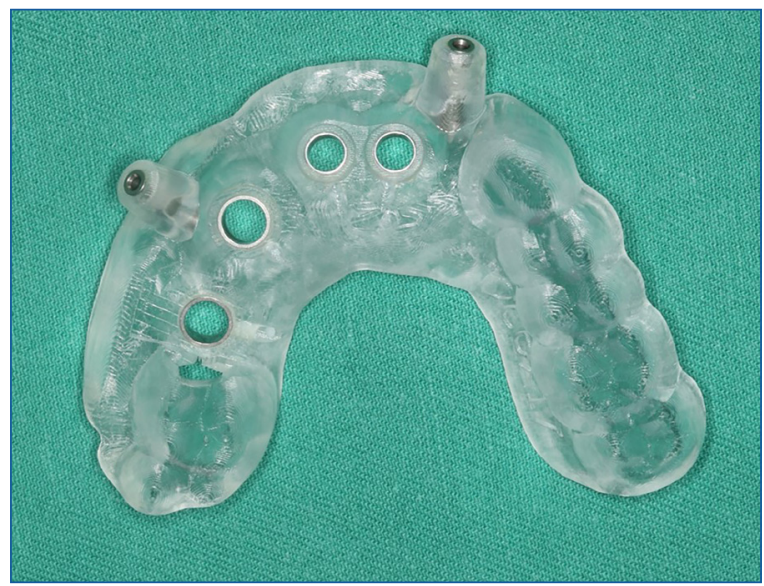

IFigure 8. (b)

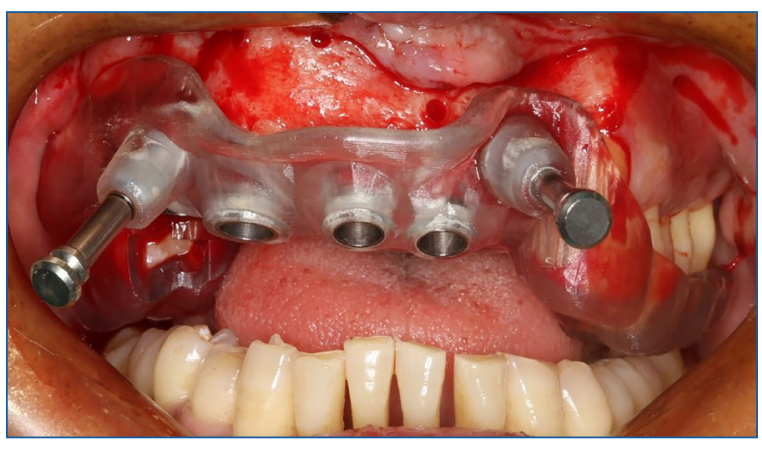

IFigure 8. (c)

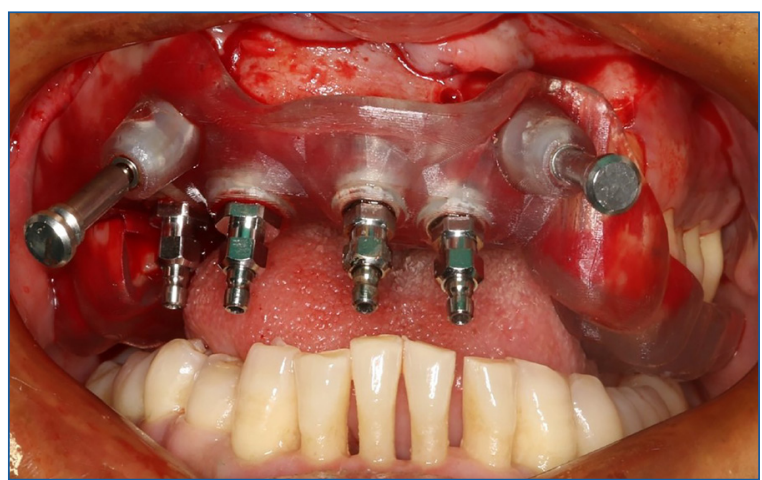

IFigure 8. (d)

I Figure 8. A restoration-oriented digital workflow for implant surgery. (a) Implant treatment was virtually designed using precious registered dataset. (b) Implant surgical guide was made by rapid prototyping technology. (c) The implant guide plate was stabilized through transverse retention nails and residual teeth. (d) Optimal implant placement under the guidance of the plate. 


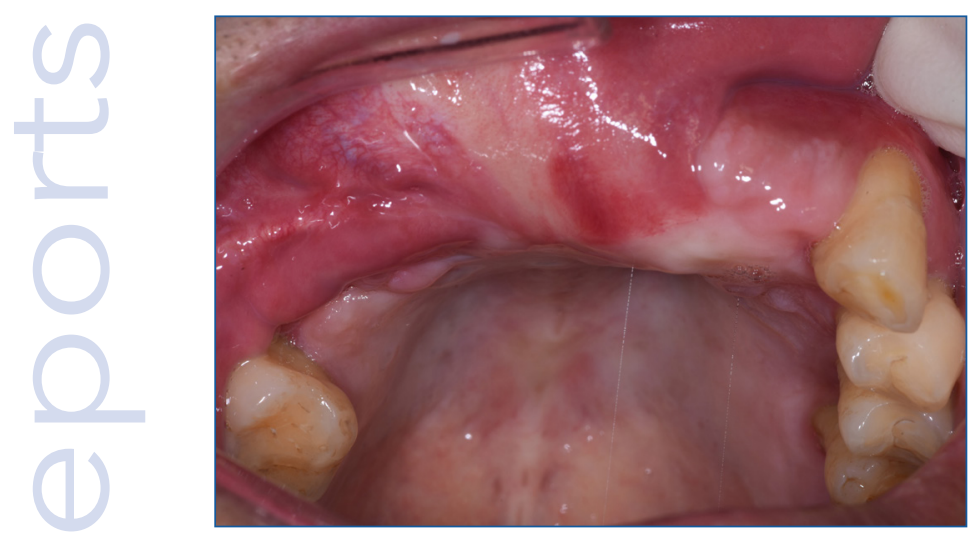

IFigure 9. (a)

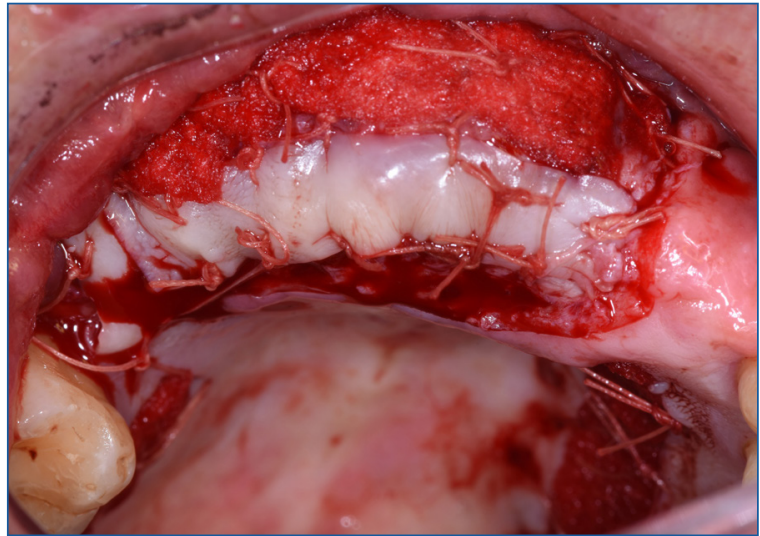

IFigure 9. (b)

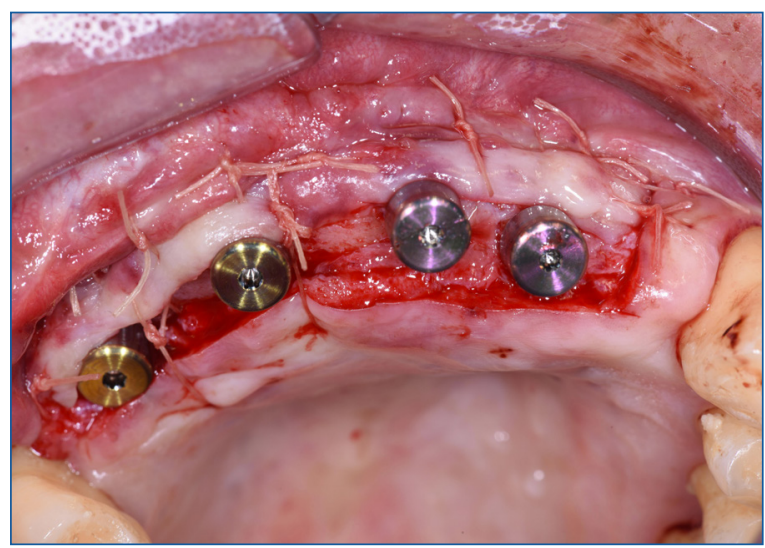

IFigure 9. (c)

I Figure 9. Tissue graft to increase width of the keratinized gingiva. (a) A deficiency of the keratinized gingiva on the buccal side of the right upper jaw. (b) Performance of vestibular extension and tissue graft. (c) The second-stage operation and apically repositioned flap surgery.

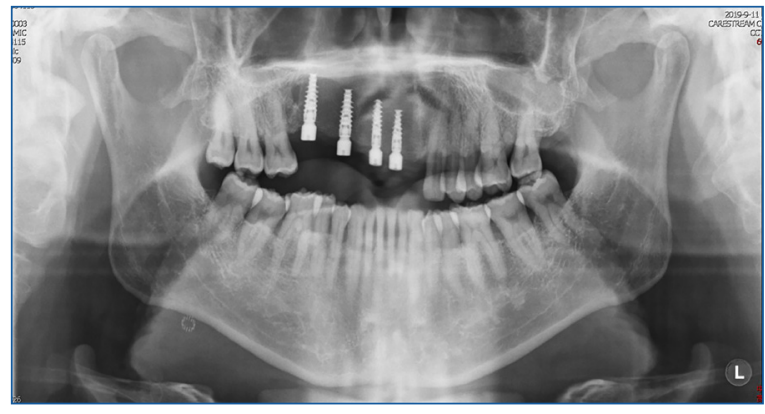

IFigure 10. Panoramic radiograph after osseointegration of implants.

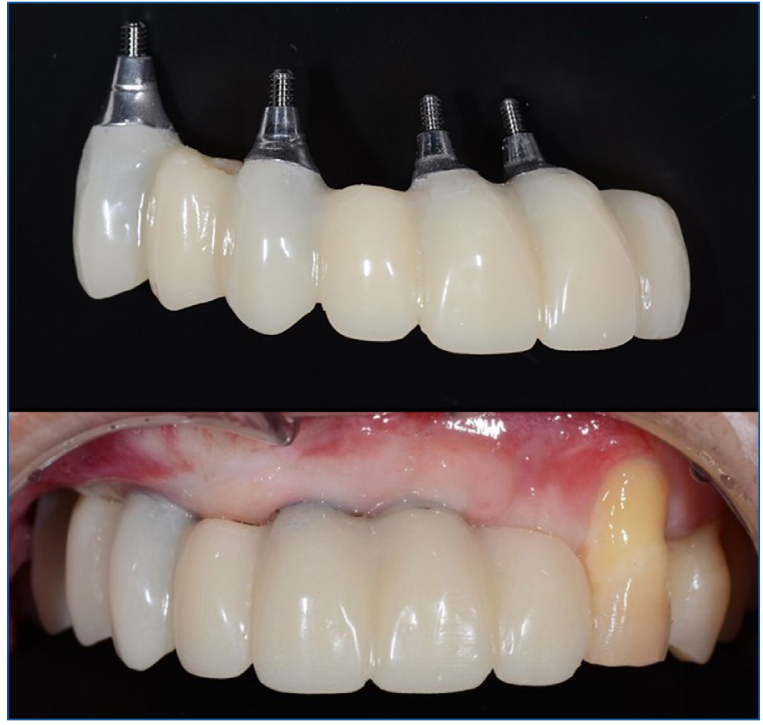

Figure 11. Temporary resin restoration milled with a 5-axis CNC machine.

Four months after surgery, the implants showed good osseointegration. Further intraoral examination showed less keratinized gingiva on the buccal side of the right upper jaw. Vestibular extension and tissue graft were performed to increase keratinized gingiva width. During the second-stage operation, the $4 \mathrm{~mm}$ buccal keratinized gingival was retained through apically repositioned flap surgery (Fig. 9). The screws were unscrewed, and the healing abutments were connected to the implants (Fig. 10).

Communicating with the patient, the final restoration was screw-retained zirconia base with labial porcelain fixed bridge. For the upper jaw, an open-tray splint implant impression was taken with a polyether material (Impregum Penta, 3M ESPE GmbH). A conventional impression of the opposing jaw was taken with alginate material (Alginoplast, Heraeus Kulzer GmbH). Temporary resin restoration was milled with a 5 -axis CNC machine. Trying in the temporary restoration, passive fit and appropriate upper lip fullness were achieved (Fig. 11). Referred to the pupil line and smile line, minus adjustment of the denture was performed on the restoration to obtain coordinated midline and incisal curve. After three months, the patient did not express discomfort. The maxillo-mandibular relationship was redetermined and transferred to the articulator by facebow. The final zirconium restoration was made with the reference of the temporary restoration. At delivery, the interproximal contact points were assessed for a strong contact using dental floss. Occlusal contact points were checked for light occlusal contacts without lateral occlusal disturbance (Arti冈Fol shimstock foil, Dr. Jean Bausch $\mathrm{GmbH} \&$ Co.). With a small amount of modified occlusal contact, the patient showed high satisfaction for the effect and comfort (Fig. 12). The panoramic radiograph showed good marginal adaptation of final restoration (Fig. 13). Twelve months after delivery, the follow-up examination revealed restoration in good condition. Oral hygiene maintenance and regular recheck were instructed (Fig. 14). 


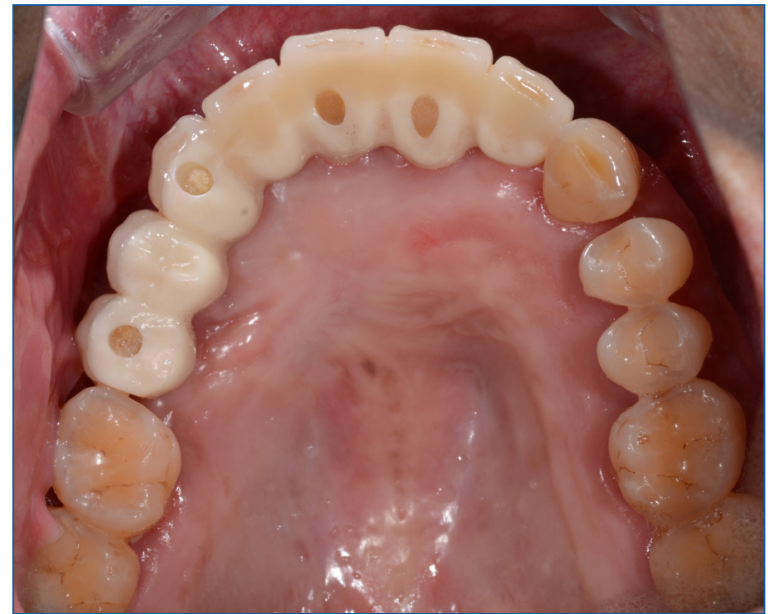

IFigure 12. (a)

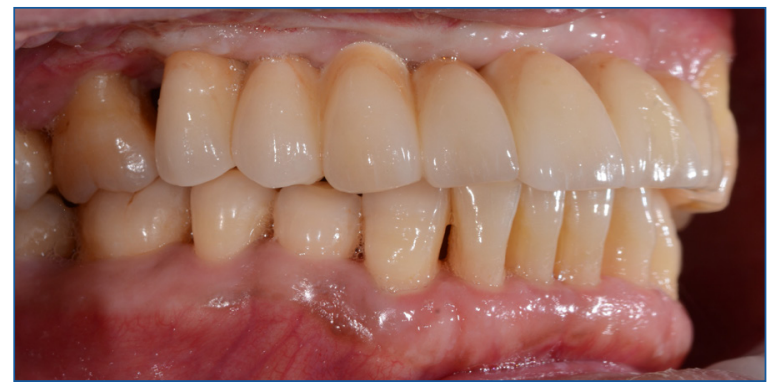

Figure 12.(b)

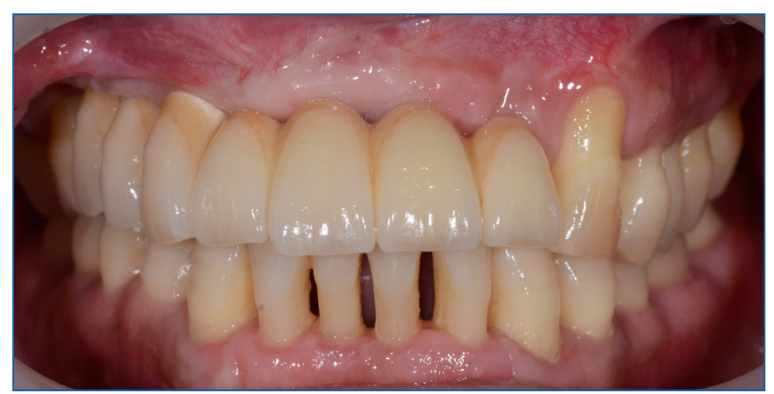

IFigure 12. (c)

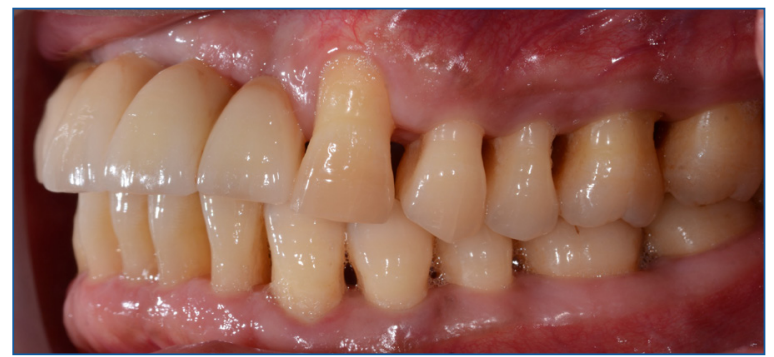

Figure 12.(d)

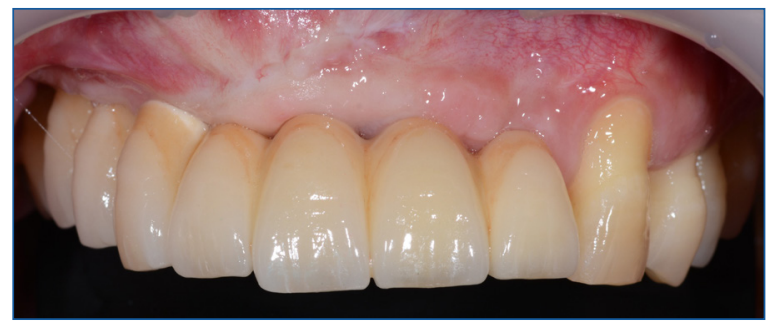

IFigure 12. (e)

I Figure 12. Perfect functional-aesthetic reconstruction with final implant supported fixed partial denture. (a) Occlusal view. (b) Centric occlusion-right. (c) Centric occlusion-left. (d) The color and contour of the restoration are consistent with adjacent teeth. (e) The gingival end of the bridge is in harmony with the soft tissue.

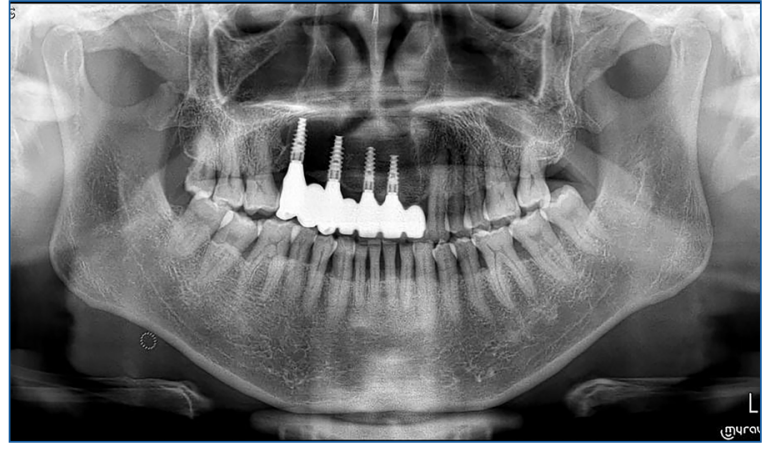

IFigure 13. Panoramic radiograph after final restoration showed passive fit.

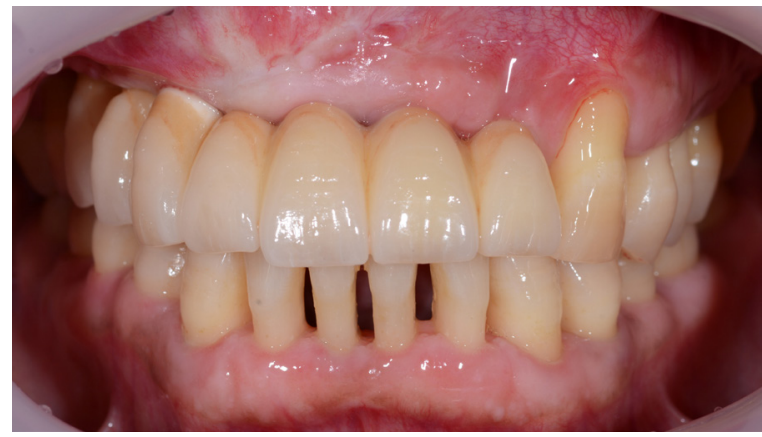

IFigure 14. (a)

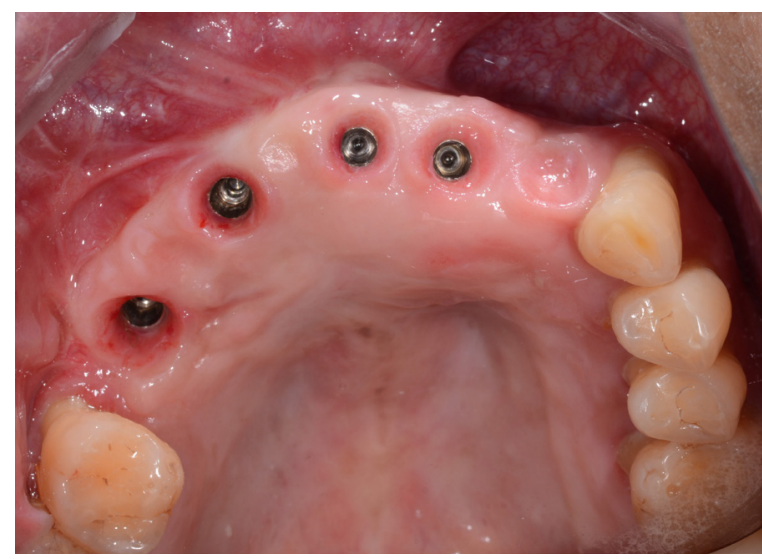

Figure 14.(b)

I Figure 14. Twelve months after delivery. (a) Restoration in good condition (b) Well maintained oral hygiene.

\section{DISCUSSION}

In this case, the patient was diagnosed with maxillary chondrosarcoma, which is a rare malignant neoplasm [13]. Chondrosarcoma(CHS) usually occurs in the pelvis, chest wall, and scapula. Maxillary chondrosarcoma is more common in men, average age range from 35 to 45 years old [14]. Maxillary chondrosarcoma may originate from the embryonic cartilage precursors of turbinate and nasal septum. According to the characteristics of the cells under the microscope, this patient is pathologically diagnosed as highly differentiated chondrosarcoma, classified as Grade I. The 5-year survival rate for patients with grade I is $89 \%$, according to WHO data $[13,15]$. Therefore, it is necessary to provide complete treatment and a rehabilitation plan for this patient to improve his survival life quality. 
Prosthetic-driven multidisciplinary approach is an important concept for maxillofacial defect rehabilitation [5]. Radical resection of the affected area of maxillary chondrosarcoma is the sole way to achieve an optimal outcome. However, common hard and soft tissue defects after resection always make it too difficult to complete optical restoration. In this case, under the guidance of final implant supported fixed restoration, the key parameters were formulated to shape the iliac bone flap, and to restore the contour and bone mass of the maxillary defect area. Based on the solid foundation, ideal implant surgery can be performed as the established design with the aid of a digital surgical guide plate. At the same time, a plan to increase the width of keratinized gingiva with palatal mucosal transplantation is made when necessary [19]. Prosthetic-driven treatment can improve the predictability of rehabilitation effect, the consistency of multidisciplinary treatment standards and the effectiveness of communication with patients.

The application of computer aided surgery (CAS) has significantly improved the accuracy and safety of the jaw reconstruction. Based on different bone defects, guided bone regeneration (GBR), onlay bone graft, distraction osteogenesis, or vascularized bone flap graft can be selected for reconstruction [17-19]. As agreed with the patient, the vascularized iliac bone flap was chosen to reconstruct his maxilla. Three common digital techniques are navigation surgery, guide plate, and a combination of navigation and plate, which can be selected according to the purpose of the operation and scope of the defect. In this case, using a static guide plate as appropriate auxiliary method to accurately guide osteotomy and fixation of the flap, consists three key steps: obtaining registered data pre-operation, virtual surgical planning, application of rapid prototype.
Implant restoration can effectively improve the rehabilitation outcome of patients with maxillofacial defects. It is reported that the cumulative survival rate of implants placed in bone flaps in jaw rehabilitation can reach $93.2 \%$ [20]. It should be noted that the long-term good prognosis of implant restoration is closely related to the dentist's treatment as well as the patient's maintenance. A reasonable preoperative design ensures a good self-cleaning for the patient. Hygiene maintenance and regular review effectively reduce complications. The limitation of this case report is that the temporary denture does not use digital preoperative design. The application of the fully digital workflow can further ensure the guiding role of the final restoration. The conventional workflow used in this case report is a time-saving and mature method. The long-term repair effect needs to be further tracked.

\section{CONCLUSION}

In this case, a new concept of multidisciplinary diagnosis and treatment approach is used to complete the maxillary reconstruction and implant supported fixed restoration for the maxillary chondrosarcoma patient. The prosthetic-driven workflow can achieve the consistency of complex treatment standards and improve the predictability of the restoration. The accuracy and efficiency of the treatment are improved with digital technology.

\section{CONFLICT OF INTEREST}

The authors declare no conflict of interest.

\section{ACKNOWLEDGMENTS}

None

\section{AUTHOR CONTRIBUTIONS}

* Yanjun Ge and Danni Guo have equally contributed as first authors. DG and YG collected data and wrote the original draft. YG, XS, LZ and $\mathrm{RL}$ performed the clinical treatment. SP and $Y Z$ lead the writing and revised the manuscript.

\section{REFERENCE}

1. Warnakulasuriya S. Global epidemiology of oral and oropharyngeal cancer. Oral Oncol. 2009 Apr-May;45(4-5):309-316. doi: 10.1016/j.oraloncology.2008.06.002. Epub 2008 Sep 18. PMID: 18804401.

Full text links CrossRef PubMed Google Scholar Scopus WoS 2. Brown JS, Shaw RJ. Reconstruction of the maxilla and midface: introducing a new classification. Lancet Oncol. 2010 Oct;11(10):10011008. doi: 10.1016/S1470-2045(10)70113-3. PMID: 20932492. Full text links CrossRef PubMed Google Scholar Scopus WoS 3. Zhang DS, Zheng JW, Zhang CP, et al. [Multidisciplinary team model for patients with oral cancer and systemic diseases: an expert consensus]. Hua Xi Kou Qiang Yi Xue Za Zhi. 2020 Dec 1;38(6):603-615. Chinese. doi: 10.7518/hxkq.2020.06.001. PMID: 33377335; PMCID: PMC7738912.

Full text links PubMed Google Scholar Scopus WoS

4. Levine JP, Bae JS, Soares M, et al. Jaw in a day: total maxillofacial reconstruction using digital technology. Plast Reconstr Surg. 2013 Jun;131(6):1386-1391. doi: 10.1097/PRS.0b013e31828bd8d0. PMID: 23714799.

Full text links PubMed Google Scholar Scopus WoS

5. Tian T, Zhang T, Ma Q, et al. Reconstruction of mandible: a fully digital workflow from visualized iliac bone grafting to implant restoration. J Oral Maxillofac Surg. 2017 Jul;75(7):1403.e1-1403.e10. doi: 10.1016/j.joms.2017.02.022. Epub 2017 Mar 7. PMID: 28359016. Full text links CrossRef PubMed Google Scholar Scopus WoS 6. Zhang HQ, Li QX, Wang YY, et al. Combination of biomechanical evaluation and accurate placement of dental implants: a new concept of virtual surgery in maxillary and mandibular functional reconstruction. Br J Oral Maxillofac Surg. 2020 Jan;58(1):62-68. doi: 10.1016/j.bjoms.2019.10.310. Epub 2019 Nov 11. PMID: 31718915. Full text links PubMed Google Scholar Scopus WoS 7. Pan S, Guo D, Zhou Y, et al. Time efficiency and quality of outcomes in a model-free digital workflow using digital impression immediately after implant placement: a double-blind self-controlled clinical trial. Clin Oral Implants Res. 2019 Jul;30(7):617-626. doi: 10.1111/clr.13447. Epub 2019 May 13. PMID: 31021451.

Full text links CrossRef PubMed Google Scholar Scopus WoS 8. Liu X, Liu J, Feng H, Pan S. Accuracy of a milled digital implant surgical guide: an in vitro study. J Prosthet Dent. $2020 \mathrm{Dec} 10: 50022$ 3913(20)30654-5. doi: 10.1016/j.prosdent.2020.07.041. Epub ahead of print. PMID: 33309294

Full text links PubMed Google Scholar Scopus

9. Qiu SY, Kang YF, Ding MK, et al. Mandibular reconstruction with the iliac flap under the guidance of a series of digital surgical guides. J Craniofac Surg. 2021 Jul-Aug 01;32(5):1777-1779. doi: 10.1097/ SCS.0000000000007494. PMID: 33534315.

Full text links CrossRef PubMed Google Scholar Scopus WoS 10. Harbison RA, Shan XF, Douglas Z, et al. Navigation guidance during free flap mandibular reconstruction: a cadaveric trial. JAMA Otolaryngol Head Neck Surg. 2017 Mar 1;143(3):226-233. doi: 10.1001/ jamaoto.2016.3204. Erratum in: JAMA Otolaryngol Head Neck Surg. 2017 Mar 1;143(3):318. PMID: 27893003; PMCID: PMC8025841.

Full text links PubMed Google Scholar Scopus WoS

11. Nguyen TTH, Eo MY, Myoung H, et al. Implant-supported fixed and removable prostheses in the fibular mandible. Int J Implant Dent. 2020 Aug 11;6(1):44. doi: 10.1186/540729-020-00241-7. PMID: 32778982; PMCID: PMC7417466.

Full text links CrossRef PubMed Google ScholarWoS 
12. Kataoka T, Akagi Y, Kagawa C, et al. A case of effective oral rehabilitation after mandibular resection. Clin Case Rep. $2019 \mathrm{Sep}$ 27;7(11):2143-2148. doi: 10.1002/ccr3.2459. PMID: 31788267; PMCID: PMC6878091.

Full text links CrossRef PubMed Google Scholar Scopus WoS 13. de Souza LL, Pontes FSC, Fonseca FP, et al. Chondrosarcoma of the jaw bones: a review of 224 cases reported to date and an analysis of prognostic factors. Int J Oral Maxillofac Surg. 2019 Apr;48(4):452-460. doi: 10.1016/j.jom.2018.11.006. Epub 2018 Dec 6. PMID: 30528199.

Full text links CrossRef PubMed Google Scholar Scopus WoS

14. Karadwal A, Chatterjee S. Chondrosarcoma of maxilla. J Oral Maxillofac Pathol. 2018 Jan;22(Suppl 1):S35-S38. doi: 10.4103/jomfp. JOMFP_169_15.PMID: 29491602; PMCID: PMC5824514.

Full text links PubMed Google Scholar

15. Cuevas-Gonzalez JC, Reyes-Escalera JO, Gonzalez JL, et al. Primary maxillary chondrosarcoma: a case report. World J Clin Cases. 2020 Jan 6;8(1):126-132. doi: 10.12998/wjcc.v8.i1.126. PMID: 31970178; PMCID: PMC6962084.

Full text links PubMed Google Scholar Scopus WoS

16. De Cicco D, Colella G, Tartaro G, et al. Wide anterior maxillary reconstruction with equine bone xenograft: a case report of 24-month follow-up. Case Rep Surg. 2020 Oct 21;2020:8890935. doi: 10.1155/2020/8890935. PMID: 33145117; PMCID: PMC7596435. Full text links CrossRef PubMed Google Scholar WoS
17. Zhang WB, Peng X, Yu Y, et al. Expert consensus for the treatment algorithm for navigation assisted reconstruction of maxillofacial deformities. Chin J Dent Res. 2020;23(1):33-42. doi: 10.3290/j.cjdr.a44334. PMID: 32232227.

Full text links PubMed Google Scholar Scopus

18. Kang YF, Liang J, He Z, et al. Orbital floor symmetry after maxillectomy and orbital floor reconstruction with individual titanium mesh using computer-assisted navigation. J Plast Reconstr Aesthet Surg. 2020 Feb;73(2):337-343. doi: 10.1016/j. bjps.2019.07.014. Epub 2019 Aug 7. PMID: 31477492.

Full text links CrossRef PubMed Google Scholar Scopus WoS

19. Li R, Meng Z, Zhang Y, et al. Soft tissue management: a critical part of implant rehabilitation after vascularized free-flap reconstruction. J Oral Maxillofac Surg. 2021 Mar;79(3):560-574. doi: 10.1016/j.joms.2020.11.006. Epub 2020 Nov 14. PMID: 33279473.

Full text links PubMed Google Scholar Scopus WoS 20. Zhang L, Ding Q, Liu C, et al. Survival, function, and complications of oral implants placed in bone flaps in jaw rehabilitation: a systematic review. Int J Prosthodont. 2016 MarApr;29(2):115-25. doi: 10.11607/ijp.4402. PMID: 26929947. Full text links CrossRef PubMed Google Scholar Scopus WoS

Dr. Ge, DDS, has been a prosthodontist and lecturer at Peking University School and Hospital of Stomatology since 2009. As an ITI member, he carried out a large number of implant treatments using digital technology. He is good at and responsible for treating prosthetic patients, especially complex case treated with the multidisciplinary approach.

\section{0uestions}

\section{What is the average age range of male patients with maxillary chondrosarcoma?}
a. 40 to 55 ;
b. 35 to 45 ;
c. 25 to 36 ;
d. 65 to 75 .

\section{Which of the following options is not a method for maxillofacial surgery to reconstruct the maxilla?}

$\square$ a. Distraction osteogenesis;

b. Vascularized bone flap graft;

c. GBR;

d. Obturator.

\section{Which is the digital method commonly used in computer-assisted surgery?}

$\square$ a. Navigation surgery;

$\square$ b. Surgical guide plate;

$\square$ c. Virtual surgical planning;

$\square \mathrm{d}$. All of the above.

\section{What is the retention survival rate of implants on the bone flap (jaw reconstruction)?}
a. $78.5 \%$;
b. $93.2 \%$;
c. $96.8 \%$;
d. $89.7 \%$. 

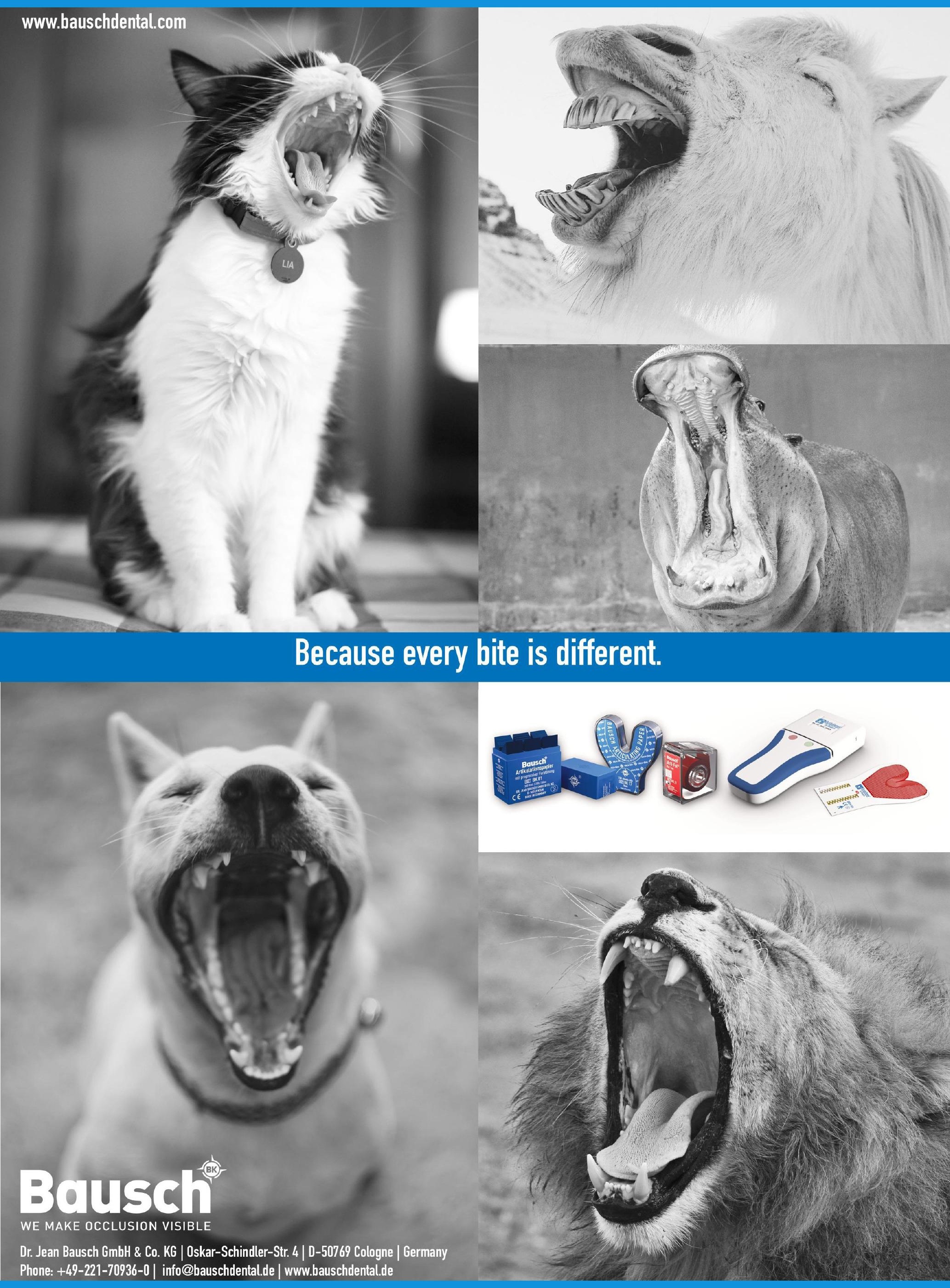


\section{THE GOLD STANDARD IN LASER DENTISTRY - SIROLASER BLUE}

The term LASER is an acronym for "Light Amplification by the Stimulated Emission of Radiation". Since its in dentistry in 1960 by Miaman and its application to oral hard and soft tissues, notable progress has been made. The laser treatment has proven to be more expensive than traditional treatment, but, as laser reduces bacterial levels and postoperative pain, it is an effective tool for increasing the efficiency, specificity, ease and comfort of dental treatment. Oral hard and soft tissues have a specific affinity for absorbing laser energy with a certain wavelength. A dental laser wavelength is the decisive factor for the level at which the laser energy is absorbed by the target tissue. The laser selection depends on the target tissue that the practitioner wants to treat. The energy radiated by the laser is basically a single color light (monochrome) and therefore a single wavelength. Currently, the practitioner has the opportunity to choose from a series of lasers, one of a single color, which he considers most useful for his daily practice.

The therapeutic indications of SiroLaser Blue depending on the color of the wavelength.

\section{Blue wavelength - $445 \mathrm{~nm}$}

The blue laser light has a much higher degree of soft tissue absorption than conventional wavelengths of infrared lasers (810 nm, $940 \mathrm{~nm}, 970 \mathrm{~nm})$. It provides a much improved soft tissue cutting efficiency without bleeding in the sterile surgical field, allows a non-contact cutting, a does not require the removal of tissue residue from the fiber during treatment. Due to the high level of hemoglobin absorption, the hemostatic effect is remarkable, which is an advantage in all surgical treatments, as well as in the CAD / CAM work-flow.

The patient has significantly lower postoperative pain, often does not need antibiotics and benefits from healing almost without scarring.

\section{Infrared wavelength - $970 \mathrm{~nm}$}

The use of infrared laser light contributes to an improved reduction of germs in endo, perio and implantation treatments.

In endodontics, the laser is used after preparing and

Here are the technical data of the SiroLaser Blue:

\begin{tabular}{|l|l|}
\hline $\begin{array}{l}\text { Wavelength and } \\
\text { operating performance }\end{array}$ & $\begin{array}{l}445 \mathrm{~nm}+/-5 \mathrm{~nm} / 0.2-3.0 \mathrm{~W} \text { (CW) } \\
660 \mathrm{~nm}+/-5 \mathrm{~nm} / 25,50 \text { and } 100 \mathrm{~mW} \text { (CW) } \\
970 \mathrm{~nm}-10 /+15 \mathrm{~nm} / 0.2-2.0 \mathrm{~W} \text { (CW) }\end{array}$ \\
\hline Laser operating mode & $\begin{array}{l}\text { Continuous Wave } \\
\text { Chopped Mode }\end{array}$ \\
\hline Frequency & $1-10.000 \mathrm{~Hz}$ \\
\hline Duty cycle & Variable \\
\hline Weight & $\sim 1,3 \mathrm{~kg}$ (incl. handpiece and battery) \\
\hline Dimensions & $\sim 19,7 \mathrm{~cm} \times 18,2 \mathrm{~cm} \mathrm{\times} \mathrm{18,9cm}$ \\
\hline
\end{tabular}

SiroLaser Blue is the world's first diode laser that includes a blue diode, an infrared diode and a red diode. All these different shapes make it a versatile tool for laser treatment suitable for different dental applications.

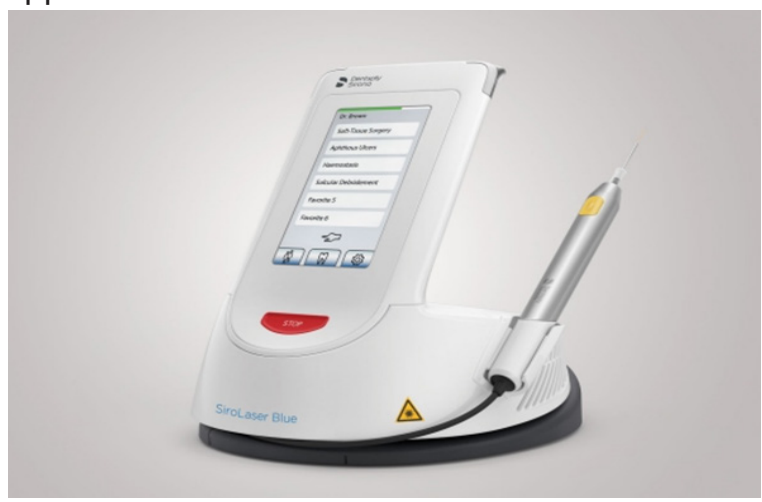

Dental diode laser - SiroLaser Blue Dentsply Sirona

\section{Sirona Dental Systems GmbH}

Fabrikstraße 31, DE-64625 Bensheim Germany

https://www.dentsplysirona.com

washing the root canal to effectively reduce germs and bacteria in areas where an irrigation fluid can never reach, leading to a better long-term prognosis. In periodontics and implantology, within the sanitization procedure, the laser supplements the descaling, contributing to the improvement of the periodontium condition, without surgery and with minimal discomfort. It also ensures the exposure of the implant, decontamination and the realization of clear preparation margins for fingerprints and scans.

\section{Red wavelength - $660 \mathrm{~nm}$}

The red laser light is used for Photobiomodulation (PBM), also known as Low-Level-Laser-Therapy (LLLT). Photobiomodulation works by applying the photonic energy of the light to the tissue. It penetrates the skin barrier and is absorbed by cells, where it initiates physiological reactions with mitochondria.

Photobiomodulation can be used in clinical cases of temporomandibular joint dysfunction (TMJD), TMJ pain, muscle masseter pain, mouth opening limitation, burning mouth-syndrome, dentin hypersensitivity, wound healing.

The technical possibilities provided by SiroLaser Blue, the world's first diode laser with three different colors, allows the practitioner to use a versatile tool that provides comfort for the appropriate laser treatment for over 20 different dental applications.

Florin - Eugen Constantinescu DMD, PhD Student Editorial Director, Product News 



\section{The Vertical Dimension in prosthesis and orthognathodontics \\ Integration between function and aesthetics}

\author{
Author: Nazzareno Bassetti \\ Publisher: Edra S.p.A., Italy \\ Language: English \\ ISBN: 978-8-821-45039-6 \\ Edition: $1 / \mathrm{e}$
}

Publish Year: 2019

Pages: 224, illustrated

Price: $€ 109,00$

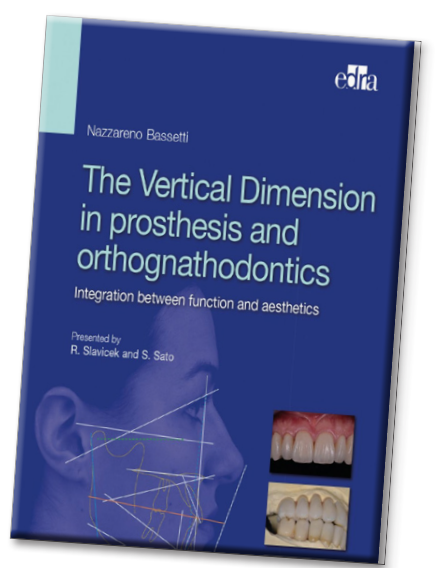

Marian-Vladimir

Constantinescu

$\mathrm{DDS}, \mathrm{MSC}, \mathrm{PhD}$

Holistic Dental \& Medical Institute

of Bucharest - ROPOSTURO

Bucharest, Romania

e-mail: dr.vladimir.constantinescu@gmail.com

Forever interested in perfecting his dental art, Dr. Nazzareno Bassetti attended the courses of Profs. Slavicek, Sato and Mehta from Donau University in Krems, Austria to obtain a master's degree in science (M.Sc.) in "Therapy of Masticatory Organ's Dysfunctions".

The theoretical knowledge accumulated is rigorously applied in his current practice both for cases that required dental prosthesis treatments, orthognathodontics, implant-prosthetic approach, and for complex cases that required a multidisciplinary approach.

"The Vertical Dimension in prosthesis and orthognathodontics" follows the approach to the patient as seen by the Vienna School of Interdisciplinary Dentistry (VieSID), so the author presents successful treatments using an individualized diagnosis and therapeutic process, finding the vertical dimension and mandibular repositioning that restore the correct combination between aesthetics and the function of the stomatognathic system.

The book is divided in eight chapters and ends with three case reports convincingly described and illustrated. Starting from the transversality of gnathologic principles, the analog and digital gnathologicdiagnostic flow are presented in detail. A separate chapter analyzes facial macroaesthetics related to the mandibular position. After approaching the occlusal plane and craniofacial development, dentition development is presented from the perspective of occlusal concepts.

Digital functional smile design (DFSD), three-dimensional management of the vertical dimension and gnathologically-guided implantology concepts are described in the vertical dimension project according to VieSID.

The key to the success of oral rehabilitation is knowledge of the mandibular repositioning techniques, Occlusal Mandibular Repositioning Technique - OMRT (Bassetti), Therapeutic Provisional and Rehabilitative Orthodontics Technique - MEAW (Sato) or Early Mandibular Repositioning Technique - EMRT. The last chapter makes a sequential presentation of the ten key points that ensure the success of the treatment plan.

Through this book accompanied by a vast iconography (approximately 700 images) Dr. Bassetti manages to successfully put into practice the theories developed for the last fifteen years by Prof. Dr. Rudolf Slavicek within VieSID.

The book addresses all practitioners concerned with oral rehabilitation, orthodontists, prosthodontists, implantologists and dental technicians, as they all need a motivated gnathological evaluation of their interventions. 


\section{Florin-Eugen}

Constantinescu

DMD, PhD Student

Holistic Dental \& Medical Institute

of Bucharest - ROPOSTURO

Bucharest, Romania

e-mail: dr.florin.constantinescu@gmail.com

\section{Regenerative Approaches in Dentistry An Evidence-Based Perspective}

Editors: Sepanta Hosseinpour,

Laurence J. Walsh, Keyvan Moharamzadeh

Publisher: Springer Nature, Switzerland

Language: English

ISBN: 978-3-030-59808-2

Edition: $1 / \mathrm{e}$

Publish Year: 2021

Pages: 267, Illustrated

Price: $€ 171,19$

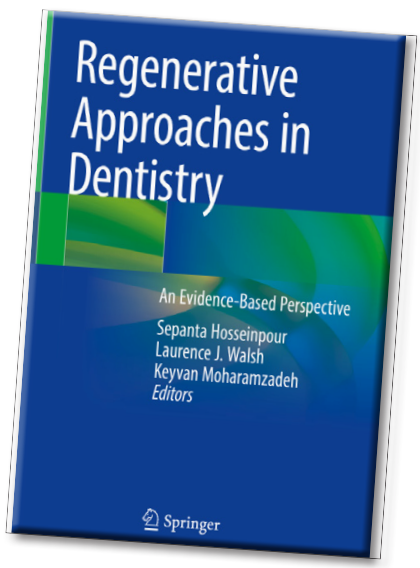

Dr. Sepanta Hosseinpour, PhD Student at The University of Queensland, Australia, Laurence J. Walsh, Professor of Dental Science at the School of Dentistry, University of Queensland, Australia, and Keyvan Moharamzadeh, Professor of Endodontics at Hamdan Bin Mohammed College of Dental Medicine (HBMCDM), Mohammed Bin Rashid University of Medicine and Health Sciences (MBRU) in Dubai, United Arab Emirates (UAE), as editors together with 34 international contributors provides us with the latest evidence-based information in the field of regenerative dentistry.

"Regenerative Approaches in Dentistry" is divided in 10 chapters, with a special focus on current and potential future clinical applications.

This book manages to collect and compare what has been done to provide evidence-based information on this emerging field of dentistry. The book aims to educate readers about the different therapeutic methods used in the reconstruction of hard and soft tissues in the maxillofacial region. It covers the regeneration of the alveolar bone, the dentinpulp complex, the enamel, the periodontium and the tissues associated with the oral cavity. It provides a complete description of regenerative approaches in dentistry, namely in regenerative endodontics and dental repair, regenerative periodontics, regenerative assisted orthodontics, regenerative approaches in oral medicine and stem cells derived from dental tissue and their potential applications.

The book, written by an international team of renowned experts, provides evidence-based information in the field of regenerative dentistry and is aimed at students (at both undergraduate and postgraduate levels), practitioners and researchers in the fields of endodontics, periodontics and implantology. 


\section{New Trends in Myofunctional Therapy \\ Occlusion, Muscle and Posture}

Authors: Sabina Saccomanno,

Licia Coceani Paskay

Publisher: Edi.Ermes, Italy

Language: English

ISBN: 978-88-7051-629-6

Edition: 1/e

Publish Year: 2020

Pages: 330, illustrated

Price: $€ 68,00$

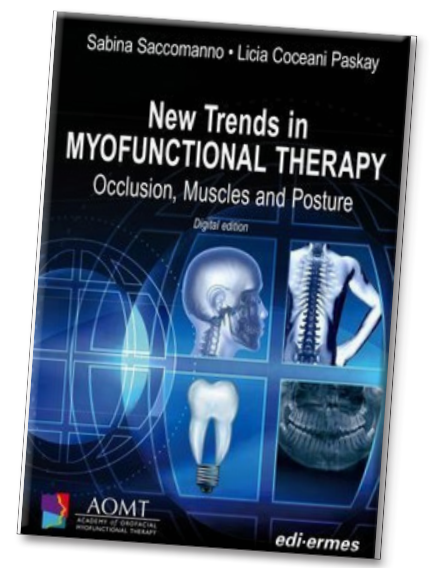

Marian-Vladimir

Constantinescu

$\mathrm{DDS}, \mathrm{MSc}, \mathrm{PhD}$

Holistic Dental \& Medical Institute

of Bucharest - ROPOSTURO

Bucharest, Romania

e-mail: dr.vladimir.constantinescu@gmail.com

In orthodontics and dento-facial orthopedics, a priority role is given to the oral function in both craniofacial growth and development, as well as in dental occlusion. Everyone is convinced that a young patient benefits from the orthodontist working in a medical team with specialists from different disciplines who follow the oral function evolution.

However, in current practice a young patient does not benefit from a holistic, inter and multidisciplinary evaluation, as a result of a concrete collaboration between doctors, dentists, orthodontists, speech therapists, myofunctional therapists, osteopaths and otorhinolaryngologists.

The book entitled "New Trends in Myofunctional Therapy" covers the experience of two editors, an orthodontist, Sabina Saccomanno, Professor Master in Clinical Orthodontics at the Catholic University of the Sacred Heart, Rome, Italy and a speech therapist Licia Coceani Paskay, Speech-Language Pathologist, with private practice, in Los Angeles, CA, USA, with 20 coauthors and 10 collaborators.

The volume has 15 chapters which approach the correlations between orofacial functions, occlusion and posture to better understand the appropriate diagnostic and therapeutic procedures that can be followed by the multidisciplinary medical team, addressing a young patient's global myofunctional disorders.

After an enumeration of medical records and multidisciplinary examination in holistic approach, an identification of malocclusion and a clinical and instrumental diagnosis of orofacial dysfunctions is made. Myofunctional therapy exercises and home-based myofunctional therapy and diary are presented in detail together with a myofunctional therapy protocol in alterations of the lingual frenulum. Orthodontic appliances in myofunctional therapy are eloquently illustrated by age groups. The book further focuses on unrelated topics in the field of orthodontics, such as orofacial pain, otitis media with effusion, obstructive sleep apnea syndrome, Down syndrome, and gloss-postural syndrome.

The book also provides practical tools, namely the Myofunctional Therapy Diary and Tongue Diary, as guides for a wide range of exercises, along with a video series explaining myofunctional therapy exercises.

The book confirms the validity of the Oro Myo Functional Therapy, proving to be a useful guide for understanding the importance of the functional balance between the craniofacial region and posture for doctors, dentists, orthodontists, speech therapists, myofunctional therapists, osteopaths and otolaryngologists. 
Marian-Vladimir Constantinescu

DDS, MSc, PhD

Holistic Dental \& Medical Institute

of Bucharest-ROPOSTURO

Bucharest, Romania

e-mail:drvladimir.constantinescu@gmail.com

\section{Trattamento semplificato in Gnatologia}

II metodo Global Occlusion

Author: Piero Silvestrini Biavati

Publisher: Edra S.p.A., Italy

Language: Italian

ISBN: 978-8-821-44767-9

Edition: $1 / \mathrm{e}$

Publish Year: 2019

Pages: 223, illustrated

Price: $€ 99,00$

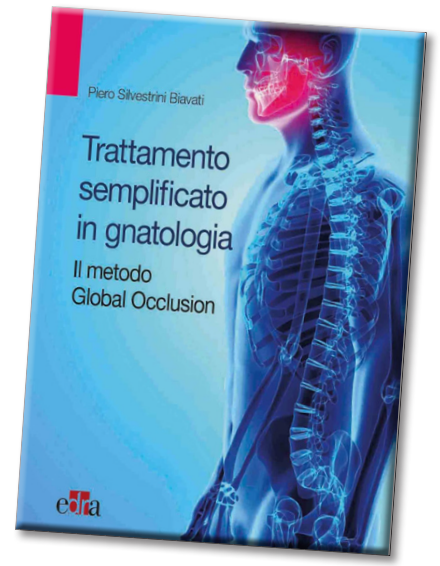

Over time, a number of renowned researchers have published books in which they have made known to the readers the basics and practice of gnathology: Niles F. Guichet - Gnathology: Every Day Dentistry, 1964; William K. Solberg - Clinical Gnathology and Occlusion, 1974; Axel Bauer, Alexander Gutowski - Gnathology: Introduction to Theory and Practice, 1976; Charles E. Stuart, Irwin B. Golden - The History of Gnathology, 1984.

Dr. Piero Silvestrini Biavati has recently provided the readers with a book in Italian [Simplified Treatment in Gnathology: The Global Occlusion Method].

This book is the author's plea for gnathology based on a practical, fast, manual and not very instrumental method: the Global Occlusion method. The book is divided in 13 chapters.

The first two chapters present the simplified anatomy and physiology of the stomatognathic system and the etiology of gnathological problems. The next chapter recalls the ideal functions of the stomatognathic system. These fundamental notions contribute to a consistent functional analysis eloquently exemplified by a multitude of clinical signs, which makes up chapter four.

The fifth chapter details the gnathological examination in its complexity. Therapeutic reasoning (chapter 6), as the basis for ensuring therapeutic success is addressed in detail in separate successive chapters: the centric method and its verification (chapter 7), the therapeutic process: rehabilitation method (chapter 8), the custom bite method - SilveSplint (chapter 9), rational use of articulators (chapter 10), postural adaptation and head-neck correlation (chapter 11) and differentiated postural analysis (chapter 12).

The last chapter is a synthesis of the aim of the Global Occlusion method in order to bring each gnathology practitioner closer to include it in the routine of working with their patients. The book is clearly written,convincingly illustrated to support the author's method. To increase the number of the more and more frequently encountered patients with gnatho-postural problems benefiting from this book, Dr. Piero Silvestrini Biavati's "Trattamento semplificato in Gnatologia: II metodo Global Occlusion" must be translated into English. 


\section{Dentsply Sirona}

\section{SDR ${ }^{\circledR}$ Plus}

Bulk Fill Flowable

\section{Confidence}

and reliability.

At peace on every level. 
The Stomatology Edu Journal (Stoma Edu J) is one of the first Green Open Access journals in the field of dental medicine publishing well-established authors, but equally committed to encouraging early career researchers and professionals alike to publish their work after a non-partisan, objective, double-blind rigorous peer-reviewed process. Our aim is to publish in the shortest possible time frame and ensure the rapid dissemination of your work via our journal page, but also through our indexing partners (Dimensions, EBSCO, KUDOS, Google Scholar, Scilit) which reach the vast mass of denta researchers, professionals and practitioners across the world This journal fully adheres and complies to the policies and principles of the Committee on Publication Ethics (COPE).

\section{Submission Instructions}

The Stomatology Edu Journal (Stoma Edu J) publishes articles written only in English. All articles will be accompanied by the signed copyright form which can be returned by e-mail, fax (as scanned documents). All the responsibility for the originality of the material sent belongs to the author(s) alone. Each article will be evaluated by the peer-review committee composed of two independent peer-reviewers, in a blinded fashion, according to the peer-review protocol. All manuscripts must be original and exclusive. The Stomatology Edu Journal Editor will consider only articles that are original, have not been published elsewhere and have been submitted exclusively to the Stomatology Edu Journal. The manuscripts should be submitted online at wwW. ManuscriptManager.net/stom.

\section{Ethics in publishing}

The Stomatology Edu Journal (Stoma Edu J) and its editorial board fully adhere and comply to the policies and principles of Committee on Publication Ethics (COPE) (https://publicationethics.org/files/2008CodeofConduct.pdf). Your manuscript should not contain any information that has already been published. If you include already published figures or images, please obtain the necessary permission from the copyright holder to publish under the CC-BY license. Plagiarism, data fabrication and image manipulation are not tolerated. Plagiarism is not acceptable in the Stomatology Edu Journal (Stoma Edu J) submissions. Plagiarism includes copying text, ideas, images, or data from another source, even from your own publications, without giving any credit to the origina source. Reuse of text that is copied from another source must be between quotes and the original source must be cited. If a study's design or the manuscript's structure or language has been inspired by previous works, these works must be explicitly cited.

If plagiarism is detected during the peer review process, the manuscript may be rejected. If plagiarism is detected after publication, we may publish a correction or retract the paper Image files must not be manipulated or adjusted in any way that could lead to misinterpretation of the information provided by the original image. To verify the originality of content submitted to our journals, we use iThenticate (www.ithenticate. com) to check submissions against previous publications. All submitted manuscripts will be checked for any possible duplication or plagiarism with iThenticate (www.ithenticate. com). Nevertheless, corresponding authors are responsible for any fraud, intentional or unintentional malpractice.

\section{Articles sent for publishing}

The Stomatology Edu Journal (Stoma Edu J) publishes: origina articles; reviews; case reports; technical procedures; consensus declaration coming from an association or from a group of specialists; letters to the editor. All articles must be up to 3,000 and 5,000 words for meta- analysis (the word count is for the manuscript text only). Letters to the editor must not exceed 400 words of text and have no more than 3 authors. Letters to the editor can be related to an article already published in the journal or it can represent original scientific contributions or events news/presentations etc. of interest for the reader.

\section{Permissions and Ethics}

For citations, tables, figures etc. which are not original, these must be accompanied by the written permission for their use and the full reference must be provided. Photographs of identifiable persons must be sent alongside the written permission of the person(s) and all regions that may allow the identification of the subject must be covered. The author must have obtained, for all studies including human subjects, the permission of the subjects to be part of the study whilst keeping their anonymity. By sending the article, the author declares that he obtained this permission from all his subjects. All studies must respect the Helsinki Declaration (2013). For human and animal studies, the authors must have obtained the approval of the ethics committee from the University/Institute/etc. where the study was done. Consent for publication is required for studies involving human subjects - ALL case reports, letters that describe cases and some original articles. Cohort studies are exempt; instead evidence of IRB approval (name of IRB, date of approval and approval code/reference number) must be provided.

\section{Manuscript preparation}

The article must be written in conformity with the general recommendations of the International Committee of Medical Journal Editors.

http://www.icmje.org/icmje-recommendations.pdf

The Stomatology Edu Journal (Stoma Edu J) uses double-blind review, which means that both the reviewer and author name(s) are not allowed to be revealed to one another for a manuscript under review. The identities of the authors are concealed from the reviewers, and vice versa. To facilitate this, please include the following separately:

Title page (with author details): This should include the title, authors' names and affiliations, and a complete address for the corresponding author including an e-mail address, Author Contributions, Acknowledgements and Curriculum Vitae.

Blinded manuscript (no author details): The main body of the paper (including the references, figures, and tables) should not include any identifying information, such as the authors' names or affiliations.The articles must be sent either as a Microsoft Word 2000 document (*.doc) or as a Microsoft Word 2003/16/19 document $\left({ }^{*}\right.$.docx). The article will be written using Times New Roman font, size 12 for the characters with one and half $(11 / 2)$ spaces between paragraphs. The manuscript must be sent in its final form. The pages will be numbered with the manuscript containing the following sections: title, authors, abstract, keywords, the text of article, contributions, acknowledgments, references, the figures and the tables legend.

A. The title of the manuscript will have a maximum of 100 characters without spaces, written in title case, centered capitals, and in 12 point bold Times New Roman font at the top of page. Abbreviations should be avoided within the title.

B. The author(s) will send their full name(s) and surname(s) the highest academic position, their full titles and their affiliations. All names are listed together and separated by commas. Provide exact and correct author names as these will be indexed in official archives. Affiliations should be keyed to the author's name with superscript numbers and be listed as follows: Laboratory, Department, Institute, Organization, City, State abbreviation (USA, Canada, Australia), and Country (without detailed address information such as city zip codes or street names).

The correspondent author will send his/her full name and surname, the highest academic position, his/her full title, his/ her affiliation, his/her institution address, his/ her telephone, fax and e-mail. The authors will send this information in the same format as that in the published articles.

\section{The Structured Abstract}

The abstract can have a maximum of 250 words. After the abstract, the author(s) must mention a maximum of 5 keywords. Keywords must be selected from Medline Mesh. Abbreviations are not accepted in the title or the abstract.

The abstract for Original Scientific Articles should be no more than 250 words using the following structure: Introduction; Methodology; Results; Conclusion.

The abstract for Review Articles should be no more than 250 words with the authors covering all the following information regarding the subject presented under the following subheadings: Background, Objective, Data Sources, Study Selection, Data Extraction, Data Synthesis.

The abstract for Case Reports should be no more than 250 words using the following structure: Aim, Summary and Key learning points: provide up to 5 short statements of the report. The abstract for Clinical Articles should be no more than 250 words using the following structure: Aim, Methodology, Results and Conclusions. 


\section{The Article Text}

\section{Headings and Sub-headings}

Except for special names (e.g. GABAergic), capitalize only the first letter of headings and subheadings. Headings and subheadings need to be defined in Times New Roman, 12, bold. You may insert up to 5 heading levels into your manuscript (not more than for example: 3.2.2.1.2 Heading title).

For original articles:

1. Introduction - a presentation of the most important aspects in the studied domain without doing a review of the literature. The purpose of this part is to present and backup the hypothesis on which the study was based.

2. Material and Methods - this section will include all required information so that the reader can verify the validity of the study including, but not limited to, subjects, measurements, statistics and ethics. The methods used should be discussed (why the methods have been chosen, which the limitations/ advantages). A paragraph about the statistical analysis is required as well.

3. Results - the results of the study will be presented in a descending order of importance. An interpretation of the results will not be done in this section.

4. Discussion - the authors will present the way the results backup the original hypothesis, as well as the way in which the results are backed up or contradicted by the published literature. A paragraph must be dedicated to presenting the limitations of the study.

5. Conclusion - The conclusion presents the implications of this latest work. In addition, authors may consider discussing future plans or recommendations for future research etc. For all other types of articles, we recommend the use of a clear structure based on sections and sub-sections.

\section{E. Author Contributions}

The Author Contributions section is mandatory for all articles, including articles by sole authors. The Author Contributions statement must describe the contributions of individual authors and, in doing so, all authors agree to be accountable for the content of the work. Please list only 2 initials for each author, without periods, but separated by commas (e.g. AC, $\mathrm{AS}$ ). In the case of two authors with the same initials, please use their middle initial to differentiate between them (e.g. AEC, ASC). Each author must be able to prove his active participation in the study by contributing to the concept, protocol, data gathering or analysis, their interpretation or by critically revising the manuscript.

\section{F. Acknowledgments}

Acknowledge persons who have made substantive contributions to the study. Specify grant or other financial support, citing the name of the supporting organization and grant number.

\section{G. References}

- The references will be written using the Vancouver style (https://www.imperial.ac.uk/media/imperial-college/ administration-and-support-services/library/public/vancouver. pdf). All references that are identified with DOI (Digital Object Identifier) must be mentioned.

- For each reference use active links to the full text (DOI link), free PMC article, PubMed, Google Scholar, Scopus pages, and WoS were they exist:

- For all references identified with DOI the full-text link must be the CrossRef hyperlink

\section{Examples}

\section{Articles with DOI}

Singbartl G. Pre-operative autologous blood donation: clinical parameters and efficacy. Blood Transfus. 2011;9(1):10-18. [CrossRef] [Free PMC Article] [PubMed] Google Scholar Scopus WoS Articles without DOI

Mehta H, Shah S. Management of Buccal Gap and Resorption of Buccal Plate in Immediate Implant Placement: A Clinical Case Report. J Int Oral Health. 2015;7(Suppl 1):72-75.

\section{[Full text links] [PubMed] Google Scholar}

- The references will be numbered, in the order they appear in the text, in square brackets, as such: [3], [5,7-9].

- All sources found in the text must be present in the bibliography and all the papers mentioned in the bibliography must appear in the text.

- For references with more than 5 authors, list the first 3 authors followed by "et al."
- Full-page ranges should be given in expanded form (e.g., 426429 , not 426-9).

- If non-English-language titles are translated into English, bracketed indication of the original language should follow the title.

- All journals will be abbreviated and italicized names of journals according to the style in PubMed; refer to the National Library of Medicine (NLM) Journals Database (http://www.ncbi.nlm. nih.gov/nlmcatalog/journals) if needed. Journal names will be abbreviated according to the List of Title Word Abbreviations - Information obtained from sources which are not published yet, but accepted for publishing will include at the end of the reference the mention "in print" between round parentheses.

- If the cited results have not been published yet the mention will be "personal communication" written in the text of article between round parentheses.

- Only references read by the authors of the article will be cited.

- An original article will have at most 50 references, a review will have at most 100 references, a letter to the editor 5 references, whilst all other types of articles will have the minimum number of references required.

\section{Curriculum Vitae - Ultra Short version}

Please provide a brief presentation of the first author and his contribution in the field, of maximum 130 words (with a $3.5 \times 4.5$ cm color photo).

\section{Figures, Images, Tables}

All illustrations must be numbered and cited in the text in order of appearance.

Figures and Images will be drawn professionally and sent in separate file(s) as jpeg, tiff or png files. Illustrations should preferably fill single column width $(54 \mathrm{~mm})$ after reduction, although in some cases $113 \mathrm{~mm}$ (double column) and $171 \mathrm{~mm}$ (full page) widths will be accepted. See the Image quality specifications chart for details. Image files also must be cropped as close to the actual image as possible.

In the text, each figure must be represented by a number, a title and a description. The authors will indicate where should the figure be placed in the text. All images or figures must come from the author's personal collection or the author must have rights to publish the image or figure. All images must be at or above intended display size with the following image resolutions: Line Art $800 \mathrm{dpi}$, Combination (Line Art + Halftone) 600 dpi, Halftone 300 dpi. We do not accept images or figures taken from the Internet.

The Tooth Identification System used in manuscripts must conform to the FDI International System. Units used in manuscripts must conform to the Système Internationale d'Unités (SI).

Tables will be included in the text and each table will have a number and a short description if required.

\section{Ownership Rights}

By sending the article for publication the author(s):

- take full responsibility for the scientific content of the text and for the accuracy of the send data;

- become (co)author(s) of the manuscript (all further plagiarism accusation are addressed solely to the author(s) who signed the manuscript);

- declare they are the rightful owners of the images, figures and/or information sent for publishing and that they have the permission to publish all the materials for which they do not own the intellectual property rights;

- declare that the message/content of the manuscript is not influenced in anyway by commercial interests/previous engagements/ any sort of relations with other people or companies;

- transfer all rights for the manuscript to the Editorial Council for the Stomatology Edu Journal (Stoma Edu J).

\section{Other}

Previously mentioned limitations can be ignored in special cases with the agreement of the chief-editor and/or the publisher. All published materials cannot be returned.

Not taking into consideration the recommendations mentioned before can lead to delay in publishing the materials or may lead to not publishing the article.

The Stomatology Edu Journal (Stoma Edu J) also helps authors measure the impact of their research through specialist partnerships with Kudos and Altmetric. 


\section{SUBSCRIPTION}

\section{I want to subscribe to}

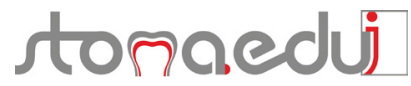

- 1 year Subscription ( 4 issues of the journal) - 280 RON (72 Euro for foreign subscribers)

- 2 years Subscription (8 issues of the journal) - 540 RON (136 Euro for foreign subscribers)

- Single Issue - 80 RON (20 Euro for foreign subscribers)

Please send the filled subscription at the following e-mail: roposturo@gmail.com.

\section{PLEASE COMPLETE ALL THE SUBSCRIPTION FIELDS IN CAPITAL LETTERS!}

Name.

Surname

Mrs. $\square$ Mr. $\square$ Ms.

Home Address

City.................................... Sector.

District

Post office code.

Mobile phone.

Web

\section{Student $\square$ Resident $\square$ Specialist doctor $\square$ Primary doctor}

Competence.

Institution.

Activity domain: $\square$ Private $\square$ Public

Department.

Position.

Specialty

Institution address

City.....

Post office code.

Sector.

District.

E-mail:

Phone....

CUI (Institution Unique Registration Code)

Web

VAT Payer: $\square$ Yes $\square$ No

Invoice - please fill all the necessary details for invoice:

Name.......................................... CNP (Personal Identification Number)....

Or

Institution

CUI (Institution Unique Registration Code).

Date

After filling the subscription, please send it together with the proof of payment to:

\section{ROPOSTURO}

Romanian Association of Oral Rehabilitation and Posturotherapy

10, lonel Perlea St., ${ }^{\text {st }}$ District, RO-010209 Bucharest, Romania

Tel: +4021314 1062, Fax: +4021312 1357

e-mail: roposturo@gmail.com

www.roposturo.ro 


\section{The New Dimension in Jaw Movement Analysis}
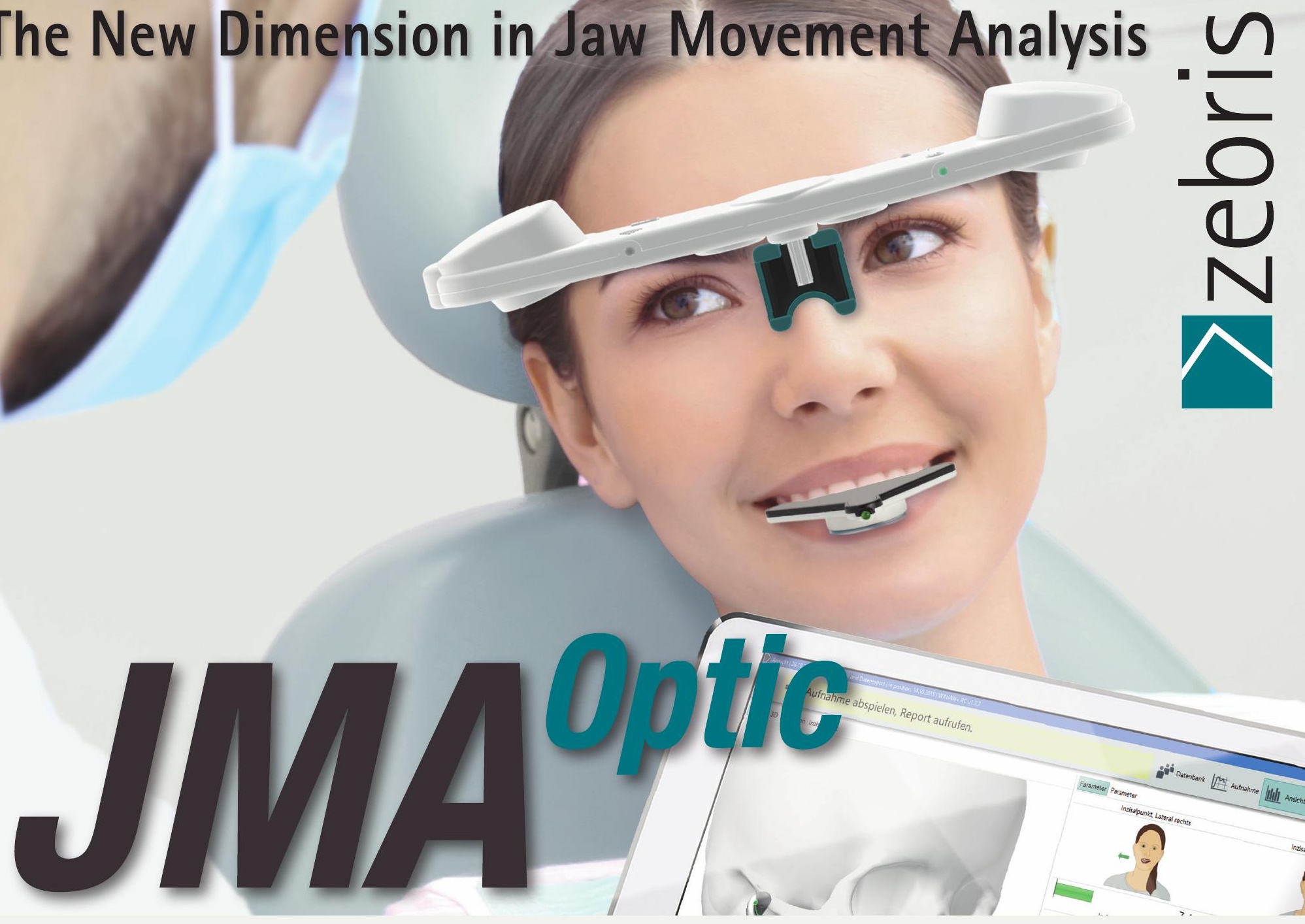

Welcome to the World of Functional Digital Dentistry

- Planning and preparation of dental restorations and dental splints under functional aspects

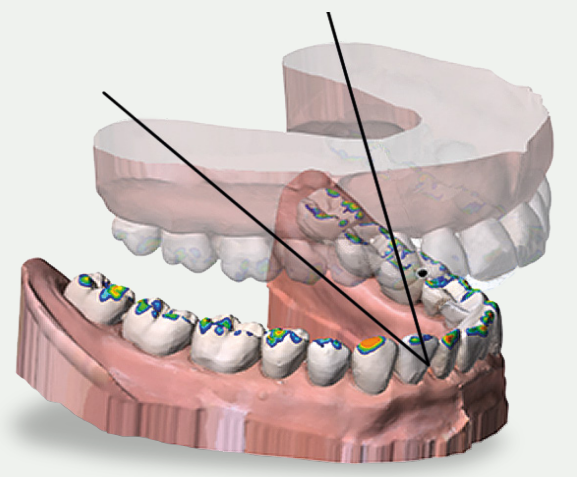

Digital function and occlusion analysis

Programming of articulators

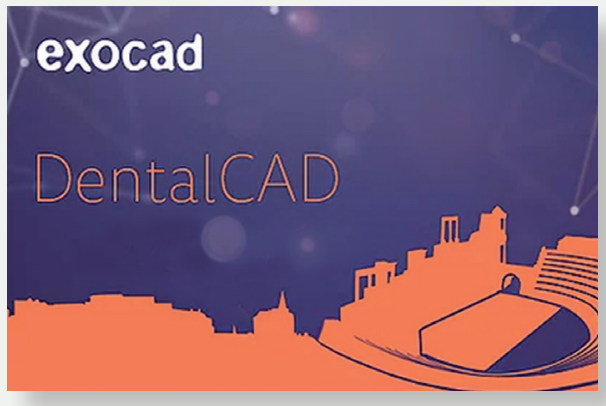

The digital workflow with exocad Export of all relevant position and movement data 


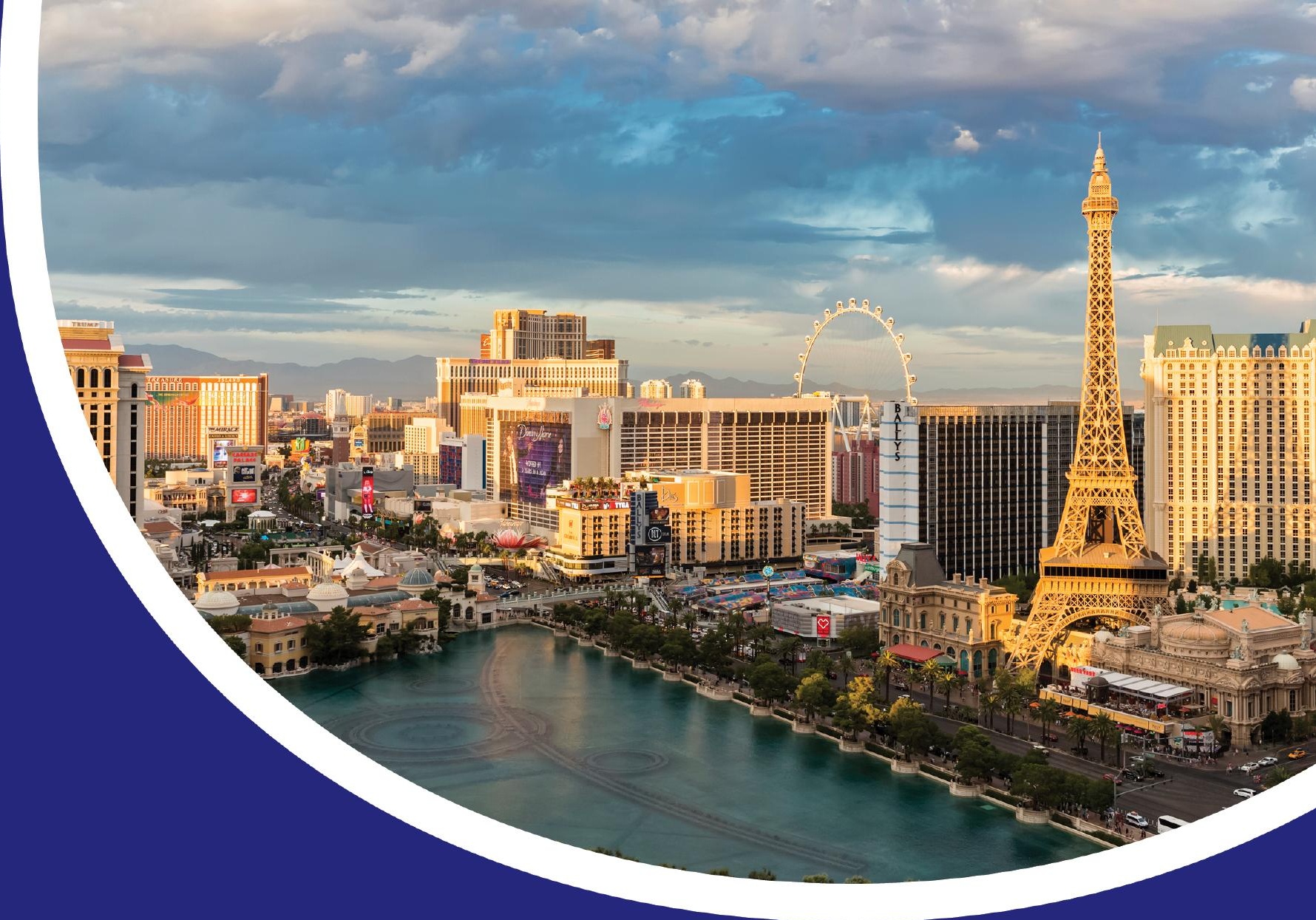

\section{Meet t}
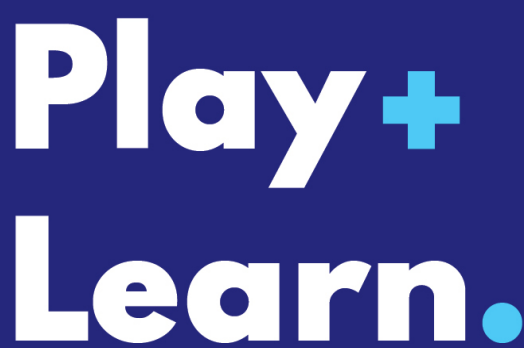

Smiles spark joy for all those around them. You and your team work tirelessly to create them and you should be rewarded with time of your own to smile-SmileCon will do just that!

Get ready to smile October 10-13, 2021. SmileCon 2021.

Get the latest updates at SmileCon.org 